\title{
Unraveling obesity's road to diabetes and cardiovascular disease
}

Citation for published version (APA):

Kusters, Y. H. A. M. (2020). Unraveling obesity's road to diabetes and cardiovascular disease:

contributors to insulin resistance, beta-cell dysfunction and vascular dysfunction. [Doctoral Thesis, Maastricht University]. Ipskamp Printing BV. https://doi.org/10.26481/dis.20200220yk

\section{Document status and date:}

Published: 01/01/2020

DOI:

10.26481/dis.20200220yk

Document Version:

Publisher's PDF, also known as Version of record

\section{Please check the document version of this publication:}

- A submitted manuscript is the version of the article upon submission and before peer-review. There can be important differences between the submitted version and the official published version of record.

People interested in the research are advised to contact the author for the final version of the publication, or visit the DOI to the publisher's website.

- The final author version and the galley proof are versions of the publication after peer review.

- The final published version features the final layout of the paper including the volume, issue and page numbers.

Link to publication

\footnotetext{
General rights rights.

- You may freely distribute the URL identifying the publication in the public portal. please follow below link for the End User Agreement:

www.umlib.nl/taverne-license

Take down policy

If you believe that this document breaches copyright please contact us at:

repository@maastrichtuniversity.nl

providing details and we will investigate your claim.
}

Copyright and moral rights for the publications made accessible in the public portal are retained by the authors and/or other copyright owners and it is a condition of accessing publications that users recognise and abide by the legal requirements associated with these

- Users may download and print one copy of any publication from the public portal for the purpose of private study or research.

- You may not further distribute the material or use it for any profit-making activity or commercial gain

If the publication is distributed under the terms of Article $25 \mathrm{fa}$ of the Dutch Copyright Act, indicated by the "Taverne" license above, 


\section{Unraveling Obesity's Road to Diabetes and Cardiovascular Disease:}

Contributors to Insulin Resistance, Beta-cell Dysfunction and Vascular Dysfunction 


\begin{tabular}{|cc|}
\hline S & $\begin{array}{c}\text { MIX } \\
\text { Paper from } \\
\text { FSC }\end{array}$ \\
responslble sources \\
www.fsc.org & FSC C128610 $^{\bullet}$ \\
\hline
\end{tabular}

(C) Yvo Kusters, Maastricht, 2020

Cover picture: Lower Antelope Canyon, Page, AZ, USA

Chapter cover pictures: The Wave \& Lower Antelope Canyon, Page, AZ, USA;

edited by Jean Scheijen

Cover design: Jean Scheijen | vierdrie.nl

Layout: Tiny Wouters

Production: Ipskamp Printing B.V.

ISBN: 978-94-028-1913-7 


\title{
Unraveling Obesity's Road to Diabetes and Cardiovascular Disease:
}

Contributors to Insulin Resistance, Beta-cell Dysfunction and Vascular Dysfunction

\author{
PROEFSCHRIFT
}

ter verkrijging van de graad van doctor aan de Universiteit Maastricht, op gezag van de Rector Magnificus, Prof. Dr. Rianne M. Letschert, volgens het besluit van het College van Decanen, in het openbaar te verdedigen op donderdag 20 februari 2020 om 16.00 uur

door

Yvo Hubert Anna Maria Kusters 
Promotor

Prof. dr. C.D.A. Stehouwer

Prof. dr. C.G. Schalkwijk

\section{Co-promotor}

Dr. A.J.H.M. Houben

\section{Beoordelingscommissie}

Prof. dr. E.E. Blaak (voorzitter)

Dr. Ir. M.C.J.M. van Dongen

Prof. dr. L.J.C. van Loon

Dr. E. Serné (Amsterdam UMC, locatie VU, Amsterdam)

Prof. dr. N. Stefan (Universität Tübingen, Tübingen, Duitsland) 


\section{Contents}

$\begin{array}{lll}\text { Chapter } 1 & \text { General introduction } & 7\end{array}$

Appendix 1.1 - Methodological considerations 37

Chapter $2 \quad$ Muscle microvasculature's structural and functional 43 specializations facilitate muscle metabolism

Appendix 2.1 - Capillary recruitment: lessons from skin 63 microvasculature

Chapter 3 Reliability, measurement error and methodology of anthropometric, vascular, metabolic and inflammatory variables

Chapter 4 Independent tissue contributors to obesity-associated insulin resistance

Chapter $5 \quad$ NK cells in human visceral adipose tissue contribute to obesity151 associated insulin resistance through macrophage polarization and low-grade inflammation

Chapter 6 Obesity-associated alterations in beta-cell function can be 181 reversed by weight loss and are partially explained by pancreatic fat: a randomized controlled trial

Chapter 7 Diet-induced weight loss improves not only cardiometabolic risk 209 markers but also markers of vascular function: a randomized controlled trial in abdominally obese men

Chapter 8 General discussion

$\begin{array}{lll}\text { Chapter } 9 \quad \text { Nederlandse samenvatting } & 269\end{array}$

$\begin{array}{ll}\text { Valorization addendum } & 279\end{array}$

List of publications $\quad 283$

Dankwoord $\quad 287$

Curriculum vitae $\quad 293$ 



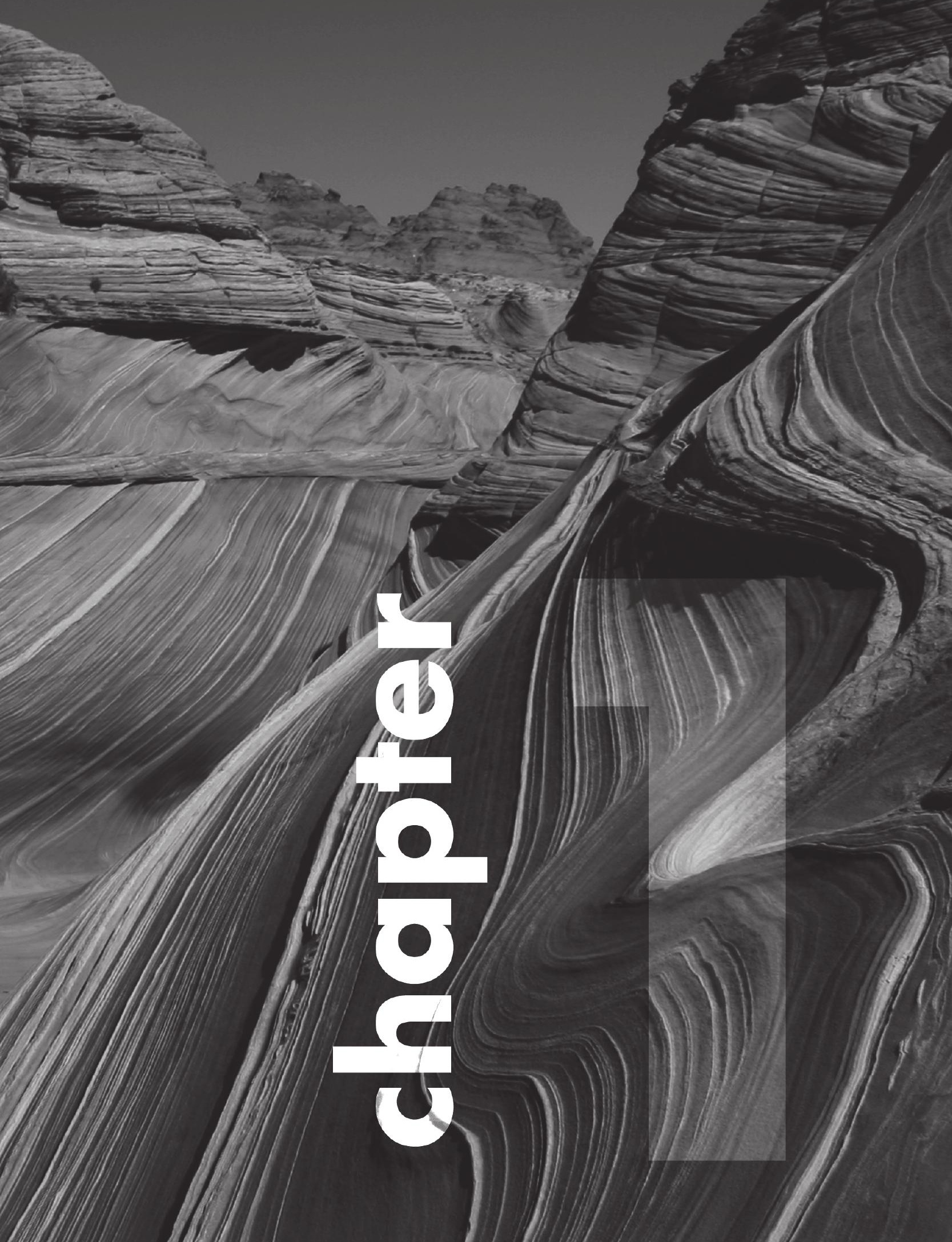


Chapter 1

General introduction 


\subsection{Introduction}

After centuries of predominantly underweight-associated deaths, overweight and obesity now kill more people than underweight. ${ }^{1}$ Even though obesity can be prevented by balancing food intake and energy expenditure, its prevalence is still steadily increasing; in the Netherlands, now more than half of the adult population is overweight and $15 \%$ is obese. ${ }^{1,2}$ As excess fat mass increases, the risk to develop type 2 diabetes mellitus (T2D), increases in parallel. ${ }^{3-5}$ Obese individuals and individuals with T2D are at increased risk to develop cardiovascular disease (CVD); CVD accounts for $52 \%$ of deaths in T2D. ${ }^{6}$ When individuals develop T2D, two core processes are usually at play: insulin resistance and beta-cell dysfunction. ${ }^{7}$ Here, we will review both processes, as well as their potential contributors, in more detail. In addition, we address vascular function as a potential mediator of CVD, as well as a surrogate for CVD risk.

\subsection{Insulin resistance}

Insulin resistance can be regarded as a decreased sensitivity to the metabolic actions of insulin that promote glucose disposal. Typically, skeletal muscle is the primary site of action for insulin-induced glucose disposal, although other tissues like liver, adipose tissue and skin contribute as well. ${ }^{8-10}$ In response to insulin, myocytes and adipocytes translocate glucose transporter 4 (GLUT4) from the cytosol to the plasma membrane to facilitate cellular glucose entry; this rapidly lowers plasma glucose levels. ${ }^{11,12}$ In an insulin resistant state, this response is blunted. ${ }^{13-15}$

The gold standard to measure insulin sensitivity is by means of a euglycemic insulin clamp, during which insulin is infused at a fixed rate while isoglycemia is maintained through a variable infusion of $20 \%$ glucose. ${ }^{16,17}$ When steady state is achieved, the rate of glucose perfusion then approximates the whole body glucose disposal (WBGD) ${ }^{16,17}$ This method is described in more detail in chapter three.

To link obesity to insulin resistance, several tissue-specific pathways, including visceral and subcutaneous adipose tissue, liver and muscle, have been proposed. These pathways have, however, never been studied simultaneously; hence, whether these pathways act independently of each other has not been elucidated.

\subsubsection{Adipose tissue}

A large organ with considerable plasticity, adipose tissue is capable of storing massive amounts of energy in the form of triacylglycerol; adipose tissue consists of roughly 
$3 \cdot 10^{10}$ adipocytes with an average size of $70 \mu \mathrm{m} .{ }^{18}$ With excess energy intake and subsequent obesity, adipocyte hyperplasia (increase in cell numbers, up to $9 \cdot 10^{10}$ ) or hypertrophy (increase in cell size, up to $120 \mu \mathrm{m}$ ) can occur to various degrees; the former is considered a favorable response and the latter pathological. ${ }^{19-22}$ In health, subcutaneous adipose tissue (SAT) is the largest compartment and the vast majority of excess energy is stored there. It has been hypothesized that with persistent positive energy balances, the capacity of SAT will be reached and storage of free fatty acids (FFAs) will shift to ectopic sites, predominantly visceral adipose tissue (VAT). ${ }^{20,22,23}$ When SAT fails to store additional FFAs, adipocyte hypertrophy is typically observed; this may result from impaired adipocyte proliferation due to insufficient angiogenesis with ensuing hypoxia (Figure 1.1)..$^{19,20,24}$

Ex vivo, hypertrophic adipocytes are capable of producing interleukin-6 (IL-6), IL-8, leptin, and tumor necrosis factor (TNF); ${ }^{25}$ it has been suggested that this may lead to massive accumulation of macrophages in adipose tissue. ${ }^{19,24,26-29}$ While under lean conditions most adipose tissue macrophages display an anti-inflammatory or so-called "M2" phenotype, obesity induces polarization toward the inflammatory " $\mathrm{M} 1$ " state. $^{26,30}$ These M1-macrophages, in turn, produce even more inflammatory cytokines (e.g., TNF); this maintains local inflammation and may result in systemic low-grade inflammation (LGI), which contributes to insulin resistance. ${ }^{19,26,29-32}$

Although many mechanisms in the adipose tissue of obese individuals have been proposed to trigger macrophage accumulation and polarization (e.g., adipocyte cell death, lipotoxicity by FFAs, increased insulin levels, hyperglycemia, and hypoxia ${ }^{19,33}$ ), the exact driver of macrophage accumulation and activation has remained unclear. Recently, several studies in mice demonstrated that natural killer (NK) cells control macrophage accumulation and polarization via the production of interferon gamma (IFN ), TNF or IL-6 in AT, which was associated with impaired insulin sensitivity and glucose handling. ${ }^{33-35}$ NK cells, which are innate lymphoid cells specialized in surveilling, recognizing and eliminating virally infected, transformed or stressed cells, are known to produce cytokines to shape an inflammatory environment. ${ }^{36}$ Moreover, it has been shown that obesity is associated with an activated phenotype of NK cells in human adipose tissue. ${ }^{37}$ However, neither NK cells' involvement in macrophage accumulation and polarization in adipose tissue, nor their contribution to ensuing insulin resistance has been investigated in humans.

Besides LGI, VAT and SAT may both contribute to insulin resistance by increased lipolysis, as well as adipokine dysregulation. ${ }^{38-40}$ Although these mechanisms may be present in SAT as well as VAT, they may contribute to insulin resistance to a different extent. This disparity may, at least in part, arise from SAT's higher ability to expand its capillary network compared to VAT. ${ }^{22,41}$ Hence, compared to SAT, VAT may be more 
potent to contribute to insulin resistance though LGI, dysregulation of adipokine release, and lipolysis. ${ }^{22,38-42}$ Interestingly, although SAT is considered to contribute to insulin resistance independent from $\mathrm{VAT}^{38}$ a fat distribution pattern with high SAT and low VAT volumes is considered a metabolically healthy phenotype. ${ }^{43}$

A

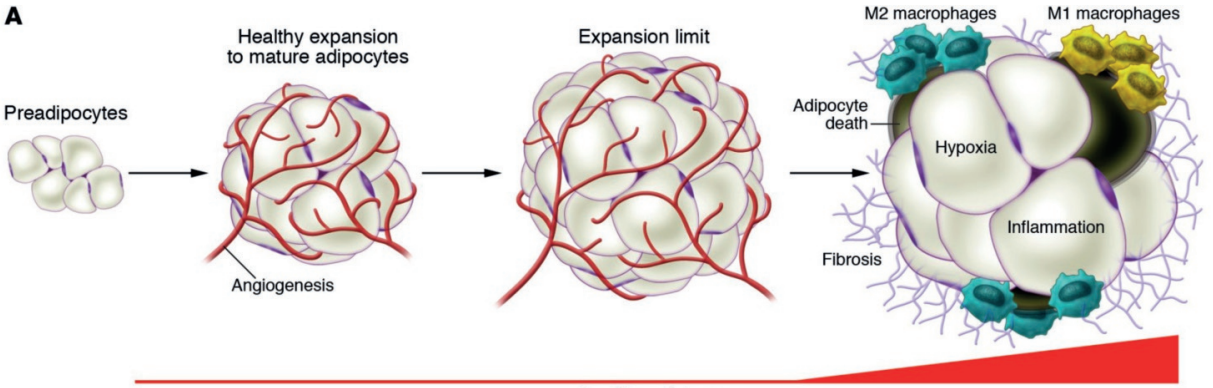

Insulin resistance

B

B Pathological expansion

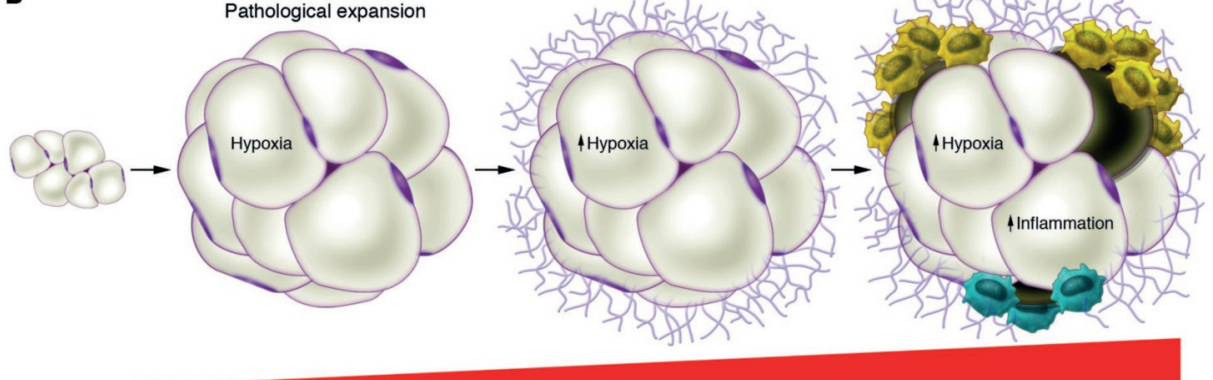

Insulin resistance

Figure 1.1 - Healthy and unhealthy adipose tissue expansion. (A) Healthy adipose tissue (AT) expansion consists of an enlargement of adipose tissue through effective recruitment of adipogenic precursor cells to the adipogenic program, along with an adequate angiogenic response and appropriate remodeling of the extracellular matrix. There are strong individual differences with respect to the potential for adipose tissue expansion. (B) In contrast, pathological adipose tissue expansion consists of massive enlargement of existing adipocytes (i.e., hypertrophy), limited angiogenesis, and ensuing hypoxia. As a result, hypoxiainducible factor 1- $\alpha$ (HIF-1 $\alpha)$ is induced, which in turn can cause the induction of a fibrotic program. Ultimately, M1-stage macrophages prevail, leading to an inflammatory phenotype that is strongly associated with systemic insulin resistance. Reproduced from Sun et al., with permission. ${ }^{19}$

\subsubsection{Intrahepatic lipids}

The liver is a key regulator in glucose metabolism; it is able to maintain normoglycemia in a fasted state through glycogenolysis and gluconeogenesis, as well as store glucose in the fed state through glycogenesis. ${ }^{10}$ With prolonged periods of energy excess, liver biopsies may reveal ectopic fat storage in macrovesicular fat globules in hepatocytes, as well as hepatic injury, illustrated by formation of Mallory's 
hyaline bodies in ballooned hepatocytes which may contain microvesicular fat. ${ }^{44}$ The macrovesicular lipid pool in hepatocytes has a variable composition, which may include saturated fatty acids, diacylglycerols and ceramides, which are suggested to exert local lipotoxic effects. ${ }^{45-47}$ In liver biopsies, non-alcoholic fatty liver disease (NAFLD) is confirmed when $\geq 5 \%$ of hepatocytes are fatty, in the absence of excess alcohol consumption or other conditions. ${ }^{44}$ Over time, NAFLD may progress to nonalcoholic steatohepatitis (NASH) and cirrhosis, some will even develop hepatocellular carcinoma. ${ }^{48,49}$ Moreover, incidence of T2D and the risk of CVD appear to be higher in individuals with NAFLD, compared to those without. ${ }^{48-54}$ Therapies proven to be effective to treat NAFLD are weight loss interventions, pioglitazone, and vitamin $E^{55,56}$

The gold standard to quantify IHL and diagnose NAFLD is by liver biopsy. ${ }^{44}$ However, non-invasive imaging techniques like proton magnetic resonance spectroscopy $\left({ }^{1} \mathrm{H}-\mathrm{MRS}\right)$ and other magnetic resonance imaging (MRI) sequences (e.g., modified Dixon (mDixon)) have been validated against liver biopsies and proven accurate to quantify IHL and diagnose NAFLD. ${ }^{57-60}{ }^{1} \mathrm{H}-\mathrm{MRS}$ is even considered to be the gold standard to diagnose NAFLD non-invasively, ${ }^{44,49,61}$ although mDixon is just as, or possibly even more, accurate (Supplementary Table S1.1). ${ }^{58,59,62}$ Of note, other techniques like computed tomography, ultrasound, or enzyme scores are inferior to these MRI-based techniques (Supplementary Table S1.1)..$^{59,63-66}$

The contribution of IHL to insulin resistance is debated; it is unclear whether insulin resistance is a cause or a consequence of IHL. Lipotoxicity of IHL with a detrimental lipid composition, LGI, and stimulation of hypertriglyceridemia by the fatty liver are suggestive of a causative role of IHL in insulin resistance, ${ }^{45-47,49,67}$ whereas adipocyte insulin resistance and subsequent FFA-fluxes towards the liver suggest IHL is a consequence of insulin resistance. ${ }^{68,69}$ In addition, with increased $\mathrm{IHL}$, hepatic glucose production is no longer suppressed (i.e., hepatic insulin resistance), which results in hyperglycemia. ${ }^{49,70}$ Nonetheless, some studies have suggested that IHL, not VAT, is associated with insulin resistance, ${ }^{71,72}$ whereas others argue in favor of mutually independent contributions of IHL and VAT. ${ }^{68,73}$ However, these were cross-sectional studies in some of which individuals were matched on one or more variables (e.g., VAT, IHL). ${ }^{71,72}$ Hence, studies that measure these potential contributors simultaneously in a random sample of the general population are required to determine whether or not they are mutually independent contributors to insulin resistance.

\subsubsection{Microcirculation}

In our circulation, arteries branch out into the microvasculature, which encompasses blood vessels $<150 \mu \mathrm{m}$ in diameter and includes arterioles, capillaries and venules. ${ }^{74}$ 
In skeletal muscle, the primary site of insulin-induced glucose uptake, arterioles ultimately branch out to terminal arterioles, which are oriented perpendicular to muscle fibers and supply them at regular intervals (Figure 2.1). A terminal arteriole and its 12-20 capillaries form the smallest unit of control for capillary perfusion; ${ }^{75-79}$ venules are oriented similar to the arterioles and are found between two terminal arterioles. As capillaries are embedded in sarcolemma, the surface area for nutrient exchange is further increased. ${ }^{80,81}$ Muscle's vasculature is capable of regulating blood flow and nutrient exchange; at the level of the terminal arterioles, endothelial surface area can be increased through vasodilation and vasomotion. Skeletal muscle's architecture, regulation of vasomotor tone, mechanisms of vasomotion, transendothelial nutrient fluxes, and the effects of exercise and insulin are described in more detail in chapter two. Nonetheless, some key intracellular mechanisms and regulatory mechanisms are summarized below.

The inner cellular lining of the vasculature, the endothelium, is a key regulator not only in vasomotor tone, vasomotion and subsequent perfusion, but also in blood cell trafficking, permeability, proliferation, and hemostasis. ${ }^{82}$ The endothelium is vastly heterogeneous along the vascular tree, as well as per organ. ${ }^{82,83}$ In skeletal muscle, the endothelium is continuous and non-fenestrated, ${ }^{82}$ which is why endothelial cells orchestrate nutrient transport to myocytes. In a hyperinsulinemic state, insulin binds to the insulin receptor on the endothelial surface, which results in activation of both vasodilator (through insulin receptor substrate-1 (IRS-1), phosphatidylinositol 3-kinase (PI3K), phosphoinositide-dependent kinase-1 (PDK-1), protein kinase B (Akt), and endothelial nitric oxide synthase (eNOS), which results in nitric oxide (NO) release) and vasoconstrictor pathways (through mitogen-activated protein kinase (MAPK) and extracellular signal-regulated kinase-1/2 (ERK1/2), which results in entothelin-1 (ET-1) production). ${ }^{84-92}$ Since the vasodilator pathway predominates in health, a net vasodilation ensues and, hence, hypoperfused capillaries and microvascular units are recruited (i.e., microvascular recruitment (MVR)). ${ }^{84,93-99}$ In obesity, endothelial dysfunction develops; through inflammation (e.g., TNF), FFA, angiotensin-II and oxidative stress, the vasodilator pathway is inhibited, which may blunt insulin-induced vasodilation or even result in paradoxical vasoconstriction (Figure 1.2). ${ }^{79,84,85,94,97-110}$ In addition, insulin is transported across the endothelium in an NO-dependent manner via caveolae, after which myocytes are stimulated by said insulin to transport GLUT4 to the plasma membrane. ${ }^{95,111-113}$ Although its activity in muscle's endothelium has not been studied, the GLUT1 transporter, which has a high capacity for glucose transport even in the absence of excess insulin, is assumed to be involved in transendothelial glucose transport in skeletal muscle, similar to human cardiac tissue. $^{114}$ 


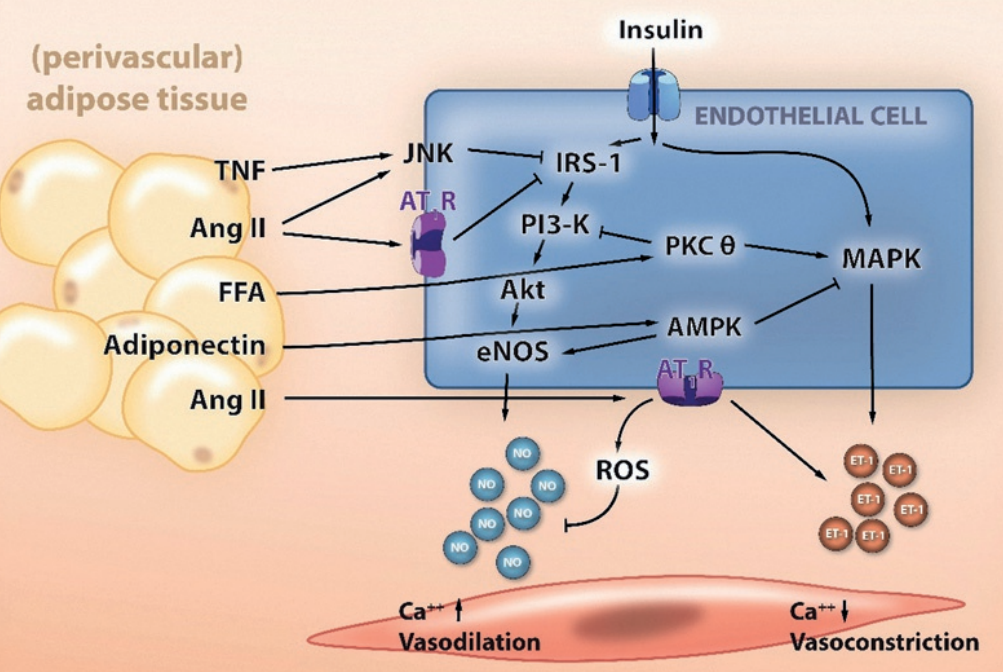

SMOOTH MUSCLE CELL

Figure 1.2 - Insulin signaling pathways in the endothelium for the production of nitric oxide (NO) and endothelin-1 (ET-1). In healthy individuals, hyperinsulinemia results in a net vasodilation, whereas in obesity, this response is either blunted or paradoxical vasoconstriction may occur. Several circulating and paracrine factors are involved: angiotensin II (AngII), tumor necrosis factor (TNF), and free fatty acid (FFA) inhibit the phosphatidylinositol 3-kinase (PI3K) pathway and stimulate the mitogen-activated protein kinase (MAPK) pathway via a crosstalk at multiple levels. TNF and Angll can inhibit IRS-1 through c-Jun N-terminal kinase (JNK). Angll can bind to the angiotensin type 1 receptor $\left(A T_{1} R\right)$ and inhibit IRS-1 and lead to the production of reactive oxygen species (ROS), which reduces NO bioavailability. FFA can activate protein kinase $C$ theta (PKC- $\theta$ ), which results in activation of the mitogen-activated protein kinase (MAPK) signaling pathway as well as in inhibition of PI3K. Adiponectin can stimulate 5'-adenosine monophosphate-activated protein kinase (AMPK), which stimulates eNOS and inhibits the MAPK pathway; in obesity, adiponectin levels are decreased. Graphical design by Dr. van Varik.

In addition to MVR, muscle perfusion may also be regulated through vasomotion, i.e., rhythmic vessel diameter oscillations. ${ }^{102,115}$ It has been demonstrated that upon increased metabolic needs, signals originating from the microvasculature travel upstream to larger arterioles and arteries, thereby influencing vessel diameter. ${ }^{116}$ In addition, stimulation of individual capillaries can trigger vasomotor responses in arterioles. ${ }^{116-118}$ Moreover, signaling from endothelial to smooth muscle cells at myoendothelial junctions can be regulated by NO; the duration of conducted vasodilation is attenuated by reduced NO production. ${ }^{116,119}$ Collectively, these findings suggest that muscle microcirculation can modulate upstream vasodilation and vasomotion. Interestingly, vasomotion may regulate microvascular blood flow 
distribution to optimize delivery of nutrients, since continuously altering blood flow delivery to vessels over time increases the number of endothelial cells exposed to plasma for nutrient or hormone exchange ${ }^{120}$ without total flow or cardiac output being changed. ${ }^{102}$

A captivating potential regulator of insulin's vascular actions is perivascular adipose tissue (PVAT) in muscle's microcirculation. ${ }^{121-123}$ Since adipocytes in PVAT are located in the vicinity of microvessels, adipokines released from PVAT are suggested to have paracrine effects on the microvasculature, including its vasomotor tone. ${ }^{103,121,123,124}$ In rodents, it has been observed that 1 ) with a high-fat diet, PVAT was infiltrated by bone marrow-derived immune cells and had become inflammatory; ${ }^{125}$ 2) arteries with excess PVAT, in contrast to those with little to none, displayed endothelial dysfunction when on a high-fat diet; ${ }^{126}$ 3) PVAT from obese mice was shown to impair insulininduced vasodilation in arterioles from lean mice; ${ }^{126} 4$ ) PVAT from lean mice could not restore insulin-induced vasodilation in arterioles from obese mice; ${ }^{125}$ and 5) by inhibition of inflammation in obese PVAT, its vasodilator properties were restored, possibly via secretion of adiponectin and stimulation of AMPK $\alpha 2$, which resulted in NO-production and inhibition of the MAPK-pathway. ${ }^{126,127}$ Limited data is available in humans, although observations in humans are in line with those in rodents. ${ }^{122,128}$ Additional studies are needed to address PVAT's contribution to insulin resistance in humans.

Of note, the contributions of impaired MVR or vasomotion responses to obesityinduced insulin resistance have never been studied in parallel with VAT, SAT, or IHL. Moreover, to the best of our knowledge, no intervention study had evaluated whether MVR can be improved by weight loss, nor assessed the contribution of changes in MVR to changes in insulin resistance.

\subsection{Beta-cell function}

In the evolution of obesity towards T2D, progressive beta-cell dysfunction is a crucial process. Initially, beta-cell function (BCF) typically adapts to progressive insulin resistance in obesity; when BCF adaptation is inadequate, hyperglycemia and, hence, T2D develop. ${ }^{129-131}$

In glucose-tolerant obese individuals, the presence of insulin resistance induces upregulation of static beta-cell responses such as basal insulin secretion and total stimulated insulin secretion; this can be interpreted as an adjustment of the set-point of BCF by insulin resistance. ${ }^{132}$ With progressive hyperglycemia, static beta-cell 
responses may, possibly due to the toxic effect of chronic hyperglycemia, ultimately fail $^{132,133}$ and beta-cell dedifferentiation ${ }^{134-138}$ and loss of beta-cell mass may develop. ${ }^{131,139,140}$

Another important aspect of BCF is the ability to appropriately increase the insulin secretion rate (ISR) to cope with acute changes in plasma glucose concentration that results from nutrient intake. The response of beta-cells to hyperglycemia is largely explained by a number of dynamic BCF properties, as described in more detail in chapters three and six (e.g., Supplementary Figure S6.1), as well as elsewhere. ${ }^{129,132,141-145}$ Briefly, in response to ingestion of a meal, ISR can be measured and mathematically modeled. From this model, beta-cell glucose sensitivity ( $\beta-G S)$ and its modulation by beta-cell potentiation (the effects of glucose itself and non-glucose secretagogues to magnify the beta-cell response to glucose over time), as well as rapid first phase insulin release (i.e., beta-cell rate sensitivity $(\beta-R S)$ ) can be measured. $^{141,142,145}$

\subsubsection{Beta-cell function in obesity and effects of weight loss}

As hyperglycemia normally develops gradually over time, it is conceivable that BCF may already, to some extent, inadequately adapt to the level of insulin resistance in obese non-diabetic individuals. Inadequate obesity-induced BCF alterations, their reversibility, and the drivers thereof are, however, largely unknown.

Inconsistent results have arisen from cross-sectional studies which evaluated dynamic BCF in obese, non-diabetic individuals. In some studies, both $\beta$-GS and potentiation factor ratio (PFR; a ratio between late and early potentiation) were decreased in obese individuals with normal ${ }^{146}$ or impaired glucose tolerance. ${ }^{130,142,146-149}$ Yet, in other studies in obese individuals with impaired glucose tolerance, an increase in $\beta$-GS or PFR, or a tendency thereto, was observed. ${ }^{148-151}$ These contradictory results may have arisen from the use of an oral glucose tolerance test (OGTT) by some, ${ }^{130,142,146-149}$ and a mixed meal test (MMT) by others. ${ }^{145,148,149,151}$ Nonetheless, in these studies BCF was often not sufficiently adjusted for the level of insulin resistance.

Several non-controlled trials have studied the effects of weight loss, by either lowcalorie diet or bariatric surgery, on various aspects of BCF in obese individuals. In (morbidly) obese individuals who underwent bariatric surgery, $\beta$-GS and PFR were unchanged two years post-surgery, while $\beta$-GS was decreased one year post surgery, although insulin resistance was markedly improved at all time points in all studies. ${ }^{150,151}$ To our knowledge, only one RCT in obese individuals has studied the effects of dietary weight loss, which demonstrated that BCF was unchanged, albeit in the presence of markedly improved insulin resistance. ${ }^{55}$ 


\subsubsection{Intrapancreatic lipids and beta-cell function}

Ectopic fat deposition in the pancreas is one of the proposed contributors to beta-cell dysfunction. ${ }^{152-154}$ In postmortem studies, obese individuals had more intrapancreatic lipid (IPL) compared to lean individuals; ${ }^{155-157}$ most fat is present in adipocytes that are primarily located in the interlobular and intralobular spaces. ${ }^{158-160}$ Alternatively, triglycerides might accumulate in islets and disrupt intracellular processes involved in insulin secretion, as demonstrated in rodents. ${ }^{161,162}$ Nonetheless, IPL is suggested to arise from prolonged elevation in plasma VLDL due to increased hepatic VLDL production in NAFLD, which eventually leads to increased exposure of beta-cells to FFA and impaired BCF. ${ }^{49,154,161,163,164}$ Moreover, NAFLD may induce beta-cell dysfunction via fetuin-A and beta-cell apoptosis via palmitate. ${ }^{165}$ Furthermore, an increased number of adipocytes located near Langerhans' islets was associated with an increased number of macrophages within islets, ${ }^{165}$ suggestive of a link between local inflammation and BCF. ${ }^{166}$ Another potential contributor to obesity-induced betacell dysfunction is endothelial dysfunction of pancreas' microvasculature. Interestingly, in rodents, hyperglycemia was able to increase islet blood flow twofold; ${ }^{167}$ whether this is insulin-induced and NO-dependent is unknown. Other mechanisms involved in the interaction between endothelial and beta-cells are described into more detail below (Figure 1.3) and elsewhere. ${ }^{168}$

Data on the association between IPL and BCF is, however, ambiguous. In obesity, an association between IPL and some, but not all, aspects of BCF was observed, albeit not consistently. ${ }^{153,154,169-172}$ Moreover, in individuals with T2D, no association between IPL and BCF could be detected. ${ }^{154}$ The discrepancy in IPL's association with BCF between obese individuals on the one hand and those with T2D on the other, may be due to differences in the localization of intrapancreatic fat depositions, as well as the association between IPL and diabetes duration. ${ }^{158,173}$ Alternatively, IPL may be a more important contributor to early beta-cell dysfunction in obese individuals than with progressive hyperglycemia or T2D.

In non-controlled studies in obese individuals, weight loss was associated with reduced IPL, ${ }^{174,175}$ but not with improved BCF. ${ }^{175}$ Data from randomized controlled weight loss trials on both BCF and IPL in obese individuals have, to the best of our knowledge, not been reported. 


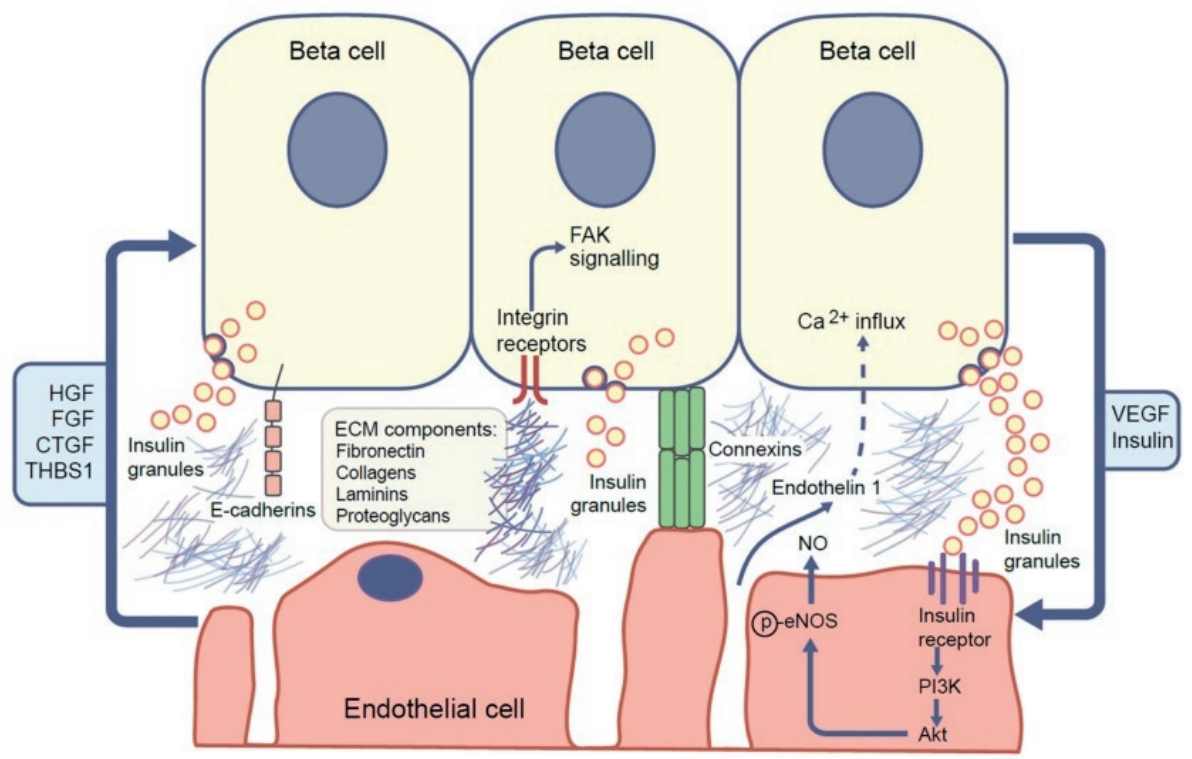

Figure 1.3 - Diagram summarizing the main factors regulating the islet beta-cell-endothelial cell axis. Islet endothelial cells produce factors that enhance beta-cell proliferation, survival and function under physiological conditions, including hepatocyte growth factor (HGF), fibroblast growth factor (FGF), connective tissue growth factor (CTGF) and thrombospondin-1 (THBS1). Additional islet endothelial cellsecreted factors modulate beta-cell function; for example, endothelin-1 increases insulin release from isolated mouse islets, possibly by triggering calcium influx into beta-cells. Extracellular matrix (ECM) molecules (e.g., fibronectin, collagens, laminins) also affect insulin expression and release from beta-cells, partly via integrins (heterodimeric cell-surface receptors with broad specificity for ECM molecules) and activation of downstream signaling pathways, including focal adhesion kinase (FAK). E-cadherin and connexins govern cell-matrix interaction and cell-cell interactions, respectively, and thus may also mediate islet endothelial-beta-cell crosstalk. Vice versa, beta-cell-secreted factors can also impact islet endothelial cell function. For example, beta-cell-derived insulin binds to the insulin receptor on endothelial cells, resulting in downstream activation of PI3K and Akt and subsequent phosphorylation (p) and activation of eNOS, leading to the production of vasodilatory NO. Furthermore, vascular endothelial growth factor (VEGF), required for maintenance of endothelial fenestration and cell viability, is produced by islet betacells and is a major source of VEGF in the islet. Reprinted from Hogan et al., with permission. ${ }^{168}$

\subsection{Vascular function}

As mentioned before, obesity is associated with an increased risk for CVD; moreover, vascular dysfunction has been implicated to contribute to CVD. ${ }^{82,176-188}$ Although microvascular responses like MVR and vasomotion are also (NO-dependent) vascular function tests (paragraph 1.2.3), we aim to briefly introduce other commonly used vascular function tests in this paragraph. Their methodology is addressed in chapters three and seven. 
Since a healthy vasculature encompasses many physiological functions (e.g., NO production, cushioning of blood flow pulsations, barrier function, regulation of hemostasis, prevention of atherosclerosis, and maintenance of vascular structure and capillary density), virtually all of these functions may be affected to some degree by obesity. Over the years, many different tests have been developed to detect impairments in vascular function.

Flow-mediated dilation is a functional marker of endothelial function, as it aims to assess the capacity of the endothelium to induce vasodilation via NO production. ${ }^{189}$ Besides its vasodilatory effects, NO also has anti-inflammatory, anti-adhesive and antithrombotic effects. ${ }^{94,190}$ Moreover, it has been demonstrated that impaired flowmediated dilation is associated with an increased risk of incident CVD. ${ }^{191-193}$

Endothelial function can also be assessed by measurements like peripheral arterial tonometry, which measures NO-dependent digital pulse volume amplitude during hyperemia, ${ }^{194}$ or plasma biomarkers of endothelial dysfunction. ${ }^{195,196}$ These plasma biomarkers are molecules that are either expressed by endothelial cells and are shed into the circulation in their soluble form via proteolysis (e.g., vascular cell adhesion molecule 1, intercellular adhesion molecule 1, endothelial selectin) or released into the circulation upon injury of the vascular wall (e.g., von Willebrand factor). ${ }^{82,83,178-180,197}$ Increased levels of these plasma biomarkers of endothelial dysfunction are also associated with an increased risk of incident CVD. ${ }^{181-186}$

Obesity, hyperglycemia, and hypertension may lead to structural remodeling of the arterial wall, for example by replacement of elastin fibers with collagen fibers and cross-linking by advanced glycation end-products, ${ }^{198-200}$ which results in arterial stiffening. In turn, arterial stiffness results in impaired cushioning function of arteries, increased pressure and flow pulsatility, and transmission of pulsatile load to the microcirculation. ${ }^{201-203}$ On the one hand, this may increase (systolic) blood pressure and decrease coronary perfusion; ${ }^{201,203}$ unsurprisingly, arterial stiffness is associated with incident CVD. ${ }^{187,188}$ On the other hand, the increased pulsatile load toward the microcirculation, like the retinal arterioles, is particularly harmful. ${ }^{201-204}$ It has been demonstrated that unfavorable retinal arteriolar and venular calibers, i.e. wider venules and narrower arterioles, were associated with incident CVD. ${ }^{205,206}$

Importantly, it should be noted that two distinctive objectives to use vascular function measurements can be differentiated in clinical trials: as a surrogate for cardiovascular end points and to evaluate certain properties of the vasculature and identify causal mechanisms. Although we used vascular function for both purposes in this thesis, it should be noted that the use of surrogate outcomes have been frequently criticized. ${ }^{207-213}$ In Appendix 1.1, the assumptions, limitations and potential of 
surrogate outcomes are further discussed. Nonetheless, investigating the effects of obesity and weight loss may provide valuable insights. Moreover, to our knowledge, the effects of obesity on the vascular function measurements mentioned before and in chapter three, have not been assessed in a single study, nor has an RCT on the effects of weight loss on these vascular functions been performed.

\subsection{Missing links}

Previous studies have investigated whether VAT, ${ }^{38,42,68,71-73,214} \mathrm{SAT}{ }^{38,42,215,216} \mathrm{IHL}^{68,71-73,214}$ or $\mathrm{MVR}^{98,128,217}$ contribute to obesity-induced peripheral insulin resistance. Several studies demonstrated that SAT'S association with insulin resistance was independent of VAT; ${ }^{38,42}$ some studies argue in favor of mutually independent contributions of VAT and $\mathrm{IHL},{ }^{68,73,214}$ whereas others find that $\mathrm{IHL}$, not VAT, is associated with insulin resistance. ${ }^{71,72}$ For MVR, it has never been shown, neither in muscle nor in skin, that its effect on obesity-induced insulin resistance is independent from other potential contributors. Moreover, although the beneficial effect of weight loss on insulin resistance is well known, ${ }^{55,218}$ it has not been investigated what drives this improvement. Nonetheless, it is crucial to identify whether VAT, SAT, IHL, and MVR act independently to increase obesity-induced insulin resistance, as mutual independence, in contrast to mutual dependence, implies that distinct mechanisms can be targeted to improve insulin resistance.

If VAT were to be an independent contributor to obesity-induced insulin resistance, which is generally accepted in literature, ${ }^{22,38-42,68,73}$ it is valuable to identify the mechanisms through which VAT can exert this effect. Previous studies have demonstrated that VAT can contribute to insulin resistance through increased lipolysis, adipokine dysregulation, and LGI. ${ }^{38-40}$ The low-grade inflammatory response in VAT has been intensively studied and signals an important role for macrophage accumulation and inflammatory polarization. ${ }^{19,24,26-32}$ What drives accumulation and inflammatory polarization of macrophages in human VAT is still open for debate. In rodents, infiltration of and cytokine release by NK cells in VAT in response to adipocyte stress have recently been demonstrated to drive macrophage infiltration and polarization. ${ }^{33-35}$ In humans, however, the role of NK cells in VAT has never been studied.

Beta-cell failure is a sine qua non for hyperglycemia and T2D to develop, yet some obese individuals never become hyperglycemic. ${ }^{129-131}$ It may be of great interest to detect early signs of inadequate beta-cell responses to hyperglycemia and identify its drivers, as it could not only lead to identification of individuals at risk for T2D, but also 
identify potential targets for treatment. Several studies have investigated whether obesity-induced changes in BCF could be detected ${ }^{129,130,142,146-151}$ and demonstrated that at least some of them were associated with progression to T2D. ${ }^{129,130}$ IPL has been implicated by some to be associated with BCF, ${ }^{152-154,163}$ yet conflicting results have arisen. ${ }^{154,169-172}$ Moreover, the effects of weight loss on BCF and IPL have never been studied concurrently in an RCT, although non-controlled studies found that both $\mathrm{BCF}^{150,151,175,219}$ as well as IPL ${ }^{152,173-175}$ were associated with weight loss, possibly in parallel. $^{175}$

Finally, it has been generally accepted that a weight loss intervention, either through diet, exercise or bariatric surgery, would be beneficial for vascular function, ${ }^{220}$ prevent incident T2D, ${ }^{221,222}$ and curate individuals from T2D. ${ }^{223-226}$ There is substantial evidence to support the latter two hypotheses, ${ }^{221-226}$ yet only few RCTs have evaluated the effect of weight loss on vascular function. ${ }^{227,228}$ In addition, those studies investigated macrovascular function by means of FMD or cfPWV. ${ }^{227,228}$ Nonetheless, it may be equally valuable to evaluate the effect of a weight loss intervention on microvascular health and function. Not only in the light of insulin resistance, but also since many complications that may develop in T2D arise from and occur in the microcirculation. ${ }^{229,230}$ If weight loss would be able to improve macro- and microvascular function, this might be a mechanism through which incident T2D or its macro- and microvascular complications could be averted. ${ }^{231-235}$ The effects of a weight loss intervention on microvascular function in particular has, however, not been evaluated in an RCT. Moreover, most RCTs that investigated effects on FMD or cfPWV were performed in participants with obesity-related morbidities. ${ }^{227,236,237}$ Also, physical exercise 227,236 or weight-loss medication ${ }^{237}$ was part of the weight-loss regimens. Hence, the effects of a weight loss intervention by caloric restriction on micro- and most of macrovascular function remains to be demonstrated.

\subsection{Outline of this thesis}

In chapter two, we reviewed the distinctive architecture and properties of muscle's vasculature and described the hierarchical, graded control of muscle perfusion that arises from cooperative interactions among the factors released locally by myocytes, by smooth muscle cells, or by endothelial cells along with systemically and neurally delivered signals. Separately, in Appendix 2.1, we present a commentary that addressed capillary recruitment in skin.

In chapter three, we assessed the reliability and measurement error of several anthropometric, vascular, metabolic, and inflammatory measurements used 
throughout this thesis, as well as describe the methodology of these measurements. The rationale for this study is described in to more detail in the methodological considerations in Appendix 1.1.

In chapter four, we investigated, in an RCT with a weight loss intervention, the mutually independent contributions of VAT, SAT, IHL and MVR to obesity-associated insulin resistance. Moreover, we investigated whether MVR can be improved by a weight loss intervention and assessed the contributions of weight-loss interventioninduced changes in VAT, SAT, IHL, and MVR on improvements in insulin sensitivity. We used state-of-the-art multiple mediation analyses to provide a deeper understanding of the mutually independence of these variables; the rationale for this statistical method is described in to more detail in the methodological considerations in Appendix 1.1.

In chapter five, we investigated the presence of NK cells in human VAT, their association with macrophage polarization, and their effects on LGI and insulin resistance in four separate studies. In the first study, NK cells were quantified and linked to macrophage polarization in biopsies from VAT and SAT; moreover, a circulating biomarker for VAT NK cells is presented. In the second study, we investigated whether NK cells from obese individuals directly affect macrophage polarization; hence, NK cells were isolated from peripheral blood and co-cultured with human monocyte-derived macrophages. In the third study, the cross-sectional analyses from the weight loss intervention trial, the associations of VAT NK cells to LGI and subsequent insulin resistance were investigated. A fourth study, the Maastricht Study, was used for validation of these associations in a population-based cohort study.

In chapter six, we investigated, in an RCT with a weight loss intervention, the obesityassociated alterations in BCF, and explored IPL as a potential contributor thereof. Moreover, we investigated whether a weight loss intervention could improve BCF and explored whether a decrease in IPL drove improvements in BCF.

In chapter seven, we investigated, in an RCT with a weight loss intervention, the obesity-associated alterations in macro- (FMD, cfPWV, peripheral arterial tonometry, and central augmentation index) and microvascular function (retinal vascular diameters), as well as circulating biomarkers of endothelial dysfunction and LGI. In addition, we investigated whether a weight-loss intervention could improve macroand microvascular function and reduce levels of circulating biomarkers of endothelial dysfunction and LGI. 
Finally, in chapter eight, we discussed the key findings of this thesis and their clinical implications, highlighted methodological considerations, and identified hypotheses worthwhile to investigate in future research. 


\section{References}

1. WHO. Obesity and overweight. Fact sheet. World Health Organisation. 2018(311):5-1.

2. CBS. Leefstijl en (preventief) gezondheidsonderzoek; persoonskenmerken. Centraal Bureau voor de Statistiek (StatLine). 2019.

3. WHO. Global Report on Diabetes. 2016.

4. Forouzanfar $\mathrm{MH}$, Alexander $\mathrm{L}$, Anderson $\mathrm{HR}$, et al. Global, regional, and national comparative risk assessment of 79 behavioural, environmental and occupational, and metabolic risks or clusters of risks in 188 countries, 1990-2013: a systematic analysis for the Global Burden of Disease Study 2013. Lancet. 2015;386(10010):2287-2323.

5. Vazquez G, Duval S, Jacobs DR, Jr., Silventoinen K. Comparison of body mass index, waist circumference, and waist/hip ratio in predicting incident diabetes: a meta-analysis. Epidemiol Rev. 2007;29:115-128.

6. Morrish NJ, Wang SL, Stevens LK, Fuller JH, Keen H. Mortality and causes of death in the WHO Multinational Study of Vascular Disease in Diabetes. Diabetologia. 2001;44 Suppl 2:S14-21.

7. Kahn SE. The relative contributions of insulin resistance and beta-cell dysfunction to the pathophysiology of Type 2 diabetes. Diabetologia. 2003;46(1):3-19.

8. DeFronzo RA, Jacot E, Jequier E, Maeder E, Wahren J, Felber JP. The effect of insulin on the disposal of intravenous glucose. Results from indirect calorimetry and hepatic and femoral venous catheterization. Diabetes. 1981;30(12):1000-1007.

9. Coppack SW, Frayn KN, Humphreys SM, Dhar H, Hockaday TD. Effects of insulin on human adipose tissue metabolism in vivo. Clin Sci (Lond). 1989;77(6):663-670.

10. Hall JE, Guyton AC. Guyton and Hall Textbook of Medical Physiology. 13th Revised edition ed: Elsevier Health Sciences 2015.

11. Jaldin-Fincati JR, Pavarotti M, Frendo-Cumbo S, Bilan PJ, Klip A. Update on GLUT4 Vesicle Traffic: A Cornerstone of Insulin Action. Trends Endocrinol Metab. 2017;28(8):597-611.

12. Carnagarin R, Dharmarajan AM, Dass CR. Molecular aspects of glucose homeostasis in skeletal muscle--A focus on the molecular mechanisms of insulin resistance. Mol Cell Endocrinol. 2015;417: $52-62$.

13. Goodyear L, Kahn BB. Exercise, glucose transport, and insulin sensitivity. Annu Rev Med. 1998;49: 235-261.

14. Koonen DP, Glatz JF, Bonen A, Luiken JJ. Long-chain fatty acid uptake and FAT/CD36 translocation in heart and skeletal muscle. Biochim Biophys Acta. 2005;1736(3):163-180.

15. King PA, Horton ED, Hirshman MF, Horton ES. Insulin resistance in obese Zucker rat (fa/fa) skeletal muscle is associated with a failure of glucose transporter translocation. J Clin Invest. 1992;90(4): 1568-1575.

16. Sherwin RS, Kramer KJ, Tobin JD, et al. A model of the kinetics of insulin in man. J Clin Invest. 1974;53(5):1481-1492.

17. DeFronzo RA, Tobin JD, Andres R. Glucose clamp technique: a method for quantifying insulin secretion and resistance. Am J Physiol. 1979;237(3):E214-223.

18. Hauner $\mathrm{H}$. The new concept of adipose tissue function. Physiol Behav. 2004;83(4):653-658.

19. Sun K, Kusminski CM, Scherer PE. Adipose tissue remodeling and obesity. J Clin Invest. 2011; 121(6):2094-2101.

20. Heilbronn L, Smith SR, Ravussin E. Failure of fat cell proliferation, mitochondrial function and fat oxidation results in ectopic fat storage, insulin resistance and type II diabetes mellitus. Int J Obes Relat Metab Disord. 2004;28 Suppl 4:S12-21.

21. Weyer C, Foley JE, Bogardus C, Tataranni PA, Pratley RE. Enlarged subcutaneous abdominal adipocyte size, but not obesity itself, predicts type II diabetes independent of insulin resistance. Diabetologia. 2000;43(12):1498-1506.

22. Britton KA, Fox CS. Ectopic fat depots and cardiovascular disease. Circulation. 2011;124(24):e837-841.

23. Despres JP, Lemieux I, Bergeron J, et al. Abdominal obesity and the metabolic syndrome: contribution to global cardiometabolic risk. Arterioscler Thromb Vasc Biol. 2008;28(6):1039-1049. 
24. Lee MJ, Wu Y, Fried SK. Adipose tissue remodeling in pathophysiology of obesity. Curr Opin Clin Nutr Metab Care. 2010;13(4):371-376.

25. Skurk T, Alberti-Huber C, Herder C, Hauner H. Relationship between adipocyte size and adipokine expression and secretion. J Clin Endocrinol Metab. 2007;92(3):1023-1033.

26. Carvalheira JB, Qiu Y, Chawla A. Blood spotlight on leukocytes and obesity. Blood. 2013;122(19): 3263-3267.

27. Ohman MK, Wright AP, Wickenheiser KJ, Luo W, Eitzman DT. Visceral adipose tissue and atherosclerosis. Curr Vasc Pharmacol. 2009;7(2):169-179.

28. Weisberg SP, McCann D, Desai M, Rosenbaum M, Leibel RL, Ferrante AW, Jr. Obesity is associated with macrophage accumulation in adipose tissue. J Clin Invest. 2003;112(12):1796-1808.

29. Xu H, Barnes GT, Yang Q, et al. Chronic inflammation in fat plays a crucial role in the development of obesity-related insulin resistance. J Clin Invest. 2003;112(12):1821-1830.

30. Lumeng CN, Bodzin JL, Saltiel AR. Obesity induces a phenotypic switch in adipose tissue macrophage polarization. J Clin Invest. 2007;117(1):175-184.

31. Hotamisligil GS, Shargill NS, Spiegelman BM. Adipose expression of tumor necrosis factor-alpha: direct role in obesity-linked insulin resistance. Science. 1993;259(5091):87-91.

32. Wentworth JM, Naselli G, Brown WA, et al. Pro-inflammatory CD11C+CD206+ adipose tissue macrophages are associated with insulin resistance in human obesity. Diabetes. 2010;59(7):16481656.

33. Lee BC, Kim MS, Pae M, et al. Adipose Natural Killer Cells Regulate Adipose Tissue Macrophages to Promote Insulin Resistance in Obesity. Cell Metab. 2016;23(4):685-698.

34. Theurich S, Tsaousidou E, Hanssen R, et al. IL-6/Stat3-Dependent Induction of a Distinct, ObesityAssociated NK Cell Subpopulation Deteriorates Energy and Glucose Homeostasis. Cell Metab. 2017;26(1):171-184 e176.

35. Wensveen FM, Jelencic V, Valentic S, et al. NK cells link obesity-induced adipose stress to inflammation and insulin resistance. Nat Immunol. 2015;16(4):376-385.

36. Vivier $\mathrm{E}$, Raulet $\mathrm{DH}$, Moretta A, et al. Innate or adaptive immunity? The example of natural killer cells. Science. 2011;331(6013):44-49.

37. O'Rourke RW, Gaston GD, Meyer KA, White AE, Marks DL. Adipose tissue NK cells manifest an activated phenotype in human obesity. Metabolism. 2013;62(11):1557-1561.

38. Preis SR, Massaro JM, Robins SJ, et al. Abdominal subcutaneous and visceral adipose tissue and insulin resistance in the Framingham heart study. Obesity (Silver Spring). 2010;18(11):2191-2198.

39. Marin P, Andersson B, Ottosson M, et al. The morphology and metabolism of intraabdominal adipose tissue in men. Metabolism. 1992;41(11):1242-1248.

40. Kershaw EE, Flier JS. Adipose tissue as an endocrine organ. J Clin Endocrinol Metab. 2004;89(6): 2548-2556.

41. Gealekman O, Guseva N, Hartigan C, et al. Depot-specific differences and insufficient subcutaneous adipose tissue angiogenesis in human obesity. Circulation. 2011;123(2):186-194.

42. Fox CS, Massaro JM, Hoffmann $U$, et al. Abdominal visceral and subcutaneous adipose tissue compartments: association with metabolic risk factors in the Framingham Heart Study. Circulation. 2007;116(1):39-48.

43. Stefan N, Haring HU, Hu FB, Schulze MB. Metabolically healthy obesity: epidemiology, mechanisms, and clinical implications. Lancet Diabetes Endocrinol. 2013;1(2):152-162.

44. Chalasani N, Younossi Z, Lavine JE, et al. The diagnosis and management of non-alcoholic fatty liver disease: practice guideline by the American Gastroenterological Association, American Association for the Study of Liver Diseases, and American College of Gastroenterology. Gastroenterology. 2012; 142(7):1592-1609.

45. Murphy AM, Morine M, Finucane $O$, et al. Monounsaturated fatty acid enriched high fat diets attenuate obesity induced hyperinsulinaemia concurrent with an altered hepatic lipidome. EASD Annual Meeting; 2015; Stockholm, Sweden.

46. Byrne CD. Dorothy Hodgkin Lecture 2012: non-alcoholic fatty liver disease, insulin resistance and ectopic fat: a new problem in diabetes management. Diabet Med. 2012;29(9):1098-1107. 
47. Apostolopoulou M, Gordillo R, Koliaki C, et al. Specific Hepatic Sphingolipids Relate to Insulin Resistance, Oxidative Stress, and Inflammation in Nonalcoholic Steatohepatitis. Diabetes Care. 2018;41(6):1235-1243.

48. Anstee QM, Targher G, Day CP. Progression of NAFLD to diabetes mellitus, cardiovascular disease or cirrhosis. Nat Rev Gastroenterol Hepatol. 2013;10(6):330-344.

49. Yki-Jarvinen $\mathrm{H}$. Non-alcoholic fatty liver disease as a cause and a consequence of metabolic syndrome. Lancet Diabetes Endocrinol. 2014;2(11):901-910.

50. Shibata M, Kihara Y, Taguchi M, Tashiro M, Otsuki M. Nonalcoholic fatty liver disease is a risk factor for type 2 diabetes in middle-aged Japanese men. Diabetes Care. 2007;30(11):2940-2944.

51. Choi JH, Rhee EJ, Bae JC, et al. Increased risk of type 2 diabetes in subjects with both elevated liver enzymes and ultrasonographically diagnosed nonalcoholic fatty liver disease: a 4-year longitudinal study. Arch Med Res. 2013;44(2):115-120.

52. Park SK, Seo MH, Shin HC, Ryoo JH. Clinical availability of nonalcoholic fatty liver disease as an early predictor of type 2 diabetes mellitus in Korean men: 5-year prospective cohort study. Hepatology. 2013;57(4):1378-1383.

53. Stepanova M, Younossi ZM. Independent association between nonalcoholic fatty liver disease and cardiovascular disease in the US population. Clin Gastroenterol Hepatol. 2012;10(6):646-650.

54. Brown TM. Nonalcoholic fatty liver disease and cardiovascular disease risk. Clin Gastroenterol Hepatol. 2012;10(6):568-569.

55. Magkos F, Fraterrigo G, Yoshino J, et al. Effects of Moderate and Subsequent Progressive Weight Loss on Metabolic Function and Adipose Tissue Biology in Humans with Obesity. Cell Metab. 2016; 23(4):591-601.

56. Sanyal AJ, Chalasani N, Kowdley KV, et al. Pioglitazone, vitamin E, or placebo for nonalcoholic steatohepatitis. N Engl J Med. 2010;362(18):1675-1685.

57. Thomsen C, Becker U, Winkler K, Christoffersen P, Jensen M, Henriksen O. Quantification of liver fat using magnetic resonance spectroscopy. Magn Reson Imaging. 1994;12(3):487-495.

58. Cowin GJ, Jonsson JR, Bauer JD, et al. Magnetic resonance imaging and spectroscopy for monitoring liver steatosis. J Magn Reson Imaging. 2008;28(4):937-945

59. Lee SS, Park SH, Kim HJ, et al. Non-invasive assessment of hepatic steatosis: prospective comparison of the accuracy of imaging examinations. J Hepatol. 2010;52(4):579-585.

60. Longo R, Pollesello $P$, Ricci $C$, et al. Proton MR spectroscopy in quantitative in vivo determination of fat content in human liver steatosis. J Magn Reson Imaging. 1995;5(3):281-285.

61. Szczepaniak LS, Nurenberg P, Leonard D, et al. Magnetic resonance spectroscopy to measure hepatic triglyceride content: prevalence of hepatic steatosis in the general population. Am J Physiol Endocrinol Metab. 2005;288(2):E462-468.

62. Hui SCN, So HK, Chan DFY, et al. Validation of water-fat MRI and proton MRS in assessment of hepatic fat and the heterogeneous distribution of hepatic fat and iron in subjects with non-alcoholic fatty liver disease. Eur J Radiol. 2018;107:7-13.

63. Hernaez R, Lazo M, Bonekamp S, et al. Diagnostic accuracy and reliability of ultrasonography for the detection of fatty liver: a meta-analysis. Hepatology. 2011;54(3):1082-1090.

64. Lee JY, Kim KM, Lee SG, et al. Prevalence and risk factors of non-alcoholic fatty liver disease in potential living liver donors in Korea: a review of 589 consecutive liver biopsies in a single center. J Hepatol. 2007;47(2):239-244.

65. Cho CS, Curran S, Schwartz LH, et al. Preoperative radiographic assessment of hepatic steatosis with histologic correlation. J Am Coll Surg. 2008;206(3):480-488.

66. Kotronen A, Peltonen M, Hakkarainen A, et al. Prediction of non-alcoholic fatty liver disease and liver fat using metabolic and genetic factors. Gastroenterology. 2009;137(3):865-872.

67. Samuel VT, Shulman GI. Mechanisms for insulin resistance: common threads and missing links. Cell. 2012;148(5):852-871.

68. Gaggini M, Morelli M, Buzzigoli E, DeFronzo RA, Bugianesi E, Gastaldelli A. Non-alcoholic fatty liver disease (NAFLD) and its connection with insulin resistance, dyslipidemia, atherosclerosis and coronary heart disease. Nutrients. 2013;5(5):1544-1560. 
69. Bugianesi E, Gastaldelli A, Vanni E, et al. Insulin resistance in non-diabetic patients with non-alcoholic fatty liver disease: sites and mechanisms. Diabetologia. 2005;48(4):634-642.

70. Kotronen A, Johansson LE, Johansson LM, et al. A common variant in PNPLA3, which encodes adiponutrin, is associated with liver fat content in humans. Diabetologia. 2009;52(6):1056-1060.

71. Fabbrini E, Magkos F, Mohammed BS, et al. Intrahepatic fat, not visceral fat, is linked with metabolic complications of obesity. Proc Natl Acad Sci U S A. 2009;106(36):15430-15435.

72. Magkos F, Fabbrini E, Mohammed BS, Patterson BW, Klein S. Increased whole-body adiposity without a concomitant increase in liver fat is not associated with augmented metabolic dysfunction. Obesity (Silver Spring). 2010;18(8):1510-1515.

73. Liu J, Fox CS, Hickson D, Bidulescu A, Carr JJ, Taylor HA. Fatty liver, abdominal visceral fat, and cardiometabolic risk factors: the Jackson Heart Study. Arterioscler Thromb Vasc Biol. 2011;31(11): 2715-2722.

74. Levy BI, Ambrosio G, Pries AR, Struijker-Boudier HA. Microcirculation in hypertension: a new target for treatment? Circulation. 2001;104(6):735-740.

75. Emerson GG, Segal SS. Alignment of microvascular units along skeletal muscle fibers of hamster retractor. J Appl Physiol. 1997;82(1):42-48.

76. Spalteholz W. Die Vertheilung der Blutgefässe im Muskel. Leipzig: S. Hirzel; 1888.

77. Krogh A. The number and distribution of capillaries in muscles with calculations of the oxygen pressure head necessary for supplying the tissue. J Physiol. 1919;52(6):409-415

78. Krogh A. The supply of oxygen to the tissues and the regulation of the capillary circulation. J Physiol. 1919;52(6):457-474.

79. Jonk A. Microvascular actions of insulin: studies on the interaction with angiotensin II and on the postprandial state, Maastricht University; 2011.

80. Glancy B, Hsu LY, Dao L, et al. In vivo microscopy reveals extensive embedding of capillaries within the sarcolemma of skeletal muscle fibers. Microcirculation. 2014;21(2):131-147.

81. Glancy B, Hartnell LM, Malide D, et al. Mitochondrial reticulum for cellular energy distribution in muscle. Nature. 2015;523(7562):617-620.

82. Aird WC. Phenotypic heterogeneity of the endothelium: I. Structure, function, and mechanisms. Circ Res. 2007;100(2):158-173.

83. Aird WC. Phenotypic heterogeneity of the endothelium: II. Representative vascular beds. Circ Res. 2007;100(2):174-190.

84. Jonk AM, Houben AJ, de Jongh RT, Serne EH, Schaper NC, Stehouwer CD. Microvascular dysfunction in obesity: a potential mechanism in the pathogenesis of obesity-associated insulin resistance and hypertension. Physiology (Bethesda). 2007;22:252-260.

85. Steinberg HO, Chaker H, Leaming R, Johnson A, Brechtel G, Baron AD. Obesity/insulin resistance is associated with endothelial dysfunction. Implications for the syndrome of insulin resistance. J Clin Invest. 1996;97(11):2601-2610.

86. Laakso M, Edelman SV, Brechtel G, Baron AD. Decreased effect of insulin to stimulate skeletal muscle blood flow in obese man. A novel mechanism for insulin resistance. J Clin Invest. 1990;85(6):18441852.

87. Baron AD, Steinberg H, Brechtel G, Johnson A. Skeletal muscle blood flow independently modulates insulin-mediated glucose uptake. Am J Physiol. 1994;266(2 Pt 1):E248-253.

88. Kim JA, Montagnani M, Koh KK, Quon MJ. Reciprocal relationships between insulin resistance and endothelial dysfunction: molecular and pathophysiological mechanisms. Circulation. 2006;113(15): 1888-1904.

89. Serne EH, de Jongh RT, Eringa EC, RG IJ, Stehouwer CD. Microvascular dysfunction: a potential pathophysiological role in the metabolic syndrome. Hypertension. 2007;50(1):204-211.

90. Shulman GI. Cellular mechanisms of insulin resistance. J Clin Invest. 2000;106(2):171-176.

91. Clark MG, Wallis MG, Barrett EJ, et al. Blood flow and muscle metabolism: a focus on insulin action. Am J Physiol Endocrinol Metab. 2003;284(2):E241-258.

92. Kubota $\mathrm{T}$, Kubota $\mathrm{N}$, Kumagai $\mathrm{H}$, et al. Impaired insulin signaling in endothelial cells reduces insulininduced glucose uptake by skeletal muscle. Cell Metab. 2011;13(3):294-307. 
93. de Jongh RT, Serne EH, RG IJ, de Vries G, Stehouwer CD. Impaired microvascular function in obesity: implications for obesity-associated microangiopathy, hypertension, and insulin resistance. Circulation. 2004;109(21):2529-2535.

94. Ko SH, Cao W, Liu Z. Hypertension management and microvascular insulin resistance in diabetes. Curr Hypertens Rep. 2010;12(4):243-251.

95. Barrett EJ, Wang H, Upchurch CT, Liu Z. Insulin regulates its own delivery to skeletal muscle by feedforward actions on the vasculature. Am J Physiol Endocrinol Metab. 2011;301(2):E252-263.

96. Barrett EJ, Liu Z. The endothelial cell: an "early responder" in the development of insulin resistance. Rev Endocr Metab Disord. 2013;14(1):21-27.

97. Rattigan S, Clark MG, Barrett EJ. Hemodynamic actions of insulin in rat skeletal muscle: evidence for capillary recruitment. Diabetes. 1997;46(9):1381-1388.

98. Clerk LH, Vincent MA, Jahn LA, Liu Z, Lindner JR, Barrett EJ. Obesity blunts insulin-mediated microvascular recruitment in human forearm muscle. Diabetes. 2006;55(5):1436-1442.

99. Coggins M, Lindner J, Rattigan S, et al. Physiologic hyperinsulinemia enhances human skeletal muscle perfusion by capillary recruitment. Diabetes. 2001;50(12):2682-2690.

100. Jonk AM, Houben AJ, Schaper NC, et al. Angiotensin II enhances insulin-stimulated whole-body glucose disposal but impairs insulin-induced capillary recruitment in healthy volunteers. J Clin Endocrinol Metab. 2010;95(8):3901-3908.

101. Jonk AM, Houben AJ, Schaper NC, et al. Acute angiotensin II receptor blockade improves insulininduced microvascular function in hypertensive individuals. Microvasc Res. 2011;82(1):77-83.

102. Muris DM, Houben AJ, Schram MT, Stehouwer CD. Microvascular dysfunction: an emerging pathway in the pathogenesis of obesity-related insulin resistance. Rev Endocr Metab Disord. 2013;14(1):29-38.

103. Eringa EC, Stehouwer CD, Walburg K, et al. Physiological concentrations of insulin induce endothelindependent vasoconstriction of skeletal muscle resistance arteries in the presence of tumor necrosis factor-alpha dependence on c-Jun N-terminal kinase. Arterioscler Thromb Vasc Biol. 2006;26(2): 274-280.

104. Rahmouni K, Mark AL, Haynes WG, Sigmund CD. Adipose depot-specific modulation of angiotensinogen gene expression in diet-induced obesity. Am J Physiol Endocrinol Metab. 2004; 286(6):E891-895.

105. Andreozzi F, Laratta E, Sciacqua A, Perticone F, Sesti G. Angiotensin II impairs the insulin signaling pathway promoting production of nitric oxide by inducing phosphorylation of insulin receptor substrate-1 on Ser312 and Ser616 in human umbilical vein endothelial cells. Circ Res. 2004; 94(9):1211-1218.

106. Velloso LA, Folli F, Sun XJ, White MF, Saad MJ, Kahn CR. Cross-talk between the insulin and angiotensin signaling systems. Proc Natl Acad Sci U S A. 1996;93(22):12490-12495.

107. Rajagopalan S, Kurz S, Munzel T, et al. Angiotensin Il-mediated hypertension in the rat increases vascular superoxide production via membrane NADH/NADPH oxidase activation. Contribution to alterations of vasomotor tone. J Clin Invest. 1996;97(8):1916-1923.

108. Zhou MS, Schulman IH, Raij L. Role of angiotensin II and oxidative stress in vascular insulin resistance linked to hypertension. Am J Physiol Heart Circ Physiol. 2009;296(3):H833-839.

109. Hong HJ, Chan P, Liu JC, et al. Angiotensin II induces endothelin-1 gene expression via extracellular signal-regulated kinase pathway in rat aortic smooth muscle cells. Cardiovasc Res. 2004;61(1): 159-168.

110. Imai T, Hirata Y, Emori T, Yanagisawa M, Masaki T, Marumo F. Induction of endothelin-1 gene by angiotensin and vasopressin in endothelial cells. Hypertension. 1992;19(6 Pt 2):753-757.

111. Wang H, Liu Z, Li G, Barrett EJ. The vascular endothelial cell mediates insulin transport into skeletal muscle. Am J Physiol Endocrinol Metab. 2006;291(2):E323-332.

112. Wang $\mathrm{H}$, Wang $\mathrm{AX}$, Barrett EJ. Caveolin-1 is required for vascular endothelial insulin uptake. Am J Physiol Endocrinol Metab. 2011;300(1):E134-144.

113. Wang $\mathrm{H}$, Wang AX, Aylor K, Barrett EJ. Caveolin-1 phosphorylation regulates vascular endothelial insulin uptake and is impaired by insulin resistance in rats. Diabetologia. 2015;58(6):1344-1353.

114. Mann GE, Yudilevich DL, Sobrevia L. Regulation of amino acid and glucose transporters in endothelial and smooth muscle cells. Physiol Rev. 2003;83(1):183-252. 
115. Jones TW. Discovery that the veins of the bat's wing (which are furnished with valves) are endowed with rythmical contractility, and that the onward flow of blood is accelerated by each contraction. Philosophical Transactions of the Royal Society of London. 1852;142:131-136.

116. Bagher P, Segal SS. Regulation of blood flow in the microcirculation: role of conducted vasodilation. Acta Physiol (Oxf). 2011;202(3):271-284.

117. Beach JM, McGahren ED, Duling BR. Capillaries and arterioles are electrically coupled in hamster cheek pouch. Am J Physiol. 1998;275(4):H1489-1496.

118. Song $\mathrm{H}, \mathrm{Tyml} \mathrm{K}$. Evidence for sensing and integration of biological signals by the capillary network. Am J Physiol. 1993;265(4 Pt 2):H1235-1242.

119. Domeier TL, Segal SS. Electromechanical and pharmacomechanical signalling pathways for conducted vasodilatation along endothelium of hamster feed arteries. J Physiol. 2007;579(Pt 1):175-186.

120. Honig $\mathrm{CR}$, Odoroff $\mathrm{CL}$, Frierson JL. Capillary recruitment in exercise: rate, extent, uniformity, and relation to blood flow. Am J Physiol. 1980;238(1):H31-42.

121. Yudkin JS, Eringa E, Stehouwer CD. "Vasocrine" signalling from perivascular fat: a mechanism linking insulin resistance to vascular disease. Lancet. 2005;365(9473):1817-1820.

122. Meijer RI, Serne EH, Yudkin JS, van Hinsbergh VW, Smulders YM, Eringa EC. Perivascular fat in human muscle. Lancet Diabetes Endocrinol. 2016;4(11):958.

123. Meijer RI, Serne EH, Smulders YM, van Hinsbergh VW, Yudkin JS, Eringa EC. Perivascular adipose tissue and its role in type 2 diabetes and cardiovascular disease. Curr Diab Rep. 2011;11(3):211-217.

124. Bakker W, Eringa EC, Sipkema P, van Hinsbergh VW. Endothelial dysfunction and diabetes: roles of hyperglycemia, impaired insulin signaling and obesity. Cell Tissue Res. 2009;335(1):165-189.

125. Meijer RI. Regulation of Microvascular Insulin-Sensitivity by Perivascular Adipose Tissue: A Translational Approach 2014

126. Meijer RI, Bakker W, Alta CL, et al. Perivascular adipose tissue control of insulin-induced vasoreactivity in muscle is impaired in db/db mice. Diabetes. 2013;62(2):590-598.

127. de Boer MP, Meijer RI, Richter EA, et al. Globular adiponectin controls insulin-mediated vasoreactivity in muscle through AMPKalpha2. Vascul Pharmacol. 2016;78:24-35.

128. Meijer RI, Serne EH, Korkmaz HI, et al. Insulin-induced changes in skeletal muscle microvascular perfusion are dependent upon perivascular adipose tissue in women. Diabetologia. 2015;58(8): 1907-1915.

129. Ferrannini E, Mari A. beta-Cell function in type 2 diabetes. Metabolism. 2014;63(10):1217-1227.

130. Ferrannini E, Natali A, Muscelli E, et al. Natural history and physiological determinants of changes in glucose tolerance in a non-diabetic population: the RISC Study. Diabetologia. 2011;54(6):1507-1516.

131. Prentki M, Nolan CJ. Islet beta cell failure in type 2 diabetes. J Clin Invest. 2006;116(7):1802-1812.

132. Ferrannini E, Camastra S, Gastaldelli A, et al. beta-cell function in obesity: effects of weight loss. Diabetes. 2004;53 Suppl 3:S26-33.

133. Robertson RP, Harmon J, Tran PO, Poitout V. Beta-cell glucose toxicity, lipotoxicity, and chronic oxidative stress in type 2 diabetes. Diabetes. 2004;53 Suppl 1:S119-124.

134. Talchai C, Xuan S, Lin HV, Sussel L, Accili D. Pancreatic beta cell dedifferentiation as a mechanism of diabetic beta cell failure. Cell. 2012;150(6):1223-1234.

135. Dor Y, Glaser B. beta-cell dedifferentiation and type 2 diabetes. N Engl J Med. 2013;368(6):572-573.

136. White MG, Marshall HL, Rigby R, et al. Expression of mesenchymal and alpha-cell phenotypic markers in islet beta-cells in recently diagnosed diabetes. Diabetes Care. 2013;36(11):3818-3820.

137. White MG, Shaw JA, Taylor R. Type 2 Diabetes: The Pathologic Basis of Reversible beta-Cell Dysfunction. Diabetes Care. 2016;39(11):2080-2088.

138. Spijker HS, Song H, Ellenbroek JH, et al. Loss of beta-Cell Identity Occurs in Type 2 Diabetes and Is Associated With Islet Amyloid Deposits. Diabetes. 2015;64(8):2928-2938.

139. Rahier J, Guiot Y, Goebbels RM, Sempoux C, Henquin JC. Pancreatic beta-cell mass in European subjects with type 2 diabetes. Diabetes Obes Metab. 2008;10 Suppl 4:32-42.

140. Butler AE, Janson J, Bonner-Weir S, Ritzel R, Rizza RA, Butler PC. Beta-cell deficit and increased betacell apoptosis in humans with type 2 diabetes. Diabetes. 2003;52(1):102-110.

141. Mari A, Tura A, Gastaldelli A, Ferrannini E. Assessing insulin secretion by modeling in multiple-meal tests: role of potentiation. Diabetes. 2002;51 Suppl 1:S221-226. 
142. Tura A, Muscelli E, Gastaldelli A, Ferrannini E, Mari A. Altered pattern of the incretin effect as assessed by modelling in individuals with glucose tolerance ranging from normal to diabetic. Diabetologia. 2014;57(6):1199-1203.

143. Mari A, Tura A, Natali A, et al. Influence of hyperinsulinemia and insulin resistance on in vivo beta-cell function: their role in human beta-cell dysfunction. Diabetes. 2011;60(12):3141-3147.

144. Walker M, Mari A, Jayapaul MK, Bennett SM, Ferrannini E. Impaired beta cell glucose sensitivity and whole-body insulin sensitivity as predictors of hyperglycaemia in non-diabetic subjects. Diabetologia. 2005;48(12):2470-2476.

145. Mari A, Schmitz O, Gastaldelli A, Oestergaard T, Nyholm B, Ferrannini E. Meal and oral glucose tests for assessment of beta -cell function: modeling analysis in normal subjects. Am J Physiol Endocrinol Metab. 2002;283(6):E1159-1166.

146. Ferrannini E, Gastaldelli A, Miyazaki Y, Matsuda M, Mari A, DeFronzo RA. beta-Cell function in subjects spanning the range from normal glucose tolerance to overt diabetes: a new analysis. J Clin Endocrinol Metab. 2005;90(1):493-500.

147. Biggelaar L, Eussen SJ, Sep SJ, et al. Associations of Dietary Glucose, Fructose, and Sucrose with betaCell Function, Insulin Sensitivity, and Type 2 Diabetes in the Maastricht Study. Nutrients. 2017;9(4).

148. Rijkelijkhuizen JM, Girman CJ, Mari A, et al. Classical and model-based estimates of beta-cell function during a mixed meal vs. an OGTT in a population-based cohort. Diabetes Res Clin Pract. 2009; 83(2):280-288.

149. Hurwitz BE, Schneiderman N, Marks JB, et al. Adaptation of beta-Cell and Endothelial Function to Carbohydrate Loading: Influence of Insulin Resistance. Diabetes. 2015;64(7):2550-2559.

150. Camastra S, Manco M, Mari A, et al. beta-cell function in morbidly obese subjects during free living: long-term effects of weight loss. Diabetes. 2005;54(8):2382-2389.

151. Camastra S, Muscelli E, Gastaldelli A, et al. Long-term effects of bariatric surgery on meal disposal and beta-cell function in diabetic and nondiabetic patients. Diabetes. 2013;62(11):3709-3717.

152. Lim EL, Hollingsworth KG, Aribisala BS, Chen MJ, Mathers JC, Taylor R. Reversal of type 2 diabetes: normalisation of beta cell function in association with decreased pancreas and liver triacylglycerol. Diabetologia. 2011;54(10):2506-2514.

153. Heni M, Machann J, Staiger $\mathrm{H}$, et al. Pancreatic fat is negatively associated with insulin secretion in individuals with impaired fasting glucose and/or impaired glucose tolerance: a nuclear magnetic resonance study. Diabetes Metab Res Rev. 2010;26(3):200-205.

154. Tushuizen ME, Bunck MC, Pouwels PJ, et al. Pancreatic fat content and beta-cell function in men with and without type 2 diabetes. Diabetes Care. 2007;30(11):2916-2921.

155. Ogilvie RF. The islands of Langerhans in 19 cases of obesity. The Journal of Pathology and Bacteriology. 1933;37(3):473-481.

156. Olsen TS. Lipomatosis of the pancreas in autopsy material and its relation to age and overweight. Acta Pathol Microbiol Scand A. 1978;86A(5):367-373.

157. Saisho $\mathrm{Y}$, Butler AE, Meier JJ, et al. Pancreas volumes in humans from birth to age one hundred taking into account sex, obesity, and presence of type-2 diabetes. Clin Anat. 2007;20(8):933-942.

158. Saisho Y. Pancreas Volume and Fat Deposition in Diabetes and Normal Physiology: Consideration of the Interplay Between Endocrine and Exocrine Pancreas. Rev Diabet Stud. 2016;13(2-3):132-147.

159. Saisho Y, Butler AE, Butler PC. Pancreatic fat content and beta-cell function in men with and without type 2 diabetes: response to Tushuizen et al. Diabetes Care. 2008;31(5):e38; author reply e39.

160. Pinnick KE, Collins SC, Londos C, Gauguier D, Clark A, Fielding BA. Pancreatic ectopic fat is characterized by adipocyte infiltration and altered lipid composition. Obesity (Silver Spring). 2008; 16(3):522-530.

161. Lee $Y$, Hirose H, Ohneda M, Johnson JH, McGarry JD, Unger RH. Beta-cell lipotoxicity in the pathogenesis of non-insulin-dependent diabetes mellitus of obese rats: impairment in adipocytebeta-cell relationships. Proc Natl Acad Sci U S A. 1994;91(23):10878-10882.

162. Lee Y, Lingvay I, Szczepaniak LS, Ravazzola M, Orci L, Unger RH. Pancreatic steatosis: harbinger of type 2 diabetes in obese rodents. Int J Obes (Lond). 2010;34(2):396-400.

163. Taylor R. Pathogenesis of type 2 diabetes: tracing the reverse route from cure to cause. Diabetologia. 2008;51(10):1781-1789. 
164. Boucher A, Lu D, Burgess SC, et al. Biochemical mechanism of lipid-induced impairment of glucosestimulated insulin secretion and reversal with a malate analogue. J Biol Chem. 2004;279(26): 27263-27271.

165. Gerst F, Wagner R, Kaiser G, et al. Metabolic crosstalk between fatty pancreas and fatty liver: effects on local inflammation and insulin secretion. Diabetologia. 2017;60(11):2240-2251.

166. Eguchi K, Manabe I, Oishi-Tanaka Y, et al. Saturated fatty acid and TLR signaling link beta cell dysfunction and islet inflammation. Cell Metab. 2012;15(4):518-533.

167. Iwase M, Tashiro K, Uchizono Y, Goto D, Yoshinari M. Pancreatic islet blood flow in conscious rats during hyperglycemia and hypoglycemia. Am J Physiol Regul Integr Comp Physiol. 2001;280(6): R1601-1605.

168. Hogan MF, Hull RL. The islet endothelial cell: a novel contributor to beta cell secretory dysfunction in diabetes. Diabetologia. 2017;60(6):952-959.

169. van der Zijl NJ, Goossens GH, Moors CC, et al. Ectopic fat storage in the pancreas, liver, and abdominal fat depots: impact on beta-cell function in individuals with impaired glucose metabolism. J Clin Endocrinol Metab. 2011;96(2):459-467.

170. Szczepaniak LS, Victor RG, Mathur R, et al. Pancreatic steatosis and its relationship to beta-cell dysfunction in humans: racial and ethnic variations. Diabetes Care. 2012;35(11):2377-2383.

171. Nowotny B, Kahl S, Kluppelholz B, et al. Circulating triacylglycerols but not pancreatic fat associate with insulin secretion in healthy humans. Metabolism. 2018;81:113-125.

172. Honka H, Hannukainen JC, Tarkia M, et al. Pancreatic metabolism, blood flow, and beta-cell function in obese humans. J Clin Endocrinol Metab. 2014;99(6):E981-990.

173. Steven S, Hollingsworth KG, Al-Mrabeh A, et al. Very Low-Calorie Diet and 6 Months of Weight Stability in Type 2 Diabetes: Pathophysiological Changes in Responders and Nonresponders. Diabetes Care. 2016;39(5):808-815.

174. Gaborit B, Abdesselam I, Kober F, et al. Ectopic fat storage in the pancreas using $1 \mathrm{H}-\mathrm{MRS}$ : importance of diabetic status and modulation with bariatric surgery-induced weight loss. Int J Obes (Lond). 2015;39(3):480-487.

175. Honka H, Koffert J, Hannukainen JC, et al. The effects of bariatric surgery on pancreatic lipid metabolism and blood flow. J Clin Endocrinol Metab. 2015;100(5):2015-2023.

176. Cohn JN, Quyyumi AA, Hollenberg NK, Jamerson KA. Surrogate markers for cardiovascular disease: functional markers. Circulation. 2004;109(25 Suppl 1):IV31-46.

177. Mancini GB, Dahlof B, Diez J. Surrogate markers for cardiovascular disease: structural markers. Circulation. 2004;109(25 Suppl 1):IV22-30.

178. Lusis AJ. Atherosclerosis. Nature. 2000;407(6801):233-241.

179. Hansson GK. Inflammation, atherosclerosis, and coronary artery disease. N Engl J Med. 2005;352(16): 1685-1695.

180. Borissoff JI, Spronk HM, ten Cate H. The hemostatic system as a modulator of atherosclerosis. N Engl J Med. 2011;364(18):1746-1760.

181. de Jager J, Dekker JM, Kooy A, et al. Endothelial dysfunction and low-grade inflammation explain much of the excess cardiovascular mortality in individuals with type 2 diabetes: the Hoorn Study. Arterioscler Thromb Vasc Biol. 2006;26(5):1086-1093.

182. Jager A, van Hinsbergh VW, Kostense PJ, et al. von Willebrand factor, C-reactive protein, and 5-year mortality in diabetic and nondiabetic subjects: the Hoorn Study. Arterioscler Thromb Vasc Biol. 1999;19(12):3071-3078.

183. Blankenberg S, Rupprecht HJ, Bickel C, et al. Circulating cell adhesion molecules and death in patients with coronary artery disease. Circulation. 2001;104(12):1336-1342.

184. Morange PE, Simon C, Alessi MC, et al. Endothelial cell markers and the risk of coronary heart disease: the Prospective Epidemiological Study of Myocardial Infarction (PRIME) study. Circulation. 2004;109(11):1343-1348.

185. Becker A, van Hinsbergh VW, Jager A, et al. Why is soluble intercellular adhesion molecule-1 related to cardiovascular mortality? Eur J Clin Invest. 2002;32(1):1-8. 
186. Ridker PM, Hennekens CH, Roitman-Johnson B, Stampfer MJ, Allen J. Plasma concentration of soluble intercellular adhesion molecule 1 and risks of future myocardial infarction in apparently healthy men. Lancet. 1998;351(9096):88-92.

187. Laurent $\mathrm{S}$, Boutouyrie $\mathrm{P}$, Asmar $\mathrm{R}$, et al. Aortic stiffness is an independent predictor of all-cause and cardiovascular mortality in hypertensive patients. Hypertension. 2001;37(5):1236-1241.

188. Vlachopoulos C, Aznaouridis K, Stefanadis C. Prediction of cardiovascular events and all-cause mortality with arterial stiffness: a systematic review and meta-analysis. J Am Coll Cardiol. 2010;55(13):1318-1327.

189. Celermajer DS, Sorensen KE, Gooch VM, et al. Non-invasive detection of endothelial dysfunction in children and adults at risk of atherosclerosis. Lancet. 1992;340(8828):1111-1115.

190. Jin RC, Loscalzo J. Vascular Nitric Oxide: Formation and Function. J Blood Med. 2010;2010(1):147-162.

191. Yeboah J, Crouse JR, Hsu FC, Burke GL, Herrington DM. Brachial flow-mediated dilation predicts incident cardiovascular events in older adults: the Cardiovascular Health Study. Circulation. 2007;115(18):2390-2397.

192. Yeboah J, Folsom AR, Burke GL, et al. Predictive value of brachial flow-mediated dilation for incident cardiovascular events in a population-based study: the multi-ethnic study of atherosclerosis. Circulation. 2009;120(6):502-509.

193. Ras RT, Streppel MT, Draijer R, Zock PL. Flow-mediated dilation and cardiovascular risk prediction: a systematic review with meta-analysis. Int J Cardiol. 2013;168(1):344-351.

194. Nohria A, Gerhard-Herman M, Creager MA, Hurley S, Mitra D, Ganz P. Role of nitric oxide in the regulation of digital pulse volume amplitude in humans. J Appl Physiol. 2006; 101(2):545-548.

195. van Bussel BC, Henry RM, Schalkwijk CG, Dekker JM, Nijpels G, Stehouwer CD. Low-grade inflammation, but not endothelial dysfunction, is associated with greater carotid stiffness in the elderly: the Hoorn Study. J Hypertens. 2012;30(4):744-752.

196. van Bussel BC, Ferreira I, van de Waarenburg MP, et al. Multiple inflammatory biomarker detection in a prospective cohort study: a cross-validation between well-established single-biomarker techniques and an electrochemiluminescense-based multi-array platform. PLoS One. 2013;8(3):e58576.

197. Ross R. Atherosclerosis--an inflammatory disease. N Engl J Med. 1999;340(2):115-126.

198. Izzo JL, Jr., Mitchell GF. Aging and arterial structure-function relations. Adv Cardiol. 2007;44:19-34.

199. Greenwald SE. Ageing of the conduit arteries. J Pathol. 2007;211(2):157-172.

200. van Eupen MG, Schram MT, van Sloten TT, et al. Skin Autofluorescence and Pentosidine Are Associated With Aortic Stiffening: The Maastricht Study. Hypertension. 2016;68(4):956-963.

201. Laurent S, Cockcroft J, Van Bortel L, et al. Expert consensus document on arterial stiffness: methodological issues and clinical applications. Eur Heart J. 2006;27(21):2588-2605.

202. Mitchell GF. Effects of central arterial aging on the structure and function of the peripheral vasculature: implications for end-organ damage. J Appl Physiol. 2008;105(5):1652-1660.

203. Kaess BM, Rong J, Larson MG, et al. Aortic stiffness, blood pressure progression, and incident hypertension. JAMA. 2012;308(9):875-881.

204. Ganesan $\mathrm{P}, \mathrm{He} \mathrm{S}, \mathrm{Xu} \mathrm{H}$. Modelling of pulsatile blood flow in arterial trees of retinal vasculature. Med Eng Phys. 2011;33(7):810-823.

205. McGeechan K, Liew G, Macaskill P, et al. Meta-analysis: retinal vessel caliber and risk for coronary heart disease. Ann Intern Med. 2009;151(6):404-413.

206. McGeechan K, Liew G, Macaskill P, et al. Prediction of incident stroke events based on retinal vessel caliber: a systematic review and individual-participant meta-analysis. Am J Epidemiol. 2009;170(11): 1323-1332.

207. Yudkin JS, Lipska KJ, Montori VM. The idolatry of the surrogate. BMJ. 2011;343:d7995.

208. McNulty SJ, Williams P. Bad medicine: using surrogate markers. BMJ. 2014;348:g2012.

209. Freemantle N, Calvert M. Composite and surrogate outcomes in randomised controlled trials. BMJ. 2007;334(7597):756-757.

210. la Cour JL, Brok J, Gotzsche PC. Inconsistent reporting of surrogate outcomes in randomised clinical trials: cohort study. BMJ. 2010;341:c3653.

211. Moynihan R. Surrogates under scrutiny: fallible correlations, fatal consequences. BMJ. 2011;343: d5160. 
212. Ciani O, Buyse M, Garside R, et al. Comparison of treatment effect sizes associated with surrogate and final patient relevant outcomes in randomised controlled trials: meta-epidemiological study. BMJ. 2013;346:f457.

213. Knopf K, Baum M, Shimp WS, et al. Interpretation of surrogate endpoints in the era of the 21st Century Cures Act. BMJ. 2016;355:i6286.

214. Kirchhoff K, Kantartzis K, Machann J, et al. Impact of different fat depots on insulin sensitivity: predominant role of liver fat. J Diabetes Sci Technol. 2007;1(5):753-759.

215. Ross R, Aru J, Freeman J, Hudson R, Janssen I. Abdominal adiposity and insulin resistance in obese men. Am J Physiol Endocrinol Metab. 2002;282(3):E657-663.

216. Rendell M, Hulthen UL, Tornquist C, Groop L, Mattiasson I. Relationship between abdominal fat compartments and glucose and lipid metabolism in early postmenopausal women. J Clin Endocrinol Metab. 2001;86(2):744-749.

217. Eggleston EM, Jahn LA, Barrett EJ. Early microvascular recruitment modulates subsequent insulinmediated skeletal muscle glucose metabolism during lipid infusion. Diabetes Care. 2013;36(1): 104-110.

218. Kashyap SR, Bhatt DL, Wolski K, et al. Metabolic effects of bariatric surgery in patients with moderate obesity and type 2 diabetes: analysis of a randomized control trial comparing surgery with intensive medical treatment. Diabetes Care. 2013;36(8):2175-2182.

219. Bradley D, Conte C, Mittendorfer B, et al. Gastric bypass and banding equally improve insulin sensitivity and beta cell function. J Clin Invest. 2012;122(12):4667-4674.

220. Joris PJ, Zeegers MP, Mensink RP. Weight loss improves fasting flow-mediated vasodilation in adults: a meta-analysis of intervention studies. Atherosclerosis. 2015;239(1):21-30.

221. LeBlanc ES, Patnode CD, Webber EM, Redmond N, Rushkin M, O'Connor EA. Behavioral and Pharmacotherapy Weight Loss Interventions to Prevent Obesity-Related Morbidity and Mortality in Adults: Updated Evidence Report and Systematic Review for the US Preventive Services Task Force. JAMA. 2018;320(11):1172-1191.

222. Knowler WC, Barrett-Connor E, Fowler SE, et al. Reduction in the incidence of type 2 diabetes with lifestyle intervention or metformin. N Engl J Med. 2002;346(6):393-403.

223. Lean ME, Leslie WS, Barnes AC, et al. Primary care-led weight management for remission of type 2 diabetes (DiRECT): an open-label, cluster-randomised trial. Lancet. 2018;391(10120):541-551.

224. Schauer PR, Kashyap SR, Wolski K, et al. Bariatric surgery versus intensive medical therapy in obese patients with diabetes. N Engl J Med. 2012;366(17):1567-1576.

225. Mingrone G, Panunzi S, De Gaetano A, et al. Bariatric surgery versus conventional medical therapy for type 2 diabetes. N Engl J Med. 2012;366(17):1577-1585.

226. Dixon JB, O'Brien PE, Playfair J, et al. Adjustable gastric banding and conventional therapy for type 2 diabetes: a randomized controlled trial. JAMA. 2008;299(3):316-323.

227. Blumenthal JA, Babyak MA, Hinderliter A, et al. Effects of the DASH diet alone and in combination with exercise and weight loss on blood pressure and cardiovascular biomarkers in men and women with high blood pressure: the ENCORE study. Arch Intern Med. 2010;170(2):126-135.

228. Pierce GL, Beske SD, Lawson BR, et al. Weight loss alone improves conduit and resistance artery endothelial function in young and older overweight/obese adults. Hypertension. 2008;52(1):72-79.

229. DeFronzo RA, Ferrannini E, Groop L, et al. Type 2 diabetes mellitus. Nat Rev Dis Primers. 2015;1:15019.

230. Stehouwer CDA. Microvascular Dysfunction and Hyperglycemia: A Vicious Cycle With Widespread Consequences. Diabetes. 2018;67(9):1729-1741.

231. Carlsson LMS, Sjoholm K, Karlsson C, et al. Long-term incidence of microvascular disease after bariatric surgery or usual care in patients with obesity, stratified by baseline glycaemic status: a posthoc analysis of participants from the Swedish Obese Subjects study. Lancet Diabetes Endocrinol. 2017;5(4):271-279.

232. Knowler WC, Bahnson JL, Bantle JP, et al. Effect of a long-term behavioural weight loss intervention on nephropathy in overweight or obese adults with type 2 diabetes: a secondary analysis of the Look AHEAD randomised clinical trial. Lancet Diabetes Endocrinol. 2014;2(10):801-809. 
233. Wing RR, Bolin $\mathrm{P}$, Brancati $\mathrm{FL}$, et al. Cardiovascular effects of intensive lifestyle intervention in type 2 diabetes. N Engl J Med. 2013;369(2):145-154.

234. Kim ES, Moon SD, Kim HS, et al. Diabetic peripheral neuropathy is associated with increased arterial stiffness without changes in carotid intima-media thickness in type 2 diabetes. Diabetes Care. 2011;34(6):1403-1405.

235. Zoungas S, Arima H, Gerstein HC, et al. Effects of intensive glucose control on microvascular outcomes in patients with type 2 diabetes: a meta-analysis of individual participant data from randomised controlled trials. Lancet Diabetes Endocrinol. 2017;5(6):431-437.

236. Dod HS, Bhardwaj R, Sajja V, et al. Effect of intensive lifestyle changes on endothelial function and on inflammatory markers of atherosclerosis. Am J Cardiol. 2010;105(3):362-367.

237. Shechter M, Beigel R, Freimark D, Matetzky S, Feinberg MS. Short-term sibutramine therapy is associated with weight loss and improved endothelial function in obese patients with coronary artery disease. Am J Cardiol. 2006;97(11):1650-1653.

238. Kusters YH, Schalkwijk CG, Houben AJ, et al. Independent tissue contributors to obesity-associated insulin resistance. JCI Insight. 2017;2(13).

239. Friedrich-Rust M, Romen D, Vermehren J, et al. Acoustic radiation force impulse-imaging and transient elastography for non-invasive assessment of liver fibrosis and steatosis in NAFLD. Eur $J$ Radiol. 2012;81(3):e325-331.

240. Altman DG. The scandal of poor medical research. BMJ. 1994;308(6924):283-284.

241. Smith R. Medical research-still a scandal. British Medical Journal Blog 2014. http://blogs.bmj.com/bmj/2014/01/31/richard-smith-medical-research-still-a-scandal/.

242. Andersen B. Methodological errors in medical research. Blackwell Oxford; 1990.

243. Pocock SJ, Hughes MD, Lee RJ. Statistical problems in the reporting of clinical trials. A survey of three medical journals. N Engl J Med. 1987;317(7):426-432.

244. Chalmers I, Glasziou P. Avoidable waste in the production and reporting of research evidence. Lancet. 2009;374(9683):86-89.

245. de Vet HC, Terwee CB, Knol DL, Bouter LM. When to use agreement versus reliability measures. J Clin Epidemiol. 2006;59(10):1033-1039.

246. de Vet HCW, Terwee CB, Mokkink LB, Knol DL. Measurement in Medicine - A practical guide. U.S.A., Cambridge University Press, New York; 2011.

247. de Vet HCW, Mokkink LB, Terwee CB, Hoekstra OS, Knol DL. Clinicians are right not to like Cohen's k. BMJ. 2013;346:f2125.

248. Bot SD, Terwee CB, van der Windt DA, Bouter LM, Dekker J, de Vet HC. Clinimetric evaluation of shoulder disability questionnaires: a systematic review of the literature. Ann Rheum Dis. 2004;63(4):335-341.

249. Ruta D, Garratt A. Reliability of such instruments needs to be proved. BMJ. 1996;313(7057):626-627.

250. Drubin D. Reproducibility - A Journal Editor's Perspective. Anat Rec (Hoboken). 2018;301(9): 1488-1490.

251. Mokkink LB, Terwee CB, Patrick DL, et al. The COSMIN study reached international consensus on taxonomy, terminology, and definitions of measurement properties for health-related patientreported outcomes. J Clin Epidemiol. 2010;63(7):737-745.

252. Bland JM, Altman DG. Statistical methods for assessing agreement between two methods of clinical measurement. Lancet. 1986;1(8476):307-310.

253. Shrout PE, Fleiss JL. Intraclass correlations: uses in assessing rater reliability. Psychol Bull. 1979;86(2): 420-428.

254. McGraw KO, Wong SP. Forming inferences about some intraclass correlation coefficients. Psychological Methods. 1996;1(1):30-46.

255. Giraudeau B. Negative values of the intraclass correlation coefficient are not theoretically possible. J Clin Epidemiol. 1996;49(10):1205.

256. Bartko JJ. On various intraclass correlation reliability coefficients. Psychol Bull. 1976;83(5):762.

257. Preacher KJ, Hayes AF. SPSS and SAS procedures for estimating indirect effects in simple mediation models. Behav Res Methods Instrum Comput. 2004;36(4):717-731. 
258. Kenny DA, Kashy DA, Bolger N. Data analysis in social psychology. In: Gilbert D, Fiske S, Lindzey G, eds. The handbook of social psychology. Vol 1. 4 ed. Boston: McGraw-Hill; 1998:233-265.

259. Preacher KJ, Hayes AF. Asymptotic and resampling strategies for assessing and comparing indirect effects in multiple mediator models. Behav Res Methods. 2008;40(3):879-891.

260. Hayes AF. Introduction to mediation, moderation, and conditional process analysis: A regressionbased approach. Guilford Publications; 2017.

261. Montoya AK, Hayes AF. Two-condition within-participant statistical mediation analysis: A pathanalytic framework. Psychological Methods. 2017;22(1):6-27.

262. Taylor AJ, Villines TC, Stanek EJ, et al. Extended-release niacin or ezetimibe and carotid intima-media thickness. N Engl J Med. 2009;361(22):2113-2122.

263. Hodis HN, Mack WJ, Henderson VW, et al. Vascular Effects of Early versus Late Postmenopausal Treatment with Estradiol. N Engl J Med. 2016;374(13):1221-1231.

264. Ikonomidis I, Vlastos D, Kourea K, et al. Electronic Cigarette Smoking Increases Arterial Stiffness and Oxidative Stress to a Lesser Extent Than a Single Conventional Cigarette: An Acute and Chronic Study. Circulation. 2018;137(3):303-306.

265. Celermajer DS, Adams MR, Clarkson P, et al. Passive smoking and impaired endothelium-dependent arterial dilatation in healthy young adults. N Engl J Med. 1996;334(3):150-154.

266. Tonetti MS, D'Aiuto F, Nibali L, et al. Treatment of periodontitis and endothelial function. N Engl J Med. 2007;356(9):911-920.

267. Ball JR, Micheel CM. Evaluation of biomarkers and surrogate endpoints in chronic disease. National Academies Press; 2010. 


\section{Supplementary material}

Table S1.1 - Comparison of various modalities to diagnose NAFLD and quantify IHL

\begin{tabular}{|c|c|c|c|c|c|c|c|c|c|}
\hline & $\begin{array}{c}\text { Biopsy } \\
\text { validated }\end{array}$ & $\begin{array}{c}{ }^{1} \mathrm{H}-\mathrm{MRS} \\
\text { validated }\end{array}$ & $\begin{array}{c}\text { Continuous } \\
\text { variable }\end{array}$ & $\begin{array}{c}\text { Different. } \\
\text { NASH }\end{array}$ & $\begin{array}{c}\text { Small } \\
\text { clinical } \\
\text { trials }\end{array}$ & $\begin{array}{c}\text { Large } \\
\text { (cohort) } \\
\text { studies }\end{array}$ & $\begin{array}{l}\text { Post- } \\
\text { hoc }\end{array}$ & Burden & Costs \\
\hline Liver biopsy & N/A & N/A & + & ++ & $+/-$ & - & - & ++ & $€ € € €$ \\
\hline${ }^{1} \mathrm{H}-\mathrm{MRS}$ & ++ & $\mathrm{N} / \mathrm{A}$ & + & - & ++ & $+/-$ & - & $+/-$ & $€ € €$ \\
\hline mDixon MRI & ++ & ++ & + & - & ++ & + & - & $+/-$ & $€ €$ \\
\hline $\mathrm{CT}$ & $+1-$ & $+/-$ & $+/-$ & - & - & - & - & + & $€ €$ \\
\hline Ultrasound & ++ & ++ & $+1-$ & $+/-$ & $+/-$ & + & - & - & $€ / € €$ \\
\hline Enzyme score & - & + & + & - & $+/-$ & ++ & + & - & $€$ \\
\hline
\end{tabular}

Techniques are rated whether they are validated against liver biopsies and ${ }^{1} \mathrm{H}-\mathrm{MRS}$, express $\mathrm{IHL}$ as a continuous variable, can differentiate NASH from NAFLD, are suited for small clinical trials and large (cohort) studies and can be assessed after the study is completed (i.e., post-hoc), as well as the burden for study participants and the costs. ${ }^{1} \mathrm{H}-\mathrm{MRS}(r=0.70-0.93, \mathrm{p}<0.001$, Cohen's kappa $0.66-0.75$; sensitivity $80 \%$, specificity $80 \%$; derived from $\left.{ }^{57-60}\right)$, mDixon $(r=0.94, p<0.001$; sensitivity $77 \%$, specificity $87 \%$; derived from $^{58,59}$ ) and ultrasound (sensitivity $85 \%$, which decreased with increased BMI, specificity $94 \%$, ROC 0.93 , $\mathrm{p}<0.001$; as published $\mathrm{in}^{63}$ ) are well validated against liver biopsies; CT was validated but performed rather poorly (sensitivity $11-50 \%$, specificity $77-100 \%$, accuracy decreased with increased BMI; from ${ }^{59,64,65}$ ) and enzyme scores were not biopsy validated. ${ }^{66}$ MDixon $(r=0.90-0.99 ;$ ICC $=0.82-0.98$; Cohen's kappa 0.79-0.90; $\mathrm{p}<0.001$; derived from ${ }^{58,62,238}$ ) and ultrasound ${ }^{59,63}$ are well validated against ${ }^{1} \mathrm{H}-\mathrm{MRS}$; the enzyme score was validated in a single cohort only (sensitivity $86 \%$, specificity $71 \%$, ROC 0.86; from ${ }^{66}$ ), whereas CT was validated but performed rather poorly. ${ }^{59}$ Liver biopsies, ${ }^{1} \mathrm{H}-\mathrm{MRS}$, mDixon and enzyme score express IHL as a continuous variable, whereas CT (Hounsfield units) and ultrasound (e.g., liver-to-kidney contrast) can be reported as a continuous variable that serves as a proxy for IHL. Only liver biopsies can reliably diagnose $\mathrm{NASH}$, yet elastography (e.g., transient elastography; $r=0.74, p<0.001$; ROC 0.62-0.71 for presence of $\mathrm{NASH}$; from $^{239}$ ) can provide some information on NASH status as it is measures the stiffness of liver parenchyma as a proxy for fibrosis. For small clinical trials, ${ }^{1} \mathrm{H}-\mathrm{MRS}$ or mDixon are preferred to assess IHL, although sometimes liver biopsies could be warranted to provide additional information on presence or severity of $\mathrm{NASH} ; \mathrm{CT}$, ultrasound and enzyme scores are deemed inferior to MRI-based techniques. For large (cohort) studies, costs, burden and time consumption often outweigh accuracy. Hence, enzyme scores, ultrasound and mDixon are preferred over biopsies and ${ }^{1} \mathrm{H}-\mathrm{MRS}$ (which can still be a valid option depending on a facility's infrastructure). We consider CT unfit for large (cohort) studies due to its inaccuracy, radiation exposure and costs. The enzyme score is the only test that can be performed upon completion of a study as it only requires stored serum. The burden for participants is highest for a liver biopsy, still rather high for CT because of radiation exposure, and doubtful for MRI-based techniques because of potential claustrophobic responses and noise. Costs of each technique may vary per institution, yet often biopsies are rather expensive, ${ }^{1} \mathrm{H}$-MRS is more expensive than mDixon due to longer acquisition time, and CT and ultrasound are still more expensive than laboratory tests on serum. N/A is noted when not applicable. 


\section{Appendix 1.1 - Methodological considerations}

Renown and recently deceased Dr. Altman once argued that it is, unfortunately, common in research to, either willfully or in ignorance, use the wrong techniques, use the right techniques wrongly, misinterpret their results, report results selectively, cite the literature selectively, and draw unjustified conclusions. ${ }^{240-243}$ He went on to state that huge amounts of money are wasted on research that is seriously flawed through the use of inappropriate designs, unrepresentative samples, small samples, incorrect methods of analysis, and faulty interpretation; ${ }^{240}$ the tremendous amount of money wasted was later even quantified by others. ${ }^{244}$ Moreover, Dr. Altman and others argued that although many journals lack statistical reviewers, they still advance to publish misleading research. ${ }^{240,241}$ In spite of this grim assessment of medical science, it would indeed be valuable to have quality assurance built in at the beginning of research, not the end. ${ }^{241}$

Several quality assessments, including analysis of reliability and responsiveness of measurements, can reduce bias and be performed before a clinical trial is conducted. Moreover, more advanced statistical methods, like multiple mediation analyses, can be used to address multiple competing hypothesis in a single model. Such quality assessments and statistical analysis, as briefly introduced below, are unfortunately also infrequently reported, reported in the wrong way, or disregarded altogether (chapter three). ${ }^{245-250}$ Finally, it is valuable to recognize that many outcomes in clinical studies are in fact surrogate outcomes; this has implications for the interpretation of data and treatment strategies. Here, we address reliability and responsiveness of measurements, multiple mediation analysis, and surrogate outcomes.

\section{Reliability}

An essential requirement of all measurements in patient care and research is that they are reliable. Reliability is defined as 'the extent to which scores for patients who have not changed are the same for repeated measurement under several conditions, e.g. over time, on different occasions by the same observer (intra-observer), or on the same occasion by different observers (inter-observer). ${ }^{246,251}$ The domain reliability, as defined in the COSMIN taxonomy, is divided into the measurement properties measurement error and, again, reliability. ${ }^{246,251}$ It is crucial to understand the difference between measurement error and reliability.

Parameters of measurement error relate to the concept agreement, i.e. the absolute difference between repeated measurements, and can be expressed as standard error of the measurement (SEM) and the limits of agreement (Bland and Altman method), as described in to more detail in chapter three and elsewhere. ${ }^{246,251,252}$ In brief, the 
SEM can be interpreted as the standard deviation around a single measurement (e.g., when BMI is assessed 100 consecutive times, the SD of these measurements equals the SEM) ${ }^{246}$ For the limits of agreement, often visualized in Bland-Altman plots, ${ }^{252}$ the difference between repeated measurements is calculated and a normal distribution of the difference scores is assumed. The limits of agreement represent the mean difference between measurements \pm 1.96 SD; hence, $95 \%$ of the difference scores will fall between the limits of agreement. ${ }^{246,252}$

Reliability parameters on the other hand, like intraclass correlation coefficients (ICC), which range in value from 0 (totally unreliable) to 1 (perfect reliability), relate the random error variance to the variance among subjects in a population. ${ }^{246,253-256}$ Consequently, a parameter of reliability is in fact only valid for the population it is measured in and the observers it is measured by.

\section{Responsiveness}

To evaluate changes in health status over time, measurement instruments should be able to detect these changes; i.e., the measurement instrument should be responsive. $^{246,251}$ To evaluate responsiveness of a measurement instrument, a study design should be chosen in which it is reasonable to expect that (a proportion of the) individuals would change on the construct under investigation. Otherwise, if the measurement does not change over time, it would be problematic to decide whether the subjects did not change, or whether the measurement instrument was not responsive. ${ }^{246}$ Clearly, responsiveness is only relevant for measurement instruments used in evaluative applications; if an instrument is only used for discriminating between patients at one point in time, responsiveness is not an issue. ${ }^{246,251}$

When a gold standard for change is available, the changes in the measurement instrument under investigation can be compared to changes in scores of the gold standard. ${ }^{246}$ If no gold standard is available, hypotheses are tested to assess responsiveness. For example, it could be hypothesized that when a measurement instrument is responsive, changes in the measurement instrument would be correlated to changes in scores on other instruments known to have adequate responsiveness. ${ }^{246}$

\section{Multiple mediation}

The use of multiple mediation analyses, compared to multivariate regression, can provide a superior reflection of the causal chain one tries to investigate. This helps unravel contributions to disease etiology and to develop targeted, effective therapies. $^{257}$ Specifically, the advantage of testing the mediating effect of multiple 
variables simultaneously is that one disentangles whether or not mediation is independent of the effect of the other mediators, which offers the possibility to compare competing theories against one another within a single model. ${ }^{258-260}$

In addition, particularly when potential mediators have little random error (i.e., the measurement is precise and reflects the underlying mechanism well), multiple mediation analyses can be used to estimate the proportion of the total effect that independent mediators account for. A mediated proportion is essentially the product of two effects: the regression coefficient of the association between determinant and mediator on one hand, and the regression coefficient of the association between mediator and outcome as assessed by multivariate regression analysis (i.e., with al mediators and the determinant in a single regression model) on the other. ${ }^{260}$ As multiple mediator models are in fact the integrated product of two multivariate regression models, they have a clear advantage over the conventional approach of analyzing each effect with separate regression analyses.

Over time, several modified multiple mediation analyses have been developed, like serial multiple mediation, repeated measures multiple mediation, and a combination of both. ${ }^{259-261}$ The serial multiple mediator model is able to assess mediation when it is assumed that one mediator affects another. ${ }^{260}$ This way, pathways in which each mediator is presumed to affect other mediators causally downstream, can be investigated as well as the proportion of each pathway of the total effect quantified. ${ }^{260,261}$ Repeated measures multiple mediation can be used when data from repeated measurement of the same people on variables in the mediation process is obtained, as in an $\mathrm{RCT} .^{261}$ This is considered a valuable addition to regular multiple mediation analyses where determinant, mediator, and outcome are measured at the same moment in time. Recently, a statistical method that combines serial and repeated measures multiple mediation has been developed; ${ }^{261}$ this allows for the assessment of multiple serial pathways in an RCT, for example.

\section{Surrogate outcomes}

Although frequently criticized, $^{207-213}$ surrogate outcomes are widely used in research $^{262-266}$ and new drugs are even commonly approved based on their effect on a surrogate outcome, in the absence of an effect on relevant end points. ${ }^{207,211,213,267}$ Moreover, as end points show substantially smaller responses to interventions than surrogate outcomes, ${ }^{212}$ many of the widely accepted strategies (e.g., for T2D) may be based on artificially inflated expectations. ${ }^{207}$ In addition, the use and limitations of surrogate outcomes are greatly underreported in RCTs. ${ }^{210}$ 
The acceptance of surrogate outcomes for clinical end points like CVD or mortality is, at least in part, due to the high costs, requisition of a large sample size, and increased follow-up duration of RCTs that investigate relevant cardiovascular end points; surrogate outcomes are, on the other hand, cheaper and easier to measure. ${ }^{207}$ In addition, it has been argued that innovation is delayed or obstructed if surrogate outcomes were to be disregarded. Nonetheless, surrogate outcomes should, preferably strongly, be associated with the incidence of relevant end points, as well as be involved in the causal pathway of the relevant end point. More importantly, surrogate outcomes are not intrinsically flawed; they can be helpful in treatment as well as in risk stratification, when interpreted appropriately. ${ }^{207}$ 





\section{Chapter 2}

\section{Muscle microvasculature's structural and functional specializations facilitate muscle metabolism}




\begin{abstract}
We review the evolving findings from studies that examine the relationship between the structural and functional properties of skeletal muscle's vasculature and muscle metabolism. Unique aspects of the organization of the muscle microvasculature are highlighted. We discuss the role of vasomotion at the microscopic level and of flowmotion at the tissue level as modulators of perfusion distribution in muscle. We then consider in some detail how insulin and exercise each modulate muscle perfusion at both the microvascular and whole tissue level. The central role of the vascular endothelial cell in modulating both perfusion and transendothelial insulin and nutrient transport is also reviewed. The relationship between muscle metabolic insulin resistance and the vascular action of insulin in muscle continues to indicate an important role for the microvasculature as a target for insulin action and that impairing insulin's microvascular action significantly affects body glucose metabolism.
\end{abstract}




\section{Introduction}

Muscle's microvasculature is the final interface through which circulating nutrients, hormones, gases, and electrolytes must pass in journeying to and from the systemic circulation. It has evolved multiple structural and functional adaptations to flexibly and efficiently fulfill its role in optimizing muscle function. Here, we examine how the minute-to-minute metabolic activity of skeletal muscle is coupled to the function of muscle's vasculature. We will discuss how bulk blood flow and flow distribution can regulate nutrient delivery to muscle microvasculature as well as how transendothelial transport processes can modulate the exchange of hormones and metabolites between plasma and the myocytes. We focus on acute regulatory relationships and defer discussion of chronic vascular or myocyte adaptation to environmental, nutritional, and most pathological processes.

Muscle blood flow has been measured in numerous classical limb balance and metabolic tracer studies of the acute effects of fasting, feeding, exercise, and hormonal manipulation on muscle nutrient exchange. These methods, however, treat muscle's vasculature as a "black box." Here, we consider muscle microvasculature's specialized architecture and how that architecture might impact nutrient fluxes into and out of the muscle. We will discuss the role of vasomotion and flowmotion in the regulation of microvascular perfusion. We recognize that factors acting on the endothelial cell (EC), the vascular smooth muscle cell (SMC), or pericytes may affect muscle perfusion. We will consider in more detail the effect insulin and exercise have on the endothelium and directly or indirectly on the vascular SMC to influence nutrient delivery.

Beyond muscle perfusion, we will consider the transit/transport of fatty acids, glucose, and insulin across the vascular endothelium of muscle, as these processes offer another pathway whereby the vasculature may regulate myocyte metabolic function. In aggregate, this review will delineate how vascular regulation of blood flow, flow distribution, and endothelial function coordinate to optimally serve myocyte function.

\section{Skeletal muscle architecture}

Pioneering work by Spalteholz ${ }^{1}$ and $\mathrm{Krogh}^{2,3}$ has demonstrated muscle's highly organized vasculature. Arterioles branch off primary arteries, down to terminal arterioles, oriented perpendicular to muscle fibers, and supplying them at regular intervals $(1 \mathrm{~mm})$. Each terminal arteriole supplies 15 - 20 capillaries running parallel to 
fibers, with many anastomoses, to form a rich network around muscle fibers. Each terminal arteriole with its capillaries forms the smallest unit of control for capillary perfusion (referred to as a microvascular unit). ${ }^{4}$ Venules are arrayed as arterioles and found between two terminal arterioles. Lymph vessels originate within muscle and can ascend with arterioles or venules (Figure 2.1).

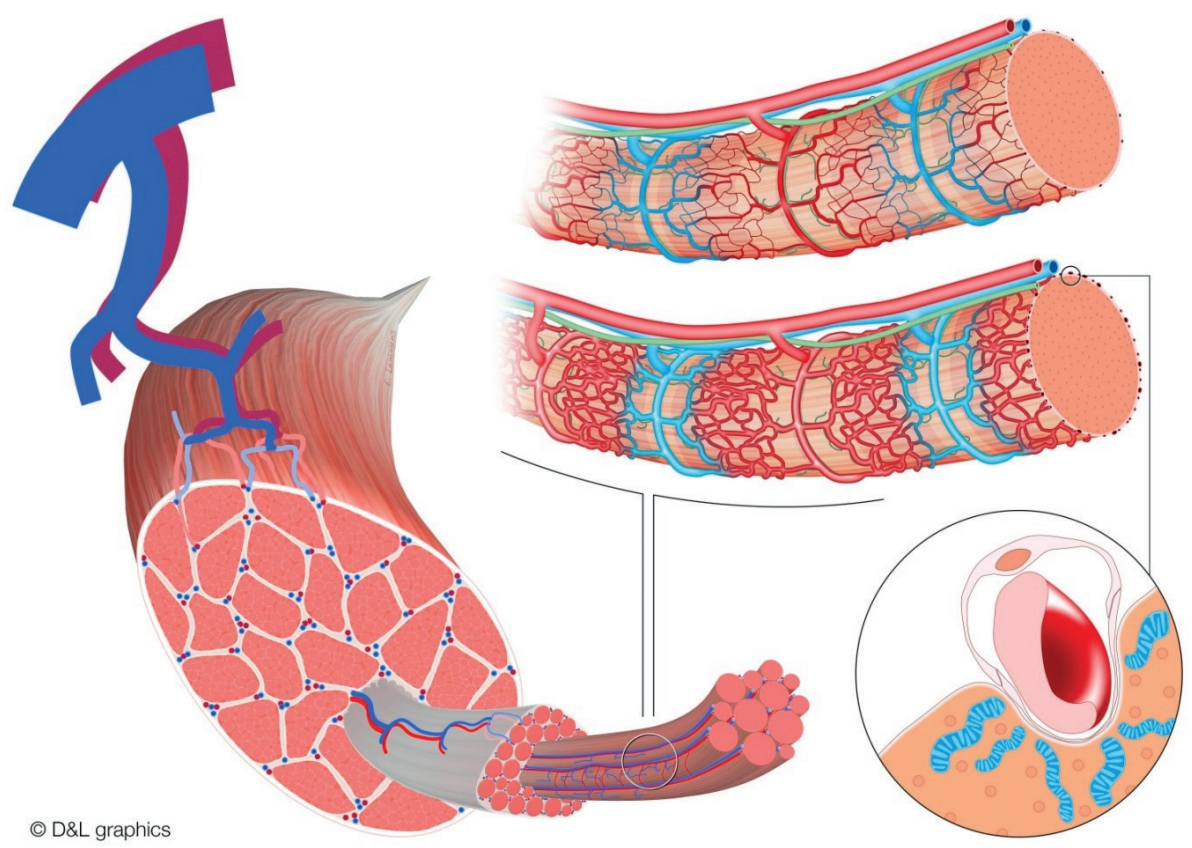

Figure 2.1 - Schematic representation of muscle's vascular architecture. Left: Arterioles branch off primary arteries, down to terminal arterioles, oriented perpendicular to muscle fibers. Top right: Two muscle fibers and their microvascular units, with terminal arterioles as smallest unit of control and lymph vessels (green) ascending along arterioles and venules. In resting muscle (top fiber), the microvasculature is intermittently and not equally perfused, whereas in insulin or exercise stimulated muscle (bottom fiber), vasodilation occurs at the level of the terminal arterioles and control of perfusion shifts upstream. Bottom right: Magnification of the capillary embedding in sarcolemma, thereby expanding the contact area between myocytes and endothelial cells. Mitochondria in myocytes cluster along the embedded capillary, in that way reducing the distance oxygen and nutrients need to diffuse.

The proximity between muscle fibers and capillaries is underscored by recent findings showing capillaries embedded in grooves indenting the sarcolemma and expanding the contact area between myocytes and ECs. Moreover, muscle fiber mitochondria appear to cluster along these grooves, thereby reducing the distance oxygen and fatty acids need to diffuse. ${ }^{7}$ Recent elegant imaging studies have also shown that muscle's "mitochondrial reticulum" is further specialized with respiratory complexes that 
generate membrane potential (e.g., complexes III and IV) enriched in the perivascular region of the mitochondrial matrix, whereas components using the proton-motive force for ATP synthesis are distributed more within the fiber. This arrangement minimizes oxygen diffusion distances and may allow conductive distribution of proton-motive force. ${ }^{8}$

Although arterioles and venules are organized similarly in most mammalian skeletal muscles, some differences in microvascular architecture exist between aerobic and anaerobic muscles. Aerobic muscles typically have more capillaries, larger capillary length per fiber, and more capillary branches per fiber, ${ }^{9}$ and microvessels may be embedded deeper in sarcolemma and have more perivascular mitochondria. ${ }^{7}$ These are all adaptations that could facilitate gas and nutrient exchange. Muscle's vascular architecture down to the level of terminal arterioles allows blood flow and nutrient exchange to be regulated at several levels. Total skeletal muscle blood flow can increase with rising arterial pressure and maintained muscle resistance artery tone or by vasodilation of resistance arterioles with maintained pressure. Terminal arterioles can increase the endothelial surface area by increasing the fraction of perfused capillaries through vasodilation and SMC-driven vasomotion, thus enhancing nutrient exchange.

\section{Muscle perfusion and nutrient flux with exercise and insulin}

Perfusion delivers oxygen, free fatty acids (FFA), glucose, triglycerides, and amino acids to and removes metabolites (amino acids, lactate, carbon dioxide, and ammonia) from muscle. Muscle is a major site of carbohydrate, protein, and fat storage during feeding and a major supplier of nutrients during periods of deprivation. The regulation of fuel fluxes in and out of muscle has been studied intensely in vivo in animals and humans using the limb balance method, which is at times supplemented with metabolite tracer measurements. Here, we will consider the relationship between muscle blood flow and nutrient supply to muscle in response to exercise or insulin stimulation, which has been studied intensively. In particular, we will emphasize data from in vivo studies in humans. We will consider both intense and very modest stimulation to provide the reader with a sense of the hierarchical relationship between muscle perfusion and metabolic function.

Total limb flow can be assessed in different ways (e.g., plethysmography, dye or thermal dilution, and Doppler ultrasound). The advantages and limitations of these methods have been reviewed elsewhere. ${ }^{10}$ Although flow measurement methods have been compared with one another, none can be considered to be the gold 
standard to measure skeletal muscle blood flow. ${ }^{10-12}$ of note is that each measures blood flow directed to all tissues of the limb, not just muscle. In overnight-fasted humans, resting limb blood flow averages $\sim 2-5 \mathrm{ml} \cdot \mathrm{min}^{-1} \cdot 100 \mathrm{ml}^{-1}$ of limb ${ }^{13-15}$ in both men and women, ${ }^{16}$ using the arm or leg. ${ }^{17-19}$ Because resting skin and subcutaneous adipose blood flow (on a per $100 \mathrm{ml}$ of tissue basis) are similar to that of muscle, ${ }^{20-22}$ these resting limb flow values are assumed to reflect average blood flow to muscle, i.e., the methods treat the limb as a homogenous tissue represented by muscle.

Vasomotion, the rhythmic vessel diameter oscillations first described by Jones ${ }^{23}$ in the bat wing in 1852, is more prevalent in small arteries and arterioles than in conduit arteries. $^{24}$ These oscillations modify blood flow and are one contribution to periodic flow fluctuations known as flowmotion. ${ }^{24,25}$ In addition to vasomotion, heart rate, respiration, and autonomic factors influence flowmotion. The several components of flowmotion are distinguished by their frequencies; heart rate and respiratory contributions arise at 1 and $0.3 \mathrm{~Hz}$, respectively, whereas low-frequency signals associated with vasomotion arise at $0.1 \mathrm{~Hz}$ for myogenic activity, $0.04 \mathrm{~Hz}$ for neurogenic activity, and $0.01 \mathrm{~Hz}$ for endothelial activity. ${ }^{26-28}$

Vasomotion originates from an oscillator component in the SMCs and synchronizing mechanisms, which are modified by ECs. ${ }^{24}$ Upon increased metabolic needs, signals originating from the microvasculature travel upstream to larger arterioles and arteries, possibly via gap junctions in the SMCs, ${ }^{29}$ thereby influencing vessel diameter. In addition, vasomotor responses in arterioles can be triggered by stimulation of individual capillaries, and changes in membrane potential appear to be responsible for these observations. ${ }^{29-31}$ Moreover, NO can regulate EC-to-SMC signaling at myoendothelial junctions, and reduced NO production attenuates the duration of conducted vasodilation. ${ }^{29,32}$ These findings suggest that muscle microcirculation modulates upstream vasodilation and vasomotion.

In vivo, vasomotion may regulate microvascular flow distribution to optimize delivery of nutrients and regulate local hydraulic resistance. ${ }^{33}$ In addition to regulating blood flow distribution, vasomotion of terminal arterioles also affects lymph flow, thus influencing water transport in muscle interstitium and tissue homeostasis. ${ }^{6}$ Vasomotion, by continuously altering flow delivery to vessels over time, increases the number of ECs exposed to plasma for nutrient or hormone exchange ${ }^{34}$ without total flow or cardiac output being changed. When perfusion demand exceeds flowmotion's compensatory capacity, blood flow control shifts upstream, enabling increases in total flow. ${ }^{24,35}$

Studying muscle vasomotion requires invasive direct blood vessel visualization (e.g., intravital microscopy), ${ }^{36-39}$ and it is affected by anesthetic agents and a host of 
experimental variables. ${ }^{37}$ Its invasive nature limits the study of vasomotion in humans. By contrast, cutaneous flowmotion can be studied using laser-Doppler flowmetry (LDF) and has become popular in clinical studies. ${ }^{40-43}$ To quantify flowmotion, Fourier or wavelet analyses methods are used to determine the relative contribution of each frequency to the observed LDF signal. ${ }^{26,37,42}$ A drawback of LDF measurements is that they are affected by nearby vessels and blood pressure fluctuations, and therefore, they may not necessarily reflect only the rhythmic activities of blood vessels themselves. $^{24,44,45}$ Several disorders influence vasomotion and flowmotion; hemorrhage increases vasomotion, whereas obesity and diabetes reduce flowmotion and vasomotion. ${ }^{24,42}$ Taken together, vasomotion provides a local mechanism for vascular adaptation to altered metabolic needs, and its regulation impacts muscle perfusion.

\section{Exercise and muscle perfusion}

Myocyte and related whole body metabolic changes with acute and chronic exercise were reviewed recently. ${ }^{46}$ Oxygen and nutrient delivery to muscle during intense exercise and the accompanying blood flow changes have been studied extensively. The increased bulk blood flow during exercise arises both from local factors [e.g., potassium, adenosine, phosphate, lactate, hydrogen ion, nitric oxide (NO), and prostaglandins] released by the muscle and by neurovascular changes that relax muscle vasculature. With very intense whole body exercise, blood flow and oxygen delivery to the tissue become limiting secondary to limitations of respiratory and cardiac function. ${ }^{47,48}$ By contrast, with intense exercise of isolated muscle groups, neither cardiorespiratory function nor hemodynamic factors limit muscle performance. Thus, blood flow to the human quadriceps can increase $>50$-fold during brief, intense exercise. ${ }^{47}$ Increasing the arterial oxygen content does not further increase quadriceps $\mathrm{O}_{2}$ extraction or peak work rate by either trained or untrained muscle. ${ }^{49}$ Muscle's remarkable flow reserve can meet even extreme muscle $\mathrm{O}_{2}$ demands. In addition to oxygen, glucose and fatty acids are important fuels during exercise. Carbohydrates (both circulating glucose and muscle glycogen) are the preferred fuel for intense, brief-duration muscle exercise. With intense muscle exercise, glucose extraction can increase more than sixfold and leg blood flow 10-fold, whereas plasma glucose changes little. ${ }^{50}$ Interestingly, whereas glucose concentrations in resting muscle cytosol are extremely low, intense exercise dramatically increases glucose both in muscle interstitium ${ }^{51}$ and within muscle cells in humans $^{50}$ and rodents. $^{52}$ The $>30$-fold increase in leg glucose uptake seen with intense exercise indicates that both the delivery of glucose to muscle 
microvasculature and transcapillary glucose transfer have capacity sufficient to meet glucose metabolic needs.

Vascular responses to light exercise (operationally, we consider $\leq 25 \%$ max as "light") have been studied much less, and their link to muscle performance is less clear. However, studies of light exercise provide insight into the hierarchical regulation of muscle perfusion. With light exercise, vasomotion within the terminal arterioles appears to cease, and the number of perfused capillary increases without significant changes in total muscle blood flow. ${ }^{34,53,54}$ Honig et al., ${ }^{34}$ by flash-freezing and sectioning muscle, showed that low-frequency electrical stimulation was nearly as effective as near-tetanic stimulation for recruiting hypoperfused microvasculature in canine gracilis muscle. Further increasing contractile activity increases total blood flow, as regulation shifts upstream to progressively larger arterioles. ${ }^{35}$ Factors driving microvascular perfusion changes include venous $\mathrm{PO}_{2}$, which, by enhancing venular $\mathrm{EC}$ NO production and erythrocyte NO release, ${ }^{35,55-57}$ promotes dilation of nearby arterioles. Hemodynamic forces, i.e., shear stress-induced NO production, further modulate hyperemic responses. ${ }^{35}$ These are aided by prostaglandins and endothelium-derived hyperpolarizing factors to increase perfusion with exercise. ${ }^{48}$ It appears that inhibition of one system (e.g., NO synthase) can be compensated by the remaining factors, since skeletal muscle blood flow is preserved in such circumstances. ${ }^{58}$ If, however, two pathways are inhibited simultaneously, the increase in skeletal muscle blood flow is reduced. ${ }^{48,59}$ These effectors act as sympatholytics to counteract the exercise-induced vasoconstriction of distal arterioles and feed arteries by sympathetic nerves. ${ }^{48}$

\section{Insulin and muscle perfusion}

The effects of insulin on limb metabolism have been studied extensively using limb balance methods combined with euglycemic insulin infusion. Andres et al. ${ }^{60}$ first reported insulin-stimulated forearm glucose uptake and noted an accompanying increase in forearm blood flow. Baron ${ }^{61}$ and Laakso et al. ${ }^{62}$ first reported that insulininduced muscle glucose uptake paralleled insulin's ability to increase total leg blood flow. In subsequent work, obesity, type 1 and type 2 diabetes, and increased plasma free fatty acid concentrations ${ }^{62-65}$ each impaired insulin-stimulated limb blood flow and glucose uptake in parallel. These studies suggested that 1) insulin stimulates limb blood flow in both humans and animals; 2) during a high-dose insulin clamp, increased limb flow correlates with muscle glucose uptake; 3) acute and chronic metabolic insulin resistance is associated with impaired insulin-stimulated increases of limb blood flow; and 4) insulin enhances limb blood flow by increasing nitric oxide 
production. ${ }^{62,65-67}$ This led investigators to suggest that impaired arteriolar relaxation in response to insulin contributes significantly to metabolic dysfunction in insulinresistant muscle.

Insulin's vasodilatory effects arise from its binding to the insulin receptor on ECs. This stimulates the phosphatidylinositol 3-kinase/Akt pathway to activate endothelial NO synthase $(\mathrm{eNOS})^{68,69}$ and induces NO-mediated vasodilation. ${ }^{70}$ Insulin also stimulates the MAPK pathway and enhances production of the vasoconstrictor endothelin$1^{66,67,71}$ In health, insulin's vasodilatory effect dominates. With endothelial dysfunction, as occurs with obesity and type 2 diabetes, the PI3K pathway appears to be selectively inhibited by low-grade inflammation, FFA, oxidative stress, and reduced perivascular adiponectin release. ${ }^{72-76}$ In these circumstances, a reduced vasodilatory response or even paradoxical vasoconstriction can be seen with hyperinsulinemia. ${ }^{72,77}$

Insulin at high physiological concentrations relaxes resistance arterioles and increases limb blood flow in humans. In addition, there is convincing evidence that this response is blunted in insulin-resistant individuals with obesity ${ }^{78}$ and type $1^{79}$ or type 2 diabetes. ${ }^{80}$ This effect of insulin on blood flow is most evident when insulin is infused continuously at a rate of $3 \mathrm{mU} \cdot \mathrm{kg}^{-1} \cdot \mathrm{min}^{-1}$ to achieve marked steady-state hyperinsulinemia for $\geq 2 \mathrm{~h}$. It has been more difficult to reproduce this effect infusing insulin at a lower rate or for shorter duration. ${ }^{81}$ This has led to questioning of the physiological importance of this response. In addition, in insulin-resistant subjects, pharmacologically increasing blood flow often does not improve insulin's metabolic action measured as limb glucose uptake. ${ }^{82}$ However, in the latter circumstance, it remains likely that while perfusion is improved insulin resistance in the myocyte persists, and short-term correction of perfusion is insufficient to overcome that metabolic defect.

Over the last 15 years, research on insulin's action on muscle perfusion has added focus on the microvasculature. There, analogous to the effect of low-frequency stimulation reported by Honig et al., ${ }^{34,53}$ relaxation of terminal arterioles could recruit hypoperfused capillaries and expand the EC surface available for nutrient exchange ${ }^{83}$ without changing total flow. However, there were no noninvasive methods available to quantify the microvascular volume perfused in intact muscle in animals or humans. In 1997, a technique was introduced to estimate the endothelial surface available for nutrient exchange based on the single-pass conversion of 1-methylxanthine (1-MX) to 1-methylurate (1-MU) by xanthine oxidase, which is present on capillary endothelium. Increased endothelial exposure to substrate (i.e., capillary recruitment) would increase 1-MX to 1-MU conversion. ${ }^{84,85}$ Later, contrast-enhanced ultrasound (CEUS) was used to investigate microvascular perfused volume regulation. ${ }^{86,87}$ Using either method, we found that in healthy animals and humans, physiological doses of insulin 
and carbohydrate-containing meals each increased microvascular perfusion volume even in the absence of increases in total limb blood flow. ${ }^{77,86,88}$ Using CEUS, we found that, from the start of an euglycemic insulin clamp, microvascular blood volume increases within 15 - $30 \mathrm{~min}$, and this microvascular change precedes and correlates with the rise in forearm glucose uptake. ${ }^{89-91}$ Moreover, chronic (obesity) and acutely induced (lipid infusion) insulin resistance are associated with an impaired microvascular response to insulin or meal ingestion. ${ }^{77,92-94}$ Using CEUS, ${ }^{54,88}$ we also confirmed the original finding by Honig et al. ${ }^{53}$ that light exercise increased microvascular perfused volume $\sim 3$-fold with minimal increases in total limb blood flow (Figure 2.2). However, with more intense exercise, both microvascular blood volume and total limb blood flow increase. ${ }^{54,88,95}$ Interestingly, cardiac muscle behaves similarly to skeletal muscle during hyperinsulinemia ${ }^{96}$ and feeding, ${ }^{97}$ and its increases in microvascular blood volume are blunted by insulin resistance as well. ${ }^{98}$
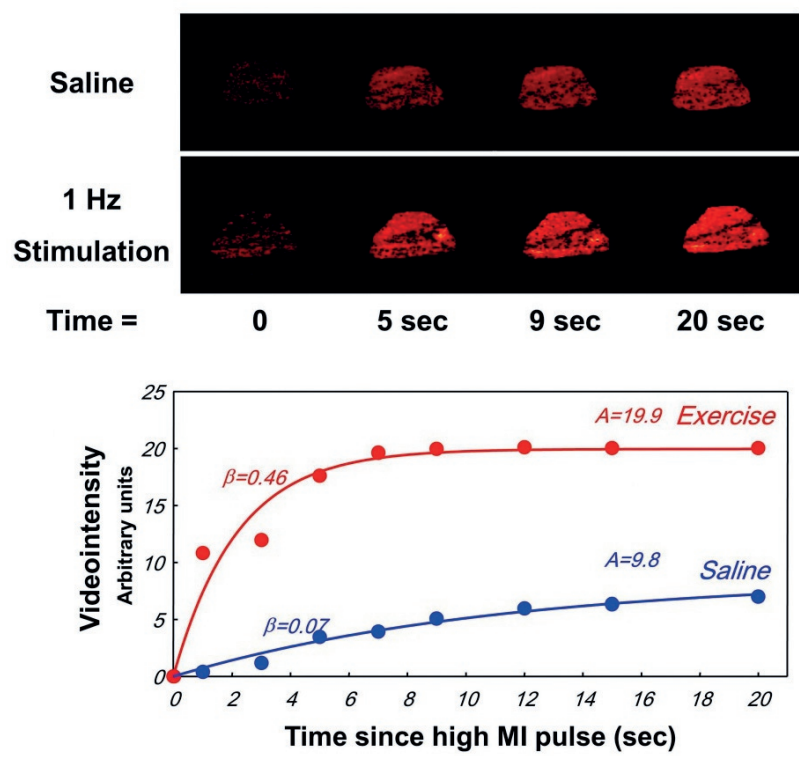

Figure 2.2. Top: contrast-enhanced ultrasound images of rat thigh muscle as a function of time after a highenergy ultrasound pulse with the muscle at rest or given a 1- $\mathrm{Hz}$ electrical stimulation. Bottom: greater plateau video intensity (red) corresponding to a larger number of microbubbles in the imaged volume of the stimulated muscle.

Insulin is not the only hormone that can "recruit" muscle microvasculature. Both glucagon-like peptide-1 (GLP-1) ${ }^{99,100}$ and adiponectin, ${ }^{101}$ like insulin, increase microvascular volume, albeit each acting by different biochemical pathways. By contrast, epinephrine can increase muscle blood flow without increasing perfused 
microvascular volume. ${ }^{102}$ The responses to physiological hyperinsulinemia and lowintensity exercise suggest a hierarchical response by muscle vasculature whereby microvascular units respond to these stimuli, whereas with more intense stimulation (high physiological insulin concentrations or heavy exercise) more proximal arterial elements also respond, leading to the flow increases seen in those settings. Whether this graded response involves antidromic signals through the vascular network or again is a response to multiple locally generated metabolic signals is not known.

\section{Nutrient and hormone transfer across the endothelium}

Here we very briefly review evolving evidence that the vascular endothelium in tissues like muscle and adipose may actively mediate the transendothelial transport (TET) of substrates (e.g., glucose or FFA) and hormones, including insulin. As would be expected, such a role for the endothelium is of consequence principally in tissues with a continuous endothelium, like muscle and adipose, but less consequential in liver and other splanchnic tissues. ${ }^{103}$

We consider first the endothelium's role in FFA transport, as FFAs are a major muscle fuel. It has long been known that lipoprotein lipase (LPL) is secreted by skeletal myocytes and adipocytes but resides on the luminal surface of the vascular EC in muscle and fat, where it cleaves fatty acid monomers from triglycerides bound to circulating lipoproteins. ${ }^{104}$ This process can be regulated by insulin, which increases LPL expression. Recently, it was found that the EC possesses a receptor for LPL [glycosylphosphotidylinositol-anchored high-density lipoprotein binding protein 1 (GPIHBP1) $]^{105}$ and that when LPL binds to GPIHBP1 a vesicular transport system mediates LPL's TET to the luminal membrane, where it encounters circulating triglycerides. ${ }^{106}$ Mutations in either GPIHBP1 or LPL that interfere with this pathway can cause severe hypertriglyceridemia in humans. ${ }^{107}$

In addition to this pathway for LPL transport that provides triglyceride-derived fatty acids to the EC, the EC possesses membrane-associated fatty acid transport proteins (FATPs) as well as fatty acid-binding proteins (FABPs). The former take up FFA derived either from triglyceride hydrolysis or circulating as FFA associated with albumin or other plasma proteins. FATP3 and FATP4 are expressed by ECs along with the scavenger receptor CD36. Each appears to be involved in movement of fatty acids across the EC luminal plasma membrane. Expression of both FATP3 and FATP4 is increased by VEGF $\beta$ secreted by myocytes and adipocytes acting via VEGFR1. Muscle expression of VEGF $\beta$ is increased by the transcriptional coactivator PGC-1 $\alpha$, which is a central player in the regulation of mitochondrial oxidative metabolism within the 
myocyte. In the context of increasing muscle oxidative capacity, muscle signaling to adjacent ECs to enhance FFA uptake may be part of an adaptive response. Expression of CD36 by ECs is upregulated by peroxisome proliferator-activated receptor- $\gamma$, which enhances fat mass and adipogenesis. Interestingly, inhibition of VEGF $\beta$ in diabetic animal models decreases muscle ectopic fat and improves glucose metabolism. ${ }^{108}$ By contrast, VEGFA knockout in muscle increases susceptibility to high-fat diet induced insulin resistance, which is due at least in part to decreased microvascular perfusion. ${ }^{109}$ The transport of FFA across the ECS is presumably bidirectional, particularly in adipose tissue, although this has not been clarified in detail.

In contrast to the complex regulatory system involved in the movement of FFA across the EC, glucose transport from the vascular lumen into and across the endothelium is mediated by the constitutive activity of the GLUT1 transporter. The system has a high capacity in the absence of exogenous insulin, as indicated by the marked increases in glucose transport that occur with exercise (see above). The GLUT1 transporter is expressed in both vascular smooth muscle and endothelial cells. In the former, the transporter activity is downregulated by high ambient glucose concentrations. ${ }^{110}$ This adaptive response is absent in aortic ECs. The function of this transporter is important to the metabolic activity of the EC, which receives a significant fraction of its energy from glycolytic ATP production. ${ }^{111}$ The specific transport capacity in brain microvascular ECs has been studied extensively, as ECs perform a critical function in assuring adequate glucose delivery to the central nervous system. Cardiac muscle microvascular glucose transport capacity has been investigated and utilizes the same high-capacity GLUT1 transporter reported for other endothelia. ${ }^{111}$ To our knowledge, GLUT1 transporter function specific to skeletal muscle microvasculature has not been studied. As noted previously, the observation that muscle interstitial and myocyte glucose concentrations rise during intense exercise suggests that glucose transport through the vascular endothelium is not limiting even under conditions of high substrate demand. Indeed, the high capacity of the system may in part be responsible for damage that occurs to the microvascular endothelium as a result of hyperglycemia in the diabetic state. ${ }^{112}$ The EC does not appear to defend itself from high levels of intracellular glucose, which via several pathways can generate reactive oxygen species. ${ }^{112,113}$ When this is unchecked, as occurs in persistent hyperglycemic states, vascular injury occurs.

The EC in tissues with a continuous endothelium also constitutes a barrier to insulin movement into the tissue. Indeed, estimates of muscle interstitial insulin concentrations using either lymphatic sampling ${ }^{114}$ or microdialysis ${ }^{115}$ suggest that insulin TET could be rate limiting for insulin's action on muscle. This led us to examine the cellular pathway of insulin TET. Most ECs express insulin, IGF-I, and the insulin/IGF-I hybrid receptor. ${ }^{116}$ In aortic ECS and preadipocytes, ${ }^{117}$ the insulin receptor 
associates with a specialized lipid raft domain, i.e., caveolae. Caveolae can be internalized and mediate TET of a variety of proteins (e.g., albumin in pulmonary microvascular ECs). ${ }^{118}$ In a series of experiments, we found that caveolae are required for insulin uptake by and transport across aortic ECs. ${ }^{119}$ In these ECs, preserved insulin signaling through phosphatidylinositol 3-kinase to Akt and eNOS is necessary for insulin TET. ${ }^{120}$ Interestingly, inflammatory cytokines or several days of high-fat diet diminish EC insulin transport. ${ }^{120}$ If muscle microvascular ECs behave similarly, then impaired EC insulin signaling and TET could contribute to the impaired muscle insulin action of insulin resistance. As we had seen for microvascular recruitment, for insulin TET, NO appears to be a critical regulatory factor. When phosphatidylinositol 3-kinase or NO synthase is inhibited, insulin transport declines. Giving sodium nitroprusside (3-30 $\mu \mathrm{M})$ can restore insulin uptake ${ }^{121}$ in aortic ECs. Surprisingly, an EC-specific insulin receptor knockout mouse (with Cre-recombinase driven by Tie-2) did not display any metabolic phenotype. ${ }^{122}$ However, more recently, another EC-specific insulin receptor knockout (with Cre-recombinase driven by a vascular endothelial-cadherin promoter) displayed glucose intolerance and delayed insulin action on insulin target tissues (Konishi M, Sakaguchi M, Cai W, Rask-Madsen C, and Kahn CR, unpublished observations). Likewise, the EC-specific IRS-2 knockout mouse is glucose intolerant and has impaired insulin-induced microvascular perfusion and diminished muscle insulin delivery. ${ }^{123}$ These genetic models underscore the role of EC insulin signaling to whole body metabolic functioning.

Recent work using adipose microvascular ECs has suggested a similar vesicle-mediated insulin TET process, and initial studies implicate clathrin-coated vesicles, not caveolae. ${ }^{124}$ However, there is a lack of data clarifying whether insulin regulates that transport or whether a transendothelial insulin concentration gradient is present in adipose tissue and whether insulin TET limits insulin action in adipose tissue. ${ }^{125}$

\section{Conclusion}

In summary, a hierarchical, graded control of muscle perfusion arises from cooperative interactions among the factors released locally by myocytes, by SMCs, or by ECs along with systemically and neurally delivered signals. Very modest contractile activity or physiological hyperinsulinemia promptly increases microvascular perfusion volume even in the absence of changes in limb blood flow. In both cases, EC exchange surface for nutrient or hormone delivery expands without requiring increased cardiac work. Greater contractile activity or hyperinsulinemia triggers signals that may ascend the vascular network and provoke relaxation of progressively larger vessels, increasing total flow to the expanded microvascular network. Beyond insulin and exercise, other 
humoral factors (e.g., GLP-1, angiotensin II, and adiponectin) similarly enhance muscle microvascular perfusion. However, the role of these factors in normal muscle physiology is still being unraveled. Evolving evidence indicates that (at least for insulin and triglycerides/FFA), beyond altered perfusion, the microvasculature, particularly the EC, actively regulates the delivery of insulin and FFA to the muscle via regulation of specialized transport mechanisms. Thus, the EC of muscle vasculature is increasingly recognized as a key regulator of normal muscle physiology and metabolic health. Much remains to be learned regarding the normal regulation of the integrated functioning of the skeletal muscle myocytes and its vasculature and how this regulation is altered by disease or dysfunction. 


\section{References}

1. $\quad$ Spalteholz W. Die Vertheilung der Blutgelfasse im Muskel. Mat-phys KI sachs Ges Wiss. 1888;14:509.

2. Krogh A. The number and distribution of capillaries in muscles with calculations of the oxygen pressure head necessary for supplying the tissue. J Physiol. 1919;52:409-415.

3. Krogh A. The supply of oxygen to the tissues and the regulation of the capillary circulation. J Physiol. 1919;52:457-474.

4. Emerson GG, Segal SS. Alignment of microvascular units along skeletal muscle fibers of hamster retractor. J Appl Physiol (1985). 1997;82:42-48.

5. Huxley VH, Scallan J. Lymphatic fluid: exchange mechanisms and regulation. J Physiol. 2011;589: 2935-2943.

6. Skalak TC, Schmid-Schonbein GW, Zweifach BW. New morphological evidence for a mechanism of lymph formation in skeletal muscle. Microvasc Res. 21984;8:95-112.

7. Glancy B, Hsu LY, Dao L, Bakalar M, French S, Chess DJ, Taylor JL, Picard M, Aponte A, Daniels MP. In vivo microscopy reveals extensive embedding of capillaries within the sarcolemma of skeletal muscle fibers. Microcirculation. 2014;21:131-147.

8. Glancy B, Hartnell LM, Malide D, Yu ZX, Combs CA, Connelly PS, Subramaniam S, Balaban RS. Mitochondrial reticulum for cellular energy distribution in muscle. Nature. 2015;523:617-620.

9. Kubinova L, Janacek J, Ribaric S, Cebasek V, Erzen I. Three-dimensional study of the capillary supply of skeletal muscle fibres using confocal microscopy. J Muscle Res Cell Motil. 2001;22:217-227.

10. Barrett EJ, Rattigan S. Muscle perfusion: its measurement and role in metabolic regulation. Diabetes. 2012;61:2661-2668.

11. Jorfeldt L, Rutberg H. Comparison of dye-dilution and plethysmographic blood flow measurements: an evaluation of the influence of invasive techniques on blood flow and on arterial and femoral venous substrate variables in man. Clin Sci (Lond). 1990;79:81-87.

12. Tschakovsky ME, Shoemaker JK, Hughson RL. Beat-by-beat forearm blood flow with Doppler ultrasound and strain-gauge plethysmography. J Appl Physiol. 1995;79:713-719.

13. Mossberg KA, Mullani N, Gould KL, Taegtmeyer H. Skeletal muscle blood flow in vivo: detection with rubidium-82 and effects of glucose, insulin, and exercise. J Nucl Med. 1987;28:1155-1163.

14. Nuutila $P$, Raitakari $M$, Laine $H$, Kirvelä $O$, Takala $T$, Utriainen $T$, Mäkimattila $S$, Pitkänen $O P$, Ruotsalainen $\mathrm{U}$, lida $\mathrm{H}$, Knuuti J, Yki-Järvinen $\mathrm{H}$. Role of blood flow in regulating insulin-stimulated glucose uptake in humans. Studies using bradykinin, [150]water, and [18F]fluoro-deoxy-glucose and positron emission tomography. J Clin Invest. 1996;97:1741-1747.

15. Rudroff T, Weissman JA, Bucci M, Seppanen M, Kaskinoro K, Heinonen I, Kalliokoski KK. Positron emission tomography detects greater blood flow and less blood flow heterogeneity in the exercising skeletal muscles of old compared with young men during fatiguing contractions. J Physiol. 2014;592: 337-349.

16. Jensen MD, Nguyen TT, Hernández Mijares A, Johnson CM, Murray MJ. Effects of gender on resting leg blood flow: implications for measurement of regional substrate oxidation. J Appl Physiol. 81998;4: 141-145.

17. Eklund B, Kaijser L, Knutsson E. Blood flow in resting (contralateral) arm and leg during isometric contraction. J Physiol. 1974;240:111-124.

18. Helge JW, Klein DK, Andersen TM, van Hall G, Calbet J, Boushel R, Saltin B. Interleukin-6 release is higher across arm than leg muscles during whole-body exercise. Exp Physiol. 2011;96:590-598.

19. Taylor JA, Joyner MJ, Chase PB, Seals DR. Differential control of forearm and calf vascular resistance during one-leg exercise. J Appl Physiol (1985). 1989;67:1791-1800.

20. Blaak E, van Baak MA, Kemerink GJ, Pakbiers MT, Heidendal GA, Saris WH. Total forearm blood flow as an indicator of skeletal muscle blood flow: effect of subcutaneous adipose tissue blood flow. Clin Sci (Lond). 1994;87:559-566.

21. Houben AJ, Slaaf DW, Huvers FC, de Leeuw PW, Nieuwenhuijzen Kruseman AC, Schaper NC. Diurnal variations in total forearm and skin microcirculatory blood flow in man. Scand J Clin Lab Invest. 1994; 54:161-168. 
22. Linde B, Hjemdahl P, Freyschuss U, Juhlin-Dannfelt A. Adipose tissue and skeletal muscle blood flow during mental stress. Am J Physiol Endocrinol Metab. 1989;256:E12-E18.

23. Jones TW. Discovery that the veins of the bat's wing (which are furnished with valves) are endowed with rythmical contractility, and that the onward flow of blood is accelerated by each contraction. Philos Trans Royal Soc London. 1852;142:131-136.

24. Aalkjaer C, Boedtkjer D, Matchkov V. Vasomotion - what is currently thought? Acta Physiol (Oxf). 2011;202:253-269.

25. Schmidt JA, Borgström $P$, Firestone GP, von Wichert $P$, Intaglietta $M$, Fronek A. Periodic hemodynamics (flow motion) in peripheral arterial occlusive disease. J Vasc Surg. 1993;18:207-215.

26. Bracic M, Stefanovska A. Wavelet-based analysis of human blood-flow dynamics. Bull Math Biol. 1998;60:919-935.

27. Kvernmo HD, Stefanovska A, Kirkeboen KA, Kvernebo K. Oscillations in the human cutaneous blood perfusion signal modified by endothelium-dependent and endothelium-independent vasodilators. Microvasc Res. 1999;57:298-309.

28. Stefanovska A, Bracic M, Kvernmo HD. Wavelet analysis of oscillations in the peripheral blood circulation measured by laser Doppler technique. IEEE Trans Biomed Eng. 1999;46:1230-1239.

29. Bagher P, Segal SS. Regulation of blood flow in the microcirculation: role of conducted vasodilation. Acta Physiol (Oxf). 2011;202:271-284.

30. Beach JM, McGahren ED, Duling BR. Capillaries and arterioles are electrically coupled in hamster cheek pouch. Am J Physiol Heart Circ Physiol. 1998;275:H1489-H1496.

31. Song $\mathrm{H}, \mathrm{Tyml} \mathrm{K}$. Evidence for sensing and integration of biological signals by the capillary network. Am J Physiol Heart Circ Physiol. 1993;265:H1235-H1242.

32. Domeier TL, Segal SS. Electromechanical and pharmacomechanical signalling pathways for conducted vasodilatation along endothelium of hamster feed arteries. J Physiol. 2007;579:175-186.

33. Muris DM, Houben AJ, Schram MT, Stehouwer CD. Microvascular dysfunction: an emerging pathway in the pathogenesis of obesity-related insulin resistance. Rev Endocr Metab Disord. 2013;14:29-38.

34. Honig CR, Odoroff CL, Frierson JL. Capillary recruitment in exercise: rate, extent, uniformity, and relation to blood flow. Am J Physiol Heart Circ Physiol. 1980;238:H31-H42.

35. Segal SS. Regulation of blood flow in the microcirculation. Microcirculation. 2005;12:33-45.

36. Bartlett IS, Crane GJ, Neild TO, Segal SS. Electrophysiological basis of arteriolar vasomotion in vivo. J Vasc Res. 2000;37:568-575.

37. Colantuoni A, Bertuglia S, Intaglietta M. Quantitation of rhythmic diameter changes in arterial microcirculation. Am J Physiol Heart Circ Physiol. 1984;246:H508-H517.

38. Gustafsson H, Mulvany MJ, Nilsson H. Rhythmic contractions of isolated small arteries from rat: influence of the endothelium. Acta Physiol Scand. 1993;148:153-163.

39. Intaglietta M, Tompkins WR. Microvascular measurements by video image shearing and splitting. Microvasc Res. 1973;5:309-312.

40. Jonk AM, Houben AJ, Schaper NC, de Leeuw PW, Serné EH, Smulders YM, Stehouwer CD. Meal-related increases in microvascular vasomotion are impaired in obese individuals: a potential mechanism in the pathogenesis of obesity-related insulin resistance. Diabetes Care. 2011;34, Suppl 2:S342-S348.

41. Montero D, Walther G, Perez-Martin A, Santamaria C, Roche E, Mercier C, Vinet A. Decreased microvascular myogenic response to insulin in severely obese adolescents. Clin Hemorheol Microcirc. 2014;57:23-32.

42. Muris DM, Houben AJ, Kroon AA, Henry RM, van der Kallen CJ, Sep SJ, Koster A, Dagnelie PC, Schram MT, Stehouwer CD. Age, waist circumference, and blood pressure are associated with skin microvascular flow motion: the Maastricht Study. J Hypertens. 2014;32:2439-2449.

43. Nilsson GE, Tenland T, Oberg PA. Evaluation of a laser Doppler flowmeter for measurement of tissue blood flow. IEEE Trans Biomed Eng. 1980;27:597-604.

44. Erni D, Sigurdsson GH, Banic A, Wheatley AM. Regular slow wave flowmotion in skeletal muscle is not determined by nitric oxide and endothelin. Microvasc Res. 1999;58:167-176.

45. Hafner HM, Brauer K, Eichner M, Koch I, Heinle H, Rocken M, Strolin A. Wavelet analysis of skin perfusion in healthy volunteers. Microcirculation. 2007;14:137-144. 
46. Egan B, Zierath JR. Exercise metabolism and the molecular regulation of skeletal muscle adaptation. Cell Metab. 2013;17:162-184.

47. Andersen P, Saltin B. Maximal perfusion of skeletal muscle in man. J Physiol. 1985;366:233-249.

48. Mortensen SP, Saltin B. Regulation of the skeletal muscle blood flow in humans. Exp Physiol. 2014;99: 1552-1558.

49. Mourtzakis M, González-Alonso J, Graham TE, Saltin B. Hemodynamics and O2 uptake during maximal knee extensor exercise in untrained and trained human quadriceps muscle: effects of hyperoxia. J Appl Physiol. 2004;97:1796-1802.

50. Katz A, Broberg S, Sahlin K, Wahren J. Leg glucose uptake during maximal dynamic exercise in humans. Am J Physiol Endocrinol Metab. 1986;251:E65-E70.

51. MacLean DA, Bangsbo J, Saltin B. Muscle interstitial glucose and lactate levels during dynamic exercise in humans determined by microdialysis. J Appl Physiol. 1999;87:1483-1490.

52. Halseth AE, Bracy DP, Wasserman DH. Limitations to exercise- and maximal insulin-stimulated muscle glucose uptake. J Appl Physiol. 1998;85:2305-2313.

53. Honig CR, Odoroff CL, Frierson JL. Active and passive capillary control in red muscle at rest and in exercise. Am J Physiol Heart Circ Physiol. 1982;243:H196-H206.

54. Inyard AC, Clerk LH, Vincent MA, Barrett EJ. Contraction stimulates nitric oxide independent microvascular recruitment and increases muscle insulin uptake. Diabetes. 2007;56:2194-2000.

55. Saito Y, Eraslan A, Hester RL. Importance of venular flow in control of arteriolar diameter in hamster cremaster muscle. Am J Physiol Heart Circ Physiol. 1993;265:H1294-H1300.

56. Stamler JS, Jia L, Eu JP, McMahon TJ, Demchenko IT, Bonaventura J, Gernert K, Piantadosi CA. Blood flow regulation by S-nitrosohemoglobinin the physiological oxygen gradient. Science. 1997;276: 2034-2037.

57. Tigno XT, Ley K, Pries AR, Gaehtgens P. Venulo-arteriolar communication and propagated response. A possible mechanism for local control of blood flow. Pflugers Arch. 1989;414:450-456.

58. Bradley SJ, Kingwell BA, McConell GK. Nitric oxide synthase inhibition reduces leg glucose uptake but not blood flow during dynamic exercise in humans. Diabetes. 1999;48:1815-1821.

59. Mortensen SP, Gonzalez-Alonso J, Damsgaard R, Saltin B, Hellsten Y. Inhibition of nitric oxide and prostaglandins, but not endothelial-derived hyperpolarizing factors, reduces blood flow and aerobic energy turnover in the exercising human leg. J Physiol. 2007;581:853-861.

60. Andres E, Baltzan MA, Cader G, Zierler KL. Effect of insulin on carbohydrate metabolism and on potassium in the forearm of man. J Clin Invest. 1962;41:108-115.

61. Baron A. Hemodynamic actions of insulin. Am J Physiol Endocrinol Metab. 1994;267:E187-E202.

62. Laakso M, Edelman SV, Olefsky JM, Brechtel G, Wallace P, Baron AD. Kinetics of in vivo muscle insulinmediated glucose uptake in human obesity. Diabetes. 1990;39:965-974.

63. Baron AD, Laakso M, Brechtel G, Edelman SV. Mechanism of insulin resistance in insulin-dependent diabetes mellitus: a major role for reduced skeletal muscle blood flow. J Clin Endocrinol Metab. 1991; 73:637-643.

64. Laakso M, Edelman SV, Brechtel G, Baron AD. Impaired insulin-mediated skeletal muscle blood flow in patients with NIDDM. Diabetes. 1992;41:1076-1083.

65. Steinberg HO, Paradisi G, Hook G, Crowder K, Cronin J, Baron AD. Free fatty acid elevation impairs insulin-mediated vasodilation and nitric oxide production. Diabetes. 2000;49:1231-1238.

66. Mather KJ, Steinberg HO, Baron AD. Insulin resistance in the vasculature. J Clin Invest. 2013;123: 1003-1004.

67. Steinberg HO, Brechtel G, Johnson A, Fineberg F, Baron AD. Insulin-mediated skeletal muscle vasodilation is nitric oxide dependent. A novel action of insulin to increase nitric oxide release. J Clin Invest. 1994;94:1172-1179.

68. Jiang ZY, Lin YW, Clemont A, Feener EP, Hein KD, Igarashi M, Yamauchi T, White MF, King GL. Characterization of selective resistance to insulin signaling in the vasculature of obese Zucker $(\mathrm{fa} / \mathrm{fa})$ rats. J Clin Invest. 1999;104:447-457.

69. Zeng G, Quon MJ. Insulin-stimulated production of nitric oxide is inhibited by wortmannin. Direct measurement in vascular endothelial cells. J Clin Invest. 1996;98:894-898. 
70. Cardillo C, Nambi SS, Kilcoyne CM, Choucair WK, Katz A, Quon MJ, Panza JA. Insulin stimulates both endothelin and nitric oxide activity in the human forearm. Circulation. 1999;100:820-825.

71. Muniyappa R, Montagnani M, Koh KK, Quon MJ. Cardiovascular actions of insulin. Endocr Rev. 2007;28:463-491.

72. Jonk AM, Houben AJ, de Jongh RT, Serné EH, Schaper NC, Stehouwer CD. Microvascular dysfunction in obesity: a potential mechanism in the pathogenesis of obesity-associated insulin resistance and hypertension. Physiology (Bethesda). 2007;22:252-260.

73. Ko SH, Cao W, Liu Z. Hypertension management and microvascular insulin resistance in diabetes. Curr Hypertens Rep. 2010;12:243-251.

74. Lteif $A$, Vaishnava $P$, Baron AD, Mather KJ. Endothelin limits insulin action in obese/insulin-resistant humans. Diabetes. 2007;56:728-734.

75. Meijer RI, Bakker W, Alta CL, Sipkema P, Yudkin JS, Viollet B, Richter EA, Smulders YM, van Hinsbergh VW, Serné EH, Eringa EC. Perivascular adipose tissue control of insulin-induced vasoreactivity in muscle is impaired in db/db mice. Diabetes. 2013;62:590-598.

76. Yudkin JS, Eringa E, Stehouwer CD. "Vasocrine" signalling from perivascular fat: a mechanism linking insulin resistance to vascular disease. Lancet. 2005;365:1817-1820.

77. Clerk LH, Vincent MA, Jahn LA, Liu Z, Lindner JR, Barrett EJ. Obesity blunts insulin-mediated microvascular recruitment in human forearm muscle. Diabetes. 2006;55:1436-1442.

78. Laakso M, Edelman SV, Brechtel G, Baron AD. Decreased effect of insulin to stimulate skeletal muscle blood flow in obese man. J Clin Invest. 1990;85:1844-1852.

79. Baron AD, Laakso M, Brechtel G, Edelman SV. Mechanism of insulin resistance in insulin-dependent diabetes mellitus: a major role for reduced skeletal muscle blood flow. J Clin Endocrinol Metab. 1991;73:637-643.

80. Baron AD, Laakso M, Brechtel G, Edelman SV. Reduced capacity and affinity of skeletal muscle for insulin-mediated glucose uptake in noninsulin- dependent diabetic subjects. Effects of insulin therapy. J Clin Invest. 1991;87:1186-1194.

81. Yki-Jarvinen H, Utriainen T. Insulin-induced vasodilatation: physiology or pharmacology? Diabetologia. 1998;41:369-379.

82. Natali A, Quinones Galvan A, Pecori N, Sanna G, Toschi E, Ferrannini E. Vasodilation with sodium nitroprusside does not improve insulin action in essential hypertension. Hypertension. 1998;31:632636.

83. Barrett EJ, Eringa EC. The vascular contribution to insulin resistance: promise, proof, and pitfalls. Diabetes. 2012;61:3063-3065.

84. Rattigan S, Clark MG, Barrett EJ. Acute insulin resistance in rat skeletal muscle in vivo induced by vasoconstriction. Diabetes. 1999;48:564-569.

85. Rattigan S, Clark MG, Barrett EJ. Hemodynamic actions of insulin in rat skeletal muscle: evidence for capillary recruitment. Diabetes. 1997;46:1381-1388

86. Coggins MP, Lindner J, Rattigan S, Fasy E, Jahn L, Kaul S, Barrett EJ. Physiologic hyperinsulinemia enhances human skeletal muscle perfusion by capillary recruitment. Diabetes. 2001;50:2682-2690.

87. Dawson D, Vincent MA, Barrett EJ, Kaul S, Clark A, Leong-Poi H, Lindner JR. Vascular recruitment in skeletal muscle during exercise and hyperinsulinemia assessed by contrast ultrasound. Am J Physiol Endocrinol Metab. 2002;282:E714-E720.

88. Vincent MA, Clerk LH, Lindner JR, Price WJ, Jahn LA, Leong-Poi H, Barrett EJ. Mixed meal and light exercise each recruit muscle capillaries in healthy humans. Am J Physiol Endocrinol Metab. 2006;290: E1191-E1197.

89. Eggleston EM, Jahn LA, Barrett EJ. Early microvascular recruitment modulates subsequent insulinmediated skeletal muscle glucose metabolism during lipid infusion. Diabetes Care. 2013;36:104-110.

90. Eggleston EM, Jahn LA, Barrett EJ. Hyperinsulinemia rapidly increases human muscle microvascular perfusion but fails to increase muscle insulin clearance: evidence that a saturable process mediates muscle insulin uptake. Diabetes. 2007;56:2958-2963.

91. Vincent MA, Dawson D, Clark AD, Lindner JR, Rattigan S, Clark MG, Barrett EJ. Skeletal muscle microvascular recruitment by physiological hyperinsulinemia precedes increases in total blood flow. Diabetes. 2002;51:42-48. 
92. Inyard AC, Chong DG, Klibanov AL, Barrett EJ. Muscle contraction, but not insulin, increases microvascular blood volume in the presence of free fatty acid-induced insulin resistance. Diabetes. 2009;58:2457-2463.

93. Keske MA, Clerk LH, Price WJ, Jahn LA, Barrett EJ. Obesity blunts microvascular recruitment in human forearm muscle after a mixed meal. Diabetes Care. 2009;32:1672-1677.

94. Liu Z, Liu J, Jahn LA, Fowler DE, Barrett EJ. Infusing lipid raises plasma free fatty acids and induces insulin resistance in muscle microvasculature. J Clin Endocrinol Metab. 2009;94:3543-3549.

95. Sjøberg KA, Rattigan S, Hiscock N, Richter EA, Kiens B. A new method to study changes in microvascular blood volume in muscle and adipose tissue: real-time imaging in humans and rat. Am J Physiol Heart Circ Physiol. 2011;301:H450-H458.

96. Liu Z. Insulin at physiological concentrations increases microvascular perfusion in human myocardium. Am J Physiol Endocrinol Metab. 2007;293:E1250-E1255.

97. Scognamiglio R, Negut C, De Kreutzenberg SV, Tiengo A, Avogaro A. Postprandial myocardial perfusion in healthy subjects and in type 2 diabetic patients. Circulation. 2005;112:179-184.

98. Liu J, Jahn LA, Fowler DE, Barrett EJ, Cao W, Liu Z. Free fatty acids induce insulin resistance in both cardiac and skeletal muscle microvasculature in humans. J Clin Endocrinol Metab. 2011;96:438-446.

99. Chai W, Dong Z, Wang N, Wang W, Tao L, Cao W, Liu Z. Glucagon-like peptide 1 recruits microvasculature and increases glucose use in muscle via a nitric oxide-dependent mechanism. Diabetes. 2012;61:888-896.

100. Subaran SC, Sauder MA, Chai W, Jahn LA, Fowler DE, Aylor KW, Basu A, Liu Z. GLP-1 at physiological concentrations recruits skeletal and cardiac muscle microvasculature in healthy humans. Clin Sci (Lond). 2014;127:163-170.

101. Zhao L, Chai W, Fu Z, Dong Z, Aylor KW, Barrett EJ, Cao W, Liu Z. Globular adiponectin enhances muscle insulin action via microvascular recruitment and increased insulin delivery. Circ Res. 2013;112: 1263-1271.

102. Clark AD, Barrett EJ, Rattigan S, Wallis MG, Clark MG. Insulin stimulates laser Doppler signal by rat muscle in vivo consistent with nutritive flow recruitment. Clin Sci (Lond). 2001;100:283-290.

103. Aird WC. Phenotypic heterogeneity of the endothelium: I. Structure, function, and mechanisms. Circ Res. 2007;100:158-173.

104. Saxena U, Klein MG, Goldberg IJ. Transport of lipoprotein lipase across endothelial cells. Proc Natl Acad Sci USA. 1991;88:2254-2258.

105. Davies BS, Beigneux AP, Barnes RH 2nd, Tu Y, Gin P, Weinstein MM, Nobumori C, Nyrén R, Goldberg I, Olivecrona G, Bensadoun A, Young SG, Fong LG. GPIHBP1 is responsible for the entry of lipoprotein lipase into capillaries. Cell Metab. 2010;12:42-52.

106. Davies BS, Goulbourne CN, Barnes RH 2nd, Turlo KA, Gin P, Vaughan S, Vaux DJ, Bensadoun A, Beigneux AP, Fong LG, Young SG. Assessing mechanisms of GPIHBP1 and lipoprotein lipase movement across endothelial cells. J Lipid Res. 2012;53:2690-2697.

107. Young SG, Davies BS, Voss CV, Gin P, Weinstein MM, Tontonoz P, Reue K, Bensadoun A, Fong LG, Beigneux AP. GPIHBP1, an endothelial cell transporter for lipoprotein lipase. J Lipid Res. 2011;52: 1869-1884.

108. Hagberg CE, Mehlem A, Falkevall A, Muhl L, Fam BC, Ortsäter H, Scotney P, Nyqvist D, Samén E, Lu L, Stone-Elander S, Proietto J, Andrikopoulos S, Sjöholm A, Nash A, Eriksson U. Targeting VEGF-B as a novel treatment for insulin resistance and type 2 diabetes. Nature. 2012;490:426-430.

109. Bonner JS, Lantier L, Hasenour CM, James FD, Bracy DP, Wasserman DH. Muscle-specific vascular endothelial growth factor deletion induces muscle capillary rarefaction creating muscle insulin resistance. Diabetes. 2013;62:5672-5580.

110. Kaiser N, Sasson S, Feener EP, Boukobza-Vardi N, Higashi S, Moller DE, Davidheiser S, Przybylski RJ, King GL. Differential regulation of glucose transport and transporters by glucose in vascular endothelial and smooth muscle cells. Diabetes. 1993;42:80-89.

111. Mann GE, Yudilevich DL, Sobrevia L. Regulation of amino acid and glucose transporters in endothelial and smooth muscle cells. Physiol Rev. 2003;83:183-252.

112. Brownlee M. Biochemistry and molecular cell biology of diabetic complications. Nature. 2001;414: 813-820. 
113. Giacco F, Brownlee M. Oxidative stress and diabetic complications. Circ Res. 2010;107:1058-1070.

114. Yang YJ, Hope ID, Ader M, Bergman RN. Insulin transport across capillaries is rate limiting for insulin action in dogs. J Clin Invest. 1989;84:1620-1628.

115. Sjöstrand $M$, Holmäng A, Lönnroth P. Measurement of interstitial insulin in human muscle. Am J Physiol Endocrinol Metab. 1999;276:E151-E154.

116. Kondo T, Vicent D, Suzuma K, Yanagisawa M, King GL, Holzenberger M, Kahn CR. Knockout of insulin and IGF-1 receptors on vascular endothelial cells protects against retinal neovascularization. J Clin Invest. 2003;111:1835-1842.

117. Foti M, Porcheron G, Fournier M, Maeder C, Carpentier JL. The neck of caveolae is a distinct plasma membrane subdomain that concentrates insulin receptors in 3T3-L1 adipocytes. Proc Natl Acad Sci USA. 2007;104:1242-1247.

118. Minshall RD, Sessa WC, Stan RV, Anderson RG, Malik AB. Caveolin regulation of endothelial function. Am J Physiol Lung Cell Mol Physiol. 2003;285:L1179-L1183.

119. Wang H, Wang AX, Barrett EJ. Caveolin-1 is required for vascular endothelial insulin uptake. Am J Physiol Endocrinol Metab. 2011;300:E134-E144.

120. Wang $H$, Wang $A X$, Liu Z, Barrett EJ. Insulin signaling stimulates insulin transport by bovine aortic endothelial cells. Diabetes. 2008;57:540-547.

121. Wang $H$, Wang $A X$, Aylor K, Barrett EJ. Nitric oxide directly promotes vascular endothelial insulin transport. Diabetes. 2013;62:4030-4042.

122. Vicent D, Ilany J, Kondo T, Naruse K, Fisher SJ, Kisanuki YY, Bursell S, Yanagisawa M, King GL, Kahn CR. The role of endothelial insulin signaling in the regulation of vascular tone and insulin resistance. J Clin Invest. 2003;111:1373-1380.

123. Kubota T, Kubota N, Kumagai H, Yamaguchi S, Kozono H, Takahashi T, Inoue M, Itoh S, Takamoto I, Sasako T, Kumagai K, Kawai T, Hashimoto S, Kobayashi T, Sato M, Tokuyama K, Nishimura S, Tsunoda M, Ide T, Murakami K, Yamazaki T, Ezaki O, Kawamura K, Masuda H, Moroi M, Sugi K, Oike Y, Shimokawa H, Yanagihara N, Tsutsui M, Terauchi Y, Tobe K, Nagai R, Kamata K, Inoue K, Kodama T, Ueki K, Kadowaki T. Impaired insulin signaling in endothelial cells reduces insulin-induced glucose uptake by skeletal muscle. Cell Metab. 2011;13:294-307.

124. Azizi PM, Zyla RE, Guan S, Wang C, Liu J, Bolz SS, Heit B, Klip A, Lee WL. Clathrin-dependent entry and vesicle-mediated exocytosis define insulin transcytosis across microvascular endothelial cells. Mol Biol Cell 2015;26:740-750.

125. Sandqvist M, Strindberg L, Schmelz M, Lonnroth P, Jansson PA. Impaired delivery of insulin to adipose tissue and skeletal muscle in obese women with postprandial hyperglycemia. J Clin Endocrinol Metab. 2011;96:E1320-E1324. 


\section{Appendix 2.1}

Capillary recruitment: lessons from skin microvasculature

Yvo H.A.M. Kusters, Coen D.A. Stehouwer

Crosstalk Series: De novo capillary recruitment in healthy muscle is/is not necessary to explain physiological outcomes

J Physiol 2015.

In this crosstalk both discussants raise important issues regarding current methodological limitations while assessing the concept of capillary recruitment. On the one hand, contrast-enhanced ultrasound is unable to visualize individual capillaries, ${ }^{1}$ whereas intravital microscopy in surgically prepared skeletal muscle is likely to disturb baseline observations. ${ }^{2}$ Because of these limitations, it is not possible to disprove either one of the models.

We do, however, believe that earlier observations in skin can add to this discussion. Although skin as a model for muscle also has limitations, the human data with skin videomicroscopy show that insulin can in fact cause capillary recruitment in at least one organ system. Our skin data show that the cutaneous microvascular response to insulin (i.e. capillary recruitment) behaves, and can be manipulated, in a way that is entirely consistent with the model described by Dr. Barrett et al., in which microcirculation and muscle behave as a functional unit with respect to insulin sensitivity and muscle glucose uptake. ${ }^{1-5}$

Hence, we do not concur with Dr. Poole that the Kroghian model of capillary recruitment can be dismissed. Yet, progress with regard to the validity of these models requires that the methodological issues discussed above be resolved. 


\section{References}

1. Poole DC. CrossTalk opposing view: De novo capillary recruitment in healthy muscle is not necessary to explain physiological outcomes. J Physiol. 2014;592,5133-5135.

2. Barrett EJ, Keske MA, Rattigan S \& Eringa EC. Rebuttal from Eugene J. Barrett, Michelle A. Keske, Stephen Rattigan and Etto C. Eringa. J Physiol 2014;592:5137-5138.

3. Serne EH, RG IJ, Gans RO, Nijveldt R, De Vries G, Evertz R, Donker AJ \& Stehouwer CD. Direct evidence for insulin-induced capillary recruitment in skin of healthy subjects during physiological hyperinsulinemia. Diabetes 2002;51:1515-1522.

4. de Jongh RT, Serne EH, ljzerman RG, de Vries G \& Stehouwer CD. Free fatty acid levels modulate microvascular function: relevance for obesity-associated insulin resistance, hypertension, and microangiopathy. Diabetes 2004;53:2873-2882.

5. de Jongh RT, Serne EH, RG IJ, de Vries G \& Stehouwer CD. Impaired microvascular function in obesity: implications for obesity-associated microangiopathy, hypertension, and insulin resistance. Circulation 2004;109:2529-2535.

6. Jonk AM, Houben AJ, Schaper NC, de Leeuw PW, Serne EH, Smulders YM \& Stehouwer CD. (2010). Angiotensin II enhances insulin-stimulated whole-body glucose disposal but impairs insulin-induced capillary recruitment in healthy volunteers. J Clin Endocrinol Metab 2010;95:3901-3908. 

S $\lim _{1}$

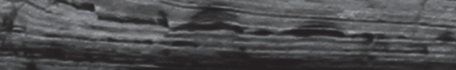

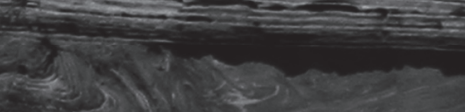

STh

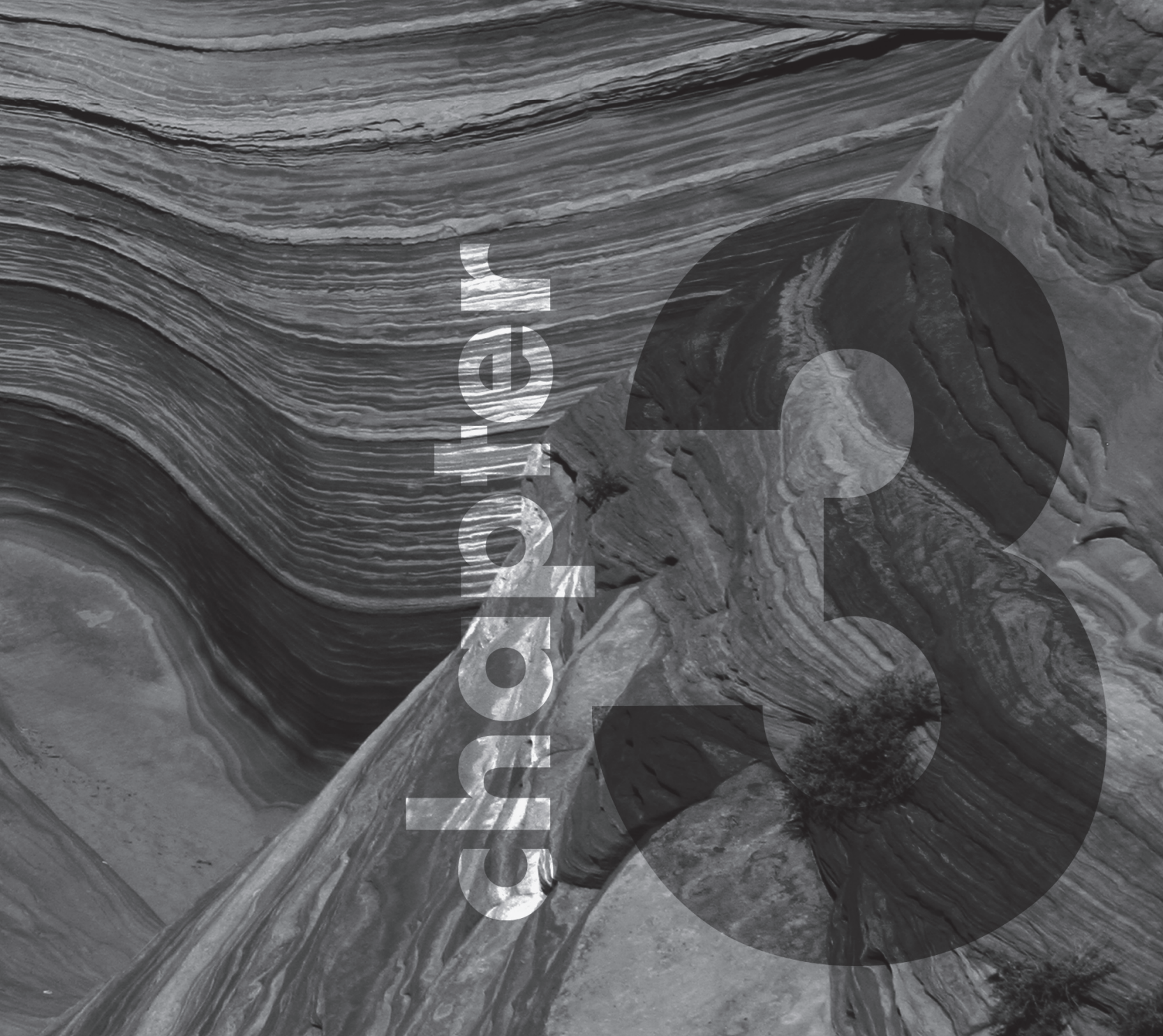




\section{Chapter 3}

\section{Reliability, measurement error and methodology of anthropometric, vascular, metabolic and inflammatory variables}

Yvo H.A.M. Kusters, Casper G. Schalkwijk, Alfons J.H.M. Houben, Jos op 't Roodt, Petra M.G. Niessen, Kristiaan Wouters, Peter J. Joris, Jogchum Plat, Ronald P. Mensink, Simone J.S. Sep, Frank C.G. van Bussel, Lucas Lindeboom, M. Eline Kooi, Eugene J. Barrett, Coen D.A. Stehouwer 


\begin{abstract}

\section{Background}

The measurement of variables is a vital part of clinical practice and biomedical research. However, the reliability of measurements is frequently misused, incompletely considered, or not at all assessed in biomedical research. We investigated the reliability, which relates the random error variance to the variance among subjects in a population, and measurement error, which is related to the concept agreement, of several commonly used anthropometric, vascular, metabolic and inflammatory variables.
\end{abstract}

\title{
Methods
}

We evaluated visceral (VAT) and subcutaneous adipose tissue (SAT), intrahepatic (IHL) and intrapancreatic lipid (IPL), muscle microvascular recruitment (MVR), capillary microscopy $(\mathrm{CM})$, flowmotion, sublingual microvascular glycocalyx, flow-mediated dilation (FMD), reactive hyperemia index (RHI), carotid-femoral pulse wave velocity (cfPWV), augmentation index (Aix), carotid distensibility, distensibility coefficient (DC), compliance coefficient (CC) and intima-media thickness of the common carotid artery (cIMT), whole body glucose disposal (WBGD), beta-cell glucose sensitivity (b-GS), betacell rate sensitivity (b-RS), potentiation factor ratio (PFR), CD11B surface expression of circulating NK cells (NK-CD11B), and a z-score of plasma biomarkers of low-grade inflammation (z-LGI). We evaluated reliability and measurement error for intra- and inter-observer comparisons as well as over time for the execution of the measurements. Similar comparisons were made for the analyses of the measurements. When available, measurements were also compared to their gold standard.

\section{Results}

Most measurements were highly reliable and had acceptable measurement error, yet sublingual microvascular glycocalyx and some indices derived from CM and flowmotion were not reliable and had a considerable measurement error. Analyses of all measurements was reliable and had acceptable measurement error. VAT, SAT and IHL were compared to their gold standard and considered valid.

\section{Conclusion}

Here, we established the reliability and measurement error of commonly used anthropometric, vascular, metabolic and inflammatory variables. This detailed understanding of sources of measurement error and the reliability of variables in a certain study population allows for the adequate selection of outcome measurements in observational and intervention studies, as well as provide data for more accurate sample size calculations for such studies. 


\section{Introduction}

The measurement of variables is a vital part of clinical practice and biomedical research. Measurements are, however, seldom perfect. ${ }^{1}$ To assess the quality of the measurement of a variable, the COSMIN statement is generally used; it defines a good measurement as reliable, responsive, valid, and interpretable (Supplementary Figure 3.1). ${ }^{2}$ However, the reliability of measurements is frequently misused, incompletely considered, or not at all assessed in biomedical research. ${ }^{3,4}$ Nonetheless, an appropriate assessment and interpretation of reliability is essential for correct study designs and power calculations, as well as to develop strategies to improve reliability in the measurement of variables.

Potentially confusingly, the domain reliability in the COSMIN taxonomy is divided into the measurement properties measurement error and, again, reliability (also known as reproducibility, repeatability, or test-retest performance; Supplementary Figure 3.1). ${ }^{1,2}$ It is important to understand the difference between measurement error and reliability. Parameters of measurement error relate to the concept agreement, i.e., the absolute difference between repeated measurements. Two commonly reported, and related, parameters of measurement error are the standard error of the measurement (SEM) and the limits of agreement (Bland and Altman method). The SEM can be interpreted as the standard deviation around a single measurement (e.g., when waist circumference is assessed 100 consecutive times, the SD of these measurements equals the SEM). ${ }^{1}$ A different parameter of measurement error are the limits of agreement. ${ }^{5}$ In Bland-Altman plots, the difference between repeated measurements is plotted against the average of those measurements. This allows for the visualization of systematic differences, as well as the limits of agreement. If one assumes a normal distribution of difference scores, $95 \%$ of the difference scores will fall between the limits of agreement. ${ }^{1,5}$

Reliability parameters on the other hand, like intraclass correlation coefficients (ICC), which range in value from 0 (totally unreliable) to 1 (perfect reliability), relate the random error variance to the variance among subjects in a population., ${ }^{1,6,7}$ Consequently, a parameter of reliability is in fact only valid for the population it is measured in and the observers it is measured by. If, for example, reliability were to be determined in a population where variance between subjects is very high (e.g., determining insulin sensitivity in a population with trained athletes and individuals with type 2 diabetes are included), reliability is generally high. When this reliability is then assumed for the measurement itself, regardless of the population (e.g., when studying only obese individuals without type 2 diabetes), the reliability of that measurement is grossly overestimated. 
Although the COSMIN Statement was primarily designed for patient reported outcomes, ${ }^{2}$ most of its criteria can be applied to observer-derived measurements as well. As observers are then, possibly, involved twice in the process, i.e., the conduction of the measurement as well as the (offline) analyses of the data, the measured variable can entail measurement error derived from both.

In this thesis, a multitude of anthropometric, vascular, metabolic and inflammatory measurements have been used. Nevertheless, the reliability of some, like muscle microvascular recruitment (MVR) by means of contrast enhanced ultrasound (CEUS), has never been reported at all. Other measurements, like nailfold capillary microscopy for example, are known for their relatively high inter-observer variance. ${ }^{8}$ As a result, researchers are commonly subjected to an extensive training program before they are deemed capable to perform or analyze such measurements. Moreover, it is important to identify where sources of error arise, as strategies to improve a measurement's reliability can be developed and deployed from this insight.

It is, therefore, important to 1) determine whether measurement error arises predominantly from the acquisition of data or its analyses; 2 ) to assess to what extent measurements differ within one observer, as well as between observers; and 3) determine to what extent a measurement varies over time. To our knowledge, this is the first study to evaluate the sources of measurement error for the measurements in this thesis and provide substantiated recommendations on the improvement of reliability.

We assessed reliability and measurement error several ways. First, we evaluated reliability and measurement error for intra- and inter-observer reliability and reliability over time, for the execution of the measurements. Then, we evaluated the reliability and measurement error for intra- and inter-observer reliability for the (offline) analyses of the measurements. Finally, we compared measurements to their gold standard, when available. For each of these assessments we provided the ICC, SEM, and Bland-Altman plot with limits of agreement.

\section{Materials and methods}

\section{Study designs}

In this manuscript on reliability, data from several separate studies are reported in order to provide as much information on reliability and measurement error as possible in a single report. Reliability data of MVR were collected in a dedicated CEUS Reproducibility Study in which individuals were measured on two occasions one week 
apart with handgrip exercises as stimulus for MVR. On each study day, CEUS was performed twice with 60 minutes in between. CEUS measurements were conducted in a temperature-controlled room $\left(T=24^{\circ} \mathrm{C} \pm 0.5^{\circ} \mathrm{C}\right)$ after a 12 -hour overnight fast and with the individuals in the supine position for at least 30 minutes prior to the measurements. Individuals were instructed to refrain from alcoholic beverages for a period of 72 hours prior to each study day and strenuous physical exercise 24 hours prior to each study day.

From a weight loss intervention (WLI) trial, which is described in more detail elsewhere, ${ }^{9,10}$ we derived data on 1 ) the reliability over time of abdominal visceral adipose tissue volume (VAT), abdominal subcutaneous tissue volume (SAT), intrahepatic lipid content (IHL), intrapancreatic lipid content (IPL), MVR, sublingual microvascular perfused boundary region (PBR), capillary microscopy, vasomotion, flow-mediated dilation (FMD), reactive hyperemia index (RHI) and whole body glucose disposal (WBGD); 2) the reliability of VAT, SAT, IHL, IPL, MVR, vasomotion, and FMD analyses; and 3) the comparison of VAT, SAT and IHL measurements to their respective gold standard. The data on reliability over time was derived from the weight stable control group that did not alter their diet or exercise pattern for eight weeks. The comparison of our VAT, SAT, and IHL measurements to their gold standard were performed in a random subsample of lean and abdominally obese individuals.

The reliability data of carotid-femoral pulse wave velocity (cfPWV), augmentation index (AIx), carotid distensibility, distensibility coefficient (DC) of the common carotid artery (CCA), compliance coefficient (CC) of the CCA, and carotid IMT (CIMT) measurements were investigated in a subsample of the Maastricht Study. ${ }^{11}$ In this subset of 12 individuals, two investigators performed these measurements consecutively on the first day. One week later, one investigator repeated these measurements. In this study, participants were asked to refrain from smoking and drinking coffee, tea or alcoholic beverages $\leq 3$ hours prior to the study. Participants were allowed to have a light meal (breakfast and/or lunch). All measurements were performed after 10 minutes of rest and talking or sleeping was not allowed during the examination. ${ }^{12}$ The reliability of VAT and SAT analyses were determined in a random subset of 29 participants in the Maastricht study. Two observers (YK and an experienced abdominal radiologist $(\mathrm{StH})$ ) analyzed all images in parallel and in a masked fashion, unaware of each other's analyses.

The reliability of capillary microscopy analyses were assessed in a standardized training set of representative images chosen from several studies. ${ }^{11,13}$ This training set has been used by previous and current researchers in order to standardize scoring criteria for (continuously) perfused capillaries. Observers were unaware of each other's analyses. 
Data on the reliability of FMD measurements have been published before, ${ }^{14}$ yet are included in this manuscript to illustrate the difference in reliability of several common vascular function measurements as well as their analyses. In this Acute Hyperglycemia Study, which aimed to normalize FMD to local wall shear stress, participants were studied on two separate days with a week in between. On each study day, participants underwent repeated FMD measurements with ten minutes in between; assessors of FMD videos were not masked. Individuals were instructed to refrain from exercise, smoking, vitamin supplement use, caffeine consumption, and alcohol consumption. Measurements were performed after a 12-hour overnight fast in supine position in a climate-controlled room.

\section{Study populations}

In the CEUS Reproducibility study, 5 women and 3 men were recruited by advertisements and enrolled at the Maastricht University Medical Center, The Netherlands, from September, 2012 to April, 2013. Participants were aged 18 55 years, non-smokers, free of cardiovascular disease, and had a BMI below $25 \mathrm{~kg} / \mathrm{m}^{2}$. Individuals were excluded when office blood pressure was $>140 / 90 \mathrm{mmHg}$, when they used medication affecting blood pressure, serum lipids or glucose metabolism, when they were pregnant or lactating, when they were allergic to the contrast agent used, and/or when they had known cardiac dysrhythmias or a family history of sudden cardiac death. The study was approved by the Maastricht University Medical Center ethics committee, performed in accordance with the Declaration of Helsinki, and registered at the Dutch research database ToetsingOnline (NL37229.068.11). All participants gave written informed consent.

The details on the individuals enrolled in the randomized controlled weight loss trial with blinded analyses are described elsewhere. ${ }^{9,10}$ Briefly, 53 abdominally obese and 25 lean men were recruited by advertisements and enrolled at the Maastricht University Medical Center in Maastricht, The Netherlands, from August, 2012 to May, 2014. Participants were aged 18 - 65 years, non-smokers, nondiabetic, free of CVD, had a waist circumference below $94 \mathrm{~cm}$ (lean) or between $102-110 \mathrm{~cm}$ (abdominally obese), and a stable body weight for at least 3 months. Men were excluded when fasting plasma glucose was $>7.0 \mathrm{mmol} / \mathrm{l}$, when $\mathrm{HbA} 1 \mathrm{c}$ was $>6.5 \%$, when serum total cholesterol was $>8.0 \mathrm{mmol} / \mathrm{l}$, when serum triacylglycerol was $>4.5 \mathrm{mmol} / \mathrm{l}$, when they had a contra-indication for magnetic resonance imaging (MRI), and/or when they used medication affecting blood pressure, serum lipid or glucose metabolism. The study was approved by the Maastricht University Medical Center ethics committee, performed in accordance with the Declaration of Helsinki, and registered at clinicaltrials.gov (NCT01675401). All participants gave written informed consent. 
The rationale and methodology of the Maastricht Study, as well as its population characteristics, have been described previously. ${ }^{11,12}$ To reiterate from, ${ }^{12}$ the study focuses on the etiology, pathophysiology, complications and comorbidities of T2DM and is characterized by an extensive phenotyping approach. Eligible for participation were all individuals aged between 40 and 75 years and living in the southern part of the Netherlands. Individuals were recruited through mass media campaigns and from the municipal registries and the regional Diabetes Patient Registry via mailings. Recruitment was stratified according to known T2DM status, with an oversampling of individuals with T2DM, for reasons of efficiency. Clinical characteristics of the individuals included in the Maastricht Study are summarized elsewhere. ${ }^{12,15}$ Reliability was assessed in a subset of 12 individuals ( 6 men; $60.8 \pm 6.8$ years; 6 TDM2). The study is registered at the Dutch research database ToetsingOnline (NL31329.068.10), has been approved by the Minister of Health, Welfare and Sports of the Netherlands, on the basis of the Health Council's opinion (Permit 131088-105234-PG), and performed in accordance with the Declaration of Helsinki. All participants gave written informed consent.

As described previously, the Acute Hyperglycemia Study, in which reliability of FMD measurements is already mentioned, consisted of 22 men. ${ }^{14}$ All individuals were nondiabetic, free of cardiovascular disease, and did not use any medication. The study was approved by the Maastricht University Medical Center ethics committee, performed in accordance with the Declaration of Helsinki, and registered at the Dutch research database ToetsingOnline (NL33485.068.10). All participants gave written informed consent.

\section{Anthropometric measurements}

\section{Visceral and subcutaneous adipose tissue volumes}

In the WLI trial, VAT and SAT volumes were obtained by MRI through two-dimensional (2D) T1-weighted turbo spin echo (TSE) imaging on a 3.0T Philips Achieva MRI scanner with a dedicated sixteen-element torso coil (XL Torso coil, Philips Healthcare, The Netherlands) as described previously. ${ }^{9}$ Nine $5 \mathrm{~mm}$ thick transverse slices with $10 \mathrm{~mm}$ gaps centered at the top of the L4 vertebral body were acquired using the following scan parameters: repetition time $(T R)=526 \mathrm{~ms}$, echo time $(T E)=10 \mathrm{~ms}$, turbo spin echo factor $=4$, number of signal averages $(N S A)=1$, field of view $(F O V)=400 \times 322$ $\mathrm{mm}$, acquired matrix size $=308 \times 164$, acquired in-plane voxel size $=1.3 \times 1.96 \mathrm{~mm}$, reconstructed matrix size $=512 \times 412$, and a reconstructed voxel size of $0.78 \times 0.78$ $\mathrm{mm}$. Images were analyzed offline after completion of the trial with dedicated software (Hippo Fat, IFC CNR, Pisa, Italy) to provide VAT and SAT volumes. ${ }^{16}$ 
In the Maastricht Study, VAT and SAT area were acquired using a 3T MRI system (MAGNETOM Prismafit, Siemens Healthineers, Erlangen, Germany) with body matrix and supine radiofrequency coils. Subjects were positioned supine. After an initial scout view, a single-slice transversal image at the top level of the L4 vertebral body was obtained during breath-hold to assess areas of the visceral and subcutaneous adipose tissue compartments using a T1-weighted TSE pulse sequence with the following parameters: acquired and reconstructed in-plane voxel size $2 \times 2 \mathrm{~mm}^{3}$, slice thickness $8 \mathrm{~mm}$, TR $550 \mathrm{~ms}$, NSA $=1$, parallel imaging (GRAPPA) factor $=2$, turbo factor $=7$. Depending on the size of the patient, the FOV was $384 \times 312 \mathrm{~mm}^{2}$ with a TE of $36 \mathrm{~ms}$ or $500 \times 406 \mathrm{~mm}^{2}$ with a TE of $38 \mathrm{~ms}$. Images were analyzed offline after completion of the trial with dedicated software (Hippo Fat, IFC CNR, Pisa, Italy) to provide VAT and SAT volumes. ${ }^{16}$

The reliability over time was derived from the weight stable control group of the WLI trial, consisting of 26 abdominally obese men. Intra- and inter-observer reliability of the analyses was assessed in a subset of 29 scans from the Maastricht study. For intraobserver reliability this subset was analyzed twice with two weeks in between. During that same period, this subset was analyzed by an experienced and certified abdominal radiologist to determine the inter-observer reliability. In addition, this subset of 29 scans was also analyzed by determining SAT and VAT pixel by pixel (MRIcron version 6.6.2013, Chris Rorden, CRNL, USA), which could be considered to be the gold standard for VAT and SAT analyses. ${ }^{16}$

\section{Intrahepatic lipid content}

With the same MRI scanner and coil, IHL was assessed through mDixon imaging as described before. ${ }^{9}$ Two $6 \mathrm{~mm}$ thick transverse slices through the liver were acquired using a 2D three-point T1-fast field echo (T1-FFE) mDixon pulse sequence, to correct for $\mathrm{T}^{*}$ relaxation. The scan parameters were as follows: $\mathrm{TR}=150 \mathrm{~ms}$, TE1 $=0.85 \mathrm{~ms}$, $\Delta \mathrm{TE}=0.7 \mathrm{~ms}$, flip angle $(\mathrm{FA})=10^{\circ}, \mathrm{NSA}=1, \mathrm{FOV}=375 \times 310 \mathrm{~mm}$, acquired matrix size $=92 \times 77$, acquired in-plane resolution $=4.08 \times 4.02 \mathrm{~mm}$, reconstructed matrix size $=384 \times 320 \mathrm{~mm}$, and a reconstructed voxel size of $0.98 \times 0.97 \mathrm{~mm}$. The intrahepatic fat percentage was calculated in three regions of interest (ROI) within the liver parenchyma, carefully avoiding blood vessels. The fat content was expressed as the weighted mean fat signal, divided by the sum of the weighted mean water and fat signal.

The reliability over time was derived from the weight stable control group of the WLI trial consisting of 26 abdominally obese men. Intra-observer reliability of the analyses was assessed by analyzing a random subset of 10 scans derived from lean and obese individuals from the WLI trial twice, with one year in between. In parallel with the 
second analysis by the first observer (YK), another subset of 15 scans was analyzed by an experienced and certified abdominal radiologist to determine the inter-observer reliability. In addition, intra-slice, inter-slice and inter-ROI reliability was assessed in the baseline scans of the WLI trial $(n=74)$.

Moreover, we compared IHL by means of the mDixon sequence to proton resonance spectroscopy $\left({ }^{1} \mathrm{H}-\mathrm{MRS}\right)$, the gold standard for non-invasive quantification of IHL, in a random subset of 45 measurements in lean and abdominally obese individuals in the WLI trial. The decision whether additional ${ }^{1} \mathrm{H}$-MRS was performed was dependent on the availability of trained personnel. The ${ }^{1} \mathrm{H}$-MRS scan was performed using the same MRI scanner and torso coil and the spectra were obtained from a $30 \times 30 \times 30 \mathrm{~mm}$ voxel placed centrally in the right lobe of the liver by using point-resolved spectroscopy volume selection (PRESS) with the following scan parameters: $\mathrm{TR}=4000 \mathrm{~ms}, \mathrm{TE}=32.5 \mathrm{~ms}, 2048$ sample points. A total of 32 spectra with NSA of 2 were acquired. A water signal was acquired as a reference (NSA $=2 \times 8$ ). To keep the TR constant, the subject was instructed to breathe exactly at the 4s-rhythm of the sequence. Shimming was performed by using second-order FASTMAP-based shimming.

\section{Intrapancreatic lipid content}

Information on IPL was obtained through mDixon imaging with the same MRI scanner and coil. A six mm thick transverse slice through the pancreas was acquired using a 2D three-point T1-fast field echo mDixon pulse sequence, to correct for T2* relaxation. The scan parameters were as follows: $\mathrm{TR}=150 \mathrm{~ms}$, TE1 $=0.85 \mathrm{~ms}, \Delta \mathrm{TE}=0.7 \mathrm{~ms}$, $\mathrm{FA}=10^{\circ}, \mathrm{NSA}=1, \mathrm{FOV}=375 \times 310 \mathrm{~mm}$, acquired matrix size $=92 \times 77$, acquired in plane resolution $=4.08 \times 4.02 \mathrm{~mm}$, reconstructed matrix size $=384 \times 320 \mathrm{~mm}$, and a reconstructed voxel size of $0.98 \times 0.97 \mathrm{~mm}$. IPL was calculated in one ROI within the pancreas parenchyma, preferably encompassing the head and body of the pancreas. In the WLI trial, the ROI was matched between baseline and follow-up measurements. IPL was expressed as the mean fat signal divided by the sum of the mean water and fat signal. The reliability over time was derived from the weight stable control group of the WLI trial consisting of 26 abdominally obese men. Intra-observer reliability of the analyses was assessed by analyzing a random subset of 15 scans derived from lean and obese individuals from the WLI trial twice, with one year in between. In parallel with the second analysis by the first observer (YK), the subset was analyzed by an experienced and certified abdominal radiologist to determine the inter-observer reliability. In contrast to IHL, ${ }^{1} \mathrm{H}-\mathrm{MRS}$ is not considered to be superior to mDixon for IPL quantification, as mDixon allows for image-based determination of the volume of interest, which reduces the risk of erroneously including non-pancreatic tissue into the volume of interest. ${ }^{17,18}$ 


\section{Microvascular measurements}

\section{Muscle microvascular recruitment}

CEUS was used to assess MVR in skeletal muscle. For these measurements, flexor muscles of the right arm were visualized with a Toshiba Aplio XG ultrasound system (Supplementary Figure 3.2A; Toshiba, Japan). On a transparent overhead projector sheet covering the display, characteristic morphological features were copied in order to visualize the exact same ROI with each measurement. The microvascular blood volume (MBV) of forearm skeletal muscle was determined with contrast harmonic imaging. Meanwhile, sulfur hexafluoride gas-filled microbubbles (SonoVue, Bracco diagnostics, The Netherlands) were intravenously and continuously infused. In the CEUS Reproducibility Study, microbubbles were infused during 10 minutes. After three minutes, when steady state microbubble concentration is typically achieved, five realtime replenishment curves of 25 seconds were obtained after microbubble disruption by a high mechanical index ultrasound pulse. Individuals were then asked to perform dynamic handgrip exercises at $80 \%$ of their maximal hand grip strength. During the first two minutes individuals contracted once every 5 seconds, followed by one contraction every 30 seconds for another 2.5 minutes, adding up to a total exercise time of 4.5 minutes. During the last 2.5 minutes, five replenishment curves of 25 seconds each were acquired in between muscle contractions. In the WLI study, microbubbles were infused for 6 minutes both in a fasted state, as well as during hyperinsulinemia. After three minutes, five real-time replenishment curves of 25 seconds were acquired after microbubble disruption by a high mechanical index ultrasound pulse. Replenishment curves were stored and analyzed offline upon completion of the study using the $\mathrm{CHI}-\mathrm{Q}$ software (Toshiba, Japan). One region of interest was drawn in the deep flexor muscles, carefully avoiding blood vessels, and was matched between all measurements. The replenishment curves were fitted to the exponential function $y=A\left(1-e^{-\beta t}\right)$ and averaged as described before. ${ }^{9,19}$ Briefly, MBV was calculated by subtracting the value of the fitted curve after one second $\left(\mathrm{y}_{1}\right)$ from the plateau phase (A-value); herewith, signal from rapid filling arterioles and venules are discarded. MVR was calculated as the increase in MBV induced by either dynamic handgrip exercises or hyperinsulinemia.

Intra-observer reliability of the measurements were determined in the CEUS Reproducibility Study by measuring microvascular recruitment induced by hand grip exercises twice on each study day $(n=8)$. The reliability over time was determined in two study populations. First, in the CEUS Reproducibility Study where MVR induced by hand grip exercises was assessed on two separate days, one week apart $(n=7)$. Second, from the weight stable control group of the WLI trial where insulin-induced MVR was assessed in 26 abdominally obese men on two separate days, eight weeks 
apart. Intra-observer reliability of the analyses was assessed by analyzing a subset of 21 CEUS recordings in lean and abdominally obese individuals that participated in the WLI trial. The subset consisted of 10 random recordings and 11 recordings of relatively poor image quality. The second assessment took place one week after the first MVR analyses were completed.

\section{Capillary microscopy}

Nailfold capillaries were visualized by means of intravital videomicroscopy, which allowed for direct visualization of nutritive skin capillaries (Capiscope, KK Technology, Devon, England). Nailfold capillaries of the dorsal skin of the third and fourth finger of the right hand were visualized with a total system magnification of $100 \mathrm{x}$ and recorded at 25 frames per second. Each frame measures $640 \times 480$ pixels with 256 grey levels per pixel. During the measurements, the investigated finger was immobilized in a mass of clay and paraffin oil was applied to the imaged area of the nailfold to improve skin translucency and reduce skin reflections as described previously (Supplementary Figure 3.2B). ${ }^{20}$ Capillaries 3 to $5 \mathrm{~mm}$ proximal to the terminal row of capillaries in the middle of the nailfold, with the exact location dependent of the image quality and perpendicularity of the visualized capillaries, were analyzed. The ROI size was $1 \mathrm{~mm}^{2}$. On a transparent overhead projector sheet covering the monitor, characteristic morphological features were copied in order to visualize the exact same ROI during each measurement, as well as between study days. In case a specific ROI could not be retrieved on the second study day, a different $\mathrm{ROI}$ that met the quality standards was recorded. Yet, only ROIs that could be matched between both visits were used to assess the data on reliability over time reported in this manuscript. For each finger, continuously ( $\geq 15$ seconds) perfused capillaries in the rested state, perfused capillaries during hyperemia, capillary recruitment by hyperemia and capillary density during venous occlusion were recorded in a fasted state and during an insulin clamp. Hyperemia was induced by inflation of a miniature cuff (Digit cuff, Hokanson Inc., Bellevue, USA) that was positioned around the base of the finger to suprasystolic pressure $(240 \mathrm{mmHg}$ ) for four minutes, after which the cuff was rapidly deflated. During the period of post-occlusive reactive hyperemia, all capillaries that were perfused at any moment during a 15-second period were counted. Capillary recruitment during post-occlusive hyperemia $(\Delta \mathrm{HE})$ was defined as the difference between number of perfused capillaries during hyperemia and the number of continuously perfused capillaries in the rested condition and is considered a functional capillary reserve capacity. Five minutes after the suprasystolic pressure was released from the cuff, the cuff was re-inflated to $50 \mathrm{mmHg}$ (i.e., subdiastolic pressure) for two minutes in order to induce venous congestion. After one minute, the number of capillaries that were erythrocyte-filled at any moment during a 15 -second period were counted; this method is considered to visualize the maximal 
number of skin capillaries. Capillary recruitment by hyperinsulinemia ( $\Delta$ Ins) was defined as difference in terms of percentage between continuously perfused capillaries during hyperinsulinemia and continuously perfused capillaries in the fasted condition. All recorded videos were stored, masked and subsequently analyzed offline by a single investigator (PN). For these offline analyses, a semi-automatic image analysis application (CapiAna, Ed Gronenschild and Alfons Houben, Maastricht, The Netherlands) was used as described into more detail elsewhere. ${ }^{8}$ To exclude a learning effect or a shift in judgment during the analyses of the WLI trial, the recordings were divided into three batches and between group effects and treatment effects were determined for each batch; nonetheless, no difference in either comparison was found between batches.

The reliability over time was derived from the weight stable control group of the WLI trial, which consists of 26 abdominally obese men, of whom 24 men had at least one ROI that was identical between both visits. The intra-observer reliability was determined in a training set of six individuals selected from the Maastricht Study and the inter-observer reliability of the analyses was determined in a second training set of five individuals selected from several previous studies ${ }^{11,13}$ and analyzed by two investigators more than one year apart.

\section{Flowmotion}

The periodic blood flow fluctuations, known as flowmotion, which in part arise from rhythmic vessel diameter oscillations known as vasomotion, ${ }^{21}$ were non-invasively assessed in skin by means of laser Doppler flowmetry (LDF; PeriFlux 5000, PeriMed $A B$, Järfälla, Sweden) as described previously. ${ }^{20}$ In summary, LDF is based on the emission of a beam of $780 \mathrm{~nm}$ wavelength laser light carried by a fiber-optic probe. As the laser light penetrates the skin, a fraction of the light is backscattered by moving erythrocytes, which leads to a shift in frequency proportional to the velocity of erythrocyte movement (i.e., the Doppler principle). The magnitude and frequency distribution of these changes in wavelength are directly related to the number (i.e., volume) and velocity of the blood cells in the sampled volume. This information is detected and transported by a returning optical fiber and converted to an electronic signal. Typically, the measuring depth is $0.5-1 \mathrm{~mm}$, yet as the exact volume that is measured is unknown, the blood flow is expressed in arbitrary units. Subsequently, flowmotion can be analyzed by either Fourier or wavelet analyses, which quantifies the relative contribution of each frequency to the observed LDF signal. Low frequency signals associated with vasomotion arise from endothelial $(\sim 0.01 \mathrm{~Hz})$, neurogenic $(\sim 0.04 \mathrm{~Hz})$, and myogenic activity $(\sim 0.1 \mathrm{~Hz}) .{ }^{21-27}$ The LDF probe was positioned at the level of the left wrist (Supplementary Figure 3.2C), which renders less movement artifacts than the fingers. All recordings were stored, masked, and analyzed offline. 
Here, we used Fast Fourier transformation of the LDF signal with the build-in software (PSW 2.5.5, PeriMed AB, Järfälla, Sweden) as it is the method used in previous papers by our research group.

The reliability over time was derived from a subset of 14 abdominally obese men randomized to the weight stable control group of the WLI trial. The subset was based on the enrollment date, i.e., the 14 individuals included in these analyses are the first weight stable controls that participated. The intra-observer reliability of the analyses was determined in a training set of six individuals selected from the Maastricht Study and analyzed more than four months apart. The inter-observer reliability of the analyses was determined in a random subset of 35 lean and abdominally obese men that participated in the WLI trial.

\section{Sublingual microvascular perfused boundary region (Glycocalyx)}

The glycocalyx was assessed in terms of the sublingual microvascular perfused boundary region (PBR), which reflects the part of the glycocalyx that can be penetrated by moving erythrocytes, and measured with a dedicated and automated on-line quantification system (GlycoCheck ${ }^{\mathrm{TM}}$, Maastricht, The Netherlands). ${ }^{28}$ The sublingual microcirculation was visualized by placement of a sidestream dark field handheld imaging device under the tongue. Here, the imaging software automatically controlled the quality of the videorecordings and only those of sufficient quality (1 - 2 minutes in total) were recorded. Upon completion of the recordings, the automated software recognizes the microvessels, divides them in over 3000 vascular segments, and calculates in them the PBR as a measure of glycocalyx barrier properties. $^{28}$ The PBR is reported for microvessels from 5 to $25 \mu \mathrm{m}$, where lower PBR-values reflect a healthier glycocalyx barrier function. The reliability over time was derived from the weight stable control group of the WLI trial consisting of 26 abdominally obese men. In contrast to the measurements, the analyses of PBR are automated and therefore observer independent.

\section{Macrovascular measurements}

\section{Flow-mediated dilation}

Details on flow-mediated dilation (FMD) measurements and part of its reliability have been published elsewhere. ${ }^{14}$ Briefly, with the individual in supine position for at least 20 minutes, the right shoulder and arm were positioned on soft supports for optimal comfort and stability. A well-accessible segment of the brachial artery was visualized with a $7.5 \mathrm{MHz}, 40 \mathrm{~mm}$ linear array ultrasound system (MyLab ${ }^{\text {TM }}$ 70, Esaote, Maastricht, The Netherlands) in Duplex-mode to record simultaneously artery diameter and center-line blood flow sonogram. The transducer position was fixed 
using a custom-made stereotactic probe holder. The electronically steered pulsedDoppler beam was set at an angle of 65 - 70 degrees with respect to the vessel long axis. The length of the pulsed-Doppler sample volume was set at approximately half the vessel diameter to ensure consistent registration of the center-line velocity despite possible movements over the recording period. A sphygmomanometer cuff (Hokanson TD 312, D.E. Hokanson Inc., Bellevue, USA) was positioned on the right lower arm and rapidly inflated to at least $200 \mathrm{mmHg}$ (or higher when simultaneous EndoPAT $^{\mathrm{TM}}$ measurements indicated incomplete arterial occlusion) for 5 minutes to elicit upon release the hyperemic response required for brachial artery flow-mediated dilation measurement. For each FMD measurement, duplex images were recorded continuously on DVD over a total of 15 minutes: a 5 minutes reference period (i.e., before cuff-inflation), 5 minutes during lower arm cuff-inflation, and 5 minutes during hyperemia following rapid cuff-release. Recorded videos were analyzed offline using proprietary wall detection and Doppler velocity tracing software (MyFMD; Prof. A.P. Hoeks, Department of Biomedical Engineering, MUMC+, Maastricht, The Netherlands) implemented in Matlab (The Mathworks, Natick, USA). In the weight loss study, recordings were masked prior to analysis.

Intra-observer reliability and reliability over time were assessed in the FMD in Acute Hyperglycemia Study. ${ }^{14}$ For intra-observer reliability, individuals were measured twice in a fasted state with ten minutes in between on each study day. The second study day was repeated one week later, from which reliability over time was obtained. In addition, reliability over time was also derived from the weight stable control group of the WLI trial, where 23 FMD measurements were available for analysis. ${ }^{10}$ Both intraand inter-observer reliability of the offline analyses were assessed in a random subset of 25 masked FMD measurements in lean and abdominally obese individuals. One observer (JoR) repeated the analyses three days apart. In that same period, a second observer (PJ) analyzed the same subset of FMD measurements.

\section{Reactive hyperemia index}

The reactive hyperemia index (RHI) was measured during FMD measurements with a dedicated device (EndoPAT 2000, Itamar Medical Ltd, Caesarea, Israel) as described previously. ${ }^{10}$ Briefly, on the index finger of both hands a pneumatic probe that measures arterial pulsatile volume changes (dubbed peripheral arterial tone (PAT) by the manufacturer) is placed. The RHI was quantified as the postocclusion to preocclusion PAT-signal in the occluded hand, normalized to the values in the control hand, then further corrected for baseline vascular tone. ${ }^{29}$ Reliability over time was determined in a subset of 14 individuals in the weight stable control group of the WLI Trial. The first 14 individuals to complete the study were included in this subset. 


\section{Carotid-femoral pulse wave velocity and augmentation index}

Carotid-femoral pulse wave velocity (cfPWV), the ratio of travelled distance divided by transit time, was determined according to recent guidelines with applanation tonometry (SphygmoCor, Atcor Medical, Australia) as described previously. ${ }^{12,30}$ Briefly, pressure waveforms were determined the right common carotid and right common femoral arteries. Difference in the time of pulse arrival from the R-wave of the electrocardiogram between the two sites (transit time) was determined with the maximum upstroke algorithm. The pulse wave travel distance was calculated as the total direct straight distance (measured with an infantometer) between the two arterial sites. The augmentation index (Aix) was determined by radial applanation tonometry and computed by built-in software (SphygmoCor v9, Atcor Medical, Sidney, Australia). ${ }^{31,32}$ Intra- and inter-observer reliability, and reliability over time were assessed in 12 individuals that participated in the Maastricht study and visited the research facility for a second time one week after their first visit. On their first visit, one observer repeated cfPWV and Aix measurements, directly thereafter a second observer repeated the measurements.

Distensibility, distensibility coefficient, compliance coefficient, and carotid intimamedia thickness

After completion of cfPWV and Aix measurements, the left common carotid artery (CCA) was visualized directly proximal from the bulbus $(0-10 \mathrm{~mm})$ in fast brightness mode with a $7.5 \mathrm{MHz}, 40 \mathrm{~mm}$ linear array ultrasound system (MyLab ${ }^{\text {TM }}$ 70, Esaote, Maastricht, The Netherlands) equipped with an ARTLAB system (Esaote, Maastricht, The Netherlands). Ultrasound data and 3-lead ECG signal were simultaneously recorded during 3 consecutive 6 seconds measurements. Herewith, measurements of diameter, distensibility, and carotid intima-media thickness (cIMT) were simultaneously acquired. The cumulative radiofrequency signals were digitized and stored and analyzed offline by custom-build software (Dist13; Prof. A.P. Hoeks, Department of Biomedical Engineering, MUMC+, Maastricht, The Netherlands). Herewith, the change in diameter as a function of time (distensibility) was estimated, diastolic diameter was calculated as the difference in position between the anterior and posterior wall markers, and the cIMT was calculated as the distance from the leading edge interface between lumen and intima to the leading edge interface between media and adventitia of the posterior wall. Subsequently, distensibility coefficient (DC), which represents arterial stiffness, and compliance coefficient, which represents arterial buffering capacity, were calculated using the following formulas ${ }^{33-35}$ : 


$$
\begin{gathered}
D C=\left(2 \Delta D \times D+\Delta D^{2}\right) /\left(P P \times D^{2}\right)\left(\text { in } 10^{-3} / \mathrm{kPa}\right) \\
C C=\pi \times\left(2 D \times \Delta D+\Delta D^{2}\right) /(4 \times P) P\left(\text { in } \mathrm{mm}^{2} / \mathrm{kPa}\right)
\end{gathered}
$$

Intra- and inter-observer reliability and reliability over time were assessed in 10 individuals that participated in the Maastricht study and visited the research facility for a second time one week after their first visit. On their first visit, one observer repeatedly measured cIMT and distensibility, directly thereafter a second observer repeated the measurements.

\section{Metabolic measurements}

Whole body glucose disposal

It is generally accepted that a euglycemic insulin clamp, as developed by Dr. Andres' group in the $70^{\prime} \mathrm{s}^{36,37}$ is the best available method to determine peripheral or whole body glucose disposal (WBGD). ${ }^{38-41}$ With this technique, exogenous insulin is administered to achieve and maintain high physiological insulin levels, usually for 2 hours or longer. Here, insulin was infused in a primed continuous matter; insulin (Novorapid, Novo Nordisk, Bagsvaerd, Denmark) was first infused at $120 \mathrm{mU} / \mathrm{kg} / \mathrm{min}$ for 10 minutes, after which its infusion rate was lowered to $60 \mathrm{mU} / \mathrm{kg} / \mathrm{min}$ for 170 minutes. As insulin adsorbs to infusion equipment, $3 \mathrm{ml}$ of whole blood was added per $60 \mathrm{ml}$ syringe to reduce adsorption. ${ }^{42}$ In order to maintain isoglycemia, a variable rate $20 \%$ glucose infusion is administered throughout the clamp. Ideally, one aims to maintain arterial glucose at a constant level, yet cannulation of the brachial artery is considered a rather invasive procedure. Instead, a hand is often heated to "arterialize" venous blood. ${ }^{37,43,44}$ This, however, alters blood flow in the heated and contralateral arms, as well as increase norepinephrine levels and thereby influence (micro)vascular and metabolic measurements. ${ }^{43}$ Therefore, we used the method by Clerk et al., which recognizes that when arterial glucose is maintained at a constant level during an insulin clamp, venous glucose concentrations decline progressively with time, and the arteriovenous glucose difference increases in proportion to insulin sensitivity. ${ }^{19}$ In this model, the target for venous glucose to decline is $0.27 \mathrm{mmol} / \mathrm{l}$ for every $1 \mathrm{mg} / \mathrm{kg} / \mathrm{min}$ increase in glucose infusion rate above the basal hepatic glucose production (estimated at $2 \mathrm{mg} / \mathrm{kg} / \mathrm{min}$ ), the rationale for which is based on previous studies and provided into more detail elsewhere. ${ }^{19}$ Whole body glucose disposal was estimated from the steady-state glucose infusion rate (90-150 $\mathrm{min}$ of the clamp). Plasma glucose concentrations during the clamp were measured by first centrifuging $0.5 \mathrm{ml}$ of whole blood at 13,000 x $\mathrm{g}$ for 30 seconds and then analyzed with an on-site YSI2300 glucose analyzer (YSI, Yellow Springs, USA). 


\section{Beta-cell function}

As beta-cell function (BCF) cannot be described by a single measure, we used three dynamic BCF measures derived from mathematically modeling mixed meal test (MMT) data, i.e., beta-cell glucose sensitivity ( $\beta-G S)$, beta-cell rate sensitivity ( $\beta-R S)$ and potentiation factor ratio (PFR). ${ }^{45-47}$ The parameter $\beta$-GS is the slope of the glucose-insulin secretion dose-response function, which reflects the dependence of insulin secretion on absolute glucose concentration at any time during the $\mathrm{MMT}^{45-47}$ The dose-response relationship is modulated by beta-cell potentiation, which accounts for higher insulin secretion during the descending phase of hyperglycemia than during the ascending phase of an OGTT or MMT for the same glucose concentration. Beta-cell potentiation is set as a positive function of time and averages 1 during the MMT. Therefore, it represents the relative potentiation of the insulin secretion response to glucose. The beta-cell potentiation parameter used in the present analysis represents the ratio of the beta-cell potentiation factor at the end of the MMT relative to the beta-cell potentiation factor at the start. Beta-cell rate sensitivity is a marker of early phase insulin release, and represents the dynamic dependence of insulin secretion on the rate of change in glucose concentration. ${ }^{45-47}$ The test meal of the MMT consisted of two muffins (containing $56.6 \mathrm{~g}$ fat) and $300 \mathrm{ml}$ low-fat milk ( $0 \%$ fat milk; Friesland-Campina, Woerden, The Netherlands). The mixed meal had an energy content of $4598 \mathrm{~kJ}$ (fat / carbohydrate / protein: $28 \mathrm{En} \%$ / $59 \mathrm{En} \%$ / $13 \mathrm{En} \%$ ) and provided $26.5 \mathrm{~g}$ protein, $121.0 \mathrm{~g}$ carbohydrates and $56.6 \mathrm{~g}$ fat (fatty acid composition: $33.9 \mathrm{~g}$ saturated fatty acids, $2.2 \mathrm{~g}$ trans fatty acids, $14.5 \mathrm{~g}$ monounsaturated fatty acids, and $2.7 \mathrm{~g}$ polyunsaturated fatty acids). One batch of muffins was prepared for the entire study by a research nurse; muffins were baked at $180^{\circ} \mathrm{C}$ in a fan-assisted oven for 20 minutes, packaged per portion, and frozen at $-20^{\circ} \mathrm{C}$. Reliability of BCF measurements over time was determined in 26 individuals in the weight stable control group of the WLI Trial.

\section{Inflammatory measurements}

\section{CD11B surface expression}

In chapter five of this thesis, we found that CD11B surface expression, measured as mean fluorescence intensity on total circulating NK cells (from here on referred to as NK-CD11B), was closely associated with NK cell accumulation in VAT. CD11B has been described as a maturation marker of NK cells. ${ }^{48,49}$ This integrin can mediate cell adhesion, but is also part of the complement receptor 3 complex, which is involved in cytotoxic activation of NK cells. ${ }^{50}$ Reliability and measurement error of NK-CD11B was determined in a subset of individuals in the weight stable control group of the WLI Trial; the last 22 individuals to complete the study were included in this subset. Blood was drawn after an overnight fast and a 30-minute acclimatization period and frozen 
for flow cytometry. Upon completion of the WLI trial, blood was thawed and stained for flow cytometry using CD3-fitc (BD 561807), CD19-fitc (BD 555412), CD66b-fitc (BD 555724), CD56-PE (BD 345810), HLA-DR-V500 (BD 561224), CD14-APC-H7 (BD 641394), CD16-PerCP (BD 560717), CD11B-BV421 (BD 562632), CD11C-PE-Cy7 (BD 561356), and CX3CR1-APC (Biolegend 341609). The gating strategy (Supplementary Figure 3.3) was as follows. From single blood cells, live cells were gated based on forward and side scatters. From live cells, NK cells were gated as negative for CD3 ( $T$ cells), CD19 (B cells), CD66b (granulocytes), HLA-DR (monocytes, dendritic cells) and positive for CD56. Singlets were gated based on both forward and side scatters. Live cells were defined as negative for live-death staining. NK cells were CD3- and CD56+, which were subdivided according to CD56 and CD16 surface expression. Each panel was optimized using fluorescence minus one (FMO) controls and isotype controls, yielding similar measures as auto-fluorescent samples. For each experiment, an autofluorescence control was performed. Samples were measured with a FACS-Canto II (BD Biosciences, San Jose, CA, USA). Results were analyzed with FACSdiva software (BD Biosciences, San Jose, CA, USA).

\section{Plasma biomarkers of low-grade inflammation}

Biomarkers of low-grade inflammation (C-reactive protein, serum amyloid $A$, interleukin-6, interleukin-8, soluble intercellular adhesion molecule-1, and tumor necrosis factor) were assessed by a multiarray detection system based on electrochemiluminescence technology (SECTOR Imager 2400, MesoScaleDiscovery, Gaithersburg, Maryland, USA) as described previously. ${ }^{51}$ This system uses multi-array plates fitted with multielectrodes per well with each electrode being coated with a different catching antibody. The assay procedure then follows that of a classic sandwich ELISA with any of the analytes of interest captured on the relevant electrode. These captured analytes were then in turn detected by a secondary analyte-specific ruthenium-conjugated antibody, which is capable of emitting light after electrochemical stimulation. A particular advantage of this system is the ability to measure different biomarkers of low-grade inflammation and/or endothelial dysfunction simultaneously in relatively small (25 or $50 \mu \mathrm{l}$ ) serum samples. For reasons of statistical efficiency and to reduce the influence of biological variability, ${ }^{52}$ overall biomarker scores were calculated for endothelial dysfunction and low-grade inflammation as follows. ${ }^{53}$ First, each individual biomarker was log-transformed if warranted. Then, a z-score was calculated according to the formula (individual value population mean)/population standard deviation (SD); the population mean and SD were determined from the baseline samples only. Finally, the resulting individual biomarker z-scores were averaged into an overall biomarker score of low-grade inflammation. 


\section{Statistical analyses}

\section{Intraclass correlation coefficients}

All variables in this paper are continuous, hence, intraclass correlation coefficients (ICC) were calculated to provide a parameter of reliability. For all reliability analyses, i.e., inter- and intra-observer reliability and reliability over time, $I C C_{\text {agreement }}$ was chosen as systematic differences between observers are included in the error variance, in contrast to $\mathrm{ICC}_{\text {consistency. }}{ }^{1,6,7}$ For all reliability analyses, except comparison with a gold standard, a two-way mixed model, where people effects are random and the item effects are fixed, was used. This model is chosen when each measurement is rated by the same observers, who are the only observers of interest. ${ }^{6}$ For the comparisons with a gold standard, a one-way random model was used. ${ }^{1}$

\section{Limits of agreement and Bland-Altman plots}

Measurement error can be found in the limits of agreement, and Bland and Altman have designed a plot in which systematic errors and limits of agreement are presented. ${ }^{5}$ In these plots, the mean of two measurements is plotted on the x-axis, whereas the difference between the measurements is plotted on the y-axis. Every comparison in measurement is added as a dot and, typically, four (horizontal) lines are added. One represents the line of perfect agreement $(y=0)$, one line is added to represent the mean difference between measurements (or observers when interobserver variance is assessed), and two lines to represent the upper and lower limit of agreement. The limits of agreement are calculated as mean difference $\pm 1.96 \mathrm{x}$ $\mathrm{SD}_{\text {difference }}$ and, hence, $95 \%$ of the dots will fall between these lines. When differences between repeated measurements or between observers are large, the lines representing the limits of agreement will be further away from the mean difference. Paired T-tests were conducted to assess statistical significance of mean differences. These Bland-Altman plots were made for each comparison.

\section{Standard error of the measurement}

The SEM is a parameter of measurement error. It shows how far apart the outcomes of repeated measures are, i.e., it is the standard deviation around a single measurement. ${ }^{1}$ A SEM may $\left(S_{\text {agreement }}\right)$ or may not (SEM $\left.M_{\text {consistency }}\right)$ include the systematic error (e.g., between observers). SEM consistency equals $\sqrt{S_{\text {error }}^{2}}$, where residual error can be found in ANOVA or variance component analyses. Yet, it can also be calculated from the limits of agreement as $S E M_{\text {consistency }}=S_{\text {difference }} / \sqrt{2}$. Of note, in

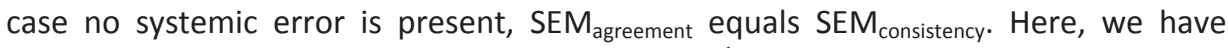

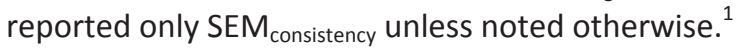




\section{Linear regression}

To analyze the association between IHL measured by means of mDixon and ${ }^{1} \mathrm{H}-\mathrm{MRS}$, linear regression was used. As two techniques were compared, with subjects and observers being identical, no confounders were added to the model.

\section{Software and data expression}

Analyses were performed using SPSS version 20. Where appropriate, data are expressed as ICC, SEM, means \pm SD, median [IQR], or count. Two-tailed p-values of $<0.05$ were considered statistically significant.

\section{Results}

\section{Anthropometric measurements}

For reliability over time of VAT, SAT, IHL and IPL measurements, data on 26 individuals from the weight stable control group were used. The ICC $_{\text {time }}$ of each was $>0.89$ (Table 3.1; $p<0.001$ ) and the SEM time was $0.17 \mathrm{~L}$ for VAT, $0.12 \mathrm{~L}$ for SAT, $1.10 \%$-point for IHL (by means of mDixon), and 1.14\%-point for IPL. The Bland-Altman plots of the reliability over time with the limits of agreement are presented below (Figures 3.1A, 3.2A, 3.3A and 3.4A).

For intra-observer reliability of analyses, data of 29 (VAT, SAT) or 10 (IHL, IPL) scans

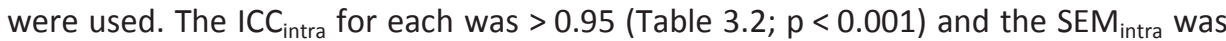
$7.9 \mathrm{~cm}^{2}$ per slice for VAT, $4.4 \mathrm{~cm}^{2}$ per slice for SAT, $0.56 \%$-point for IHL, and $0.66 \%$ point for IPL. The Bland-Altman plots of the intra-observer reliability of the analyses with the limits of agreement are presented below (Figures 3.1B, 3.2B, 3.3B and 3.4B). In addition, we assessed for IHL the ICC for intra-slice $(0.976 ; n=74)$, inter-slice (0.968; $n=73$ ) and overall inter-ROI reliability (0.966; $p<0.001$ for each; $n=73$ ), as well as the $\mathrm{SEM}_{\text {intra-slice }}\left(0.79 \%\right.$-point) and $\mathrm{SEM}_{\text {inter-slice }}(0.84 \%$-point).

Inter-observer reliability of analyses was assessed in 29 (VAT, SAT), 15 (IHL) or 14 scans (IPL; one excluded due to technical difficulties). The $I C_{\text {inter }}$ was $>0.97$ for VAT, SAT and IHL, and 0.88 for IPL ( $p<0.001$ for each). The $S E M_{\text {inter }}$ was $11.4 \mathrm{~cm}^{2}$ per slice for VAT, $6.8 \mathrm{~cm}^{2}$ per slice for SAT, $0.33 \%$ for IHL, and $1.72 \%$ for IPL. The BlandAltman plots of the inter-observer reliability of the analyses with the limits of agreement are presented below (Figures 3.1C, 3.2C, 3.3C and 3.4C). 
Table 3.1 - Intraclass correlation coefficients for measurements.

\begin{tabular}{|c|c|c|c|}
\hline & Intra-observer & Inter-observer & Over Time \\
\hline \multicolumn{4}{|l|}{ Anthropometric variables } \\
\hline Visceral Adipose Tissue & N/A & N/A & $0.974^{* * * a}$ \\
\hline Subcutaneous Adipose Tissue & N/A & N/A & $0.988^{* * * a}$ \\
\hline Intrahepatic Lipid & N/A & N/A & $0.972^{* * * a}$ \\
\hline Intrapancreatic Lipid & N/A & N/A & $0.897^{* * * a}$ \\
\hline \multicolumn{4}{|l|}{ Microvascular variables } \\
\hline Muscle Microvascular Recruitment & $0.886^{* b}$ & N/A & $\begin{array}{l}0.828^{*} \mathrm{c} \\
0.613^{*}{ }^{\prime}\end{array}$ \\
\hline Capillary Microscopy (continuously perfused) & $\mathrm{N} / \mathrm{A}$ & $\mathrm{N} / \mathrm{A}$ & $0.660^{* * d}$ \\
\hline Capillary Microscopy ( $\Delta$ Insulin) & $\mathrm{N} / \mathrm{A}$ & N/A & $0.049^{d}$ \\
\hline Capillary Microscopy (HE) & N/A & N/A & $0.815^{* * * d}$ \\
\hline Capillary Microscopy $(\Delta \mathrm{HE})$ & N/A & N/A & $0.670^{* * d}$ \\
\hline Capillary Microscopy (VO) & $\mathrm{N} / \mathrm{A}$ & N/A & $0.811^{* * * d}$ \\
\hline Flowmotion (endothelial component) & N/A & N/A & $0.628^{\mathrm{e}}$ \\
\hline Flowmotion (neurogenic component) & N/A & N/A & $0.696^{*} \mathrm{e}$ \\
\hline Flowmotion (myogenic component) & $\mathrm{N} / \mathrm{A}$ & N/A & $0.000^{\mathrm{e}}$ \\
\hline Sublingual microvascular perfused boundary region & N/A & N/A & $0.000^{\mathrm{a} \S}$ \\
\hline \multicolumn{4}{|l|}{ Macrovascular variables } \\
\hline Flow-mediated Dilation & $0.677^{* f}$ & N/A & $\begin{array}{l}0.526^{* f} \\
0.533^{* *} \mathrm{~g}\end{array}$ \\
\hline Reactive Hyperemia Index (EndoPAT ${ }^{\mathrm{TM}}$ ) & N/A & N/A & $0.579^{* h}$ \\
\hline Carotid-Femoral Pulse Wave Velocity & $0.984^{* * * i}$ & $0.815^{* *_{i}}$ & $0.931^{* * * j}$ \\
\hline Augmentation Index (@75bpm) & $0.610^{* *_{\mathrm{i}}}$ & $0.597^{*_{\mathrm{i}}}$ & $0.853^{* * j}$ \\
\hline Carotid Distensibility & $0.906^{* * * i}$ & $0.750^{* i}$ & $0.902^{* * * k}$ \\
\hline Distensibility coefficient CCA & N/A & $0.846^{* * i}$ & $0.916^{* * * 1}$ \\
\hline Compliance coefficient CCA & N/A & $0.840^{* *_{i}}$ & $0.974^{* * * 1}$ \\
\hline Intima-Media Thickness CCA & $0.840^{* * * k}$ & $0.265^{i}$ & $0.867^{* * \mathrm{k}}$ \\
\hline \multicolumn{4}{|l|}{ Metabolic variables } \\
\hline Whole Body Glucose Disposal & $\mathrm{N} / \mathrm{A}$ & N/A & $0.881^{* * * a}$ \\
\hline Beta-cell Glucose Sensitivity & N/A & $\mathrm{N} / \mathrm{A}$ & $0.461^{* a}$ \\
\hline Beta-cell Rate Sensitivity & N/A & N/A & $0.447^{* a}$ \\
\hline Potentiation Factor Ratio & N/A & N/A & $0.418^{* a}$ \\
\hline \multicolumn{4}{|l|}{ Inflammatory variables } \\
\hline CD11B Expression on Circulating Natural Killer Cells & N/A & N/A & $0.738^{* * m}$ \\
\hline Z-Score Low-Grade Inflammation Plasma Biomarkers & $\mathrm{N} / \mathrm{A}$ & N/A & $0.949^{* * * a}$ \\
\hline
\end{tabular}

Data presented as intraclass correlation coefficient (ICC) with absolute agreement in a two-way mixed effects model. Intra-observer, inter-observer ICCS and ICC over time are presented. ${ }^{*} \mathrm{p}<0.05, * * \mathrm{p}<0.01$, *** $p<0.001$. Analyzed in ${ }^{a} n=26 ;^{b} n=7 ;{ }^{c} n=6 ;{ }^{d} n=24 ;{ }^{e} n=13 ;{ }^{f} n=22$, as reported in Van Bussel et al. - with permission ${ }^{14} ;{ }^{g} \mathrm{n}=23 ;{ }^{\mathrm{h}} \mathrm{n}=14 ;{ }^{\mathrm{i}} \mathrm{n}=12 ;{ }^{\mathrm{j}} \mathrm{n}=11 ;{ }^{\mathrm{k}} \mathrm{n}=10 ;{ }^{\mathrm{l}} \mathrm{n}=9 ;{ }^{\mathrm{m}} \mathrm{n}=22 .{ }^{\S}$ Negative ICC values were reported as zero, as described before. $\Delta$ Insulin = capillary recruitment by hyperinsulinemia, $\mathrm{HE}=$ hyperemia, $\triangle \mathrm{HE}=$ capillary recruitment by hyperemia, $\mathrm{VO}=$ venous occlusion, $\mathrm{CCA}=$ common carotid artery, N/A was noted when data was not available or not applicable.

For VAT and SAT analyses, pixel-by-pixel quantification had been considered the gold standard. ${ }^{16}$ Hence, the VAT and SAT surface per slice obtained by the Hippo Fat software was compared to pixel-by-pixel analyses. The ICC for both was $>0.96$ (Table 3.3; $p<0.001$ for each; $n=29$ ) and the SEM was $7.9 \mathrm{~cm}^{2}$ per slice for VAT and $4.4 \mathrm{~cm}^{2}$ 
per slice for SAT. Both VAT and SAT tended to be slightly underestimated when analyzed with the Hippo Fat software. The companion Bland-Altman plots are presented below (Figures 3.1D and 3.2D).
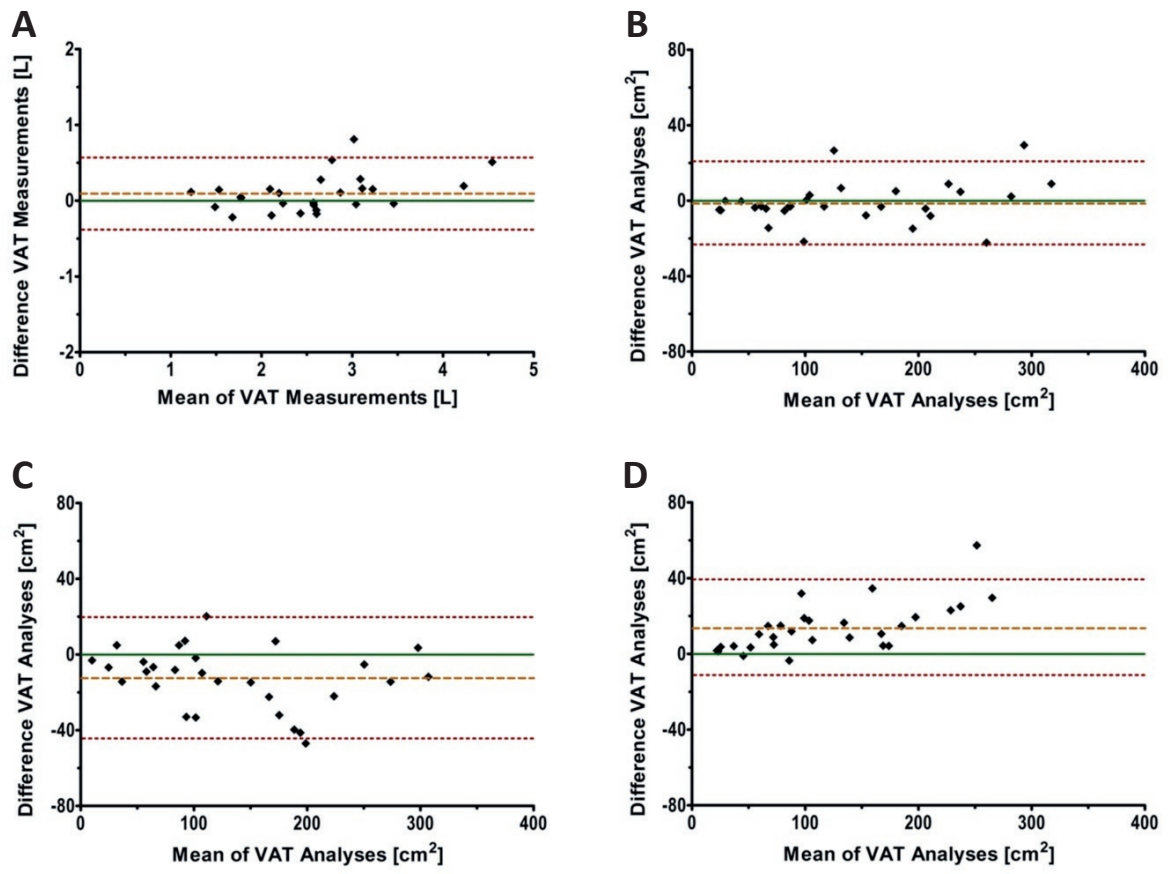

Figure 3.1 - Bland-Altman plots of abdominal visceral adipose tissue (VAT) measurements and analyses. The green line represents perfect agreement, the orange line represents the mean difference, and the red lines represent the limits of agreement. A. Agreement over time between two VAT volume measurements with 8 weeks in between; the mean difference was not statistically significant. B. Intra-observer agreement in analyses of VAT area in a single slice; the mean difference was not statistically significant. C. Inter-observer agreement in analyses of VAT area in a single slice; the mean difference was statistically significant $\left(-12.5 \mathrm{~cm}^{2} ; \mathrm{p}<0.05\right)$. D. Agreement between pixel-by-pixel quantification and Hippo Fat software of VAT area, the mean difference was statistically significant $\left(13.8 \mathrm{~cm}^{2} ; \mathrm{p}<0.05\right)$. Visually, a trend towards greater increase in measurement error with increasing mean VAT area was seen, yet was not statistically significant ( $\beta=0.005 ; p=0.86$ ) Nonetheless, these limits of agreement should be interpreted with care.

As for IHL analyses, the mDixon sequence was compared to ${ }^{1} \mathrm{H}-\mathrm{MRS}$ with the latter considered to be the gold standard. The ICC between both techniques was 0.82 $(p<0.001 ; n=45)$, whereas the SEM was not calculated due to structural overestimation in individuals with low $\mathrm{IHL}$ and underestimation in individuals with high IHL, as illustrated by the Bland-Altman plot (Figure 3.3D). By means of linear regression, we found that IHL by means of mDixon was associated with IHL by means of ${ }^{1} \mathrm{H}$-MRS (Figure 3.3E; $\beta=0.432 ; \mathrm{p}<0.001$ ). Moreover, the presence of NAFLD could 
be differentiated nearly as well with mDixon as compared to ${ }^{1} \mathrm{H}-\mathrm{MRS}$ (Cohen's kappa 0.90).
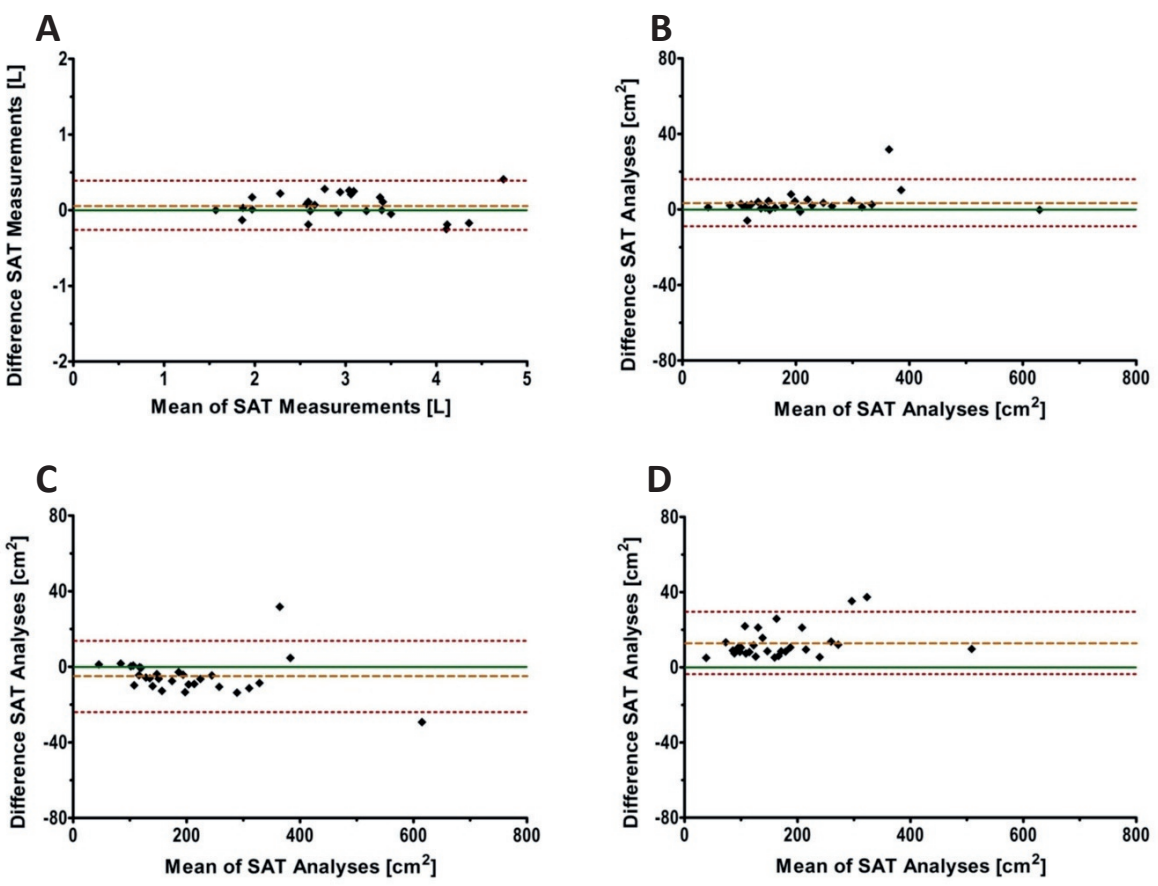

Figure 3.2 - Bland-Altman plots of abdominal subcutaneous adipose tissue (SAT) measurements and analyses. The green line represents perfect agreement, the orange line represents the mean difference, and the red lines represent the limits of agreement. A. Agreement over time between two SAT volume measurements with 8 weeks in between; the mean difference was not statistically significant. B. Intraobserver agreement in analyses of SAT area in a single slice; the mean difference was not statistically significant. C. Inter-observer agreement in analyses of SAT area in a single slice; the mean difference was statistically significant $\left(-5.2 \mathrm{~cm}^{2} ; \mathrm{p}<0.05\right)$. D. Agreement between pixel-by-pixel quantification and Hippo Fat software of SAT area; the mean difference was statistically significant $\left(16.1 \mathrm{~cm}^{2} ; p<0.05\right)$. 
A

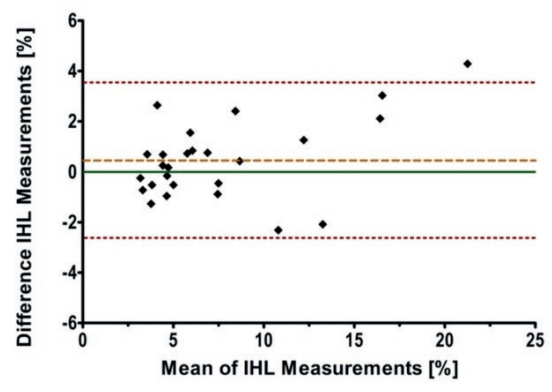

C

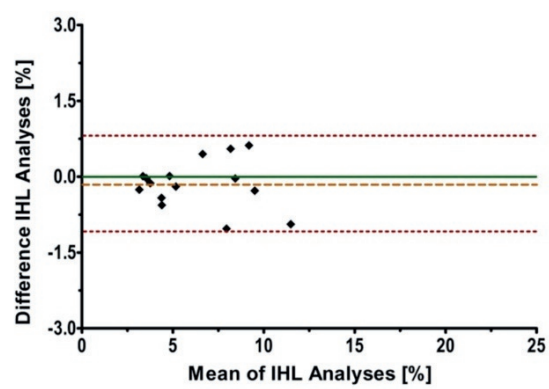

E

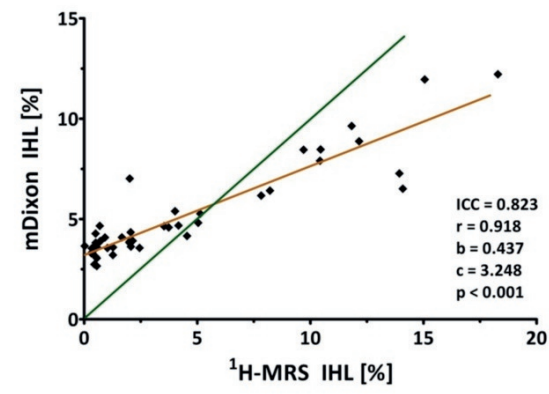

B

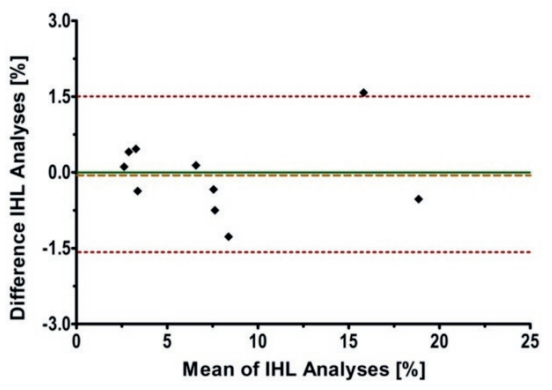

D

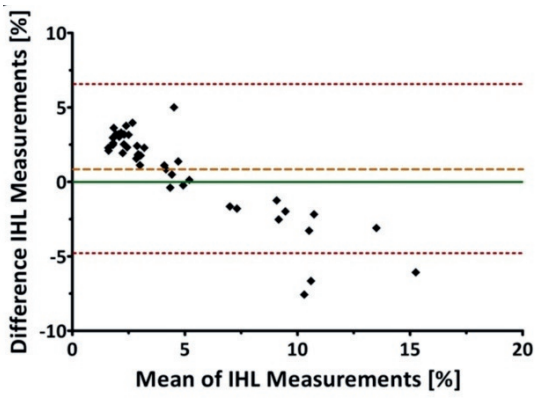

Figure 3.3 - In panel A-D, Bland-Altman plots of intrahepatic lipid (IHL; in \%-points) measurements and analyses are presented, where the green line represents perfect agreement, the orange line represents the mean difference, and the red lines represent the limits of agreement. A. Agreement over time between two IHL measurements with 8 weeks in between; the mean difference was not statistically significant. B. Intraobserver agreement in analyses of IHL; the mean difference was not statistically significant. C. Interobserver agreement in analyses of IHL; the mean difference was not statistically significant. D. Agreement between IHL quantification by means of mDixon and ${ }^{1} \mathrm{H}$-MRS. As the assumptions of the Bland-Altman analyses are violated, the mean difference and limits of agreement are useless. E. Scatterplot between IHL by means of ${ }^{1} \mathrm{H}-\mathrm{MRS}$ and mDixon. The green line represents perfect agreement, whereas the orange line represents the regression equation fitted to the data. 
A

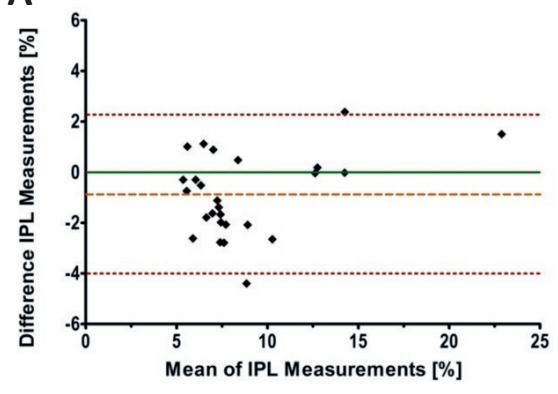

C

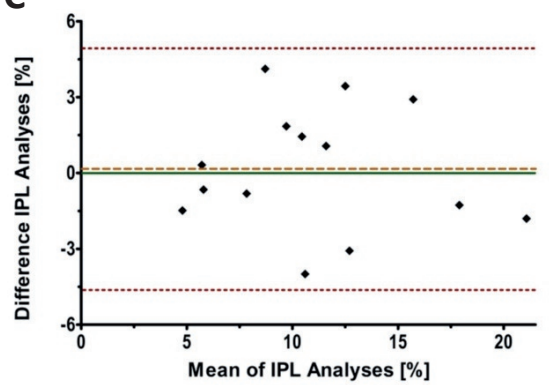

B

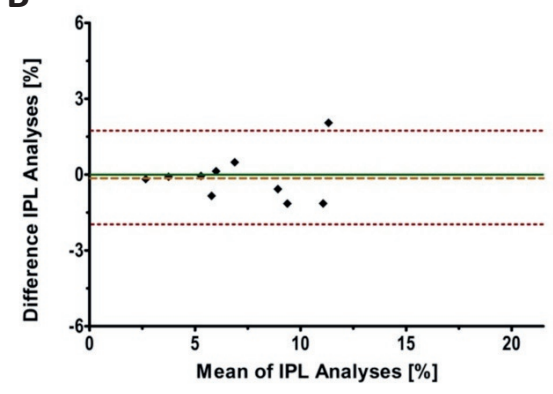

Figure 3.4 - Bland-Altman plots of intrapancreatic lipid (IPL; in \%-points) measurements and analyses. The green line represents perfect agreement, the orange line represents the mean difference, and the red lines represent the limits of agreement. A. Agreement over time between two IPL measurements with 8 weeks in between; the mean difference was not statistically significant. B. Intra-observer agreement in analyses of IPL; the mean difference was not statistically significant. C. Inter-observer agreement in analyses of IPL; the mean difference was not statistically significant.

Table 3.2 - Intraclass correlation coefficients for analyses.

Anthropometric variables

Subcutaneous Adipose Tissue

Visceral Adipose Tissue

Intrahepatic Lipid

Intrapancreatic Lipid

Microvascular variables

Muscle Microvascular Recruitment

Capillary Microscopy (baseline)

Capillary Microscopy (HE)

Capillary Microscopy $(\Delta \mathrm{HE})$

Capillary Microscopy (VO)

Flowmotion (endothelial component)

Flowmotion (neurogenic component)

Flowmotion (myogenic component)

Macrovascular variables

Flow-mediated Dilation
Intra-observer

$0.998^{* * * a}$
$0.992^{* * * a}$
$0.995^{* * * b}$
$0.955^{* * * b}$

$$
\begin{aligned}
& 0.977^{* * *} \mathrm{e} \\
& 0.940^{* * \mathrm{f}} \\
& 0.995^{* * \mathrm{f}} \\
& 0.881^{* * \mathrm{f}} \\
& 0.956^{* * \mathrm{f}} \\
& 1.000^{* * *} \mathrm{~g} \\
& 0.987^{* * *} \mathrm{~g} \\
& 0.988^{* * *} \mathrm{~g}
\end{aligned}
$$

$0.881^{* * *}$
Inter-observer

$$
\begin{aligned}
& 0.996^{* * * a} \\
& 0.971^{* * * a} \\
& 0.992^{* * * c} \\
& 0.882^{* * * d}
\end{aligned}
$$

Data presented as intraclass correlation coefficient (ICC) with absolute agreement in a two-way mixed effects model. Intra- and inter-observer ICCS are presented. ${ }^{*} p<0.05,{ }^{*} p<0.01,{ }^{* * *} p<0.001$. Analyzed in ${ }^{a} \mathrm{n}=29$; $^{\mathrm{b}}$ $n=10 ;{ }^{c} n=15 ;^{d} n=14 ;^{e} n=21 ;{ }^{f} n=6 ;^{g} n=5 ;{ }^{h} n=35 ;{ }^{i} n=25$. N/A is noted when data was not available. 
Table 3.3 - Intraclass correlation coefficients between current method and gold standard.

\begin{tabular}{ll}
\hline Visceral Adipose Tissue & $0.967^{* * * a}$ \\
Subcutaneous Adipose Tissue & $0.987^{* * * a}$ \\
Intrahepatic Lipid & $0.823^{* * \mathrm{~b}}$
\end{tabular}

Data presented as one-way intraclass correlation coefficient (ICC). ICC SAT and VAT compares analyses with Hippo Fat software to pixel-by-pixel analyses. ICC IHL compares mDixon sequence to $1 \mathrm{H}-\mathrm{MRS}$. $* * * \mathrm{p}<0.001$. Analyzed in ${ }^{\mathrm{a}} \mathrm{n}=29,^{\mathrm{b}} \mathrm{n}=45$.

\section{Microvascular measurements}

\section{Muscle microvascular recruitment}

In the CEUS Reproducibility Study, the intra-observer reliability of MVR measurement by means of CEUS was assessed in 7 individuals (one individual lacked one MVR measurement due to technical issues) and in 6 individuals over time (two individuals dropped out because of personal issues). $\mathrm{ICC}_{\text {intra }}$ and $\mathrm{ICC}_{\text {time }}$ were 0.89 and 0.83 , respectively (Table 3.1; $\mathrm{p}<0.05$ for each), whereas $\mathrm{SEM}_{\text {intra }}$ was 0.17 and $\mathrm{SEM}_{\text {time }}$ was 0.43 (videointensity). The companion Bland-Altman plots are presented below (Figures 3.5A and 3.5B). The overall intra-observer reliability of MVR measurements was 0.86 ( ICC $_{\text {overall }}$ p < 0.001). In addition, the reliability of MVR measurements over time was also assessed in the weight stable control group of the WLI trial $(n=26)$, where the $I C_{\text {time }}$ was $0.61(p<0.05)$, SEM $_{\text {time }}$ was $20 \%$, and its Bland-Altman plot is depicted below (Figure 3.5C).

As for the analyses of MVR, ICC intra $_{\text {was }} 0.98(p<0.001)$ and SEM intra $_{\text {was }} 9.0 \%(n=21)$. The Bland-Altman plot of the intra-observer reliability of the analyses with the limits of agreement is presented below (Figure 3.5D). Of note, no adverse events related to CEUS were observed in 143 measurements in 82 unique individuals.

\section{Capillary microscopy}

For reliability over time of capillary microscopy measurements, data on 24 individuals from the weight stable control group of the WLI Trial were used as two of the 26 controls (i.e., 8\%) had no matching ROI between baseline and follow-up measurements. The $\mathrm{ICC}_{\text {time }}$ of continuously perfused capillaries, insulin-induced capillary recruitment, perfused capillaries during post-occlusive hyperemia, capillary recruitment by hyperemia and erythrocyte-filled capillaries during venous occlusion were $0.66,0.05,0.82,0.67$, and 0.81 respectively (Table 3.1 ). The SEM $_{\text {time }}$ was 11.3 continuously perfused capillaries, 18\%-point insulin-induced capillary recruitment, 9.6 capillaries during hyperemia, 8.5 recruited capillaries, and 9.8 capillaries during venous occlusion. The respective Bland-Altman plots are presented below (Figures $3.6 \mathrm{~A}, 3.7,3.8 \mathrm{~A}, 3.9 \mathrm{~A}$ and $3.10 \mathrm{~A})$. The intra- and inter-observer reliability of capillary 
microscopy analyses were assessed in 6 and 5 individuals, respectively. ICC intra for analyses of continuously perfused capillaries, perfused capillaries during postocclusive hyperemia, capillary recruitment by hyperemia and erythrocyte-filled capillaries during venous occlusion were all $>0.88$ ( $p<0.01$ for each), as their respective $\mathrm{SEM}_{\text {intra }}$ was $2.9,1.2,3.9$ and 4.4 capillaries. $\mathrm{ICC}_{\text {inter }}$ was $>0.96$ for continuously perfused capillaries, perfused capillaries during post-occlusive hyperemia and erythrocyte-filled capillaries during venous occlusion, yet for capillary recruitment by hyperemia was markedly lower $(0.49 ; p<0.01$ for each ICC; Table 3.2). $\mathrm{SEM}_{\text {inter }}$ was 1.4 continuously perfused capillaries, 3.4 capillaries during hyperemia, 3.2 recruited capillaries, and 3.5 capillaries during venous occlusion. The Bland-Altman plots of intra-observer (Figures 3.6B, 3.8B and 3.9B) and inter-observer agreement (Figures 3.6C, 3.8C, 3.9C and 3.10C) are presented below.

A

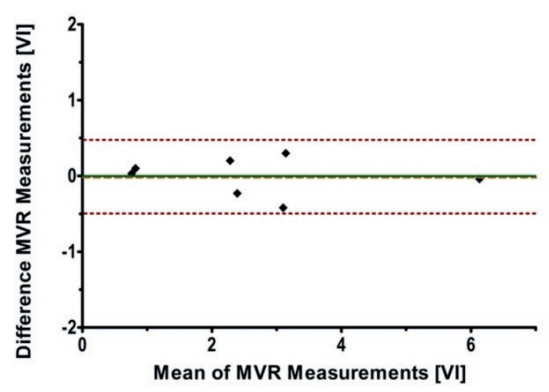

C

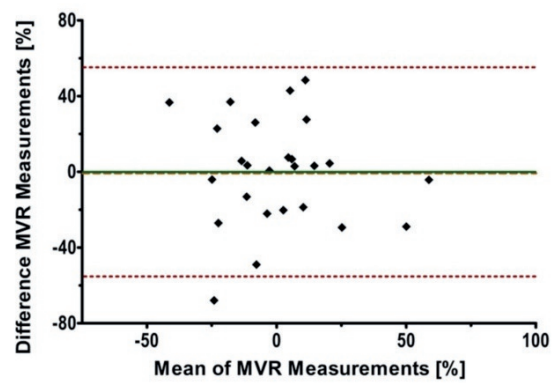

B

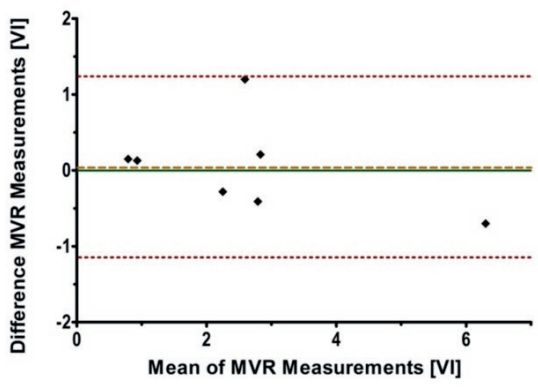

D

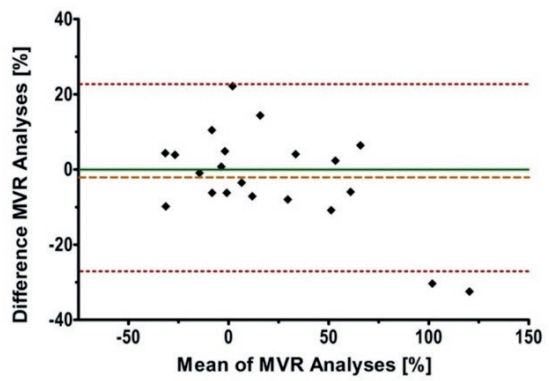

Figure 3.5 - Bland-Altman plots of measurements and analyses of microvascular recruitment (MVR; in \%-points) in forearm skeletal muscle. The green line represents perfect agreement, the orange line represents the mean difference, and the red lines represent the limits of agreement. A. Intra-observer agreement between two MVR measurements performed on the same day (1 hour in between); the mean difference was not statistically significant. B. Agreement over time between two MVR measurements with 1 week in between; the mean difference was not statistically significant. C. Agreement over time between two MVR measurements with 8 weeks in between; the mean difference was not statistically significant. D. Intra-observer agreement in analyses of MVR; the mean difference was not statistically significant. 

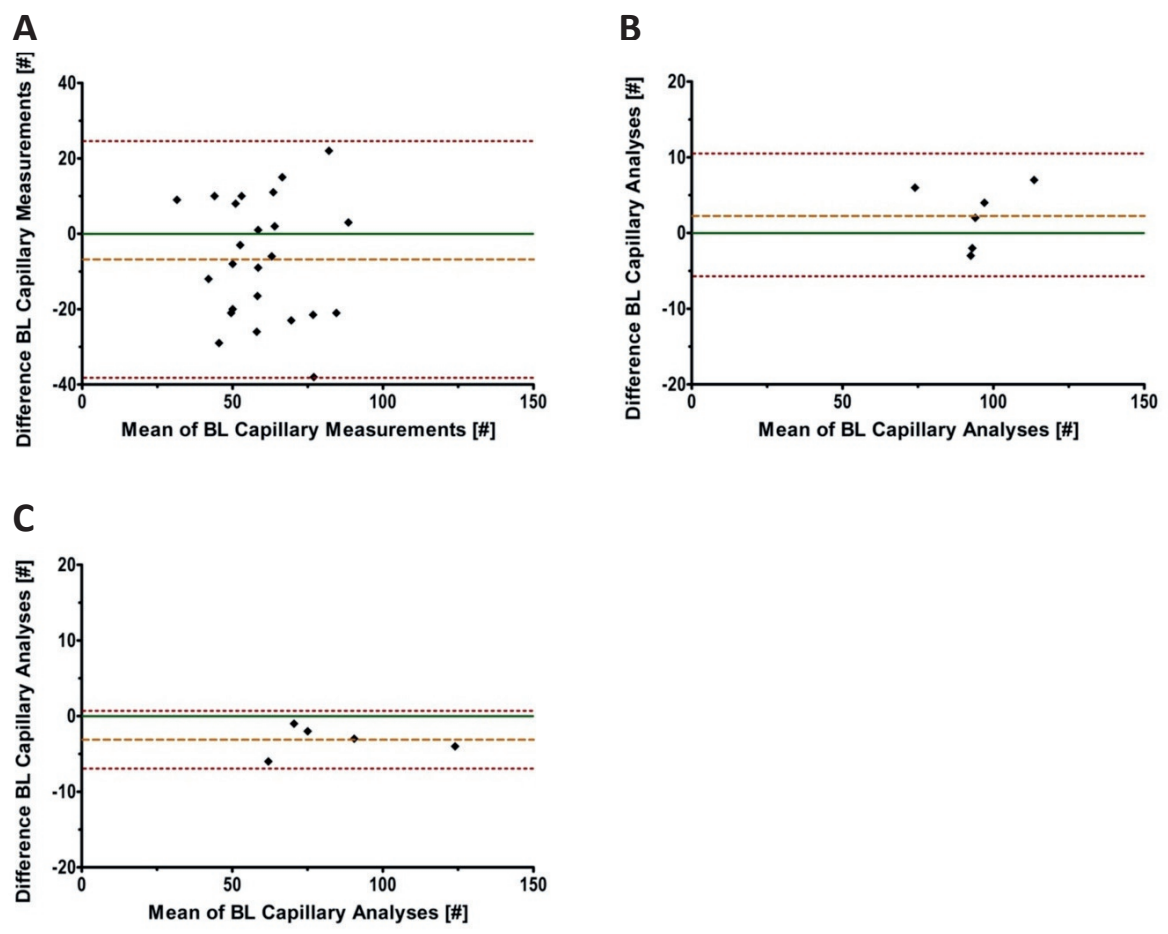

Figure 3.6 - Bland-Altman plots of continuously perfused nailfold capillaries at baseline (BL; i.e., fasted) by means of nailfold capillary videomicroscopy measurements and analyses. The green line represents perfect agreement, the orange line represents the mean difference, and the red lines represent the limits of agreement. A. Agreement over time between two capillary videomicroscopy measurements with 8 weeks in between; the mean difference was not statistically significant. B. Intra-observer agreement in analyses of capillary videomicroscopy; the mean difference was not statistically significant. C. Inter-observer agreement in analyses of capillary videomicroscopy; the mean difference was statistically significant $(-3.2$ capillaries; $p<0.05)$.

\section{Flowmotion}

Data from 13 individuals from the weight stable control group of the WLI Trial were used to assess the reliability of flowmotion analyses over time. For the endothelial $\left(\right.$ ICC $\left._{\text {time }} 0.63 ; p=0.06\right)$ and neurogenic component of flowmotion (ICC time 0.70 ; $\mathrm{p}<0.05$ ) appeared to be reliable over time to some extent, whereas the myogenic component was not (Table 3.1; ICC time -0.03 and thus converted to $0.00 ; p=0.52$ )..$^{44,55}$ The latter could, however, be attributed to one measurement that contained several artifacts; when this measurement was excluded, the reliability increased substantially (ICC $_{\text {time }} 0.67 ; p<0.05 ; n=12$ ). The SEM time was 0.55 arbitrary units (AU) for the endothelial, $0.88 \mathrm{AU}$ for the neurogenic, and $1.57 \mathrm{AU}$ for the myogenic component. If the measurement with artifacts was excluded, $\mathrm{SEM}_{\text {time }}$ for the myogenic component dropped to $0.77 \mathrm{AU}$. The companion Bland-Altman plots are presented below (Figures 3.11A, 3.12A, 3.13A and 3.13B). 


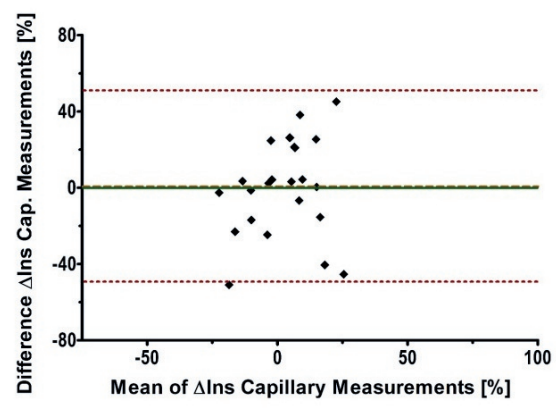

Figure 3.7 - Bland-Altman plot of agreement over time in insulin-induced increase in continuously perfused nailfold capillaries ( $\Delta \mathrm{Ins}$; in \%-points) by means of nailfold capillary videomicroscopy measurements; the mean difference was not statistically significant. The green line represents perfect agreement, the orange line represents the mean difference, and the red lines represent the limits of agreement.

A

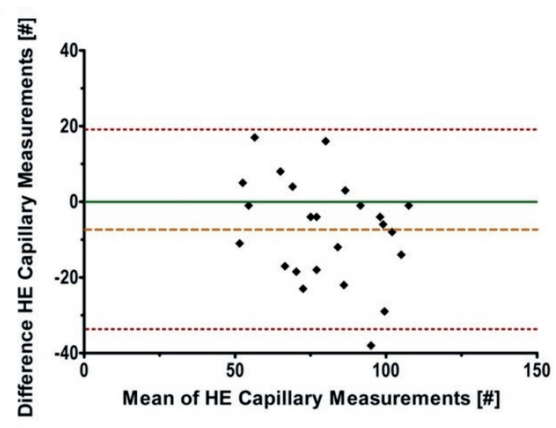

C

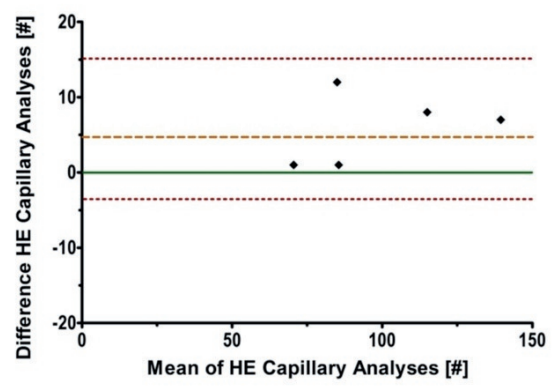

\section{B}

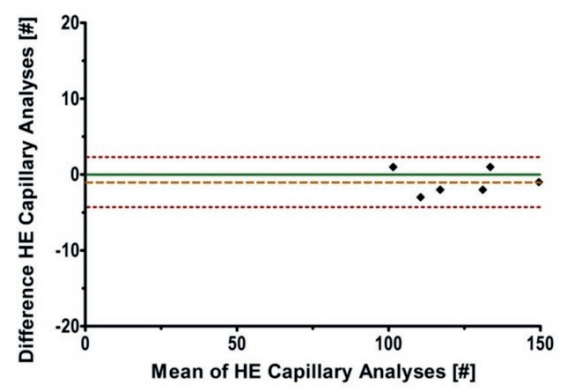

Figure 3.8 - Bland-Altman plots of perfused nailfold capillaries during post-occlusive hyperemia (HE) by means of nailfold capillary videomicroscopy measurements and analyses. The green line represents perfect agreement, the orange line represents the mean difference, and the red lines represent the limits of agreement. A. Agreement over time between two capillary videomicroscopy measurements with 8 weeks in between; the mean difference was statistically significant (-7.4 capillaries; $p<0.05)$. B. Intra-observer agreement in analyses of capillary videomicroscopy; the mean difference was not statistically significant. C. Inter-observer agreement in analyses of capillary videomicroscopy; the mean difference was not statistically significant. 
A

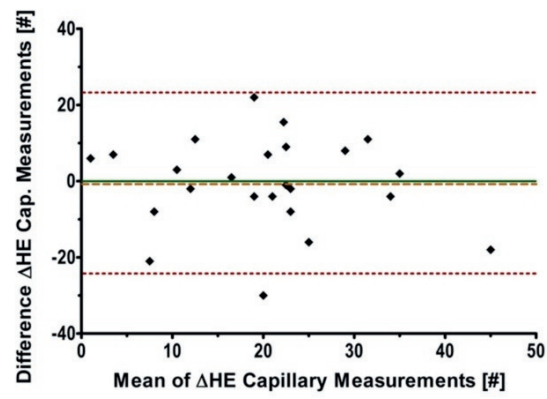

C

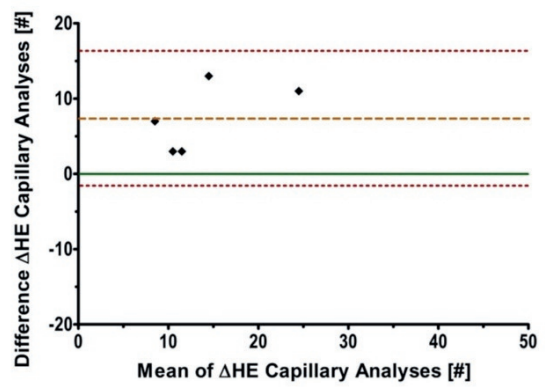

B

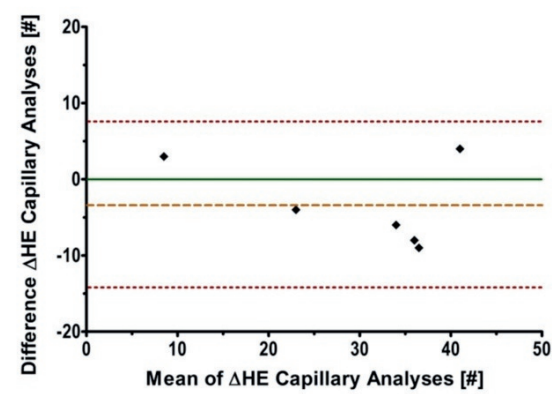

Figure 3.9 - Bland-Altman plots of capillary recruitment by hyperemia $(\Delta \mathrm{HE})$ by means of nailfold capillary videomicroscopy measurements and analyses. The green line represents perfect agreement, the orange line represents the mean difference, and the red lines represent the limits of agreement. A. Agreement over time between two capillary videomicroscopy measurements with 8 weeks in between; the mean difference was not statistically significant. B. Intra-observer agreement in analyses of capillary videomicroscopy; the mean difference was not statistically significant. C. Inter-observer agreement in analyses of capillary videomicroscopy; the mean difference was statistically significant $(7.4$ capillaries; $p<0.05)$.

Intra-observer reliability of flowmotion analyses was assessed in a subset of participants of the Maastricht Study $(n=5)$, whereas the inter-observer reliability $(n=35)$ of flowmotion analyses was evaluated in a masked subset of the WLI trial. $\mathrm{ICC}_{\text {intra }}$ was 1.00 for the endothelial, 0.99 for the neurogenic and 0.99 for the myogenic component (Table 3.2; $\mathrm{p}<0.001$ for each), as the $\mathrm{SEM}_{\text {intra }}$ of the respective components were $0.02,0.26$ and $0.27 \mathrm{AU}$. The $\mathrm{ICC}_{\text {inter }}$ was lower for all components, yet was still $>0.84$ (Table 3.2; $p<0.001$ ) for each. The SEM $_{\text {inter }}$ was 0.30 arbitrary units $(\mathrm{AU})$ for the endothelial, $0.32 \mathrm{AU}$ for the neurogenic, and $0.62 \mathrm{AU}$ for the myogenic component. The Bland-Altman plots of intra-observer (Figures 3.11B, 3.12B and 3.13C) and inter-observer agreement (Figures 3.11C, 3.12C and 3.13D) are presented below. 
A

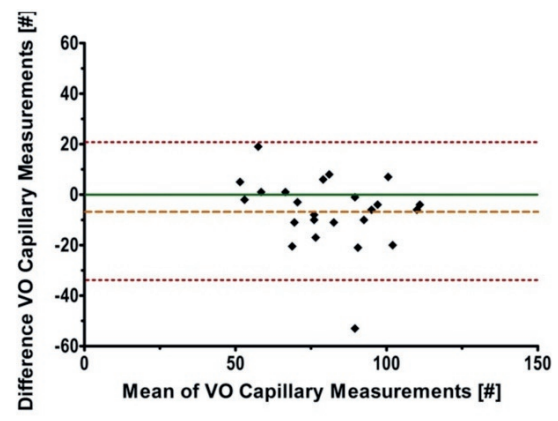

C

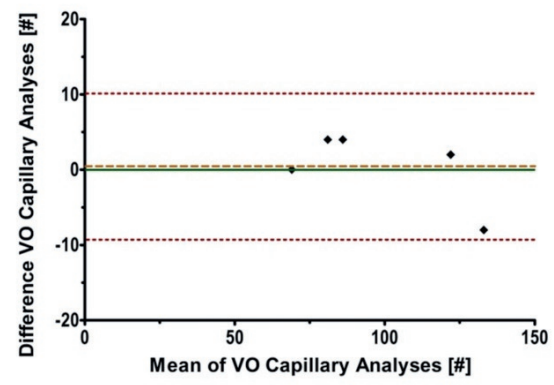

B

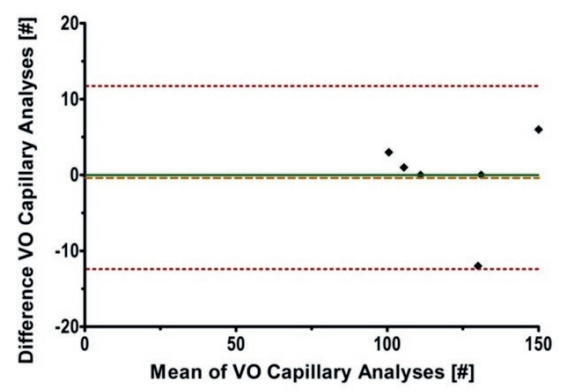

Figure 3.10 - Bland-Altman plots of erythrocyte-filled capillaries during venous occlusion (VO) by means of nailfold capillary videomicroscopy measurements and analyses. The green line represents perfect agreement, the orange line represents the mean difference, and the red lines represent the limits of agreement. A. Agreement over time between two capillary videomicroscopy measurements with 8 weeks in between; the mean difference was statistically significant $(-6.7$ capillaries; $p<0.05)$. B. Intra-observer agreement in analyses of capillary videomicroscopy; the mean difference was not statistically significant. C. Inter-observer agreement in analyses of capillary videomicroscopy; the mean difference was not statistically significant.

\section{Sublingual microvascular perfused boundary region (Glycocalyx)}

Reliability over time of PBR was assessed in 26 individuals from the weight stable control group of the WLI Trial. ICC time was -0.15 and was thus converted to 0.00 $\left(p=0.76 ;{ }^{54}\right)$ and $\mathrm{SEM}_{\text {time }}$ was $0.20 \mu \mathrm{m}$. The Bland-Altman plot is presented below (Figure 3.14). 
A

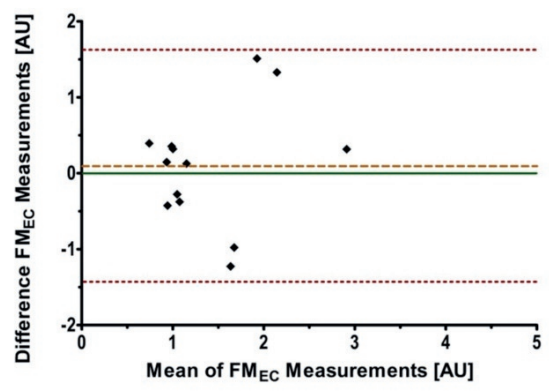

C

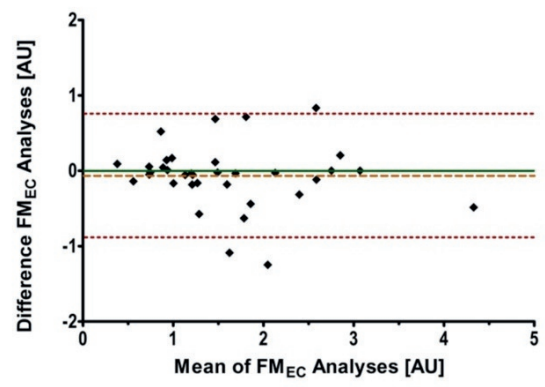

B

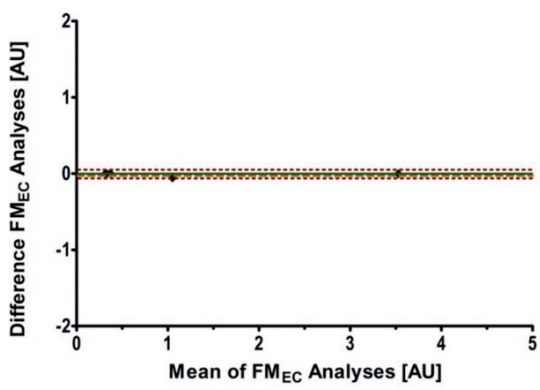

Figure 3.11 - Bland-Altman plots of the endothelial-derived flowmotion spectrum (FMEC) by means of laser Doppler flowmetry (LDF) measurements and analyses. The green line represents perfect agreement, the orange line represents the mean difference, and the red lines represent the limits of agreement. A. Agreement over time between two LDF measurements with 8 weeks in between; the mean difference was not statistically significant. B. Intra-observer agreement in analyses of $\mathrm{FM}_{\mathrm{EC}}$; the mean difference was not statistically significant. C. Inter-observer agreement in analyses of $\mathrm{FM}_{\mathrm{EC}}$; the mean difference was not statistically significant. 
A

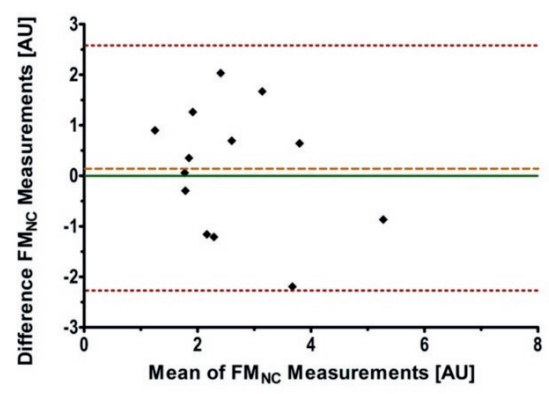

C

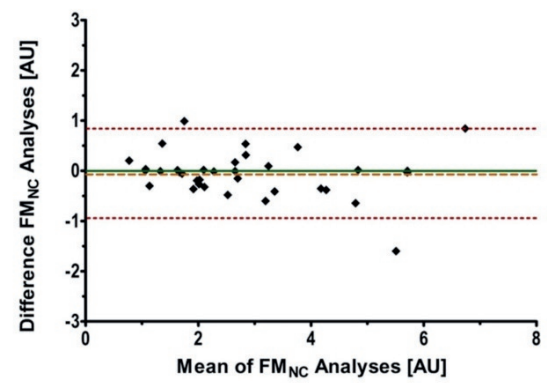

B

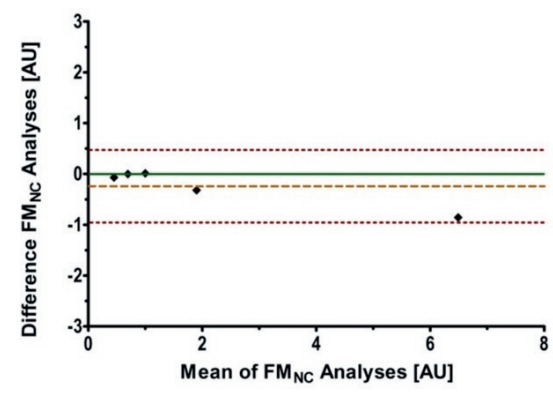

Figure 3.12 - Bland-Altman plots of the neurogenic flowmotion spectrum (FM $\mathrm{FC}_{\mathrm{NC}}$ ) by means of laser Doppler flowmetry (LDF) measurements and analyses. The green line represents perfect agreement, the orange line represents the mean difference, and the red lines represent the limits of agreement. A. Agreement over time between two LDF measurements with 8 weeks in between; the mean difference was not statistically significant. B. Intra-observer agreement in analyses of $\mathrm{FM}_{\mathrm{NC}}$; the mean difference was not statistically significant. C. Inter-observer agreement in analyses of $\mathrm{FM}_{\mathrm{NC}}$; the mean difference was not statistically significant. 
A

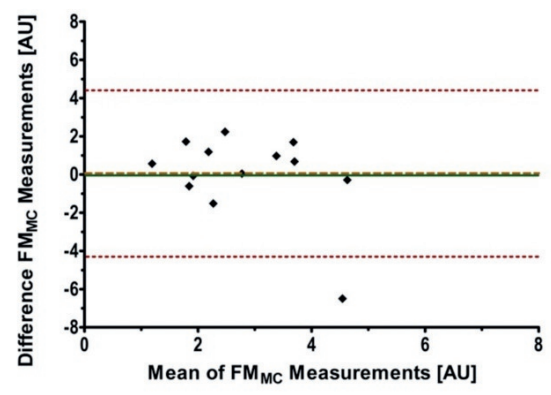

C

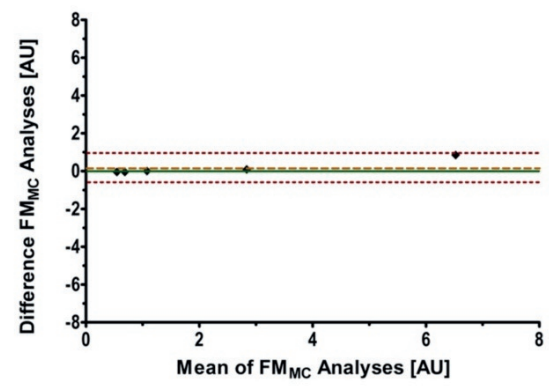

B

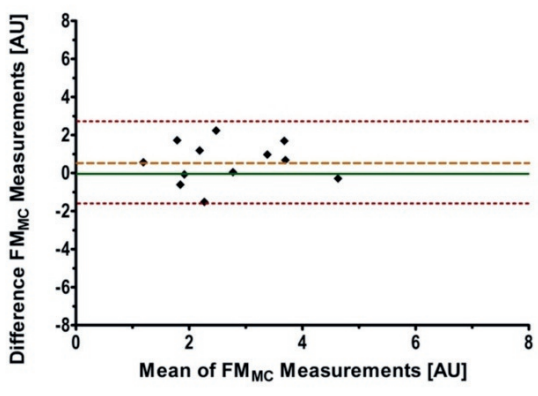

D

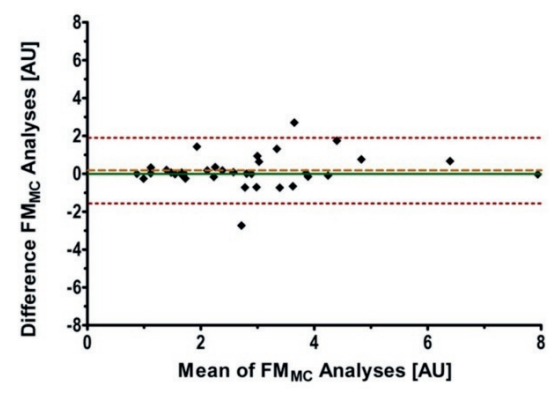

Figure 3.13 - Bland-Altman plots of the myogenic flowmotion spectrum (FM $\mathrm{MC}_{\mathrm{C}}$ ) by means of laser Doppler flowmetry (LDF) measurements and analyses. The green line represents perfect agreement, the orange line represents the mean difference, and the red lines represent the limits of agreement. A. Agreement over time between two LDF measurements with 8 weeks in between; the mean difference was not statistically significant. B. Agreement over time between two LDF measurements with 8 weeks in between, one outlier was excluded to illustrate its effect on agreement; the mean difference was not statistically significant. C. Intra-observer agreement in analyses of $\mathrm{FM}_{\mathrm{Mc}}$; the mean difference was not statistically significant. $\mathbf{D}$. Inter-observer agreement in analyses of $\mathrm{FM}_{\mathrm{MC}}$; the mean difference was not statistically significant.

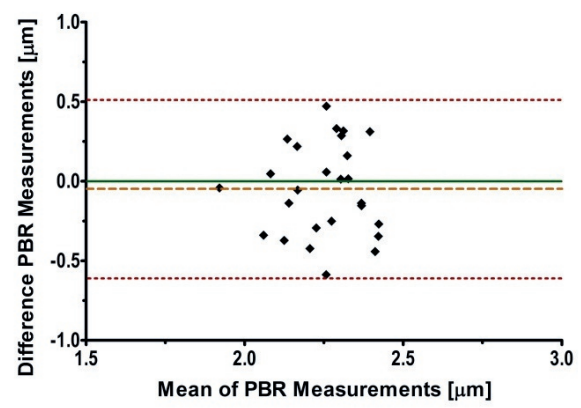

Figure 3.14 - Bland-Altman plot of agreement over time in sublingual microvascular perfused boundary region (PBR) measurements with 8 weeks in between; the mean difference was not statistically significant. The green line represents perfect agreement, the orange line represents the mean difference, and the red lines represent the limits of agreement. 
Macrovascular measurements

\section{Flow-mediated dilation}

As published before, intra-observer reliability and reliability over time of FMD measurements was determined in a group of 22 individuals from the Acute Hyperglycemia Study. ${ }^{14}$ In this study, $I C C_{\text {intra }}$ was $0.68, I{ }^{2} C_{\text {time }}$ was 0.53 (Table 3.1; $\mathrm{p}<0.05$ for each), $\mathrm{SEM}_{\text {intra }}$ was $1.3 \%$-point and $\mathrm{SEM}_{\text {time }}$ was $1.9 \%$-point; the BlandAltman plots are presented below (Figures 3.15A and 3.15B). Additionally, we also evaluated reliability over time in 23 individuals from the weight stable control group of the WLI Trial ( 3 of 26 controls were excluded due to technical issue), which yielded similar results for $\operatorname{ICC}_{\text {time }}(0.53 ; p<0.01$; Table 3.1$)$ and $\mathrm{SEM}_{\text {time }}$ (1.8\%-point).

Intra- and inter-observer reliability of FMD analyses were assessed in a subset of 25 lean and abdominally obese individuals that participated in the WLI trial. ICC intra was 0.88, ICC $_{\text {inter }}$ was 0.84 (Table 3.2; $\mathrm{p}<0.001$ for each), $\mathrm{SEM}_{\text {intra }}$ was $0.3 \%$-point, and $\mathrm{SEM}_{\text {inter }}$ was $0.7 \%$-point. The Bland-Altman plots of intra-observer and inter-observer agreement of the analyses are presented below (Figures 3.15C and 3.15D).

\section{Reactive Hyperemia Index}

Reliability of RHI measurements over time was assessed in a subset of 14 individuals from the weight stable control group of the WLI trial (i.e., the control subjects that were enrolled when $60 \%$ of the trial was completed). In this subset, ICC $\mathrm{C}_{\text {time }}$ was 0.58 (Table 3.1; $\mathrm{p}<0.001$ ) and SEM $_{\text {time }}$ was $0.32 \%$-point; the Bland-Altman plot is presented below (Figure 3.16).

\section{Carotid-femoral pulse wave velocity and augmentation index}

The intra- and inter-observer reliability $(n=12)$, as well as the reliability over time of cfPWV and Aix measurements ( $n=11)$ were determined in a subset of individuals from the Maastricht Study. For cfPWV all ICCs were $>0.81$ (Table 3.1; $p<0.01$ for each), whereas for Aix ICC intra $(0.61)$ and ICC inter $(0.60$; Table 3.1; $p<0.05$ for each) were considerably lower. For cfPWV, SEM intra was $0.3 \mathrm{~m} / \mathrm{s}, \mathrm{SEM}_{\text {inter }}$ was $1.0 \mathrm{~m} / \mathrm{s}$ and $\mathrm{SEM}_{\text {time }}$ was $0.9 \mathrm{~m} / \mathrm{s}$. As for Aix, $\mathrm{SEM}_{\text {intra }}, \mathrm{SEM}_{\text {inter }}$ and $\mathrm{SEM}_{\text {time }}$ were 1.8, 4.3 and 3.1\%-point, respectively. The companion Bland-Altman plots are presented below (Figures 3.17A-C and 3.18A-C). 
A

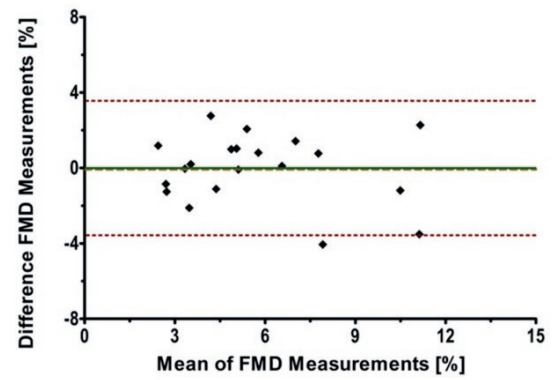

C

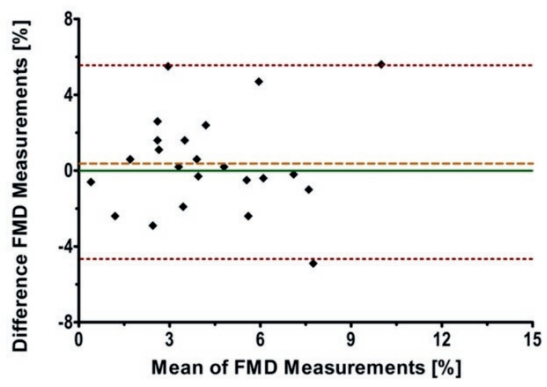

E

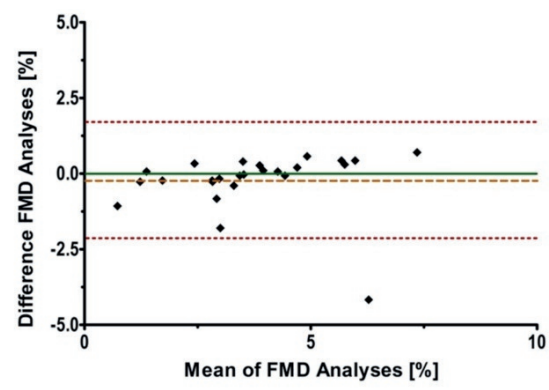

B

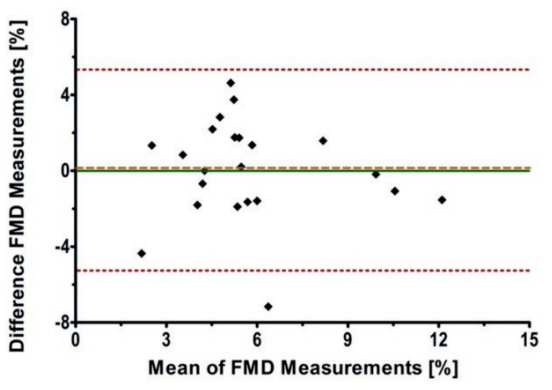

D

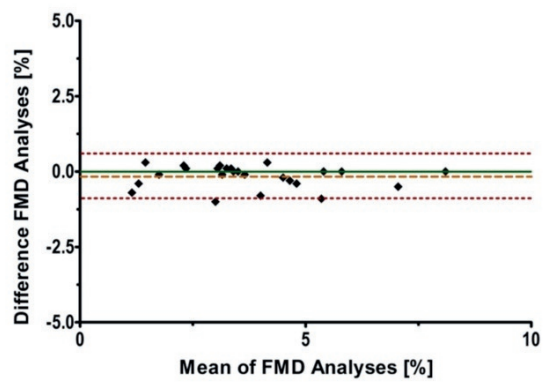

Figure 3.15 - Bland-Altman plots of Flow-mediated Dilation (FMD; in \%-points) measurements and analyses. The green line represents perfect agreement, the orange line represents the mean difference, and the red lines represent the limits of agreement. A. Intra-observer agreement of FMD measurements; the mean difference was not statistically significant. B. Agreement over time between two FMD measurements with 1 week in between; the mean difference was not statistically significant. C. Intra-observer agreement over time between two FMD measurements with 8 weeks in between; the mean difference was not statistically significant. D. Intra-observer agreement in FMD analyses; the mean difference was statistically significant (-0.2\%-point; $\mathrm{p}<0.05)$. E. Inter-observer agreement in FMD analyses; the mean difference was not statistically significant. 


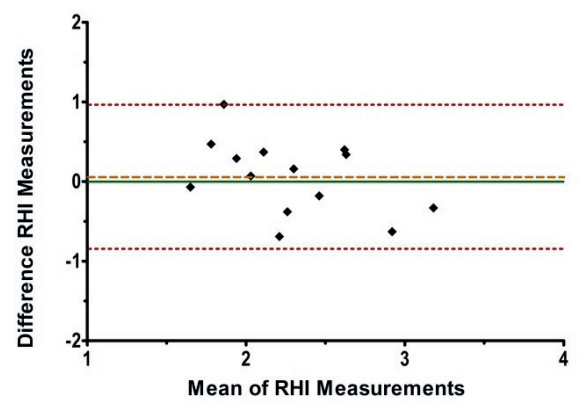

Figure 3.16 - Bland-Altman plot of agreement over time in Reactive Hyperemia Index (RHI) measurements with 8 weeks in between; the mean difference was not statistically significant. The green line represents perfect agreement, the orange line represents the mean difference, and the red lines represent the limits of agreement.

A

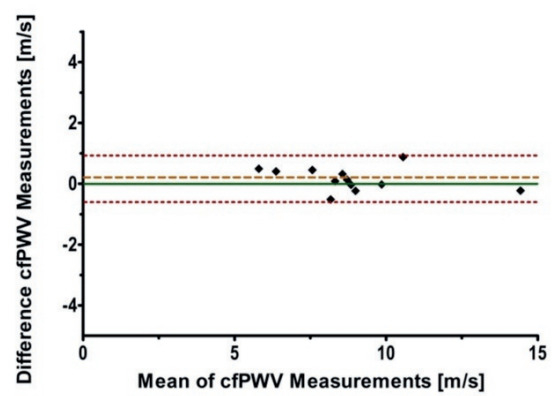

C

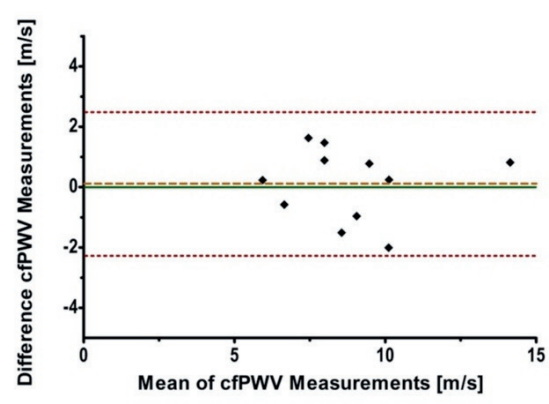

B

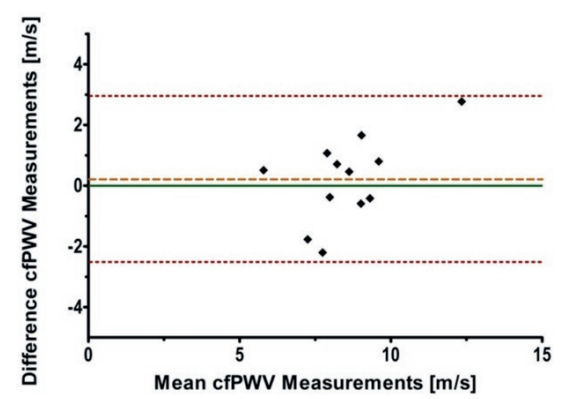

Figure 3.17 - Bland-Altman plots of carotid-femoral pulse wave velocity (cfPWV) measurements. The green line represents perfect agreement, the orange line represents the mean difference, and the red lines represent the limits of agreement. A. Intra-observer agreement of cfPWV measurements; the mean difference was not statistically significant. B. Inter-observer agreement of cfPWV measurements; the mean difference was not statistically significant. C. Agreement over time between two cfPWV measurements with 1 week in between; the mean difference was not statistically significant. 
A

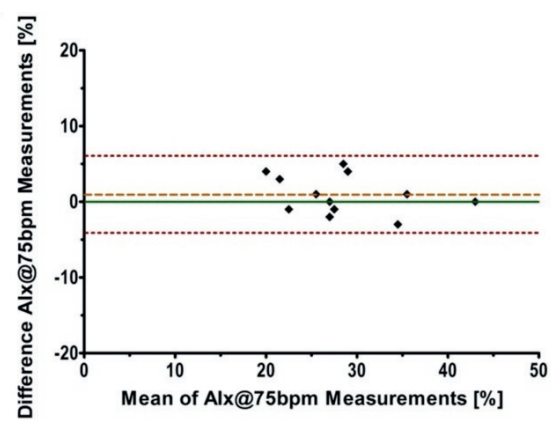

C

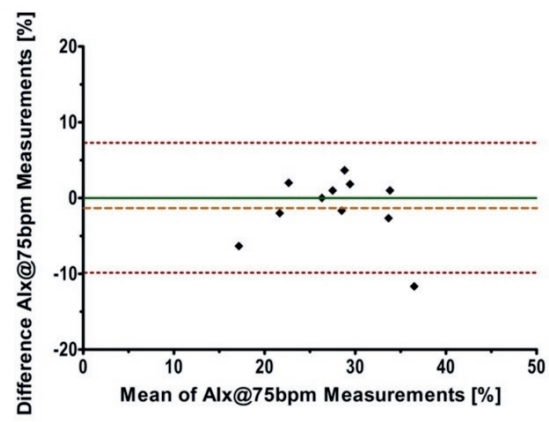

B

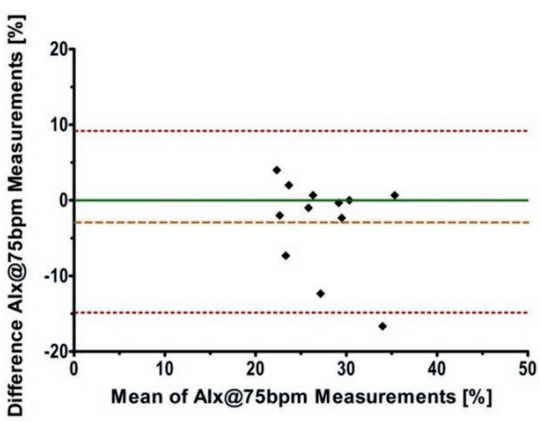

Figure 3.18 - Bland-Altman plots of augmentation index (at 75 heartbeats per minute; Aix @75bpm; in \%-points) measurements and analyses. The green line represents perfect agreement, the orange line represents the mean difference, and the red lines represent the limits of agreement. A. Intra-observer agreement of Aix @75bpm measurements; the mean difference was not statistically significant. B. Interobserver agreement of Aix @75bpm measurements; the mean difference was not statistically significant. C. Agreement over time between two Aix @75bpm measurements with 1 week in between; the mean difference was not statistically significant.

Carotid distensibility, distensibility coefficient, compliance coefficient, and intimamedia thickness

The intra-observer reliability of carotid distensibility $(n=12)$ and cIMT $(n=11)$, the inter-observer reliability of carotid distensibility, DC, CC and CIMT ( $n=12$ for each), and reliability over time of carotid distensibility $(n=11)$, DC $(n=9), C C(n=9)$ and cIMT $(n=11)$ were determined in a subset of individuals from the Maastricht Study. For carotid distensibility, all ICCs were $>0.75$ (Table 3.1; $p<0.05$ for each) as SEM $_{\text {intra, }}$ $\mathrm{SEM}_{\text {inter }}$ and $\mathrm{SEM}_{\text {time }}$ were 0.4, 0.8 and 0.5\%-point, respectively. For both DC and CC, ICC inter and $\mathrm{ICC}_{\text {time }}$ were $>0.84$ (Table 3.1; $\mathrm{p}<0.01$ for each). For DC SEM inter and $\mathrm{SEM}_{\text {time }}$ were 1.1 and $2.510^{-3} / \mathrm{kPa}$, respectively, whereas for CC, SEM inter was 0.14 and $\mathrm{SEM}_{\text {time }}$ was $0.06 \mathrm{~mm}^{2} / \mathrm{kPa}$. As for cIMT, both $\mathrm{ICC}_{\text {intra }}$ and $\mathrm{ICC}_{\text {time }}$ were $>0.84(\mathrm{p}<0.01$ 
for each), whereas ICC inter $_{\text {was remarkably low (0.27; Table 3.1); SEM }}$ intra, SEM inter $_{\text {and }}$ $\mathrm{SEM}_{\text {time }}$ were estimated at 31, 93 and $49 \mu \mathrm{m}$, respectively. The companion BlandAltman plots are presented below (Figures 3.19-22).

A

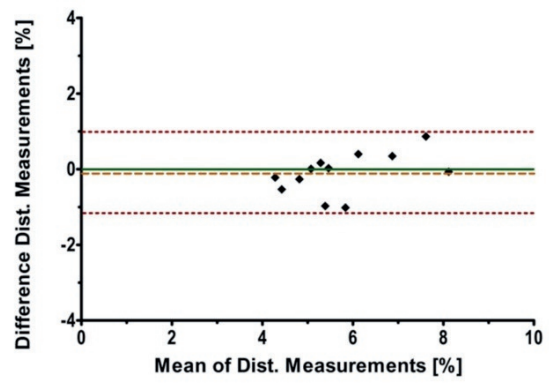

C

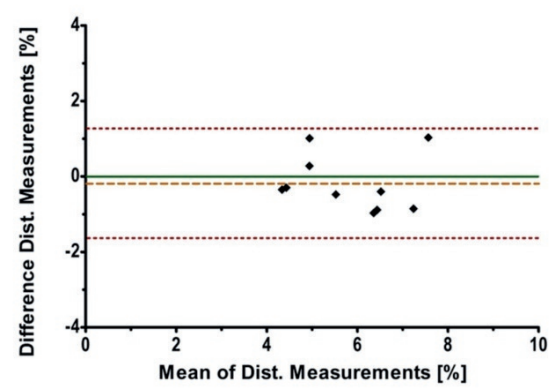

B

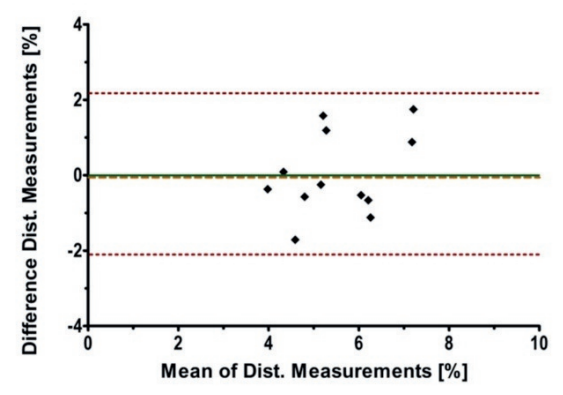

Figure 3.19 - Bland-Altman plots of carotid distensibility (Dist.; in \%-points) measurements. The green line represents perfect agreement, the orange line represents the mean difference, and the red lines represent the limits of agreement. A. Intra-observer agreement of carotid distensibility measurements; the mean difference was not statistically significant. B. Inter-observer agreement of carotid distensibility measurements; the mean difference was not statistically significant. C. Agreement over time between two carotid distensibility measurements with 1 week in between; the mean difference was not statistically significant. 
A

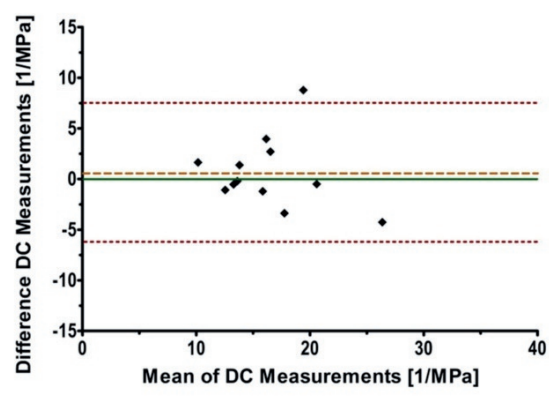

B

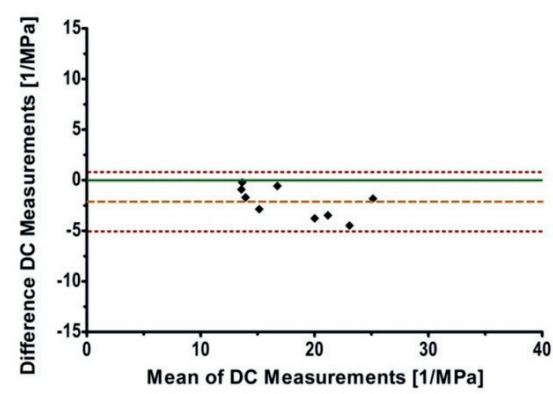

Figure 3.20 - Bland-Altman plots of carotid distensibility coefficient (DC) measurements. The green line represents perfect agreement, the orange line represents the mean difference, and the red lines represent the limits of agreement. A. Inter-observer agreement DC measurements; the mean difference was not statistically significant. B. Agreement over time between two DC measurements with 1 week in between; the mean difference was statistically significant $(-2.2 / \mathrm{MPa} ; \mathrm{p}<0.05)$.

A

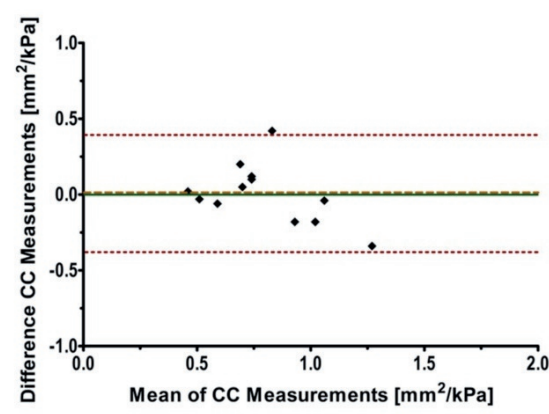

B

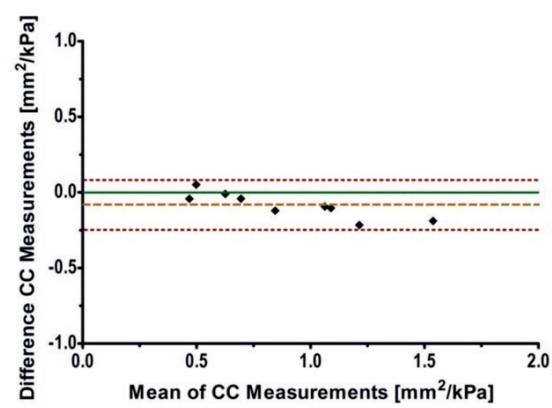

Figure 3.21 - Bland-Altman plots of carotid compliance coefficient (CC) measurements. The green line represents perfect agreement, the orange line represents the mean difference, and the red lines represent the limits of agreement. A. Inter-observer agreement CC measurements; the mean difference was not statistically significant. B. Agreement over time between two CC measurements with 1 week in between; the mean difference was statistically significant $\left(-0.08 \mathrm{~mm}^{2} / \mathrm{kPa} ; \mathrm{p}<0.05\right)$. 
A

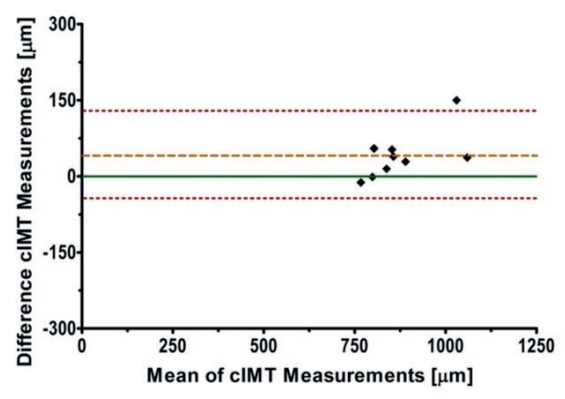

C

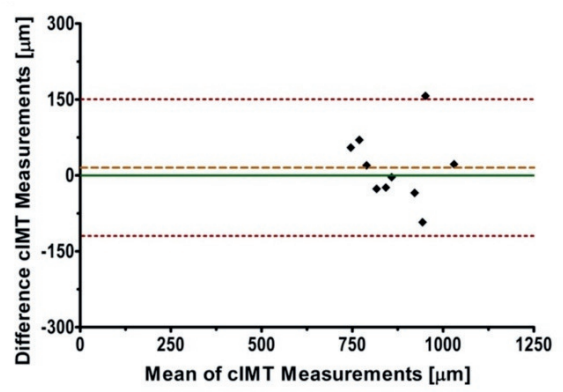

B

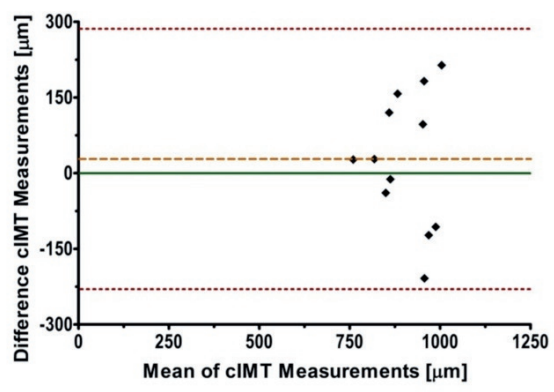

Figure 3.22 - Bland-Altman plots of carotid intima-media thickness (cIMT) measurements. The green line represents perfect agreement, the orange line represents the mean difference, and the red lines represent the limits of agreement. A. Intra-observer agreement of cIMT measurements; the mean difference was statistically significant $(42 \mu \mathrm{m} ; \mathrm{p}<0.05)$. B. Inter-observer agreement of cIMT measurements; the mean difference was not statistically significant. C. Agreement over time between two cIMT measurements with 1 week in between; the mean difference was not statistically significant.

\section{Metabolic measurements}

\section{Whole body glucose disposal}

The reliability over time of WBGD measurement by means of a euglycemic insulin clamp was assessed in the weight stable control group of the WLI trial $(n=26)$. In this study population, $\quad \mathrm{ICC}_{\text {time }}$ was 0.88 (Table $3.1 ; \mathrm{p}<0.001$ ) and $\mathrm{SEM}_{\text {time }}$ was $0.61 \mathrm{mg} / \mathrm{kg} / \mathrm{min}$; the Bland-Altman plot is presented below (Figure 3.23). No adverse events (e.g., hypoglycemia) occurred in 129 clamps in 79 unique individuals.

\section{Beta-cell function}

The reliability over time of BCF measurements were assessed in the weight stable control group of the WLI trial $(n=26)$. The ICC $\mathrm{Itime}_{\text {for }} \beta-\mathrm{GS}, \beta-\mathrm{RS}$ and PFR were 0.46 , 0.45 , and 0.42 respectively ( $p<0.05$ for each). The $\mathrm{SEM}_{\text {time }}$ was $11.9 \mathrm{pmol} / \mathrm{min} / \mathrm{m}^{2} / \mathrm{mM}$ 
for $\beta$-GS, $203 \mathrm{pmol} / \mathrm{m}^{2} / \mathrm{mM}$ for $\beta$-RS, and 0.16 for PFR. The respective Bland-Altman plots are presented below (Figures 3.24-26).

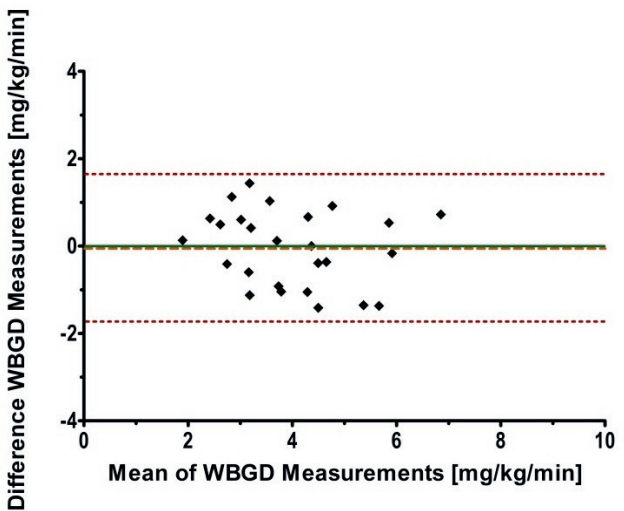

Figure 3.23 - Bland-Altman plot of agreement over time in whole body glucose disposal (WBGD) measurements by means of a euglycemic insulin clamp with 8 weeks in between; the mean difference was not statistically significant. The green line represents perfect agreement, the orange line represents the mean difference, and the red lines represent the limits of agreement.

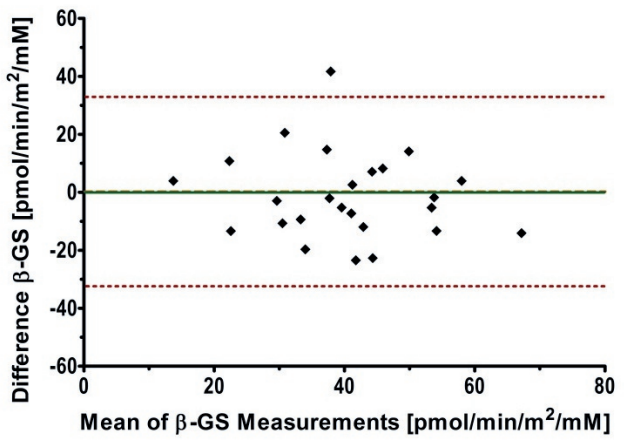

Figure 3.24 - Bland-Altman plot of agreement over time in beta-cell glucose sensitivity ( $\beta$-GS) measurements by means of mathematically modeling mixed meal test data with 8 weeks in between; the mean difference was not statistically significant. The green line represents perfect agreement, the orange line represents the mean difference, and the red lines represent the limits of agreement. 


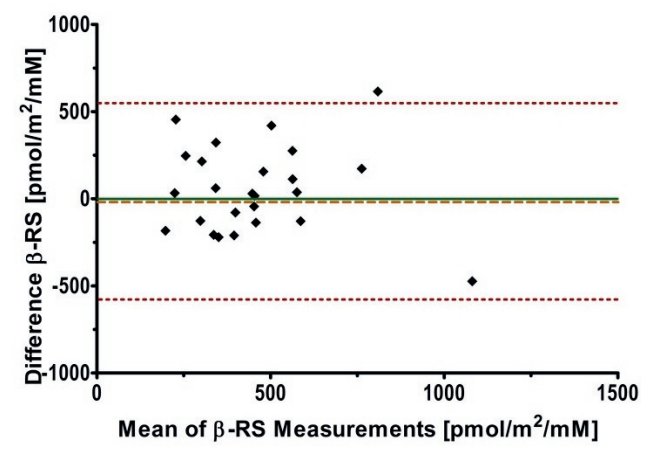

Figure 3.25 - Bland-Altman plot of agreement over time in beta-cell rate sensitivity ( $\beta$-RS) measurements by means of mathematically modeling mixed meal test data with 8 weeks in between; the mean difference was not statistically significant. The green line represents perfect agreement, the orange line represents the mean difference, and the red lines represent the limits of agreement.

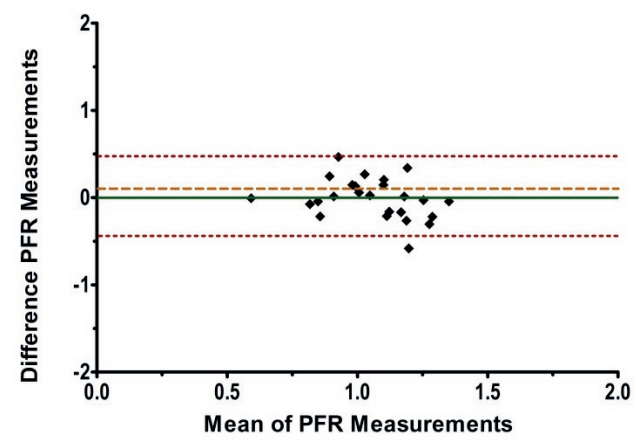

Figure 3.26 - Bland-Altman plot of agreement over time in potentiation factor ratio (PFR) measurements by means of mathematically modeling mixed meal test data with 8 weeks in between; the mean difference was not statistically significant. The green line represents perfect agreement, the orange line represents the mean difference, and the red lines represent the limits of agreement.

\section{Inflammatory measurements}

\section{CD11B surface expression}

Data from 22 individuals from the weight stable control group of the WLI Trial were used to assess the reliability of NK-CD11B over time. ICC time was $0.74(p<0.01)$ and $\mathrm{SEM}_{\text {time }}$ was 2231 arbitrary units. The respective Bland-Altman plot is presented below (Figure 3.27). 


\section{Plasma biomarkers of low-grade inflammation}

The reliability over time of z-LGI was assessed in the weight stable control group of the WLI trial $(n=26)$; $I C C_{\text {time }}$ was $0.949(p<0.001)$. Since $z-L G I$ is dependent of the population it is measured in, neither SEM time was calculated, nor was a Bland-Altman plot created.

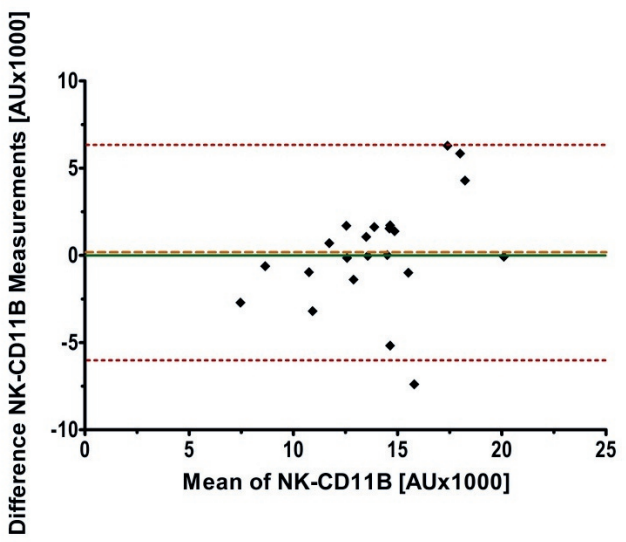

Figure 3.27 - Bland-Altman plot of agreement over time CD11B expression on circulating NK cells (NKCD11B) measurements by means of flow cytometry with 8 weeks in between; the mean difference was not statistically significant. The green line represents perfect agreement, the orange line represents the mean difference, and the red lines represent the limits of agreement.

\section{Discussion}

In this report we established the reliability and measurement error of the measurement and analyses of several anthropometric, vascular, metabolic, and inflammatory variables. To our knowledge, it is the first study that A) reported the reliability and measurement error on these variables within a single research group, B) reported the reliability and measurement error of the measurement and (offline) analyses of these variables separately, and C) reported reliability and measurement error of MVR by means of CEUS. We will address the reliability and measurement error of the gamut of variables below.

\section{Anthropometric variables}

The measurements and the analyses of both VAT and SAT volumes were very reliable and had little measurement error. The reliability presented here is in line with intraand inter-observer reliability of VAT and SAT quantification by means of computed 
tomography (CT) analyses in the Framingham Study (ICC $=0.99$ for each). ${ }^{56,57}$ Only when we compare VAT quantification methods, was there a non-significant trend towards increasing differences between both methods with increasing VAT volume. This difference may have arisen from the limitations of pixel-by-pixel analyses, in which an observer often either does or does not count a pixel at the edges between VAT and surrounding tissue, whereas software like Hippo Fat uses thresholding of grey scales to quantify VAT. Hence, although pixel-by-pixel analyses are often considered to be the gold standard, this may be open for debate. As both VAT and SAT volumes are very reliable within and between trained observers, there are no objections to letting multiple observers analyze such data, though it would be advisable to adjust for systematic differences between observers.

As for IHL and IPL, measurements and analyses were reliable, although both tended to have a considerable measurement error over a time course of 8 weeks. This may, at least in part, be due to the expected biological variance in a control group of a WLI Trial in which some controls are likely to better their life style whereas others may loosen the reins. In many weight loss intervention studies a control group is, however, lacking; as a result data on biological variance of IHL and IPL are scarce. As the SEM $\mathrm{M}_{\text {time }}$ of IHL and IPL were comparable, this indicates more variance over time in IPL values than IHL. In addition, since regional differences in the lipid content of both liver and pancreas are common, it would be recommended to standardize the location of measurement, in particular in repeated measurements, as well as to determine IHL and IPL in multiple volume of interest, if possible. ${ }^{17,58}$

With regard to the comparison of mDixon to ${ }^{1} \mathrm{H}-\mathrm{MRS}$ to assess $\mathrm{IHL}$, there was a high level of agreement and NAFLD could be differentiated well. Yet, there was some overestimation of IHL at low levels and an underestimation at higher IHL-levels, which would make mDixon prone to type 2 errors. As the signal intensity in water and fat images of mDixon can only adopt positive values, noise is erroneously counted as IHL, particularly at low IHL levels. Thus, this appears to be intrinsic to the mDixon sequence. In a recent study comparing mDixon to ${ }^{1} \mathrm{H}-\mathrm{MRS}$, the ICC between both methods was substantially higher $(0.98)$ and the SEM was very low $0.01 \%$-point, calculated from $^{58}$ ). This difference might be due to incorporation of bile ducts and blood vessels in the volume of interest, which ${ }^{1} \mathrm{H}$-MRS does as well, as well as due to different scan parameters. Therefore, we chose not to recalculate IHL values based on the available data. It is worthwhile to compare our current mDixon settings to those used in different studies to evaluate whether reliability and measurement error can be further improved and type 2 errors avoided. 


\section{Microvascular variables}

Here, we first present the reliability and measurement error of MVR by means of CEUS. We consider the CEUS-based measurements of MVR to be safe, reliable, and to have a low intra-observer measurement error (i.e., within-day) and a moderate measurement error over time (20\%-point MVR by hyperinsulinemia, 8 weeks between visits). When the time interval was shorter and handgrip exercises were used to induce MVR instead of hyperinsulinemia, the reliability of MVR measurements obviously increase. Nonetheless, the overall reliability and measurement error of MVR measurements, either induced by exercise or hyperinsulinemia, would endorse the use of CEUS even in relatively small study populations. Of note, when the expected effect of an intervention is estimated to be lower than the measurement error of this technique, the sample size needed to demonstrate an effect on MVR will increase considerably. ${ }^{1}$

With regard to MVR analyses, the intra-observer reliability of a single, well-trained observer is considered to be excellent, whereas inter-observer reliability was not assessed at this time. Likely, the intra-observer reliability reported here is even underestimated, as measurements of substandard image quality were oversampled. Because inter-observer reliability is lacking here, we cannot advise whether MVR can be measured or analyzed by multiple observers without introducing considerable error. Nonetheless, no benefit is to be expected from letting multiple observers analyze the same data to improve reliability. Instead, stakeholders should invest in adequate training of study staff to minimize error in the acquisition and analyses of MVR data, as well as limit the number of observers trained to perform CEUS and its analyses to ensure sufficient expertise.

In contrast to MVR by means of CEUS, we found that reliability was lower for other microvascular variables. Although the reliability of continuously perfused capillaries, perfused capillaries during post-occlusive hyperemia and erythrocyte-filled capillaries during venous occlusion for both measurements as well as analyses were reasonably good, the reliability of capillary recruitment by hyperemia or hyperinsulinemia was either considerably lower or absent. This allows for several conclusions. First, this illustrates the importance of measurement error, as measurement error was comparable between all videomicroscopy measures, whereas mainly the betweensubject variance differs between these variables and, by extension, oft provides a false sense of reliability when other variables than capillary recruitment are reported. Second, the reliability of nailfold capillary recruitment by hyperemia is comparable to that of FMD, a generally accepted vascular function measurement. Third, insulininduced capillary recruitment has a comparable measurement error as MVR, yet has substantially less between-subject variance. Finally, inter-observer variance is 
particularly bothersome in nailfold videomicroscopy. As capillary videomicroscopy analyses are laborious, we advise to adjust for the systematic error between observers and to limit the number of observers; to analyze data by more than one observer to increase reliability is far from realistic for most studies.

As for flowmotion, reliability over time for the endothelial and neurogenic component were reasonable, whereas no reliability was found for the myogenic component, although the latter could be attributed to a measurement that contained multiple artifacts. This underscores the importance of efforts to reduce the influence of recorded artifacts, either by using different analyses (e.g., wavelet analyses), by improving the quality of the recordings, or by extending the duration of the measurements to allow the selection of an artifact-free time frame.

As it is impossible to measure flowmotion at the exact same recording site twice, ${ }^{59,60}$ it could be considered to measure flowmotion at several standardized sites and then average the results of those recordings. One could justify the latter by the assumption that the microvascular dysfunction one strives to quantify would affect the skin microvasculature as a whole, not just focally. Although inter-observer reliability of flowmotion analyses was good, the difference between observers is most obvious in recordings of poor quality. Hence, reliability of analyses would profit by using different analyses (e.g., wavelet analyses), by improving the quality and number of the recordings, by limiting the number of observers to one observer, or - in contrast - by increasing the number of observers. To differentiate whether just one experienced observer or multiple observers should analyze flowmotion data, one should study the raw data to identify the origin of error. For example, does one observer handle data, perhaps those of poor quality, in a wrong way or just differently? Or are the differences due to the selection of the analyzed timeframe in the recordings? This should be further investigated in future reliability studies.

Lastly, reliability over time of PBR (i.e., glycocalyx) in the sublingual vascular bed was absent in this study population. In statistical terms this means that the betweensubject variance was very low, whereas the measurement error was large, which is visible in the Bland-Altman plot and the SEM. The absence of reliability is in contrast to the whitepaper by the manufacturer, which states that PBR is "highly reproducible", although data on reliability was not provided, nor cited. ${ }^{28} \mathrm{We}$, therefore, advise against the use of this technique for research questions where the estimated effect size is low (e.g., below the SEM), like in the subset of abdominally obese individuals without T2DM used in our analyses. Conversely, in situations with large between-subject variance, like a septic shock, PBR might be more reliable. This is illustrated by a recent study that assessed inter-observer reliability of PBR in a combined population of patients in the emergency room or intensive care unit, where 
reliability was markedly higher $($ ICC $=0.75)$ as a result of larger between-subject variance (i.e., PBR ranged from $\sim 1.8$ to $3.2{ }^{61}$ Interestingly, the SEM was comparable to our data (SEM $0.18 \mu \mathrm{m}$, calculated from ${ }^{61}$ ). Hence, as we stated before, reliability data should only be judged in the population and clinical setting it is measured in.

\section{Macrovascular variables}

As published before, the intra-observer reliability of FMD measurements as well as the reliability over time, were reasonable. ${ }^{14}$ The reliability over time of FMD measurements in obese individuals randomized to the weight stable control group was comparable to data from our ${ }^{14}$ and other research groups. ${ }^{62-66}$ As for the analyses of FMD, intra-observer reliability was excellent, whereas inter-observer reliability was slightly lower, mainly in measurements of substandard image quality. We should, however, not neglect that the measurement error of FMD measurements is substantial, which should significantly impact power calculations. If we, however, compare FMD to other endothelial-dependent and nitric-oxide mediated vascular measurements like MVR, nailfold capillary recruitment and the endothelial component of flowmotion, the reliability of FMD appeared to be slightly lower, although not statistically significantly. The reliability of RHI over time was acceptable and comparable to the ICC and SEM in adult volunteers reported elsewhere (ICCS 0.56-0.73; SEM $_{\text {time }} 0.38 ;{ }^{67,68}$ ). In our study population, reliability of RHI and FMD were comparable, whereas often FMD is considered to be somewhat more reliable when measured simultaneously. ${ }^{67}$ As FMD and RHI measurements had a SEM comparable to other studies, ${ }^{14,62,65-67}$ either FMD had less between-subject variance, or RHI had more between-subject variance than expected.

Our data on the inter-observer and intra-observer reliability and measurement error of cfPWV and Aix were excellent and are slightly better than reported in individuals with type 2 diabetes. ${ }^{69}$ In a different study, where both healthy individuals and individuals with end-stage renal disease were included, reliability was obviously higher, yet SEM or limits of agreement were not presented. ${ }^{70}$

As for carotid distensibility, DC and CC, reliability and measurement error were excellent and were comparable to those reported by others. ${ }^{71-73}$ As these measurements are already usually repeated three times, little improvement in reliability is to be expected from increasing the number of measurements or observers. Unfortunately, no data was available to determine the reliability and measurement error of the analyses of these variables. It would be advisable to determine these in the near future, though, since variables like these are used in large study samples (e.g., the Maastricht Study), where having a single observer for analyses is often not feasible. 
The intra-observer reliability and reliability over time of CIMT, as well as their measurement error were excellent and comparable to those reported by others. ${ }^{71}$ The inter-observer reliability was, however, considerably lower, without any evidence for a structural difference between the two observers. Although inter-observer reliability was poor in this study population, its SEM was actually comparable to studies that reported good inter-observer reliability. ${ }^{71}$ Here, again, the crux is the lack of betweensubject variance, as all cIMT measurements in our population were between 0.75 and $1 \mathrm{~mm}$. The appreciation of cIMT measurements should therefore, as with every measurement, be related on the population and situation it is determined in. In addition, it is known that cIMT measurements have a substantial measurement error that depends, for example, on the system used, the anatomical location measured and the observer that performs the measurement. ${ }^{74}$ Thus, standardization of cIMT measurements is essential to reduce measurement error. From our data, it would also be sensible to either have each individual measured by multiple observers or to have one observer measure all individuals.

\section{Metabolic variables}

The reliability of WBGD over time in our population was excellent. We can compare the reliability and measurement error of WBGD in our study population to the first study on the euglycemic insulin clamp, in which arterial blood glucose was drawn and repeated measures were available in four individuals. In that study, ${ }^{37}$ the $\mathrm{ICC}_{\text {time }}$ was 0.97 and the $\mathrm{SEM}_{\text {time }}$ was $0.32 \mathrm{mg} / \mathrm{kg} / \mathrm{min}$. That study most likely had a superior reliability compared to ours due to 1 ) the use of arterial blood glucose levels, 2) less biological variance over time, because there was less time in between measurements (1 week vs. 8 weeks), and 3) a greater between-subject variance of WBGD. As for dynamic BCF measurements on the other hand, reliability was modest and SEM $\mathrm{S}_{\text {time }}$ was reasonable. Since obese men were studied, between-subject variance may have been relatively small; this may have reduced the reliability of the BCF measurements.

\section{Inflammatory measurements}

To our knowledge, the reliability of NK-CD11B over time had not been described previously, yet it proved to be very good. For z-LGI, reliability over time was downright excellent, which illustrates the statistical effectiveness of this approach, as argued before. $^{51,52}$

Our study has several strengths. First, we simultaneously presented various commonly used anthropometric, vascular, metabolic and inflammatory variables, many of which are reported in this thesis. In addition, we assessed not only reliability, but also measurement error in order to gain a deeper understanding of the performance of 
each technique regardless from the between-subject variance in the study population. Moreover, we assessed reliability and measurement error for both the measurement of a variable as well as its analyses, which allows for a more detailed understanding of sources of error.

Several limitations of this reliability study should also be noted. First, for many variables the sample size was relatively small to obtain a robust estimate of reliability. Second, reliability data were currently not available for all possible comparisons; future studies should fill in the gaps. Third, we often used the weight stable control group of the WLI trial which consisted of abdominally obese men only that were partaking in a life style trial. It is known that participation in a trial in itself leads to changes in behavior that influence outcome variables, which by extension reduces reliability. As this held true for many variables, their reliability can be effectively compared to one another. Fourth, ICCs are only relevant in the population it is measured in and (when applicable) to the stimulus used (e.g., handgrip exercises or hyperinsulinemia for MVR). Finally, reliability and measurement error are dependent on the observer(s) who performed the measurements or analyses; they may differ substantially when other observers are evaluated.

\section{Conclusion}

Here, we established the reliability and measurement error of MVR by means of CEUS for the first time, as well as determine reliability and measurement error of other commonly used anthropometric, vascular, metabolic and inflammatory variables. This detailed understanding of sources of measurement error and the reliability of variables in a certain study population allows for the adequate selection of outcome measurements in observational and intervention studies, as well as provide data for more accurate sample size calculations for such studies.

\section{Acknowledgements}

We thank Dr. T.T. van Sloten, Mr. J. Smets, Dr. B.C.T. van Bussel, Dr. R.M.A. Henry (department of Internal Medicine, Maastricht University Medical Center), Dr. S.A.J. ter Horst (Radiologist at Quantib B.V.), Dr. F.C.G. van Bussel, Dr. K.D. Reesink (department of Biomedical Engineering, Maastricht University Medical Center) and the management team of the Maastricht Study for the collection of reliability data, Dr. A.P.G. Hoeks (department of Biomedical Engineering, Maastricht University Medical Center) for the provided analyses software, and Dr. C.J.A.W. van Gool (department of Epidemiology, Maastricht University) and Dr. S.M.J. van Kuijk (KEMTA, Maastricht University Medical Center) for epidemiological counseling. The CEUS Reproducibility study and WLI Trial were supported by research grant $\mathrm{CHOO1}$ from the Top Institute 
Food and Nutrition, a public-private partnership on precompetitive research in food and nutrition. The public partners are responsible for the study design, data collection and analysis, decision to publish, and preparation of the manuscript. 


\section{References}

1. de Vet HCW, Terwee CB, Mokkink LB, Knol DL. Measurement in Medicine - A practical guide. U.S.A., Cambridge University Press, New York; 2011.

2. Mokkink LB, Terwee CB, Patrick DL, et al. The COSMIN study reached international consensus on taxonomy, terminology, and definitions of measurement properties for health-related patientreported outcomes. J Clin Epidemiol. 2010;63(7):737-745.

3. Altman DG. The scandal of poor medical research. Bmj. 1994;308(6924):283-284.

4. Bland JM, Altman DG. Agreed statistics: measurement method comparison. Anesthesiology. 2012;116(1):182-185.

5. Bland JM, Altman DG. Statistical methods for assessing agreement between two methods of clinical measurement. Lancet. 1986;1(8476):307-310.

6. Shrout PE, Fleiss JL. Intraclass correlations: uses in assessing rater reliability. Psychol Bull. 1979;86(2):420-428.

7. McGraw KO, Wong SP. Forming inferences about some intraclass correlation coefficients. Psychological Methods. 1996;1(1):30-46.

8. Gronenschild EH, Muris DM, Schram MT, Karaca U, Stehouwer CD, Houben AJ. Semi-automatic assessment of skin capillary density: proof of principle and validation. Microvasc Res. 2013;90: 192-198.

9. Kusters $\mathrm{YH}$, Schalkwijk CG, Houben AJ, et al. Independent tissue contributors to obesity-associated insulin resistance. JCI Insight. 2017;2(13).

10. Joris PJ, Plat J, Kusters $\mathrm{YH}$, et al. Diet-induced weight loss improves not only cardiometabolic risk markers but also markers of vascular function: a randomized controlled trial in abdominally obese men. Am J Clin Nutr. 2017;105(1):23-31.

11. Schram MT, Sep SJ, van der Kallen CJ, et al. The Maastricht Study: an extensive phenotyping study on determinants of type 2 diabetes, its complications and its comorbidities. Eur J Epidemiol. 2014; 29(6):439-451.

12. van Sloten TT, Czernichow S, Houben AJ, et al. Association Between Arterial Stiffness and Skin Microvascular Function: The SUVIMAX2 Study and The Maastricht Study. Am J Hypertens. 2015;28(7): 868-876.

13. Jonk AM, Houben AJ, Schaper NC, et al. Obesity is associated with impaired endothelial function in the postprandial state. Microvasc Res. 2011;82(3):423-429.

14. van Bussel FC, van Bussel BC, Hoeks AP, et al. A control systems approach to quantify wall shear stress normalization by flow-mediated dilation in the brachial artery. PLoS One. 2015;10(2):e0115977.

15. Muris DM, Houben AJ, Kroon AA, et al. Age, waist circumference, and blood pressure are associated with skin microvascular flow motion: the Maastricht Study. J Hypertens. 2014;32(12):2439-2449.

16. Positano V, Gastaldelli A, Sironi AM, Santarelli MF, Lombardi M, Landini L. An accurate and robust method for unsupervised assessment of abdominal fat by MRI. J Magn Reson Imaging. 2004;20(4): 684-689.

17. Al-Mrabeh A, Hollingsworth KG, Steven S, Tiniakos D, Taylor R. Quantification of intrapancreatic fat in type 2 diabetes by MRI. PLoS One. 2017;12(4):e0174660.

18. Macauley M, Percival K, Thelwall PE, Hollingsworth KG, Taylor R. Altered volume, morphology and composition of the pancreas in type 2 diabetes. PLoS One. 2015;10(5):e0126825.

19. Clerk LH, Vincent MA, Jahn LA, Liu Z, Lindner JR, Barrett EJ. Obesity blunts insulin-mediated microvascular recruitment in human forearm muscle. Diabetes. 2006;55(5):1436-1442.

20. Jonk A. Microvascular actions of insulin: studies on the interaction with angiotensin II and on the postprandial state, Maastricht University; 2011.

21. Kusters YH, Barrett EJ. Muscle microvasculature's structural and functional specializations facilitate muscle metabolism. Am J Physiol Endocrinol Metab. 2016;310(6):E379-387.

22. Kvernmo HD, Stefanovska A, Bracic M, Kirkeboen KA, Kvernebo K. Spectral analysis of the laser Doppler perfusion signal in human skin before and after exercise. Microvasc Res. 1998;56(3):173-182. 
23. Bracic M, Stefanovska A. Wavelet-based analysis of human blood-flow dynamics. Bull Math Biol. 1998;60(5):919-935.

24. Johnson PC. The myogenic response. The resistance vasculature: Springer; 1991:159-168.

25. Kastrup J, Bulow J, Lassen NA. Vasomotion in human skin before and after local heating recorded with laser Doppler flowmetry. A method for induction of vasomotion. Int J Microcirc Clin Exp. 1989;8(2):205-215.

26. Bertuglia S, Colantuoni A, Intaglietta M. Effects of L-NMMA and indomethacin on arteriolar vasomotion in skeletal muscle microcirculation of conscious and anesthetized hamsters. Microvasc Res. 1994;48(1):68-84.

27. Kvandal P, Stefanovska A, Veber M, Kvermmo HD, Kirkebøen KA. Regulation of human cutaneous circulation evaluated by laser Doppler flowmetry, iontophoresis, and spectral analysis: importance of nitric oxide and prostaglandines. Microvasc Res. 2003;65(3):160-171.

28. van Teeffelen J, Vink H. Clinical assessment of vascular health with GlycoCheck ${ }^{\mathrm{TM}}$ Glycocalyx Measurement Software: A GlycoCheck ${ }^{\mathrm{TM}}$ Whitepaper. 2012.

29. Axtell AL, Gomari FA, Cooke JP. Assessing endothelial vasodilator function with the Endo-PAT 2000. J Vis Exp. 2010(44).

30. Van Bortel LM, Laurent S, Boutouyrie $P$, et al. Expert consensus document on the measurement of aortic stiffness in daily practice using carotid-femoral pulse wave velocity. J Hypertens. 2012;30(3):445-448.

31. van Sloten TT, Schram MT, van den Hurk K, et al. Local stiffness of the carotid and femoral artery is associated with incident cardiovascular events and all-cause mortality: the Hoorn study. J Am Coll Cardiol. 2014;63(17):1739-1747.

32. Laurent S, Cockcroft J, Van Bortel L, et al. Expert consensus document on arterial stiffness: methodological issues and clinical applications. Eur Heart J. 2006;27(21):2588-2605.

33. Van Sloten TT. Vascular dysfunction: at the heart of cardiovascular disease, cognitive impairment and depressive symptoms, Maastricht University; 2015.

34. Henry RM, Kostense PJ, Spijkerman AM, et al. Arterial stiffness increases with deteriorating glucose tolerance status: the Hoorn Study. Circulation. 2003;107(16):2089-2095.

35. Van Bortel LM, Duprez D, Starmans-Kool MJ, et al. Clinical applications of arterial stiffness, Task Force III: recommendations for user procedures. Am J Hypertens. 2002;15(5):445-452.

36. Sherwin RS, Kramer KJ, Tobin JD, et al. A model of the kinetics of insulin in man. The Journal of clinical investigation. 1974;53(5):1481-1492.

37. DeFronzo RA, Tobin JD, Andres R. Glucose clamp technique: a method for quantifying insulin secretion and resistance. Am J Physiol. 1979;237(3):E214-223.

38. Mather KJ, Hunt AE, Steinberg HO, et al. Repeatability characteristics of simple indices of insulin resistance: implications for research applications. J Clin Endocrinol Metab. 2001;86(11):5457-5464.

39. Singh B, Saxena A. Surrogate markers of insulin resistance: A review. World J Diabetes. 2010;1(2): 36-47.

40. King-Morris KR, Deger SM, Hung AM, et al. Measurement and Correlation of Indices of Insulin Resistance in Patients on Peritoneal Dialysis. Perit Dial Int. 2016;36(4):433-441.

41. Rudvik A, Mansson M. Evaluation of surrogate measures of insulin sensitivity - correlation with gold standard is not enough. BMC Med Res Methodol. 2018;18(1):64.

42. Petty C, Cunningham NL. Insulin adsorption by glass infusion bottles, polyvinylchloride infusion containers, and intravenous tubing. Anesthesiology. 1974;40(4):400-404.

43. Astrup A, Simonsen L, Bulow J, Christensen NJ. Measurement of forearm oxygen consumption: role of heating the contralateral hand. Am J Physiol. 1988;255(4 Pt 1):E572-578.

44. Ferrannini E, Barrett E, Bevilacqua S, DeFronzo RA. Effect of fatty acids on glucose production and utilization in man. The Journal of clinical investigation. 1983;72(5):1737-1747.

45. Mari A, Tura A, Gastaldelli A, Ferrannini E. Assessing insulin secretion by modeling in multiple-meal tests: role of potentiation. Diabetes. 2002;51 Suppl 1:S221-226.

46. Mari A, Schmitz O, Gastaldelli A, Oestergaard T, Nyholm B, Ferrannini E. Meal and oral glucose tests for assessment of beta -cell function: modeling analysis in normal subjects. Am J Physiol Endocrinol Metab. 2002;283(6):E1159-1166. 
47. Biggelaar L, Eussen SJ, Sep SJ, et al. Associations of Dietary Glucose, Fructose, and Sucrose with betaCell Function, Insulin Sensitivity, and Type 2 Diabetes in the Maastricht Study. Nutrients. 2017;9(4).

48. Chiossone L, Chaix J, Fuseri N, Roth C, Vivier E, Walzer T. Maturation of mouse NK cells is a 4-stage developmental program. Blood. 2009;113(22):5488-5496.

49. Fu B, Wang F, Sun R, Ling B, Tian Z, Wei H. CD11b and CD27 reflect distinct population and functional specialization in human natural killer cells. Immunology. 2011;133(3):350-359.

50. Ross GD, Vetvicka V. CR3 (CD11b, CD18): a phagocyte and NK cell membrane receptor with multiple ligand specificities and functions. Clin Exp Immunol. 1993;92(2):181-184.

51. van Bussel BC, Henry RM, Schalkwijk CG, Dekker JM, Nijpels G, Stehouwer CD. Low-grade inflammation, but not endothelial dysfunction, is associated with greater carotid stiffness in the elderly: the Hoorn Study. J Hypertens. 2012;30(4):744-752.

52. Yudkin JS, Stehouwer CD, Emeis JJ, Coppack SW. C-reactive protein in healthy subjects: associations with obesity, insulin resistance, and endothelial dysfunction: a potential role for cytokines originating from adipose tissue? Arterioscler Thromb Vasc Biol. 1999;19(4):972-978.

53. van Bussel BC, Henry RM, Ferreira I, et al. A healthy diet is associated with less endothelial dysfunction and less low-grade inflammation over a 7-year period in adults at risk of cardiovascular disease. J Nutr. 2015;145(3):532-540.

54. Bartko JJ. On various intraclass correlation reliability coefficients. Psychol Bull. 1976;83(5):762.

55. Giraudeau B. Negative values of the intraclass correlation coefficient are not theoretically possible. J Clin Epidemiol. 1996;49(10):1205.

56. Maurovich-Horvat P, Massaro J, Fox CS, Moselewski F, O'Donnell CJ, Hoffmann U. Comparison of anthropometric, area- and volume-based assessment of abdominal subcutaneous and visceral adipose tissue volumes using multi-detector computed tomography. Int J Obes (Lond). 2007;31(3): 500-506.

57. Fox CS, Massaro JM, Hoffmann U, et al. Abdominal visceral and subcutaneous adipose tissue compartments: association with metabolic risk factors in the Framingham Heart Study. Circulation. 2007;116(1):39-48.

58. Hui SCN, So HK, Chan DFY, et al. Validation of water-fat MRI and proton MRS in assessment of hepatic fat and the heterogeneous distribution of hepatic fat and iron in subjects with non-alcoholic fatty liver disease. Eur J Radiol. 2018;107:7-13.

59. Cracowski JL, Minson CT, Salvat-Melis M, Halliwill JR. Methodological issues in the assessment of skin microvascular endothelial function in humans. Trends Pharmacol Sci. 2006;27(9):503-508.

60. Schabauer AM, Rooke TW. Cutaneous laser Doppler flowmetry: applications and findings. Mayo Clin Proc. 1994;69(6):564-574.

61. Rovas $\mathrm{A}$, Lukasz $\mathrm{AH}$, Vink $\mathrm{H}$, et al. Bedside analysis of the sublingual microvascular glycocalyx in the emergency room and intensive care unit - the GlycoNurse study. Scand J Trauma Resusc Emerg Med. 2018;26(1):16.

62. Pala S, Kahveci G, Akcakoyun M, et al. Reliability of ultrasonography in detecting flow mediated dilation. Int J Cardiovasc Imaging. 2009;25(7):705-711.

63. Ghiadoni L, Faita F, Salvetti M, et al. Assessment of flow-mediated dilation reproducibility: a nationwide multicenter study. J Hypertens. 2012;30(7):1399-1405.

64. Harris RA, Padilla J, Rink LD, Wallace JP. Variability of flow-mediated dilation measurements with repetitive reactive hyperemia. Vasc Med. 2006;11(1):1-6.

65. West SG, Wagner P, Schoemer SL, et al. Biological correlates of day-to-day variation in flow-mediated dilation in individuals with Type 2 diabetes: a study of test-retest reliability. Diabetologia. 2004;47(9):1625-1631.

66. Hijmering ML, Stroes ES, Pasterkamp G, Sierevogel M, Banga JD, Rabelink TJ. Variability of flow mediated dilation: consequences for clinical application. Atherosclerosis. 2001;157(2):369-373.

67. Onkelinx S, Cornelissen V, Goetschalckx K, Thomaes T, Verhamme P, Vanhees L. Reproducibility of different methods to measure the endothelial function. Vasc Med. 2012;17(2):79-84.

68. Reisner Y, Lusky R, Shay-EI Y, Schnall R, Herscovici S. Reproducibility of endothelial function and arterial stiffness assessed using finger peripheral arterial tonometry. Paper presented at: European heart journal2008. 
69. Laugesen E, Rossen NB, Hoyem P, et al. Reproducibility of pulse wave analysis and pulse wave velocity in patients with type 2 diabetes. Scand J Clin Lab Invest. 2013;73(5):428-435.

70. Sigrist MK, Chiarelli G, Levin A, Romann A, Weber C. Pulse wave velocity measurements are reproducible in multiple trained observers: a short report. Nephron Clin Pract. 2010;116(1):c60-64.

71. Kanters SD, Elgersma OE, Banga JD, van Leeuwen MS, Algra A. Reproducibility of measurements of intima-media thickness and distensibility in the common carotid artery. Eur J Vasc Endovasc Surg. 1998;16(1):28-35.

72. Arnett DK, Chambless LE, Kim H, Evans GW, Riley W. Variability in ultrasonic measurements of arterial stiffness in the Atherosclerosis Risk in Communities study. Ultrasound Med Biol. 1999;25(2):175-180.

73. Godia EC, Madhok R, Pittman J, et al. Carotid artery distensibility: a reliability study. J Ultrasound Med. 2007;26(9):1157-1165.

74. Engelen L, Ferreira I, Stehouwer CD, Boutouyrie P, Laurent S. Reference intervals for common carotid intima-media thickness measured with echotracking: relation with risk factors. Eur Heart J. 2013;34(30):2368-2380.

75. Streiner DL, Norman GR, Cairney J. Health measurement scales: a practical guide to their development and use. Oxford University Press, USA; 2015. 


\section{Supplementary material}

Table S3.1 - Study population characteristics CEUS Reproducibility Study.

Age $[\mathrm{Yr}]$

Sex $[M / F]$

yWeight $[\mathrm{kg}]$

BMI $\left[\mathrm{kg} / \mathrm{m}^{2}\right]$

Office Systolic Blood Pressure [mmHg]

Office Diastolic Blood Pressure [mmHg]

Maximum handgrip power [kg]

Data presented as median [IQR] or count.

$26.4[20.3-29.4]$

$3 / 5$

68.3 [54.4 - 78.9]

20.9 [20.3 - 24.0]

118 [113 - 128]

$70[66-78]$

$21[17-31]$ 


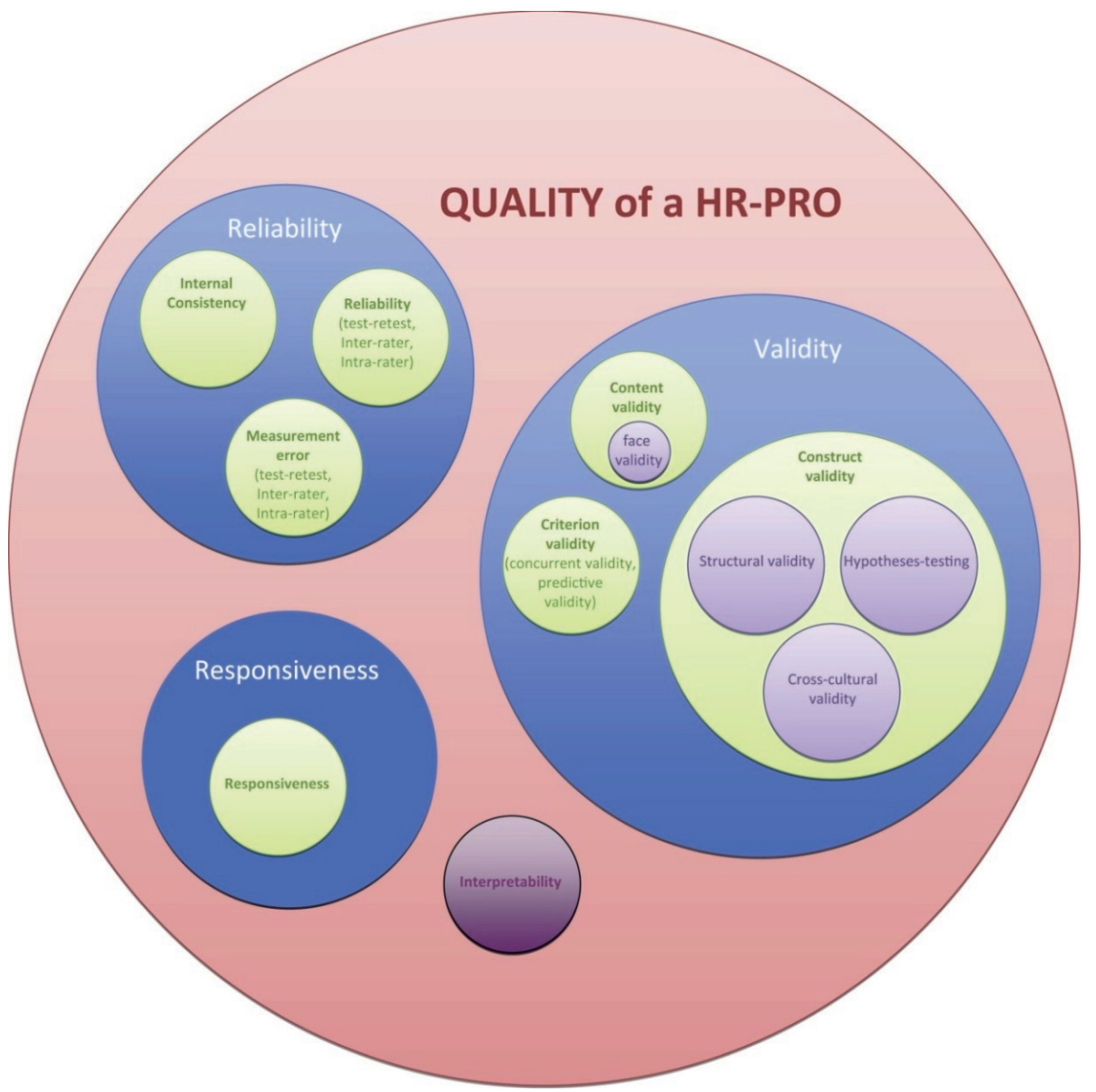

Figure S3.1 - Domains of health measurement instruments and relationships of measurement properties according to the COSMIN taxonomy. The domain reliability refers to the extent to which scores for individuals who have not changed are the same for repeated measurement under several conditions. The domain reliability consists of three measurement properties. Internal consistency is specific to patient reported outcomes and is not applicable to the variables we investigated in this paper. The measurement property reliability refers to the proportion of the total variance in the measurements which is due to the "true" differences between individuals, as described in the classical test theory. ${ }^{2,75}$ Measurement error refers to the systematic and random error of a patients' score that is not attributed to true changes in the construct to be measured. ${ }^{2}$ Both reliability and measurement error can be further subdivided in intraobserver (repeated measurements by one observer), inter-observer (repeated measurements on the same occasion by different observers), or over time (test-retest with relevant amount of time in between). For further explanation of the orther domains, we refer to the original COSMIN statement. ${ }^{2}$ COSMIN, COnsensus-based Standards for the selection of health Measurement INstruments; HR-PRO, health relatedpatient reported outcome. Reproduced from: Mokkink et al. 2010, with permission. ${ }^{2}$ 
A

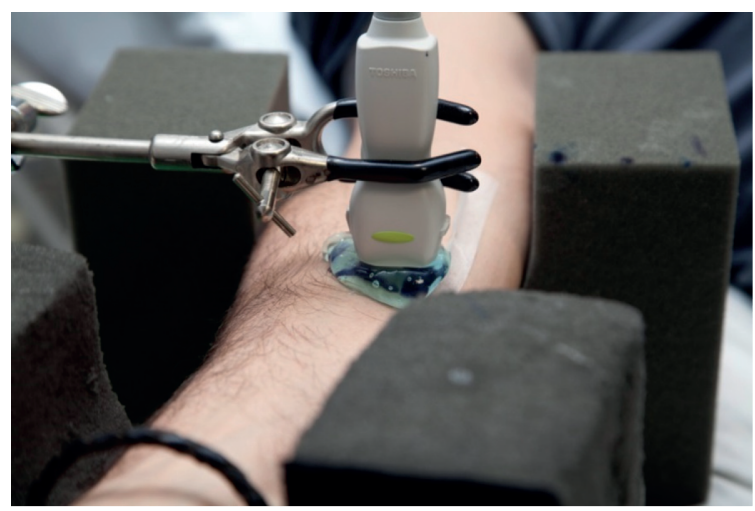

C

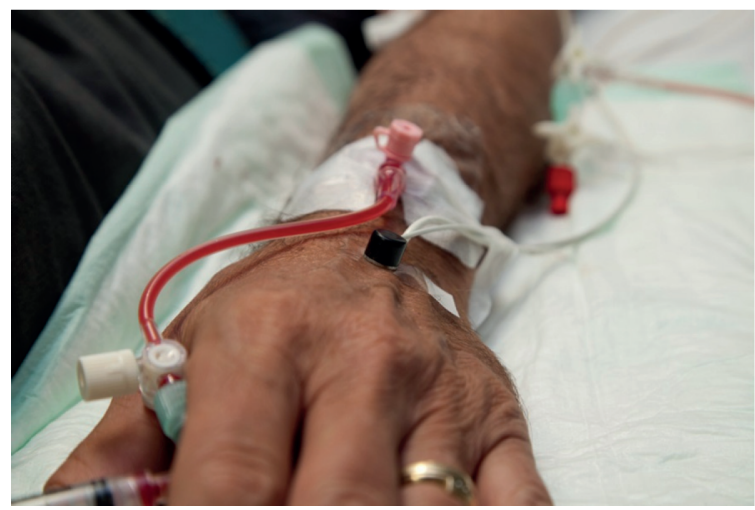

B

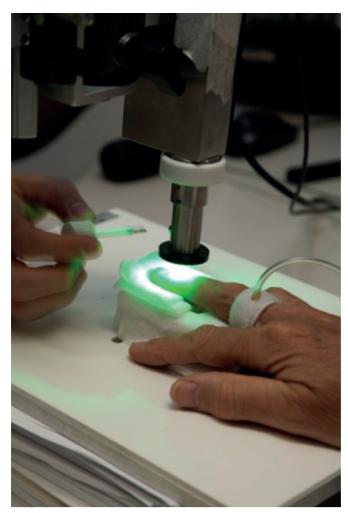

Figure S3.2 - Position of individuals during several microvascular measurements. A. Position of the transducer to image the right forearm flexor muscles by means of contrast enhanced ultrasound. B. Capillary videomicroscopy of the right middle finger. C. Flowmotion measurement (laser Doppler flowmetry) located at the left hand, just distal of the wrist. Photography by Dr. J.L.J.M. Scheijen, with permission. 

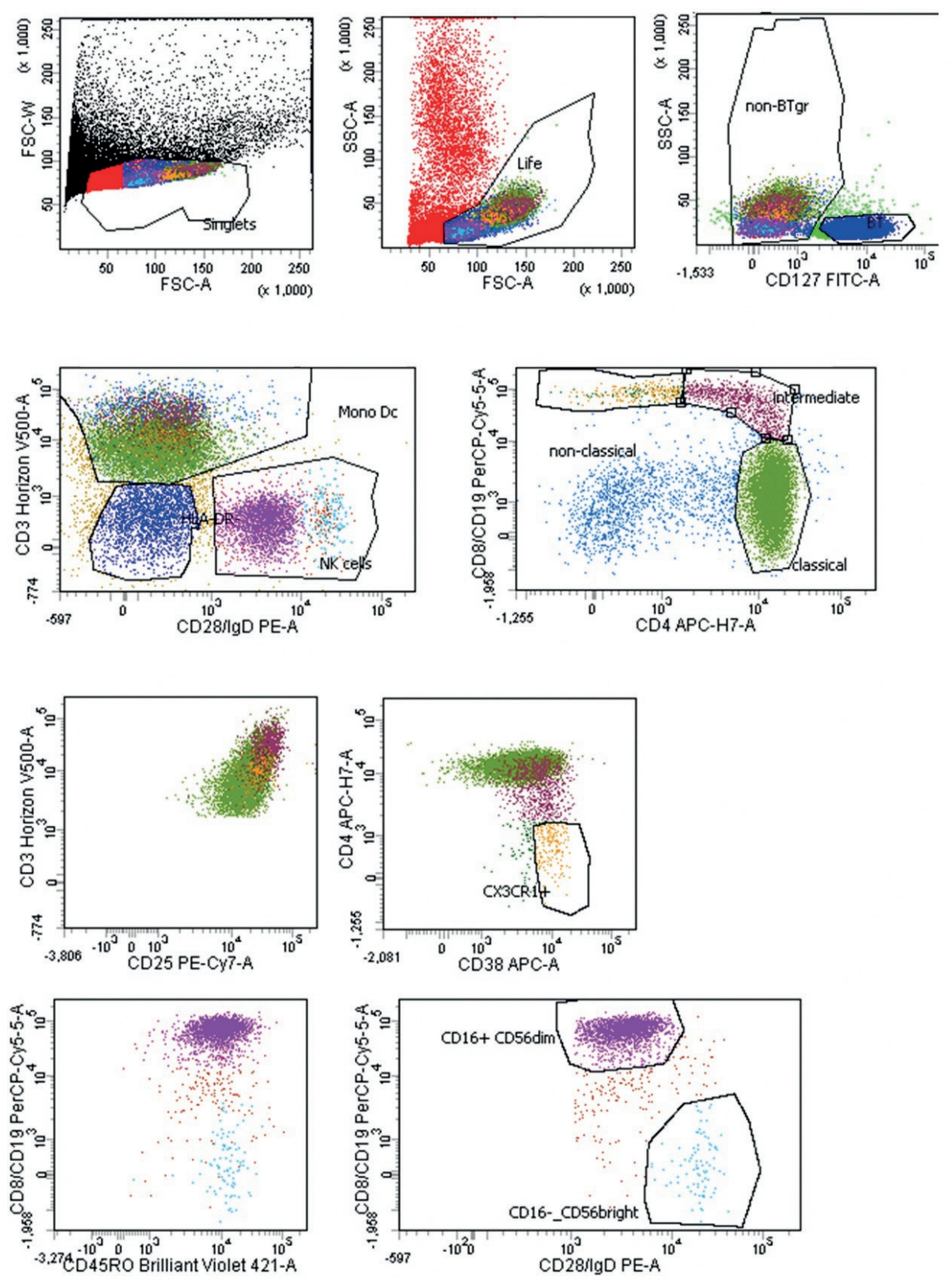

Figure S3.3 - Gating strategy for flow cytometry in the weight loss intervention trial, which is described into more detail in the main text. 




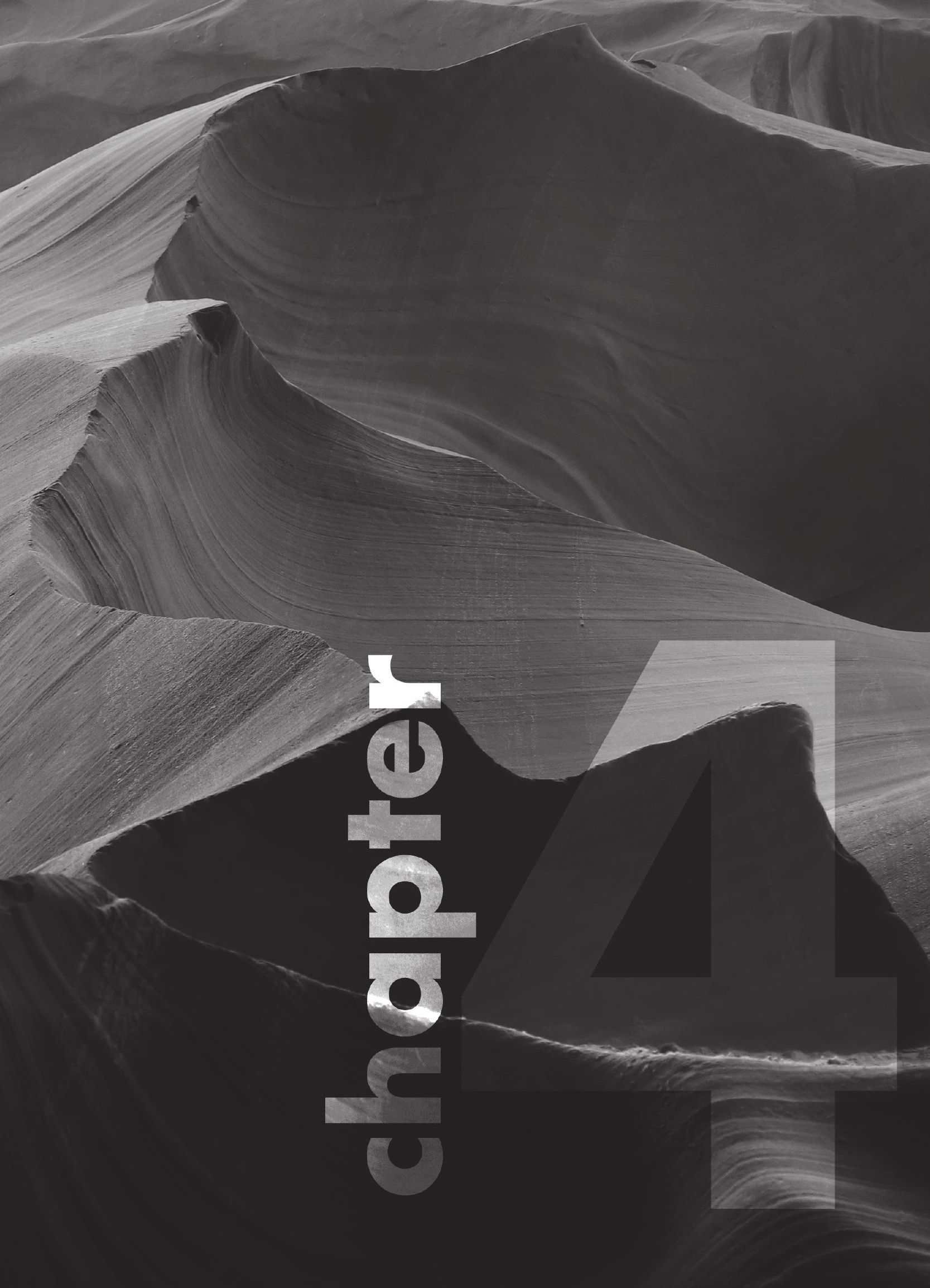




\section{Chapter 4}

\section{Independent tissue contributors to obesity-associated insulin resistance}

Yvo H.A.M. Kusters, Casper G. Schalkwijk, Alfons J.H.M. Houben, M. Eline Kooi, Lucas Lindeboom, Jos op 't Roodt, Peter J. Joris, Jogchum Plat, Ronald P. Mensink, Eugene J. Barrett, Coen D.A. Stehouwer J Clin Invest Insight. 2017 Jul 6;2(13) 


\begin{abstract}

\section{Background}

Induction of insulin resistance is a key pathway through which obesity increases risk of type 2 diabetes, hypertension, dyslipidemia, and cardiovascular events. Although the detrimental effects of obesity on insulin sensitivity are incompletely understood, accumulation of visceral, subcutaneous and liver fat, and impairment of insulininduced muscle microvascular recruitment (MVR) may be involved. As these phenotypic changes often coincide in obesity, we aimed to unravel whether they independently contribute to insulin resistance and thus constitute separate targets for intervention.
\end{abstract}

\title{
Methods
}

We measured visceral (VAT) and subcutaneous adipose tissue (SAT) volumes and intrahepatic lipid content (IHL) by MRI, and whole body glucose disposal (WBGD) and MVR (using contrast-enhanced ultrasound) responses to a euglycemic insulin clamp in lean $(n=25)$ and abdominally obese men $(n=52)$. Abdominally obese men were randomized to dietary weight loss intervention or habitual diet.

\section{Results}

Obesity-associated increases in VAT, SAT and IHL, along with the decrease in MVR, contributed independently to insulin resistance. Moreover, a dietary weight loss intervention reduced insulin resistance and mediation analyses showed that decreased IHL and insulin-induced MVR, but not decreased VAT or SAT volumes, independently contributed to improved insulin resistance seen with weight loss.

\section{Conclusion}

Quantifying the mutually independent contributions of visceral and subcutaneous adipose tissue, intrahepatic lipid, and insulin-induced muscle microvascular recruitment reveals distinct targets for treating obesity-associated insulin resistance. 


\section{Introduction}

Insulin resistance, i.e. reduced insulin-induced whole body glucose disposal (WBGD), is common in obesity and plays a key role in obesity-associated type 2 diabetes, hypertension, dyslipidemia and cardiovascular disease. ${ }^{1,2}$ Several tissue-specific pathways, including adipose tissue, liver and muscle, have been proposed to link obesity to insulin resistance; however, whether these pathways act independently of each other has not been elucidated.

Excess visceral adipose tissue (VAT) in obesity causes insulin resistance through increased lipolysis, dysregulation of adipokine release, and induction of low-grade inflammation. ${ }^{2-4}$ However, additional mechanisms that explain insulin resistance in obesity have been postulated, notably increased subcutaneous adipose tissue (SAT), ${ }^{2}$ increased intrahepatic lipid (IHL) accumulation, ${ }^{5}$ and impairment of insulin-induced microvascular recruitment (MVR) in muscle. ${ }^{6}$

SAT's effect on insulin resistance is controversial; the increased lipolysis and adipokine dysregulation in SAT is considered to contribute to insulin resistance, ${ }^{2}$ yet a fat distribution pattern with high SAT and low VAT volumes is considered a metabolically healthy phenotype. ${ }^{7}$ The involvement of IHL on the other hand is also debated, as IHL has been postulated as both a cause and consequence of insulin resistance. Lipotoxicity of IHL rich in saturated fatty acids, diacylglycerols and ceramides; secretion of inflammatory cytokines; and increased triglyceride synthesis by the fatty liver are suggestive of the former, ${ }^{8-10}$ whereas adipocyte insulin resistance with increased NEFA fluxes towards the liver suggest the latter. ${ }^{11,12}$ In turn, skeletal muscle's vasculature can contribute to insulin resistance when physiological insulininduced, nitric oxide-mediated MVR is impaired. ${ }^{13}$

A key question is whether VAT, SAT, IHL, and MVR act independently to increase insulin resistance. Mutual independence, in contrast to mutual dependence, implies that distinct mechanisms can be targeted to improve insulin resistance.

We addressed this issue in two ways. First, we determined the independent contributions of VAT, SAT, IHL, and MVR to insulin resistance in 25 lean and 52 abdominally obese men (flow diagram in Figure 4.1). Next, we assessed their contributions to weight loss-induced improvement of insulin resistance by randomizing the abdominally obese men to either an 8-week dietary weight loss program or habitual diet (control group). 


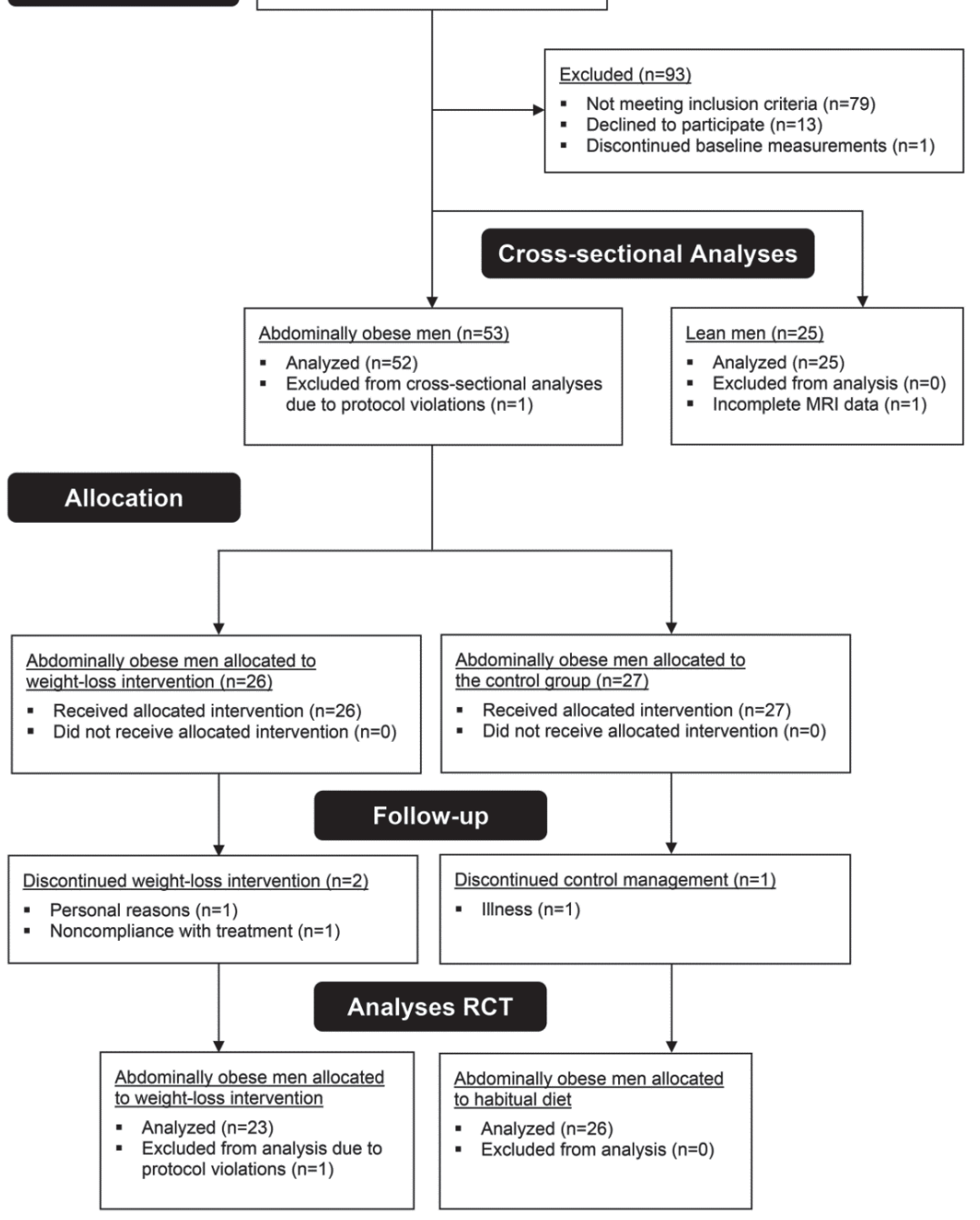

Figure 4.1 - A flow diagram of participants throughout the study. After screening, 25 lean men were eligible for participation and all completed the study. Baseline measurements were performed in 54 abdominally obese men; one dropped out for personal reasons before completing the measurements. For the crosssectional analyses, all lean men and 52 abdominally obese men were included, one was excluded from analyses due to protocol violations (use of anti-hypertensive medication during participation). One lean individual did not complete the MR imaging due to claustrophobia. A total of 53 abdominally obese men were randomized to weight-loss intervention or weight-stable control groups. One individual discontinued control treatment because of illness, one dropped out because of noncompliance with the program to lose weight and another individual dropped out for personal reasons after assignment to the weight-loss treatment. One individual completed the trial but was excluded from all analyses because of protocol violations. In agreement with the protocol, the study was stopped after 50 completed follow-up measurements. Few harms were observed during this study; one individual had an incidental finding on MRI which required further analysis and another individual developed thrombophlebitis after the follow-up measurements. 


\section{Methods}

\section{Study population}

In this randomized controlled trial with blinded analyses, 53 abdominally obese and 25 lean men were recruited by advertisements and enrolled at the Maastricht University Medical Center in Maastricht, The Netherlands, from August, 2012 to May, 2014. Participants were aged 18 - 65 years, non-smokers, nondiabetic, free of CVD, had a waist circumference below $94 \mathrm{~cm}$ (lean) or between $102-110 \mathrm{~cm}$ (abdominally obese), and a stable body weight for at least 3 months. Men were excluded when fasting plasma glucose was $>7.0 \mathrm{mmol} / \mathrm{l}$, when $\mathrm{HbA}_{1 \mathrm{c}}$ was $>6.5 \%$, when serum total cholesterol was $>8.0 \mathrm{mmol} / \mathrm{l}$, when serum triacylglycerol was $>4.5 \mathrm{mmol} / \mathrm{l}$, when they had a contra-indication for MR imaging, and/or when they used medication affecting blood pressure, serum lipid or glucose metabolism.

\section{Study design}

Abdominally obese men were randomly assigned in a 1:1 ratio to either an 8-week weight loss program or maintaining their habitual diet for 8 weeks. Abdominally obese men were studied at baseline and after completion of their 8-week program. Lean men were studied at baseline only and thus not randomized. Randomization was performed by an independent investigator using block randomization with variable block sizes and stratifying for ages below and above 50 years. The allocation was revealed by the independent investigator to the participant and research team upon completion of all baseline measurements. Study data were blinded to the assessor prior to analysis and de-blinded upon completion of all analyses by an independent investigator.

The weight loss program consisted of 4-5 weeks of a very low calorie diet providing 2.1 MJ/day (Modifast, Novartis Nutrition, Breda, The Netherlands), 1 - 2 weeks of energy-restricted diet providing 4.2 MJ/day, a weight stable phase of 2 weeks to maintain the newly achieved weight, and weekly dietary counseling. During their 8-week habitual diet, the control group was monitored as well in order to avert fluctuations in weight. Both groups were instructed not to alter their exercise pattern throughout the study. Three individuals dropped out and one individual was excluded from analyses due to protocol violations (Figure 4.1). A sample size of 25 individuals per group was calculated to detect a mean difference in MVR, the least precise of the techniques used, of $20 \%$ with a power (1- $\beta$ ) of 0.80 with $\alpha=0.95$. In agreement with our protocol, the study was stopped after 50 completed follow-up measurements. 
Measurements were conducted in a temperature-controlled room $\left(\mathrm{T}=24^{\circ} \mathrm{C} \pm 0.5^{\circ} \mathrm{C}\right)$ after a 12-hour overnight fast with the individuals in the supine position. Individuals were instructed to refrain from alcohol and meals rich in lipids for a period of 24 hours prior to each study day, and strenuous physical exercise for a period of 48 hours prior to each study day. After insertion of two intravenous catheters and a 30-minute acclimatization period, baseline vascular measurements were performed.

\section{Hyperinsulinemic euglycemic clamp}

Metabolic insulin sensitivity was assessed by a $1 \mathrm{mU} / \mathrm{kg} / \mathrm{min}$ euglycemic insulin clamp as described previously. ${ }^{29}$ Briefly, insulin (Novorapid, Novo Nordisk, Bagsvaerd, Denmark) was infused in a primed continuous manner for 180 minutes. Meanwhile, isoglycemia was maintained with a variable rate $20 \%$ glucose infusion. Metabolic insulin sensitivity was estimated from the steady-state glucose infusion rate (90 - 150 min of the clamp).

\section{Contrast enhanced ultrasound}

Microvascular blood volume of forearm skeletal muscle was measured with a Toshiba Aplio XG ultrasound system (Toshiba, Otawara, Japan) during continuous infusion of sulfur hexafluoride gas-filled microbubbles (SonoVue, Bracco diagnostics, Amsterdam, The Netherlands). After steady state microbubble concentration was achieved (3 minutes), five real-time replenishment curves of $30^{\prime \prime}$ were obtained after microbubble disruption by a high mechanical index ultrasound pulse. These replenishment curves were stored and analyzed offline in a blinded fashion upon completion of the trial using the $\mathrm{CHI}-\mathrm{Q}$ software (Toshiba, Otawara, Japan). The replenishment curves were fitted to the exponential function $y=A\left(1-e^{-\beta t}\right)$ and averaged as described before ${ }^{26}$ providing reliable estimations of MVR $\left(I_{\text {intra-observer }}=0.86 ; p<0.001\right)$. MVR was calculated as the relative increase in microvascular blood volume induced by the insulin clamp.

\section{Visceral and subcutaneous fat volumes, and intrahepatic lipid}

Information on visceral and subcutaneous adipose tissue volumes was obtained through two-dimensional (2D) T1-weighted turbo spin echo (TSE) imaging on a 3.0T Philips Achieva MRI scanner with a dedicated sixteen-element torso coil (XL Torso coil, Philips Healthcare, Best, The Netherlands). Nine $5 \mathrm{~mm}$ thick transverse slices with $10 \mathrm{~mm}$ gaps centered at the top of the $\mathrm{L} 4$ vertebral body were acquired using the following scan parameters: repetition time $(T R)=526 \mathrm{~ms}$, echo time $(T E)=10 \mathrm{~ms}$, turbo spin echo factor $=4$, number of signal averages $($ NSA) $=1$, field of view $(\mathrm{FOV})=400 \times 322 \mathrm{~mm}$, acquired matrix size $=308 \times 164$, acquired in-plane voxel size $=1.3 \times 1.96 \mathrm{~mm}$, reconstructed matrix size $=512 \times 412$, and a reconstructed voxel 
size of $0.78 \times 0.78 \mathrm{~mm}$. Images were analyzed offline after completion of the trial with dedicated software (Hippo Fat, IFC CNR, Pisa, Italy) to provide subcutaneous and visceral fat volumes.

The same MRI scanner and coil were used to assess intrahepatic lipid content through mDixon imaging. Two $6 \mathrm{~mm}$ thick transverse slices through the liver were acquired using a 2D three-point T1-fast field echo (T1-FFE) mDixon pulse sequence, to correct for $\mathrm{T}^{*}$ relaxation. The scan parameters were as follows: $\mathrm{TR}=150 \mathrm{~ms}$, TE1 $=0.85 \mathrm{~ms}$, $\triangle T E=0.7 \mathrm{~ms}$, flip angle $(\mathrm{FA})=10^{\circ}, \mathrm{NSA}=1, \mathrm{FOV}=375 \times 310 \mathrm{~mm}$, acquired matrix size $=92 \times 77$, acquired in-plane resolution $=4.08 \times 4.02 \mathrm{~mm}$, reconstructed matrix size $=384 \times 320 \mathrm{~mm}$, and a reconstructed voxel size of $0.98 \times 0.97 \mathrm{~mm}$. The intrahepatic fat percentage was calculated in three regions of interest within the liver parenchyma, carefully avoiding blood vessels. The fat content was expressed as the weighted mean fat signal, divided by the sum of the weighted mean water and fat signal. The mDixon sequence was validated against ${ }^{1} \mathrm{H}-\mathrm{MRS}$ in a random subset of participants and yielded comparable results ( $n=45 ; \mathrm{ICC}=0.82 ; \mathrm{p}<0.001$ ). The ${ }^{1} \mathrm{H}$-MRS scan was performed using the same MRI scanner and torso coil and the spectra were obtained from a $30 \times 30 \times 30 \mathrm{~mm}$ voxel placed centrally in the right lobe of the liver by using point-resolved spectroscopy volume selection (PRESS) with the following scan parameters: TR $=4000 \mathrm{~ms}, \mathrm{TE}=32.5 \mathrm{~ms}, 2048$ sample points. A total of 32 spectra with NSA of 2 were acquired. A water signal was acquired as a reference (NSA = $2 \times 8$ ). To keep the TR constant, the subject was instructed to breathe exactly at the 4s-rhythm of the sequence. Shimming was performed by using second-order FASTMAP-based shimming.

\section{Plasma measurements}

Plasma glucose was determined with a YSI2300 glucose analyzer (YSI, Yellow Springs, $\mathrm{OH}, \mathrm{USA}$ ). Samples were analyzed for total cholesterol (CHOD-PAP method; Roche Diagnostics, Mannheim, Germany), HDL cholesterol (precipitation method; Roche Diagnostics, Mannheim, Germany), triacylglycerol with correction for free glycerol (GPO Trinder; Sigma-Aldrich, St. Louis, MO, USA), HbA1c (Bio-Rad, Hercules, CA, USA), and insulin (RIA; Millipore, Billerica, MA, USA).

\section{Statistics}

Data are expressed as means \pm SD or median $\left[25^{\text {th }}-75^{\text {th }}\right.$ percentile]. Two-tailed independent Student's t-tests or Mann-Whitney $U$ tests were used to assess differences between groups at baseline. We used one-factor ANCOVA with the baseline value as a covariate to detect differences between groups over time. Analyses were performed using SPSS version 20. Multiple mediation analyses were 
carried out with the PROGRESS plug-in for SPSS version 2.13 (A.F. Hayes, Ohio State University, $\mathrm{OH}, \mathrm{USA})$. In the cross-sectional mediation model, complete mediation was found. Therefore, the independent variable BMI was omitted from the model to estimate the contributions of each mediator ${ }^{30}$ and Monte Carlo confidence intervals were calculated with $\mathrm{R}$ statistical software (version 3.2.2). For sensitivity analyses we also used multiple mediation analyses with a repeated measures design, which were carried out with the MEMORE plug-in for SPSS. All regression and mediation models were adjusted for the potential confounder age. Two-tailed $p$-values of $<0.05$ were considered statistically significant.

\section{Study approval}

The study was approved by the Maastricht University Medical Center ethics committee, performed in accordance with the Declaration of Helsinki, and registered at clinicaltrials.gov (NCT01675401). All participants gave written informed consent.

\section{Results}

\section{Demographic and metabolic features of the study population}

After a screening procedure, 25 lean and 52 abdominally obese individuals were enrolled in this study (Figure 4.1). Compared with lean men, abdominally obese men had higher BMI, VAT, SAT and IHL, and lower MVR and WBGD during an insulin clamp (Figure 4.2; $p<0.001$ for each). In addition, abdominally obese men had higher baseline HOMA-IR, fasting plasma glucose, and fasting insulin levels compared to lean men (Table 4.1; $p<0.001$ for each). At baseline, abdominally obese individuals randomized to the weight loss program and those randomized to the habitual diet were comparable (Table 4.1).

\section{Contributors to obesity-associated insulin resistance}

We observed that VAT $(r=-0.615 ; p<0.001)$, SAT $(r=-0.564 ; p<0.001)$, IHL $(r=-0.603 ; p<0.001)$, and MVR $(r=0.567 ; p<0.001)$ were each associated with WBGD (Figure 4.3). As expected, VAT, SAT, IHL, and MVR were all associated with one another, which can be inferred from the attenuation in the individual regression coefficients when the age-adjusted associations were additionally adjusted for the other variables (Table 4.2). Yet, a multivariate regression model including VAT, SAT, $I H L$, and MVR as determinants of WBGD shows that each was independently associated with WBGD (Table 4.2). Of note, no statistically significant interaction between VAT and SAT was found $(p=0.223)$. 

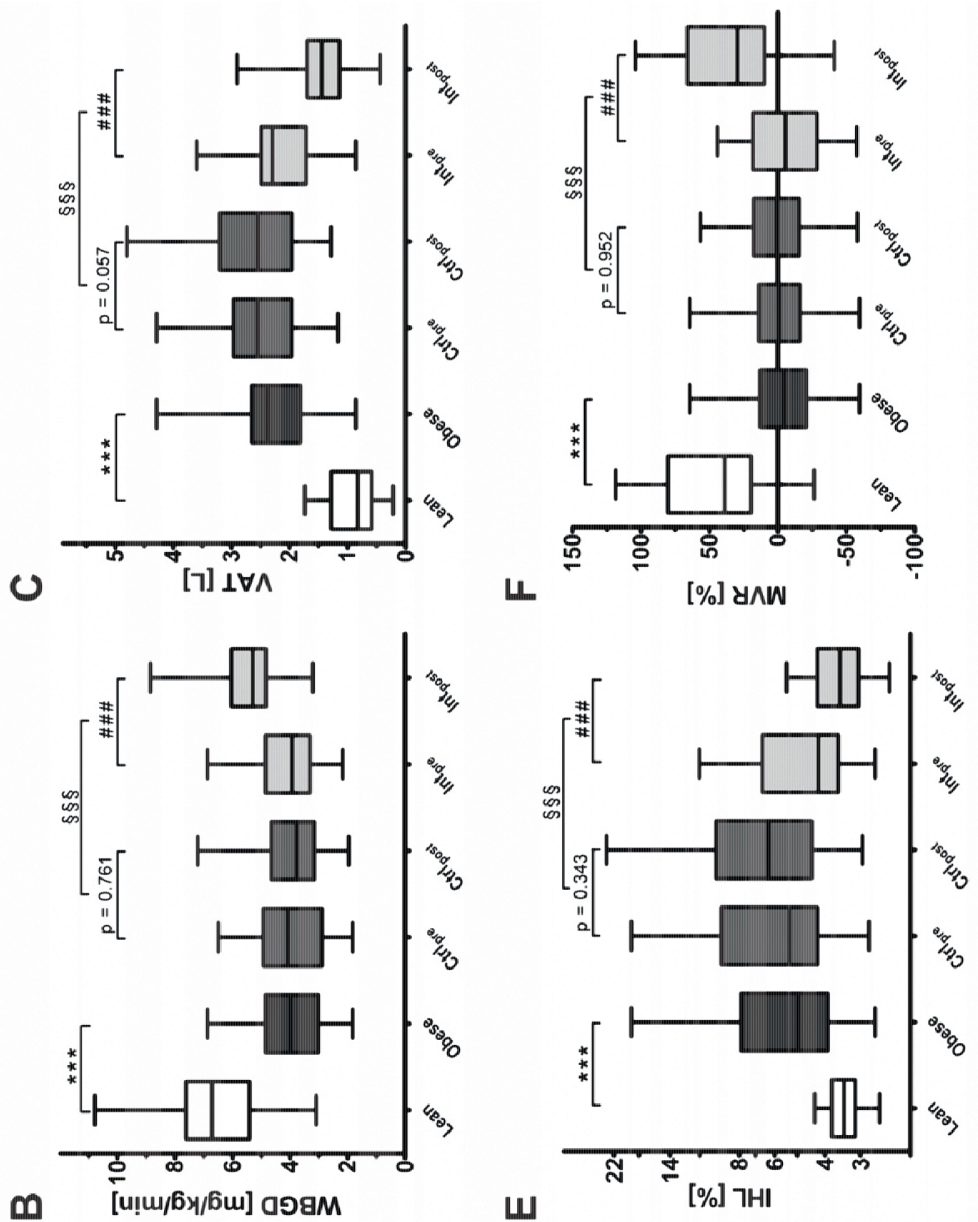

๓ [u!w/6y/6u] वэgM
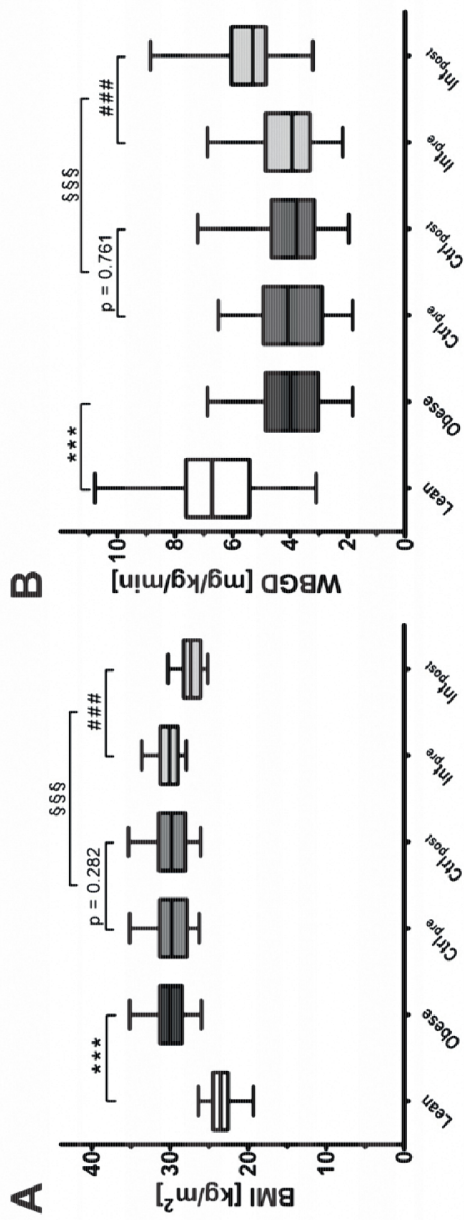

Ш

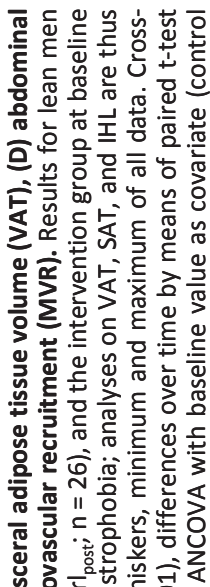

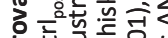

은

谷원

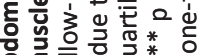

त ह 윤

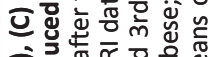

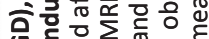

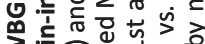

उ宗过培

들 11 过

으ㅇㅡㅡ.

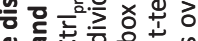

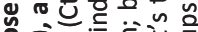

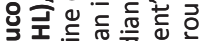

以。

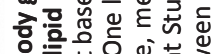

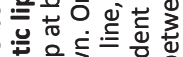

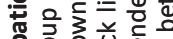

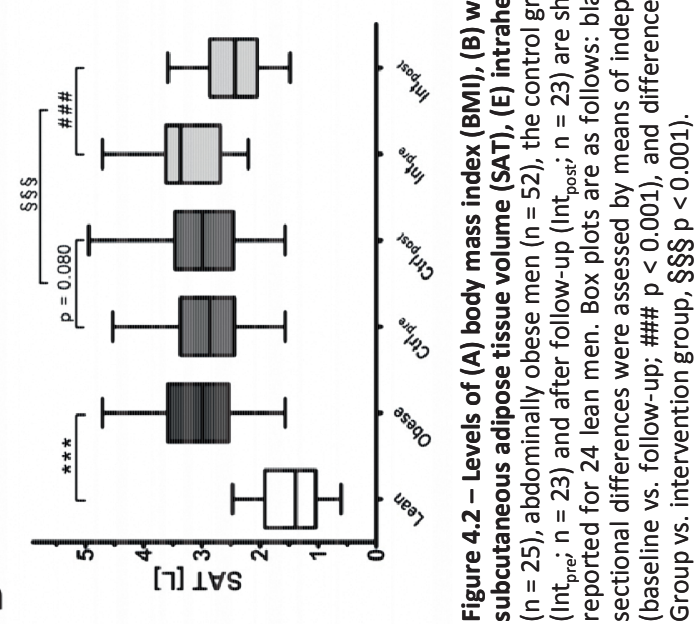


Table 4.1 - Study population characteristics.

\begin{tabular}{|c|c|c|c|c|}
\hline Parameter & $\begin{array}{l}\text { Lean } \\
(n=25)\end{array}$ & $\begin{array}{l}\text { Obese } \\
(n=52)\end{array}$ & $\begin{array}{c}\text { Weight Stable } \\
\text { Baseline } \\
(n=26)\end{array}$ & $\begin{array}{l}\text { Weight Loss } \\
\text { Baseline } \\
(n=23)\end{array}$ \\
\hline Age $[\mathrm{Yr}]$ & $53.7[25.0-61.6]$ & $51.8[45.7-60.7]$ & $52.0[45.4-61.1]$ & $52.4[46.8-61.7]$ \\
\hline Weight [kg] & $74.9 \pm 8.3$ & $96.9 \pm 8.4^{* * *}$ & $95.9 \pm 8.9$ & $98.2 \pm 8.1$ \\
\hline Fat Free Mass [kg] & $60.8 \pm 6.4$ & $69.6 \pm 6.1^{* * *}$ & $69.2 \pm 6.6$ & $69.7 \pm 5.9$ \\
\hline Fat Mass $[\mathrm{kg}]$ & $14.1 \pm 4.8$ & $27.2 \pm 4.6^{* * *}$ & $26.7 \pm 4.6$ & $28.5 \pm 4.2$ \\
\hline $\mathrm{BMI}\left[\mathrm{kg} / \mathrm{m}^{2}\right]$ & $23.3 \pm 1.8$ & $30.1 \pm 2.1^{* * *}$ & $29.9 \pm 2.5$ & $30.2 \pm 1.5$ \\
\hline Waist Circumference [cm] & $84.9 \pm 6.3$ & $106.5 \pm 3.6^{* * *}$ & $106.2 \pm 3.8$ & $106.8 \pm 3.4$ \\
\hline Hip Circumference [cm] & $96.6 \pm 4.3$ & $107.5 \pm 5.2^{* * *}$ & $107.2 \pm 6.0$ & $108.1 \pm 4.4$ \\
\hline Visceral Fat $[\mathrm{L}]^{\mathrm{a}}$ & $0.890 \pm 0.417$ & $2.341 \pm 0.720^{* * *}$ & $2.526 \pm 0.752$ & $2.167 \pm 0.643$ \\
\hline Subcutaneous Fat $[\mathrm{L}]^{\mathrm{a}}$ & $1.452 \pm 0.513$ & $3.089 \pm 0.780^{* * *}$ & $2.915 \pm 0.811$ & $3.226 \pm 0.642$ \\
\hline Intrahepatic Lipid [\%] ${ }^{a}$ & $3.43[3.13-3.78]$ & $4.96[3.90-7.86]^{* * *}$ & $5.34[4.24-9.23]$ & $4.21[3.59-6.63]$ \\
\hline Microvascular Recruitment [\%] & $44.4 \pm 41.3$ & $-3.5 \pm 27.3^{* * *}$ & $0.7 \pm 27.6$ & $-5.0 \pm 26.6$ \\
\hline $\begin{array}{l}\text { Whole Body Glucose Disposal } \\
\text { [mg/kg/min] }\end{array}$ & $6.76 \pm 1.79$ & $4.08 \pm 1.30^{* * *}$ & $4.03 \pm 1.38$ & $4.14 \pm 1.25$ \\
\hline HOMA-IR & $1.65 \pm 0.46$ & $2.84 \pm 1.38^{* * *}$ & $2.90 \pm 1.40$ & $2.64 \pm 1.21$ \\
\hline Fasting Plasma Glucose [mmol/l] & $5.35 \pm 0.29$ & $5.64 \pm 0.48^{* *}$ & $5.75 \pm 0.53$ & $5.49 \pm 0.37$ \\
\hline Fasting Plasma Insulin [mlU/I] & $7.1 \pm 1.9$ & $11.6 \pm 5.4^{* * *}$ & $11.5 \pm 5.6$ & $11.2 \pm 5.0$ \\
\hline Clamped Plasma Insulin [mIU/l] & $71.0 \pm 18.0$ & $100.0 \pm 33.3^{* * *}$ & $91.3 \pm 30.3$ & $112.3 \pm 34.7$ \\
\hline $\mathrm{HbA} 1 \mathrm{c}[\%]$ & $5.18 \pm 0.37$ & $5.30 \pm 0.37$ & $5.33 \pm 0.39$ & $5.24 \pm 0.35$ \\
\hline Total Cholesterol [mmol/l] & $4.55 \pm 0.78$ & $5.56 \pm 0.97^{* * *}$ & $5.63 \pm 0.86$ & $5.60 \pm 1.09$ \\
\hline LDL Cholesterol $[\mathrm{mmol} / \mathrm{l}]^{\mathrm{b}}$ & $2.82 \pm 0.70$ & $3.68 \pm 0.89^{* * *}$ & $3.71 \pm 0.85$ & $3.70 \pm 0.96$ \\
\hline HDL Cholesterol [mmol/l] & $1.26 \pm 0.26$ & $1.11 \pm 0.21^{* *}$ & $1.08 \pm 0.23$ & $1.15 \pm 0.17$ \\
\hline Triacylglycerol [mmol/l] & $0.95[0.67-1.11]$ & $1.66[1.17-2.19]^{* * *}$ & $1.75[1.20-2.38]$ & $1.43[0.94-2.02]$ \\
\hline $\begin{array}{l}\text { 24-h Systolic Blood Pressure } \\
{[\mathrm{mmHg}]}\end{array}$ & $117.5 \pm 8.8$ & $123.4 \pm 8.7^{* *}$ & $125.6 \pm 7.6$ & $120.2 \pm 9.2$ \\
\hline $\begin{array}{l}\text { 24-h Diastolic Blood Pressure } \\
{[\mathrm{mmHg}]}\end{array}$ & $72.5 \pm 9.4$ & $80.4 \pm 7.3^{* * *}$ & $82.0 \pm 6.7$ & $78.3 \pm 7.6$ \\
\hline
\end{tabular}

Data presented as mean \pm SD or median [25-75th percentile]. Baseline differences between obese and lean men were assessed by means of independent Student's T-test or Mann-Whitney $U$ test where appropriate; $* \mathrm{p}<0.05, * * \mathrm{p}<0.01, * * * \mathrm{p}<0.001$ compared to baseline values of the lean men. Analyzed in ${ }^{\mathrm{a}} 24$ lean and 52 obese men; ${ }^{\mathrm{b}} 25$ lean and 50 obese men.

In addition, VAT (20.7\%; 2.4 to $46.6 \%)$, SAT (34.6\%; 7.6 to $53.5 \%)$, IHL (26.5\%; 11.8 to $44.7 \%)$, and MVR (18.3\%; 5.8 to $34.0 \%$ ) were independent mediators of the association between BMI and WBGD (Figure 4.4A). Since the confidence intervals of the four mediators overlap, we cannot conclude that any one mediator is more important than any other.

\section{Effects of weight loss}

In abdominally obese men randomized to the control group, BMI, VAT, SAT, IHL, MVR, and WBGD were unchanged over time (Figure 4.2). Conversely, in abdominally obese men randomized to the weight loss intervention, BMI $\left(-3.04 \pm 0.77 \mathrm{~kg} / \mathrm{m}^{2}\right)$, VAT $(-0.723 \pm 0.371 \mathrm{~L})$, SAT $(-0.782 \pm 0.261 \mathrm{~L})$, and IHL $(-1.69 \pm 2.05 \%)$ decreased, whereas $\operatorname{MVR}(39.5 \pm 49.0 \%)$ and WBGD $(1.31 \pm 1.22 \mathrm{mg} / \mathrm{kg} / \mathrm{min})$ increased (Figure 4.2; 
$p<0.001$ for each vs. baseline; $p<0.001$ for each vs. control group). After weight loss, $\mathrm{IHL}$ and MVR were similar to the mean values in lean men while VAT and SAT remained increased and WBGD remained impaired. In addition, HOMA-IR $(0.06 \pm 0.84)$, fasting plasma glucose $(0.00 \pm 0.28 \mathrm{mmol} / \mathrm{l})$, and fasting insulin levels $(0.2 \pm 3.0 \mathrm{mIU} / \mathrm{l})$ did not change in the control group, whereas clamped insulin levels increased (15.2 $\pm 28.7 \mathrm{mIU} / \mathrm{l} ; \mathrm{p}=0.012$ ). In abdominally obese men randomized to the weight loss intervention on the other hand, HOMA-IR $(-0.97 \pm 0.92 ; p<0.001)$, fasting plasma glucose $(-0.21 \pm 0.33 \mathrm{mmol} / \mathrm{l} ; \mathrm{p}<0.05)$, fasting insulin levels $(-3.8 \pm 3.5 \mathrm{mIU} / \mathrm{l}$; $p<0.001)$, and clamped insulin levels $(-26.1 \pm 35.6 \mathrm{mlU} / \mathrm{l} ; \mathrm{p}=0.002)$ decreased ( $p<0.05$ for each vs. control group).

A

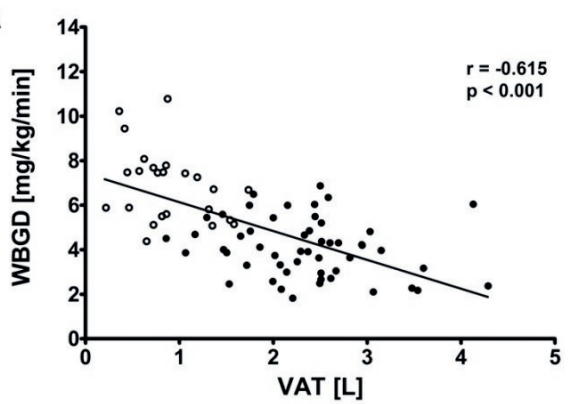

C

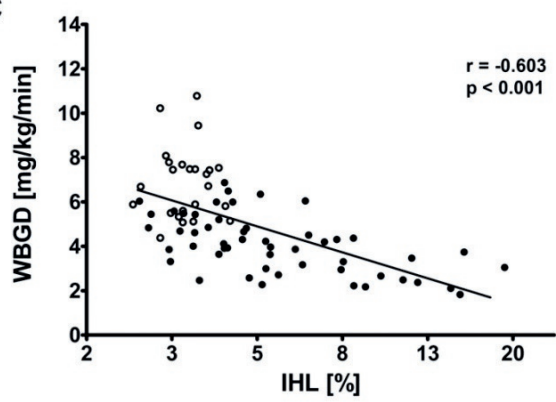

B

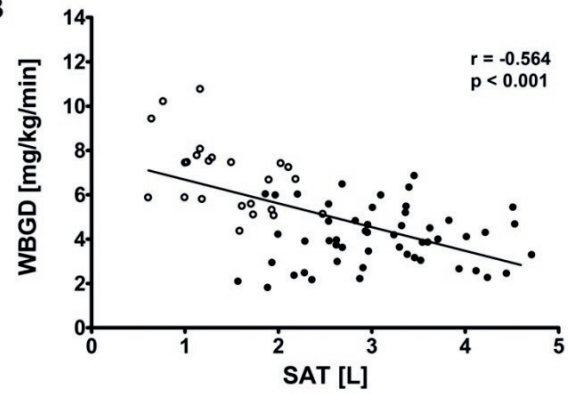

D

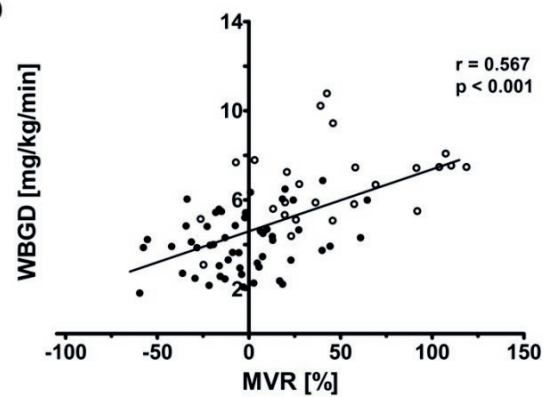

Figure 4.3 - Cross-sectional bivariate associations between abdominal visceral adipose tissue (VAT), subcutaneous adipose tissue (SAT), intrahepatic lipid (IHL) and insulin-induced muscle microvascular recruitment (MVR), and whole body glucose disposal (WBGD). (A) Association between VAT and WBGD in lean $(n=24)$ and abdominally obese men $(n=52)$. (B) Association between SAT and WBGD in lean $(n=24)$ and abdominally obese men $(n=52)$. (C) Association between IHL and WBGD in lean $(n=24)$ and abdominally obese men $(n=52)$. (D) Association between MVR and WBGD in lean $(n=25)$ and abdominally obese men $(n=52)$. Data of lean ( $O$ open circles) and abdominally obese men ( closed circles) are shown. Pearson's correlation coefficients and their p-values are reported for all bivariate associations. 
Table 4.2 - Cross-sectional multivariate regression models with WBGD as dependent variable

\begin{tabular}{lcccc}
\hline & $\beta$ (Age-adjusted) & $p$-value & $\beta$ (Fully Adjusted) & $p$-value \\
\hline VAT [L] & -1.525 & $<0.001$ & -0.509 & 0.032 \\
SAT [L] & -1.070 & $<0.001$ & -0.444 & 0.011 \\
Ln IHL [\%] & -2.539 & $<0.001$ & -1.498 & $<0.001$ \\
MVR [\%] & 0.0279 & $<0.001$ & 0.0128 & 0.003 \\
\hline
\end{tabular}

The associations between abdominal visceral adipose tissue (VAT), abdominal subcutaneous adipose tissue (SAT), log-transformed intrahepatic lipid content ( $\mathrm{Ln} \mathrm{IHL})$ or insulin-induced muscle microvascular recruitment (MVR), and whole body glucose disposal (WBGD) were assessed by means of linear regression. In all models, age-adjusted regression coefficients and regression coefficients adjusted for age and each of the other variables are reported, as well as their respective $p$-values ( $n=76$ for all models).

\section{Association with improved insulin resistance}

Changes in VAT $(r=-0.551 ; p<0.001)$, SAT $(r=-0.528 ; p<0.001)$, IHL $(r=-0.501$; $p<0.001)$, and MVR $(r=0.499 ; p<0.001)$ were associated with changes in WBGD (Figure 4.5). Changes in VAT, SAT, IHL, and MVR were associated with one another, which was reflected by the attenuation in the individual regression coefficients when the age-adjusted associations were additionally adjusted for the other variables (Table 4.3). In a multivariate regression model, changes in IHL and changes in MVR, but not changes in VAT or SAT, were independently associated with changes in WBGD (Table 4.3). Consequently, the association between weight loss intervention and change in WBGD was independently mediated by changes in IHL (26.6\%; 4.4 to $69.6 \%$ ) and changes in MVR (26.3\%; 2.4 to $59.9 \%$ ), but not statistically significantly by changes in VAT or SAT (Figure 4.4B).

Table 4.3 - Multivariate regression models in the RCT with $\triangle \mathrm{WBGD}$ as dependent variable.

\begin{tabular}{lcccc}
\hline & $\beta$ (Age-adjusted) & $\mathrm{p}$-value & $\beta$ (Fully Adjusted) & $\mathrm{p}$-value \\
\hline$\Delta$ VAT [L] & -1.331 & $<0.001$ & -0.516 & 0.190 \\
$\Delta$ SAT [L] & -1.366 & $<0.001$ & -0.245 & 0.567 \\
$\Delta$ IHL [\%] & -0.295 & $<0.001$ & -0.170 & 0.031 \\
$\Delta$ MVR [\%] & 0.0146 & $<0.001$ & 0.0089 & 0.017 \\
\hline
\end{tabular}

The associations between change in abdominal visceral adipose tissue ( $\triangle \mathrm{VAT}$ ), change in abdominal subcutaneous adipose tissue $(\triangle \mathrm{SAT})$, change in intrahepatic lipid content $(\Delta \mathrm{HL})$ or change in insulin-induced muscle microvascular recruitment $(\triangle M V R)$, and change in whole body glucose disposal $(\triangle W B G D)$ were investigated by means of linear regression. In all models, age-adjusted regression coefficients and regression coefficients adjusted for age and all of the other variables are reported, as well as $p$-values for both models $(n=49)$. 
A

$20.7 \%$

$(\beta-0.075(-0.168$ to -0.009$))$

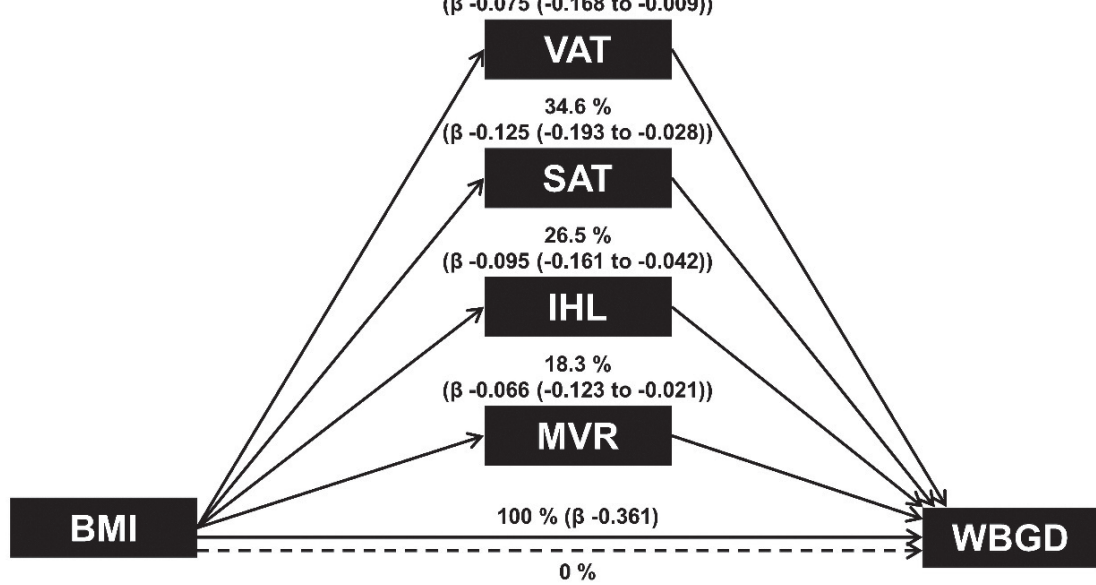

B

$30.0 \%$

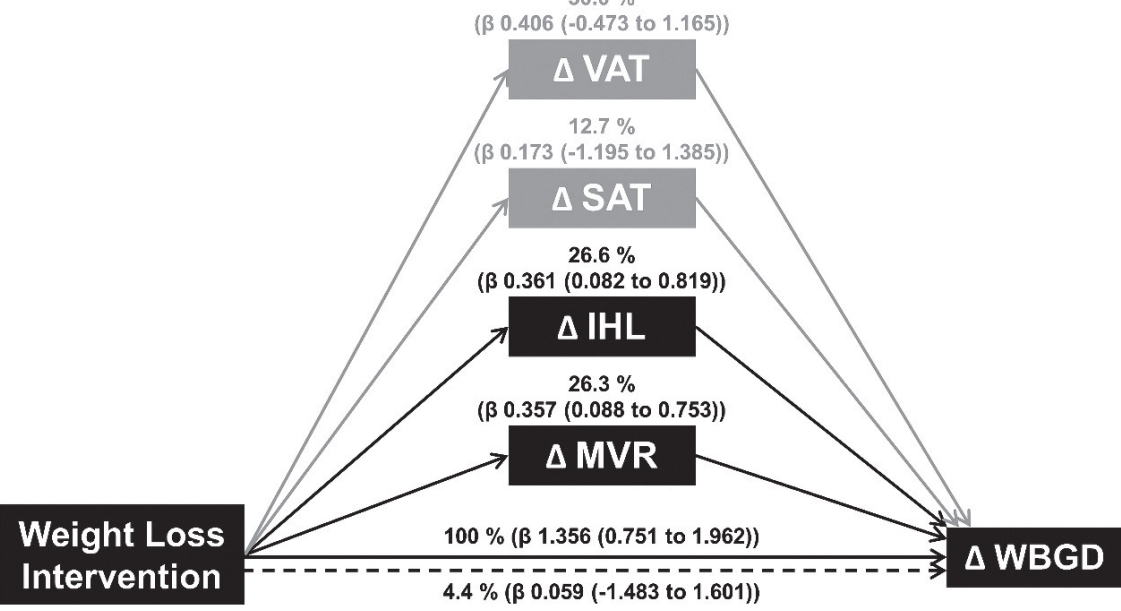

Figure 4.4 - Multiple mediator models. (A) Multiple mediator model with VAT, SAT, Ln IHL, and MVR as statistically significant mediators (percentage of total effect mediated ( $\beta$ of mediated effect $(95 \%-\mathrm{Cl}$ using the Monte Carlo method)) of the association between BMI and WBGD ( $n=76$, age-adjusted). The confidence intervals of the mediators overlap, which implies that no mediator contributes more than the other. (B) Multiple mediator model with $\triangle \mathrm{IHL}$ and $\triangle \mathrm{MVR}$ as statistically significant mediators (percentage of total effect mediated ( $\beta$ of mediated effect (bootstrapped $95 \%-\mathrm{Cl})$ )) of the association between the weight loss intervention and $\triangle W B G D(n=49$, age-adjusted). The variables $\triangle V A T$ and $\triangle S A T$ were not statistically significant mediators of this association. The confidence intervals of the mediators overlap, which implies that no mediator contributes more than the other. 


\section{Sensitivity analyses}

We conducted sensitivity analyses by including the individual left out for protocol violations in the analyses, as well as using waist circumference or total fat mass in our model instead of BMI to reflect obesity, which did not materially change the results (data not shown). Moreover, we used WBGD with glucose space correction and WBGD with adjustment for insulin levels during the clamp as outcome in our models, which did not materially change the results (data not shown). Additionally, we performed multiple mediation analyses in the intervention group only, using a repeated measures design. These analyses confirmed that changes in IHL and changes in MVR were statistically significant mediators, whereas changes in VAT or SAT were not (data not shown).

A

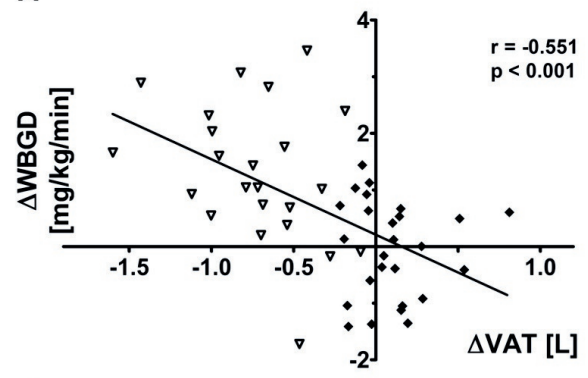

C

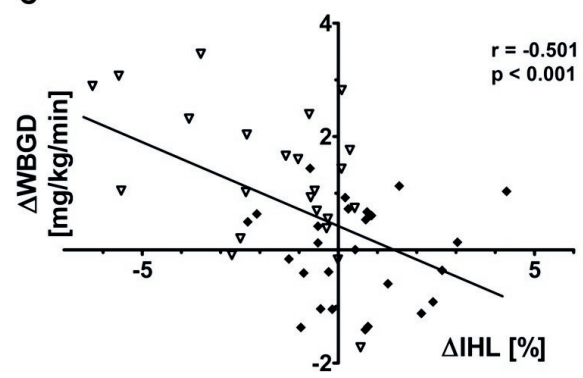

B

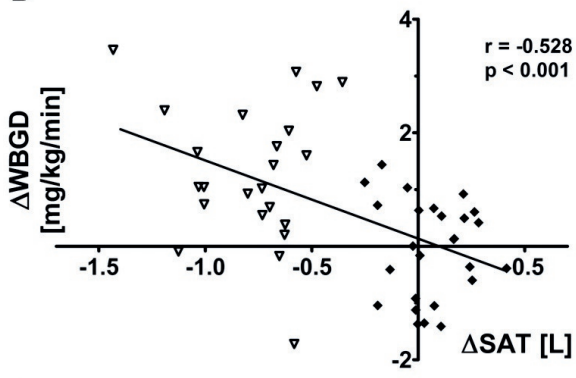

D

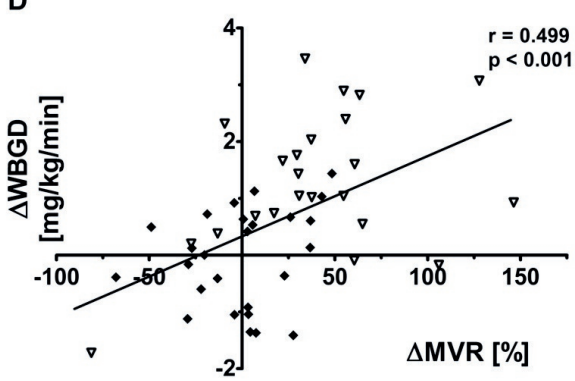

Figure 4.5 - Bivariate associations between change in abdominal visceral adipose tissue volume (DVAT), change in abdominal subcutaneous adipose tissue volume ( $\triangle \mathrm{SAT}$ ), change in intrahepatic lipid content

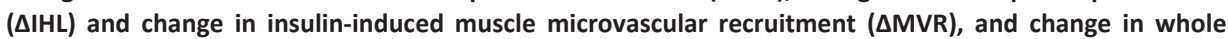
body glucose disposal $(\triangle \mathrm{WBGD} ; \mathrm{n}=49$ ). (A) Association between $\triangle \mathrm{VAT}$ and $\triangle \mathrm{WBGD}$. (B) Association between $\triangle \mathrm{SAT}$ and $\triangle \mathrm{WBGD}$. (C) Association between $\triangle \mathrm{IHL}$ and $\triangle \mathrm{WBGD}$. (D) Association between $\triangle M V R$ and $\triangle W B G D$. Data of abdominally obese controls ( closed diamonds, $n=26$ ) and abdominally obese men undergoing the weight loss intervention ( $\nabla$ open triangles, $n=23$ ) are shown. Pearson's correlation coefficients and their $\mathrm{p}$-values are reported for all bivariate associations. 


\section{Discussion}

In this report we identified VAT, SAT, IHL, and MVR as mutually independent contributors to obesity-associated insulin resistance, which therefore constitute separate targets for intervention. To our knowledge, no studies have simultaneously determined multiple tissue contributors to insulin resistance using state of the art techniques in humans, or assessed their mutual independence, either in the basal steady state or after a minimal weight loss intervention. Studies on the contributions of VAT, SAT, and IHL to insulin resistance in the basal state have been ambiguous. Some argue in favor of mutually independent contributions of VAT and IHL, ${ }^{11,14}$ whereas others find that IHL, not VAT, associates with insulin resistance. ${ }^{5,15}$ Similarly, the SAT contribution to insulin resistance, independent of VAT, is both supported ${ }^{2}$ and disputed. ${ }^{16,17}$ In addition, the contribution of MVR to insulin resistance has never been studied in parallel with VAT, SAT, or IHL. By measuring VAT, SAT, IHL, and MVR simultaneously, our data clarify that, at least in abdominally obese men, these variables contribute to insulin resistance independently and to a similar extent.

By decreasing obesity and insulin resistance with a weight loss intervention, we show that changes in IHL and MVR contribute to improved insulin sensitivity, which supports their tight connection with insulin resistance. Our data are insufficiently precise to exclude that changes in VAT and SAT contribute to improved insulin resistance with weight loss. At least for changes in VAT, involvement seems probable as it is estimated to mediate, albeit not statistically significantly, $\sim 30 \%$ of the change in WBGD, an effect size consistent with its contribution to WBGD in the basal state. As we observed significant bivariate but not multivariate associations between changes in VAT and SAT on the one hand and WBGD on the other, the degree of VAT and SAT reduction achieved here may have been insufficient to improve insulin resistance in an independent way. This observation is in line with studies using interventions such as omentectomy ( 0.3 to $1.0 \mathrm{~kg}$ VAT loss) ${ }^{18,19}$ or liposuction (0.4 to $1.7 \mathrm{~kg}$ SAT loss) $)^{20}$ which have limited effects on insulin resistance.

In addition to establishing relationships between VAT, SAT, IHL, and MVR on the one hand and WBGD on the other, we aimed to provide a deeper understanding of the processes that contribute to obesity-associated insulin resistance. Multiple mediation analyses, as compared to multivariate regression, can provide a superior reflection of the causal chain one tries to investigate. This helps unravel contributions to disease etiology and to develop targeted, effective therapies. ${ }^{21}$ Specifically, the advantage of testing the mediating effect of multiple variables simultaneously is that one learns whether or not mediation is independent of the effect of the other mediators, which offers the possibility to compare competing theories against one another within a single model. ${ }^{22,23}$ In addition, particularly when potential mediators have little random 
error (i.e. the measurement is precise and reflects the underlying mechanism well), multiple mediation analyses can be used to estimate the proportion of the total effect that independent mediators account for. A mediated proportion is essentially the product of two effects; in our analyses, the effect of obesity on each mediator is the first, and the independent effect of each mediator on insulin resistance is the second effect. Such multiple mediator models are therefore the integrated product of two multivariate regression models, which has clear advantages over the conventional approach of analyzing each effect with separate regression analyses. By using these multiple mediation analyses in this report we were able to provide an estimate of the magnitude of the independent contributions of VAT, SAT, IHL, and MVR to obesityassociated insulin resistance.

Of note, the fact that we found complete statistical mediation (i.e., a sufficient set of potential component causes) ${ }^{24}$ in the cross-sectional model provides no information about the existence of other possible contributors that were not included in our statistical model. For example, determinants and consequences of the mediators identified could contribute if included in the analyses. We therefore do not claim to have identified all tissue contributors to obesity-associated insulin resistance.

Our study has some limitations. First, no additional measurements were conducted between baseline and follow-up, so we could not determine a temporal hierarchy of improvements for various contributors to insulin resistance. We emphasize that the aim of this study was not to provide an accurate time course for the exerted effects. Rather we used a weight loss intervention, an instrument to modify insulin resistance, to probe the contributions of changes in VAT, SAT, IHL, and MVR to improvement of insulin resistance. Also, this study was carried out in men only. Nevertheless, studies have shown similar (bivariate) associations between VAT, SAT, IHL, MVR, and insulin resistance in women, as well as improvements in these variables with weight loss. ${ }^{2,25-28}$ Amounts of IHL and VAT are, however, typically greater in men, whereas the amount of SAT is greater in women; ${ }^{2,10}$ this might affect the relative contribution of each mediator in women in the multiple mediator models. Whilst we identified the relative contribution of each mediator in men in this study, their proportional contributions in women remain to be explored.

Here we have established for the first time the mutually independent contributions of VAT, SAT, IHL, and MVR to insulin resistance. This finding implies that, compared to interventions with a single target tissue, interventions aimed at multiple contributors to insulin resistance will yield superior effectiveness. Hence, therapies aimed at multiple therapeutic targets for insulin resistance will be most effective in reducing the global burden of type 2 diabetes and cardiovascular diseases. 


\section{Acknowledgements}

We thank our dieticians Ms. N.A.W.M. Wystyrk and Ms. D.J. Luiten for the dietary counseling of the individuals in this trial, Dr. P.M.G. Niessen (department of Internal Medicine, Maastricht University Medical Center) for her assistance during the execution of this study, and Dr. C.J.A.W. van Gool (department of Epidemiology, Maastricht University) for epidemiological counseling. This work was supported by research grant $\mathrm{CHOO1}$ from the Top Institute Food and Nutrition, a public-private partnership on precompetitive research in food and nutrition. The public partners are responsible for the study design, data collection and analysis, decision to publish, and preparation of the manuscript. 


\section{References}

1. DeFronzo RA, Ferrannini E. Insulin resistance. A multifaceted syndrome responsible for NIDDM, obesity, hypertension, dyslipidemia, and atherosclerotic cardiovascular disease. Diabetes Care. 1991; 14(3):173-194.

2. Preis SR, Massaro JM, Robins SJ, et al. Abdominal subcutaneous and visceral adipose tissue and insulin resistance in the Framingham heart study. Obesity (Silver Spring). 2010;18(11):2191-2198.

3. Marin $\mathrm{P}$, Andersson B, Ottosson $\mathrm{M}$, et al. The morphology and metabolism of intraabdominal adipose tissue in men. Metabolism. 1992;41(11):1242-1248.

4. Kershaw EE, Flier JS. Adipose tissue as an endocrine organ. J Clin Endocrinol Metab. 2004;89(6): 2548-2556.

5. Fabbrini E, Magkos F, Mohammed BS, et al. Intrahepatic fat, not visceral fat, is linked with metabolic complications of obesity. Proc Natl Acad Sci U S A. 2009;106(36):15430-15435.

6. de Jongh RT, Serne EH, IJzerman RG, de Vries G, Stehouwer CD. Impaired microvascular function in obesity: implications for obesity-associated microangiopathy, hypertension, and insulin resistance. Circulation. 2004;109(21):2529-2535.

7. Stefan N, Haring HU, Hu FB, Schulze MB. Metabolically healthy obesity: epidemiology, mechanisms, and clinical implications. Lancet Diabetes Endocrinol. 2013;1(2):152-162.

8. Samuel VT, Shulman GI. Mechanisms for insulin resistance: common threads and missing links. Cell. 2012;148(5):852-871.

9. Byrne CD. Dorothy Hodgkin Lecture 2012: non-alcoholic fatty liver disease, insulin resistance and ectopic fat: a new problem in diabetes management. Diabet Med. 2012;29(9):1098-1107.

10. Yki-Jarvinen $\mathrm{H}$. Non-alcoholic fatty liver disease as a cause and a consequence of metabolic syndrome. Lancet Diabetes Endocrinol. 2014;2(11):901-910.

11. Gaggini M, Morelli M, Buzzigoli E, DeFronzo RA, Bugianesi E, Gastaldelli A. Non-alcoholic fatty liver disease (NAFLD) and its connection with insulin resistance, dyslipidemia, atherosclerosis and coronary heart disease. Nutrients. 2013;5(5):1544-1560.

12. Bugianesi E, Gastaldelli A, Vanni E, et al. Insulin resistance in non-diabetic patients with non-alcoholic fatty liver disease: sites and mechanisms. Diabetologia. 2005;48(4):634-642.

13. Jonk AM, Houben AJ, de Jongh RT, Serne EH, Schaper NC, Stehouwer CD. Microvascular dysfunction in obesity: a potential mechanism in the pathogenesis of obesity-associated insulin resistance and hypertension. Physiology (Bethesda). 2007;22:252-260.

14. Liu J, Fox CS, Hickson D, Bidulescu A, Carr JJ, Taylor HA. Fatty liver, abdominal visceral fat, and cardiometabolic risk factors: the Jackson Heart Study. Arterioscler Thromb Vasc Biol. 2011;31(11): 2715-2722.

15. Magkos F, Fabbrini E, Mohammed BS, Patterson BW, Klein S. Increased whole-body adiposity without a concomitant increase in liver fat is not associated with augmented metabolic dysfunction. Obesity (Silver Spring). 2010;18(8):1510-1515.

16. Ross R, Aru J, Freeman J, Hudson R, Janssen I. Abdominal adiposity and insulin resistance in obese men. Am J Physiol Endocrinol Metab. 2002;282(3):E657-663.

17. Rendell M, Hulthen UL, Tornquist C, Groop L, Mattiasson I. Relationship between abdominal fat compartments and glucose and lipid metabolism in early postmenopausal women. J Clin Endocrinol Metab. 2001;86(2):744-749.

18. Lima MM, Pareja JC, Alegre SM, et al. Visceral fat resection in humans: effect on insulin sensitivity, beta-cell function, adipokines, and inflammatory markers. Obesity (Silver Spring). 2013;21(3): E182-189.

19. Fabbrini E, Tamboli RA, Magkos F, et al. Surgical removal of omental fat does not improve insulin sensitivity and cardiovascular risk factors in obese adults. Gastroenterology. 2010;139(2):448-455.

20. Klein S, Fontana L, Young VL, et al. Absence of an effect of liposuction on insulin action and risk factors for coronary heart disease. N Engl J Med. 2004;350(25):2549-2557.

21. Preacher KJ, Hayes AF. SPSS and SAS procedures for estimating indirect effects in simple mediation models. Behav Res Methods Instrum Comput. 2004;36(4):717-731. 
22. Kenny DA, Kashy DA, Bolger N. Data analysis in social psychology. In: Gilbert D, Fiske S, Lindzey G, eds. The handbook of social psychology. Vol 1. 4 ed. Boston: McGraw-Hill; 1998:233-265.

23. Preacher KJ, Hayes AF. Asymptotic and resampling strategies for assessing and comparing indirect effects in multiple mediator models. Behav Res Methods. 2008;40(3):879-891.

24. Rothman KJ. Causes. Am J Epidemiol. 1976;104(6):587-592.

25. Pourhassan M, Bosy-Westphal A, Schautz B, Braun W, Gluer CC, Muller MJ. Impact of body composition during weight change on resting energy expenditure and homeostasis model assessment index in overweight nonsmoking adults. Am J Clin Nutr. 2014;99(4):779-791.

26. Clerk LH, Vincent MA, Jahn LA, Liu Z, Lindner JR, Barrett EJ. Obesity blunts insulin-mediated microvascular recruitment in human forearm muscle. Diabetes. 2006;55(5):1436-1442.

27. Kotronen A, Johansson LE, Johansson LM, et al. A common variant in PNPLA3, which encodes adiponutrin, is associated with liver fat content in humans. Diabetologia. 2009;52(6):1056-1060.

28. Petersen KF, Dufour S, Befroy D, Lehrke M, Hendler RE, Shulman GI. Reversal of nonalcoholic hepatic steatosis, hepatic insulin resistance, and hyperglycemia by moderate weight reduction in patients with type 2 diabetes. Diabetes. 2005;54(3):603-608.

29. DeFronzo RA, Tobin JD, Andres R. Glucose clamp technique: a method for quantifying insulin secretion and resistance. Am J Physiol. 1979;237(3):E214-223.

30. Shrout PE, Bolger N. Mediation in experimental and nonexperimental studies: new procedures and recommendations. Psychol Methods. 2002;7(4):422-445. 



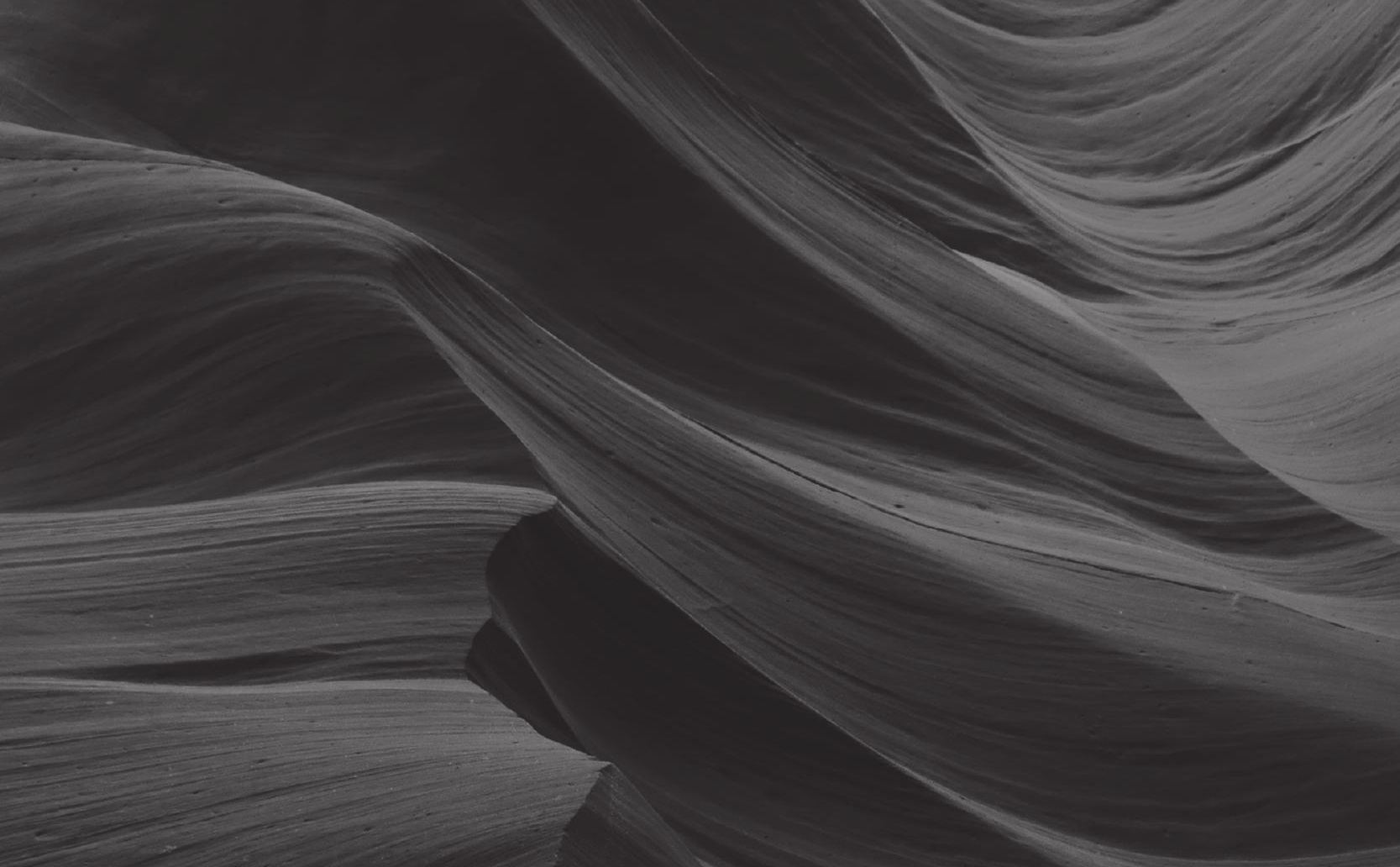


\section{Chapter 5}

\section{NK cells in human visceral adipose tissue contribute to obesity-associated insulin resistance through macrophage polarization and low-grade inflammation}

Yvo H.A.M. Kusters*, Kristiaan Wouters*, Mitchell Bijnen, Suzan Wetzels, Xiaodi Zhang, Pauline B.C. Linssen, Katrien Gaens, Alfons J.H.M. Houben, Peter J. Joris, Jogchum Plat, M. Eline Kooi, Carla J.H. van der Kallen, Ronald P. Mensink, Kenneth Verboven, Johan Jocken, Dominique Hansen, Ellen E. Blaak, Femke Ehlers, Lotte Wieten, Sander Rensen, Jan W. Greve, Coen D.A. Stehouwer, Casper G. Schalkwijk

* both authors contributed equally to this work Under review 


\begin{abstract}
Obesity-associated insulin resistance is a major risk factor for type 2 diabetes. Experimental evidence suggests that natural killer (NK) cell accumulation in visceral adipose tissue (VAT) is a primary event causing insulin resistance. Data on the role of NK cells in insulin resistance in humans are, however, absent.

We show that NK cell accumulation in VAT is associated with inflammatory adipose tissue macrophages and is reflected by CD11B surface expression on circulating NK cells. In addition, CD11B on circulating NK cells was associated with VAT volume, systemic low-grade inflammation (LGI), and insulin resistance. Moreover, CD11B surface expression on circulating NK cells partially explained the pathway between VAT, LGI, and insulin resistance. NK cells from obese donors produced higher levels of TNF and were able to drive inflammatory polarization of macrophages. We confirmed NK cells' involvement in obesity-associated insulin resistance in a population-based cohort of 839 individuals. Taken together, these data show that NK cell accumulation in VAT contributes to LGI and subsequent insulin resistance in humans.
\end{abstract}




\section{Introduction}

The global prevalence of obesity is rising at an alarming rate. Obesity is a major driver of insulin resistance, which increases the risk of developing type 2 diabetes, hypertension, dyslipidemia, and cardiovascular events. ${ }^{1}$ Ever since Hotamisligil et al. discovered in 1993 that tumor necrosis factor (TNF) is a determinant of insulin resistance and is produced by hypertrophic adipose tissue (AT), ${ }^{2}$ insights have been emerging that chronic low-grade inflammation (LGI) in AT caused by massive macrophage infiltration in AT is important for the development of insulin resistance. ${ }^{3-6}$ Not only quantitative, but also qualitative shifts in macrophage phenotype take place in expanding AT. While under lean conditions most macrophages display an antiinflammatory or so-called "M2" phenotype, obesity induces the polarization of AT macrophages toward the inflammatory "M1" state. ${ }^{7}$ Phenotypically, these AT macrophage (ATM) subsets could be distinguished by the surface expression of the integrin $\mathrm{CD}_{11 \mathrm{C}^{7}}{ }^{7}$ The accumulation of inflammatory $\mathrm{CD}_{11 \mathrm{C}^{+}}$ATMs correlates with insulin resistance in humans. ${ }^{8}$ The inflammatory cytokines that are secreted from $\mathrm{CD}_{11 C^{+}}$ATMs are thought to be major contributors to the low-grade chronic inflammatory state of AT that drives systemic insulin resistance. ${ }^{9}$ Many factors in AT of obese individuals have been proposed to trigger macrophage accumulation and polarization, such as adipocyte cell death, lipotoxicity by fatty acids, increased insulin levels, hyperglycemia, and hypoxia. ${ }^{9}$ However, the exact driver of macrophage accumulation and activation remains unclear. Recently, several studies showed, using experimental mouse models, that natural killer (NK) cells control macrophage accumulation and polarization via the production of interferon gamma (IFN $\gamma$ ), TNF or IL-6 in AT, resulting in impaired insulin sensitivity and glucose handling. ${ }^{9-11}$ These important findings may provide essential insight in the origin of inflammatory macrophages and could offer new pathways to target inflammation in the context of insulin resistance development. NK cells are innate lymphoid cells that are specialized in surveilling, recognizing and eliminating virally infected, transformed or stressed cells. In addition, NK cells also produce cytokines to shape an inflammatory environment. ${ }^{12}$ Moreover, human obesity is associated with an activated phenotype of NK cells in AT. ${ }^{13}$ However, no data is available showing whether NK cells contribute to AT macrophage accumulation and polarization and consequent insulin resistance in humans. Therefore, the aim of this study is to evaluate whether NK cells accumulate in human AT and, through LGI, contribute to insulin resistance and the development of type 2 diabetes in humans.

We addressed this by first conducting two cross-sectional studies using biopsies from visceral and subcutaneous adipose tissue, followed by an in-depth metabolic phenotyping study in a larger study population. Finally, we validated our findings in a large population-based cohort study. 


\section{Results \& discussion}

\section{VAT NK cells accumulate in obesity and are associated with inflammatory macrophage polarization}

To investigate whether NK cells accumulate in human AT, we analyzed stromal vascular fractions of VAT and subcutaneous adipose tissue (SAT) in lean and abdominally obese men using flow cytometry (baseline characteristics, SupplementaryTable S5.1). ${ }^{14}$ Obese men had a higher waist circumference (124.0 [121.3-130.3] vs. 89.0 [86.0-93.0] cm; $p<0.0001)$ and were more insulin resistant as reflected by higher HOMA-IR (5.63 [3.54-7.16] vs. 1.73 [1.27-3.30]; $p<0.0001$ ) compared to lean men. Moreover, obese men displayed increased levels of NK cells in their VAT (Figure 5.1A), but not in SAT (3.77 \pm 1.84 vs. $3.52 \pm 2.10 \% ; p=0.758$; Figure $5.2 A)$ or blood $\left(0.28\right.$ [0.15-0.44] vs. 0.20 [0.14-0.41] $\times 10^{9} / \mathrm{l} ; \mathrm{p}=0.401$; Table S5.1). These data are in line with previous studies in mice showing that VAT is the predominant AT depot displaying NK cell accumulation. ${ }^{9-11,15}$ In a second study, using adipose tissue biopsies from female controls and female obese women (BMI $28.1 \pm$ 3.1 vs. $42.6 \pm 1.6 \mathrm{~kg} / \mathrm{m}^{2} ; p=0.001$ ), we found that the fraction of $C D 56^{\text {dim }} C D 16^{\text {bright }} \mathrm{NK}$ cells in VAT was increased in obese individuals $(50.1 \pm 7.3 \%$ vs. $87.4 \pm 4.5 \%$; $p=0.0021)$ while the fraction of $C D 56^{\text {bright }} \mathrm{CD} 16^{-}$cells was decreased $(43.5 \pm 10.8 \%$ vs. $2.9 \pm 1.2 \% ; p<0.0001$ ) compared to controls. In SAT of these individuals, a significant decrease of $\mathrm{CD} 56^{\text {bright }} \mathrm{CD} 16^{-} \mathrm{NK}$ cells $(12.6 \pm 4.1 \%$ vs. $1.4 \pm 0.9 \% ; p=0.0018)$, but no increase in $\mathrm{CD}_{56}{ }^{\mathrm{dim}} \mathrm{CD} 16^{\text {bright }}$ NK cells $(85.1 \pm 3.3 \%$ vs. $91.7 \pm 3.3 \% ; p=0.285)$ was observed. These data are in concordance with a study showing that, despite total NK cells in VAT being equal, there was a shift towards more CD56 ${ }^{\text {dim }}$ NK cells and less CD56 ${ }^{\text {bright }}$ NK cells in VAT of obese individuals. ${ }^{16}$ It was previously shown that VAT, but not SAT, from humans contained ligands of the activating receptor NKp46. ${ }^{11}$ We now report a trend towards increased surface expression of NKp46 in the CD56 ${ }^{\text {dim }}$ CD $16^{\text {bright }}$ NK cell subset in VAT (635 \pm 96 vs $397 \pm 45$ mean fluorescence intensity (MFI), $p=0.06$; Figure 5.3A), albeit not statistically significantly. No difference was found in surface expression level of NKG2D (2704 \pm 181 vs. $2970 \pm 497 \mathrm{MFI} ; \mathrm{p}=0.772$ ), another activating receptor of VAT NK cells. In SAT, NKp46 surface expression was not different. Interestingly, in contrast to blood NK cell subsets, neither VAT nor SAT NK cell subsets displayed increased CD11B expression (data not shown). The aforementioned experimental mouse studies showed that NK cell infiltration in VAT leads to inflammatory macrophage polarization, which is hallmarked by an accumulation of " $\mathrm{M} 1$ " polarized $\mathrm{CD} 11 \mathrm{C}^{+}$macrophages compared to resident " $\mathrm{M} 2$ " CD11C polarized macrophages. We next investigated whether increased levels of NK cells in VAT is associated with macrophage polarization and found that an increase in VAT-resident NK cells was associated with a higher inflammatory macrophage ratio in VAT (M1/M2 ratio; $r=0.511 ; p=0.003$; Figure 5.1B). Additional adjustment for the 
potential confounder age did not materially change this association. In SAT, NK cells did not coincide with macrophage polarization ( $r=0.109 ; p=0.597$; Figure 5.2B-C). These findings support the involvement of VAT-resident NK cells in M1 macrophage polarization, as previously described in rodents. ${ }^{9-11}$ In contrast, while NK cells are present in SAT, they do not seem to exert the same effects as in VAT. This observation is in line with the findings of O'Rourke et al., showing that compared to SAT, VAT is particularly enriched in IFN -producing NK cells. ${ }^{16}$ Hence, SAT's contribution to insulin resistance appears to be mediated by different pathways compared to VAT, which may involve adipocyte lipolysis and adipokine dysregulation. ${ }^{17}$

A

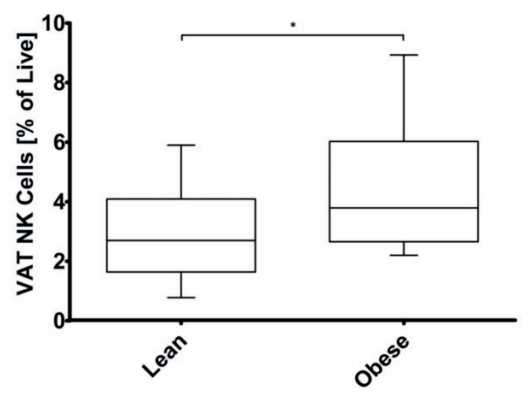

C

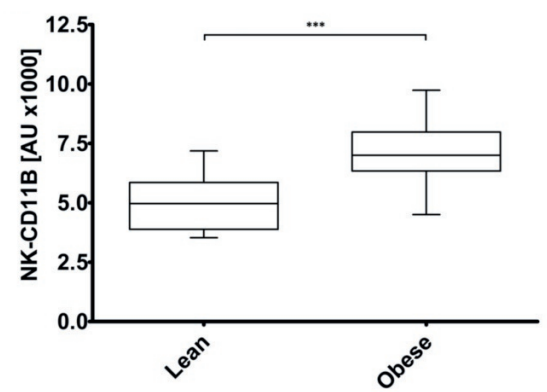

B

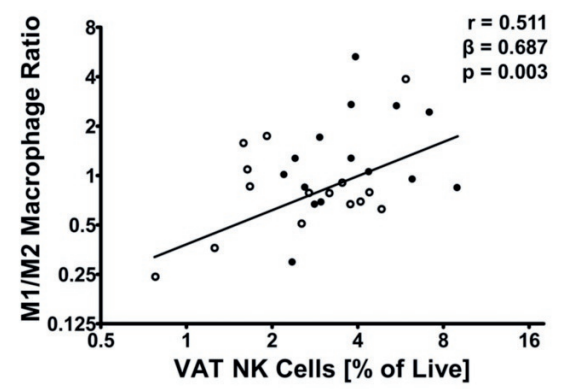

D

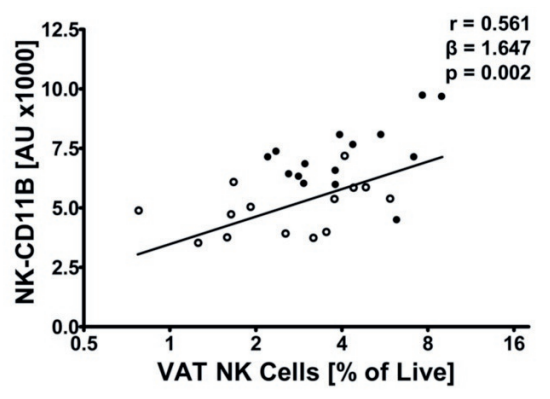

Figure 5.1 - Biopsy Study, visceral adipose tissue. (A) NK cells in visceral adipose tissue (VAT) in lean and obese individuals ( $\mathrm{n}=31 ;{ }^{*} \mathrm{p}<0.05$ ). (B) Association between NK cells in VAT and M1-to-M2 ratio in VAT $(n=31)$. (C) CD11B expression on circulating NK cells (NK-CD11B) in lean and obese individuals $(n=31$; $* * * p<0.001)$. (D) Association between NK cells in VAT and NK-CD11B $(n=29)$. Differences between groups were assessed by means of independent Student's t-tests (panels A, C). Box plots are as follows: black line, median; box edges, 1st and 3rd quartiles; whiskers, minimum and maximum of all data. Pearson's correlation coefficients, regression coefficients, and their $\mathrm{p}$-values are reported for all bivariate associations (panels B, D). Data of lean (o open circles) and obese men ( $\bullet$ closed circles) are shown. 
A

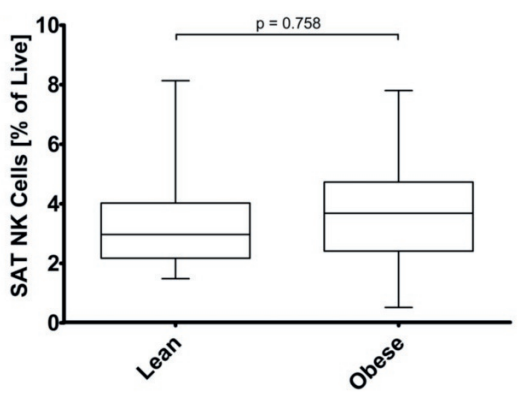

C

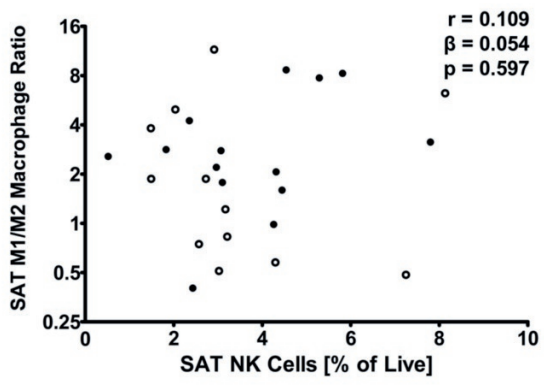

B

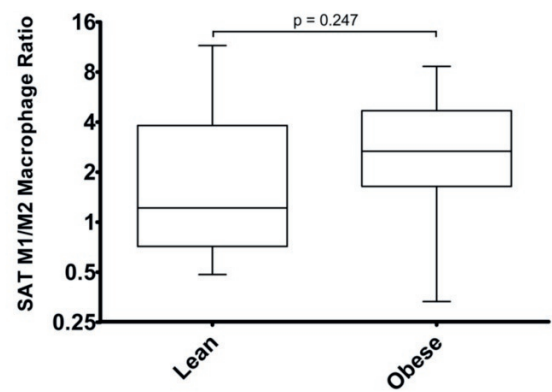

D

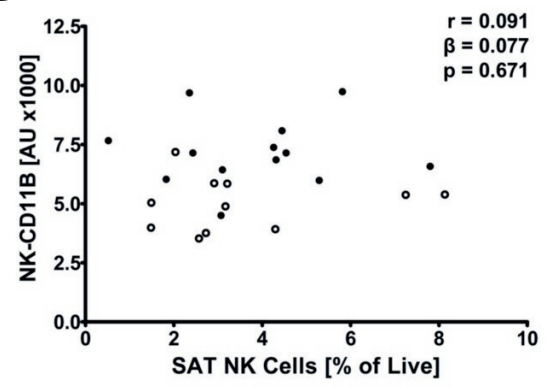

Figure 5.2 - Biopsy Study, subcutaneous adipose tissue. (A) NK cells in subcutaneous adipose tissue (SAT) in lean and obese individuals ( $n=26)$. (B) M1 macrophage polarization (M1-to-M2 ratio) in SAT in lean and obese individuals $(n=31)$. (C) Association between NK cells in SAT and M1-to-M2 ratio in SAT $(n=26)$. (D) Association between NK cells in SAT and CD11B expression on circulating NK cells (NK-CD11B; $n=24$ ). Differences between groups were assessed by means of independent Student's t-tests (panels A-B). Box plots are as follows: black line, median; box edges, 1st and 3rd quartiles; whiskers, minimum and maximum of all data. Pearson's correlation coefficients, regression coefficients, and their p-values are reported for bivariate associations (panels C-D). Data of lean (o open circles) and obese men (• closed circles) are shown.

\section{VAT NK cells are reflected by CD11B on circulating NK cells}

Since biopsies are burdensome for study participants and are virtually impossible to implement in large studies, we searched for a proxy for NK cell accumulation in VAT. We primarily focused on NK cells in peripheral blood. Interestingly, NK cell numbers in blood were not associated with NK cell numbers in VAT $(r=0.058, p=0.759)$. We did, however, find a suitable candidate in CD11B expression on these circulating NK cells. CD11B has been described as a maturation marker of NK cells. ${ }^{18,19}$ This integrin can mediate cell adhesion, but is also part of the complement receptor 3 complex, which is involved in cytotoxic activation of NK cells. ${ }^{20}$ We found that CD11B surface expression, measured as MFI, on total circulating NK cells (from here on referred to as NK-CD11B) is higher in obese compared to lean men (Figure 5.1C). Moreover, NK- 
CD11B was closely associated with NK cell accumulation in VAT $(r=0.561, p=0.002$; Figure 5.1D). Additional adjustment for the potential confounder age did not materially change this association. NK cells in SAT on the other hand were not associated with NK-CD11B ( $r=0.091 ; p=0.671$; Figure 5.2D). Since VAT NK cells were associated with an increase in the $M 1 / M 2$ ratio, we confirmed that the $M 1 / M 2$ ratio was associated with NK-CD11B as well ( $r=0.364 ; p=0.048)$. In conclusion, NK cells accumulate in VAT of obese individuals and are associated with inflammatory macrophage polarization. Moreover, CD11B surface expression on circulating NK cells can be used as a surrogate marker for VAT NK cell accumulation in studies where VAT biopsies are neither available nor feasible.

A

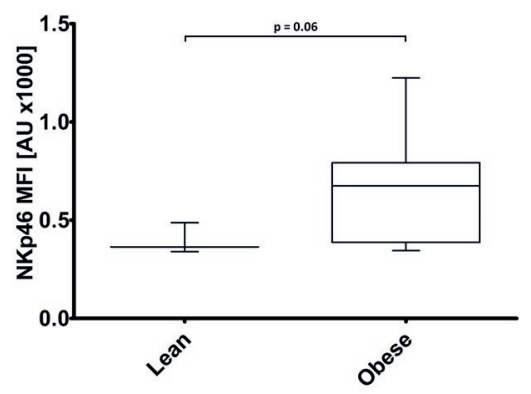

C

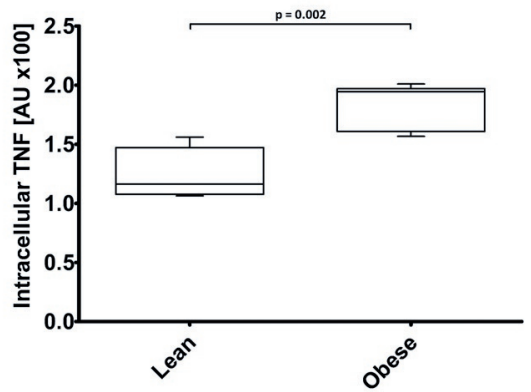

B

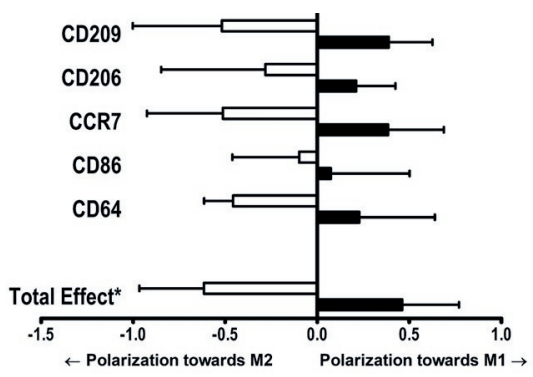

D

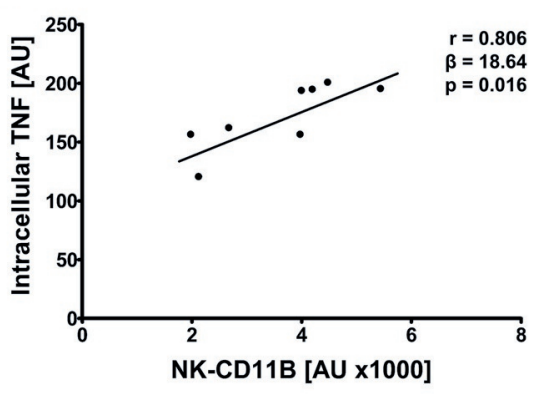

Figure 5.3 - NK cell function. (A) Surface expression of NKp46 on VAT NK cells from lean $(n=3)$ and obese individuals $(n=6)$. (B) Blood-derived NK cells from lean $(n=6$; white bars) and obese individuals $(n=8$; black bars) were isolated and co-cultured with either human monocyte derived macrophages where after surface expression of M1 markers (CCR7, CD86 and CD64), or incubated with monocytes that were first polarized to an M2 phenotype where after loss of M2 markers (loss of CD209 and CD206; i.e., polarization towards M1) was assessed. An aggregate total effect of polarization towards an M1 state was calculated (i.e., a z-score composed of -CD209, -CD206, CCR7, CD86, and CD64); compared to lean individuals, obese individuals displayed more polarization towards the M1 phenotype (mean difference $1.08 \quad(95 \%-\mathrm{Cl}$ 0.06-2.10; * $\mathrm{p}<0.05)$ ). (C) Intracellular TNF levels were measured in blood-derived NK cells of lean $(n=4)$ and obese individuals $(n=6)$ using flow cytometry. (D) Association between CD11B surface expression and intracellular TNF levels of blood-derived NK cells $(n=8)$. 
A

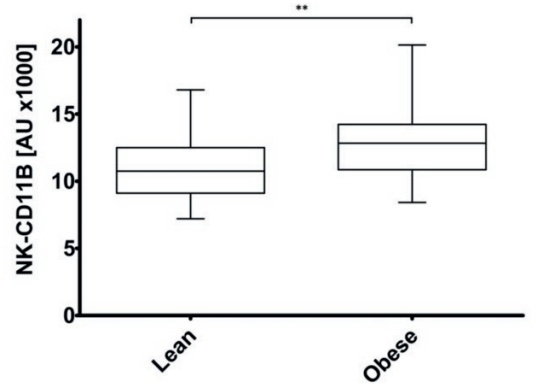

C

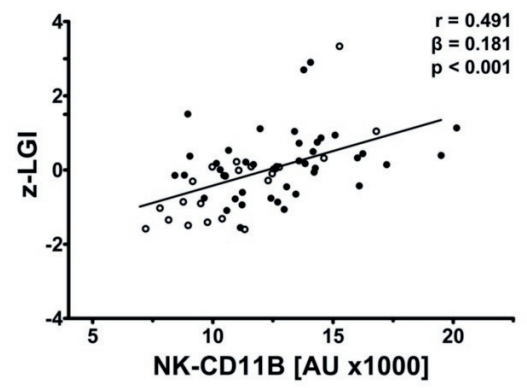

B

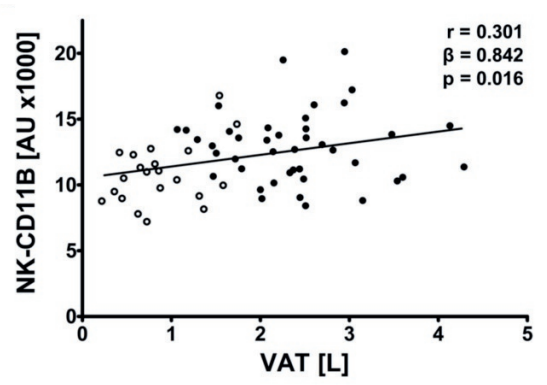

D

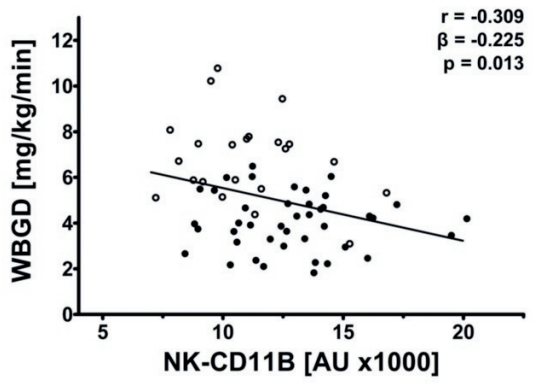

Figure 5.4 - Metabolic phenotyping study. (A) CD11B expression on circulating NK cells (NK-CD11B) in lean and abdominally obese individuals $(n=64 ; * * p<0.01)$. (B) Association between visceral adipose tissue volume (VAT) and NK-CD11B in lean and abdominally obese individuals $(n=63)$. (C) Association between NK-CD11B and low-grade inflammation (z-LGI; composite z-score of CRP, SAA, IL-6, IL-8, sICAM-1, and TNF) in lean and abdominally obese individuals $(n=64)$. (D) Association between NK-CD11B and whole-body glucose disposal (WBGD) during a hyperinsulinemic, euglycemic clamp in lean and abdominally obese individuals $(n=64)$. Difference between groups was assessed by means of independent Student's $t$-tests (panel A). Box plots are as follows: black line, median; box edges, 1st and 3rd quartiles; whiskers, minimum and maximum of all data. Pearson's correlation coefficients, regression coefficients, and their p-values are reported for all bivariate associations (panels B-D). Data of lean (o open circles) and obese men ( $\bullet$ closed circles) are shown.

NK cells from obese individuals produce enhanced levels of TNF and induce inflammatory polarization of macrophages

In the second study, we investigated whether NK cells from obese individuals directly affect macrophage polarization. Hence, NK cells were isolated from peripheral blood and co-cultured with human monocyte-derived macrophages. We investigated the capacity of NK cells to either promote the expression of M1 surface markers (CCR7, CD86 and CD64) in resting macrophages or to inhibit M2 surface marker expression (CD206 and CD209) in M2-polarized macrophages, as a model for resident adipose tissue macrophages. ${ }^{7}$ Compared to NK cells from lean individuals, NK cells from obese donors promoted M1 polarization in monocyte-derived macrophages $(p=0.040$; 
Figure 5.3B). This observation that NK cells can induce M1 polarization in obesity is in line with the association between VAT NK cell numbers and M1/M2 ratio demonstrated in the first study (Figure 5.1B).

Furthermore, compared to lean donors, peripheral blood NK cells from obese subjects displayed higher intracellular TNF levels (124 \pm 22 vs. $184 \pm 19 \mathrm{MFI}, \mathrm{p}=0.002$; Figure $5.3 \mathrm{C})$. These data are in accordance with the report of Lee et al. showing that epididymal adipose tissue NK cells from obese mice produce enhanced levels of TNF. ${ }^{9}$ Although IFN $\gamma$ also has been implicated in the causal contribution of mouse adipose tissue inflammation and concomitant insulin resistance, ${ }^{11}$ we did not observe elevated IFNy levels in the NK cells of obese individuals (data not shown). Finally, CD11B surface expression on NK cells was closely associated with TNF production in these cells $(r=0.806, p=0.016$; Figure 5.3D). Additional adjustment for the potential confounder age did not materially change this association. The expression of CD11B on NK cells may thus be a reflection of their activation level and their capacity to polarize macrophages towards a more inflammatory state. However, whether CD11B has a role in either the migration of NK cells into VAT or in macrophage polarization, or is a mere reflection of a closely related mechanism should be elucidated by future studies. Collectively, these data show that NK cells from obese individuals promote inflammatory polarization of macrophages, possibly via the increased production of TNF.

\section{NK cells are inversely associated with insulin resistance and partially} mediate the association between VAT volume and insulin resistance

To determine the relation between VAT NK cells and insulin resistance, we performed analyses in a third study including 25 lean (waist circumference $<94 \mathrm{~cm}$ ) and 53 abdominally obese men (waist circumference $102-110 \mathrm{~cm}$ ). ${ }^{21}$ We used state-of-theart in-depth metabolic and inflammatory phenotyping to provide precise estimations of VAT and SAT volumes and insulin resistance. FACS data were available in 22 lean and 42 abdominally obese men who were consecutively enrolled. In this study, VAT and SAT volumes were determined by magnetic resonance imaging (MRI), plasma cytokine levels with the MSD system, ${ }^{22}$ and insulin sensitivity by means of a $1 \mathrm{mU} / \mathrm{kg} / \mathrm{min}$ euglycemic insulin clamp. By design, obese men had an increased waist circumference compared to lean men (106.6 [103.5-109.1] vs. 85.8 [80.6-89.8] cm; $\mathrm{p}<0.001)$, as well as higher VAT $(2.384 \pm 0.751$ vs. $0.872 \pm 0.434 \mathrm{~L} ; \mathrm{p}<0.001)$ and SAT volumes (3.067 \pm 0.798 vs. $1.437 \pm 0.527 \mathrm{~L} ; \mathrm{p}<0.001)$, and a decreased whole-body glucose disposal (WBGD; $4.04 \pm 1.23$ vs. $6.85 \pm 1.85 \mathrm{mg} / \mathrm{kg} / \mathrm{min} ; \mathrm{p}<0.001$; Table S5.2; STAR Methods). NK-CD11B was significantly higher in obese compared to lean men (Figure 5.3A), reflecting increased VAT NK cell accumulation. As expected, increased VAT volume was inversely associated with WBGD $(r=-0.640, p<0.001)$. Moreover, 
VAT volume was associated with higher NK-CD11B ( $r=0.302 ; p=0.016$; Figure 5.3B), confirming the relationship between NK-CD11B and VAT expansion. In addition, NK-CD11B was associated with a LGI z-score (i.e., composite score of CRP, SAA, IL-6, IL-8, sICAM-1, and TNF; $r=0.491 ; p<0.001$; Figure 5.3C), and WBGD $(r=-0.309$; $p=0.013$; Figure 5.3D). Additional adjustment for age did not materially change any of these associations.

We next explored whether VAT NK cells, by means of NK-CD11B, and consecutive systemic LGI contribute to the association between VAT volume and insulin resistance. We investigated the contribution of this pathway to insulin resistance by means of multiple mediation analyses. VAT NK cells, by means of NK-CD11B, and subsequent LGI partially explained the association between VAT and insulin resistance $(\beta-0.075$ (-0.233 to -0.011$)$; Figure S5.1). As a result, $53.9 \%$ of the contribution of LGI to VATassociated insulin resistance appears to be explained by NK-CD11B. This is indicative that, in humans, NK cell accumulation in VAT leads to systemic LGI and subsequent induction of insulin resistance and thereby constitutes a separate target for intervention.

Finally, as recent literature in mice suggests that the inflammatory cytokines TNF and IL- 6 in particular may be responsible for the association between VAT NK cells and insulin resistance, ${ }^{9,10}$ we explored whether VAT NK cells contribute to insulin resistance via these cytokines in humans as well. We found that NK-CD11B was associated with both TNF $(r=0.349 ; p=0.005)$ and IL-6 $(r=0.274 ; p=0.029)$. In additional pathway analyses we found that VAT NK cells contribute to VAT-associated insulin resistance mainly through TNF ( $\beta-0.048(-0.170$ to -0.006$))$, but not statistically significantly via IL-6 ( $\beta-0.018(-0.077$ to 0.043$))$.

Collectively, our data thus show that, in humans, NK cell accumulation in VAT is associated with inflammatory macrophage polarization, systemic LGI, and insulin resistance. Interestingly, our multiple mediation analyses argue for a robust involvement of NK cells and LGI in obesity-associated insulin resistance. These data are in line with previously published data showing that more TNF-producing NK cells accumulate in the AT of obese mice. ${ }^{9}$ Intriguingly, in mice, obesity regulated NK cell numbers in VAT by enhanced recruitment and local proliferation. ${ }^{9,11}$ Here we show a close association between NK-CD11B and NK cell accumulation in human VAT. Moreover, NK-CD11B mediated the association between VAT volume, LGI, and insulin resistance. These results are at least suggestive that in humans, recruitment of NK cells from the circulation plays an important quantitative role in the development of VAT inflammation and systemic LGI. This does, however, not exclude the possibility that either recruited or resident NK cells may proliferate in AT during the development of obesity. Nevertheless, it is tempting to speculate that increased 
integrin expression on NK cell surface may lead to enhanced recruitment of NK cells in VAT, although blocking CD11B on NK cells failed to attenuate in vitro adhesion to endothelial cells. ${ }^{23}$ Since CD11B has been linked to NK cell activation, ${ }^{20}$ circulating NK cells of obese people were found to display an activated, but exhausted, phenotype, rendering these cells less functional. ${ }^{24}$ It would be of great interest to evaluate whether CD11B also mechanistically contributes to VAT NK cell accumulation, or merely reflects NK cell activation in VAT. In the former case, CD11B would be an interesting target to prevent NK cell accumulation in human VAT to reduce insulin resistance, as was shown in mice. ${ }^{9,11,15}$

\section{Validation of findings in external cohort}

We aimed to validate our findings in a population-based cohort study. Hereto, we used an observational population-based cohort study enriched with type 2 diabetes. In this study, individuals underwent VAT and SAT quantification by means of MRI; NK cells were determined in blood by flow cytometry; insulin sensitivity was quantified by means of the Matsuda Index; and glucose metabolism status was assessed through fasting plasma glucose and an oral glucose tolerance test as described elsewhere. ${ }^{25}$ First, we reconfirm that VAT is associated with LGI (standardized $\beta 0.252 ; p<0.001$; $\mathrm{n}=696$; fully adjusted model) and insulin resistance by means of the Matsuda Index (standardized $\beta-0.462 ; p<0.001 ; n=397$; fully adjusted model). More importantly, VAT volume was associated with NK cell accumulation in VAT as assessed by NKCD11B ( $p=0.006$; Table 5.1). There was no interaction with sex or diabetes status. When diabetic individuals or individuals that used blood-pressure-lowering, lipidlowering, glucose-lowering, or anti-inflammatory medication were excluded from the analysis, the results did not materially change. Adjusting the model for SAT volume did not alter the results (data not shown). In addition, NK-CD11B was positively associated with the z-score of LGI, plasma TNF levels, and plasma IL-6 levels ( $p<0.05$ for each; Table S5.4). Finally, we found that NK-CD11B, as a measure of VAT NK cells, was associated with insulin resistance $(p=0.013$; Table 5.2). There was again no interaction with sex or diabetes status, nor did the exclusion of diabetic individuals or individuals that used blood-pressure-lowering, lipid-lowering, glucose-lowering, or anti-inflammatory medication materially change the results (data not shown). We can therefore conclude that the findings of the first three independent studies were validated in a cohort study that was obtained from the general population. 
Table 5.1 - Associations between VAT and NK-CD11B ( $n=696)$.

\begin{tabular}{lccc}
\hline & Model & \multicolumn{2}{c}{ NK-CD11B [AU] } \\
\cline { 3 - 4 } & & $3(95 \%-\mathrm{Cl})$ & $\mathrm{p}$-value \\
\hline VAT $\left[\mathrm{cm}^{2}\right]$ & 1 & $3.90(1.84 ; 5.97)$ & $<0.001$ \\
& 2 & $3.21(0.94 ; 5.48)$ & 0.006 \\
\hline
\end{tabular}

Model 1: Adjusted for age, sex, and glucose metabolism status. Model 2: Fully adjusted model (model $1+$ systolic blood pressure, total-to-HDL cholesterol ratio, smoking status, prior cardiovascular disease, and use of antihypertensive, anti-inflammatory, glucose-lowering or lipid-lowering medication). Multiple linear regression analyses in individuals with normal glucose metabolism $(n=405)$, prediabetes $(n=93)$, and type 2 diabetes $(n=198)$. The beta of each model is presented along with its respective $95 \%-\mathrm{Cl}$ and $p$-value.

Table 5.2 - Associations between NK-CD11B and the Matsuda Index ( $n=540)$.

\begin{tabular}{lccc}
\hline & Model & \multicolumn{2}{c}{ Matsuda Index } \\
\cline { 3 - 4 } & & $2337(95 \%-C l)$ & $p$-value \\
\hline NK-CD11B & 1 & $2212(440 ; 3783)$ & 0.008 \\
& 2 & 0.013 \\
\hline
\end{tabular}

Model 1: Adjusted for age, sex, and glucose metabolism status. Model 2: Fully adjusted model (model $1+$ systolic blood pressure, total-to-HDL cholesterol ratio, smoking status, prior cardiovascular disease, and use of antihypertensive, anti-inflammatory, glucose-lowering or lipid-lowering medication). Multiple linear regression analyses in individuals with normal glucose metabolism $(n=313)$, prediabetes $(n=71)$, and type 2 diabetes $(n=156)$. The beta of each model is presented along with its respective $95 \%-\mathrm{Cl}$ and $p$-value. NKCD11B was transformed to 1 / NK-CD11B and the Matsuda Index to SQRT Matsuda Index to fulfill the assumptions of the regression model and are presented as such.

In conclusion, we show for the first time that NK cells in VAT contribute to LGI and subsequent insulin resistance in humans. Since experimental studies suggest that NK cell accumulation is an early event in the development of VAT inflammation, targeting these cells may hold great promise to inhibit this pathway leading to insulin resistance. These findings pave the way for novel therapeutic strategies to target the inflammatory component of insulin resistance development, which has until now been proven rather unsatisfactory. ${ }^{26}$ Moreover, we identified CD11B surface expression on circulating NK cells to be a reflection of NK cell accumulation in VAT. Aside from the obvious benefit of this minimally invasive measurement as a marker of VAT inflammation, future studies should address whether CD11B on NK cells contributes to their accumulation and can be used as therapeutic target. 


\section{Acknowledgements}

Maria Vroomen, José van de Gaar, and Jos op 't Roodt are greatly acknowledged for their technical assistance. We thank Marleen van Greevenbroek for epidemiological counseling. Part of this study was financed by The Netherlands Organization for Scientific Research (NWO) (Veni 916.12.056), The Netherlands Heart Foundation (2013T143), and a Seventh Framework Program (FP7) Grant (CIG 322070) to KW. The metabolic phenotyping study was supported by research grant $\mathrm{CHOO1}$ from the Top Institute Food and Nutrition, a public-private partnership on precompetitive research in food and nutrition. The public partners are responsible for the study design, data collection and analysis, decision to publish, and preparation of the manuscript. The validation study was supported by the European Regional Development Fund via OPZuid, the Province of Limburg, the Dutch Ministry of Economic Affairs (grant 310.041), Stichting De Weijerhorst (Maastricht, the Netherlands), the Pearl String Initiative Diabetes (Amsterdam, the Netherlands), CARIM School for Cardiovascular Diseases (Maastricht, the Netherlands), Stichting Annadal (Maastricht, the Netherlands), Health Foundation Limburg (Maastricht, the Netherlands) and by unrestricted grants from Janssen-Cilag B.V. (Tilburg, the Netherlands), Novo Nordisk Farma B.V. (Alphen aan den Rijn, the Netherlands) and Sanofi-Aventis Netherlands B.V. (Gouda, the Netherlands). 


\section{References}

1. DeFronzo, R.A., and Ferrannini, E. (1991). Insulin resistance. A multifaceted syndrome responsible for NIDDM, obesity, hypertension, dyslipidemia, and atherosclerotic cardiovascular disease. Diabetes Care 14, 173-194.

2. Hotamisligil, G.S., Shargill, N.S., and Spiegelman, B.M. (1993). Adipose expression of tumor necrosis factor-alpha: direct role in obesity-linked insulin resistance. Science 259, 87-91.

3. Carvalheira, J.B., Qiu, Y., and Chawla, A. (2013). Blood spotlight on leukocytes and obesity. Blood 122, 3263-3267.

4. Ohman, M.K., Wright, A.P., Wickenheiser, K.J., Luo, W., and Eitzman, D.T. (2009). Visceral adipose tissue and atherosclerosis. Current vascular pharmacology 7, 169-179.

5. Weisberg, S.P., McCann, D., Desai, M., Rosenbaum, M., Leibel, R.L., and Ferrante, A.W., Jr. (2003). Obesity is associated with macrophage accumulation in adipose tissue. The Journal of clinical investigation 112, 1796-1808.

6. Xu, H., Barnes, G.T., Yang, Q., Tan, G., Yang, D., Chou, C.J., Sole, J., Nichols, A., Ross, J.S., Tartaglia, L.A., et al. (2003). Chronic inflammation in fat plays a crucial role in the development of obesity-related insulin resistance. The Journal of clinical investigation 112, 1821-1830.

7. Lumeng, C.N., Bodzin, J.L., and Saltiel, A.R. (2007). Obesity induces a phenotypic switch in adipose tissue macrophage polarization. The Journal of clinical investigation 117, 175-184.

8. Wentworth, J.M., Naselli, G., Brown, W.A., Doyle, L., Phipson, B., Smyth, G.K., Wabitsch, M., O'Brien, P.E., and Harrison, L.C. (2010). Pro-inflammatory CD11c+CD206+ adipose tissue macrophages are associated with insulin resistance in human obesity. Diabetes 59, 1648-1656.

9. Lee, B.C., Kim, M.S., Pae, M., Yamamoto, Y., Eberle, D., Shimada, T., Kamei, N., Park, H.S., Sasorith, S., Woo, J.R., et al. (2016). Adipose Natural Killer Cells Regulate Adipose Tissue Macrophages to Promote Insulin Resistance in Obesity. Cell metabolism 23, 685-698.

10. Theurich, S., Tsaousidou, E., Hanssen, R., Lempradl, A.M., Mauer, J., Timper, K., Schilbach, K., FolzDonahue, K., Heilinger, C., Sexl, V., et al. (2017). IL-6/Stat3-Dependent Induction of a Distinct, ObesityAssociated NK Cell Subpopulation Deteriorates Energy and Glucose Homeostasis. Cell metabolism 26, 171-184 e176.

11. Wensveen, F.M., Jelencic, V., Valentic, S., Sestan, M., Wensveen, T.T., Theurich, S., Glasner, A., Mendrila, D., Stimac, D., Wunderlich, F.T., et al. (2015). NK cells link obesity-induced adipose stress to inflammation and insulin resistance. Nature immunology 16, 376-385.

12. Vivier, E., Raulet, D.H., Moretta, A., Caligiuri, M.A., Zitvogel, L., Lanier, L.L., Yokoyama, W.M., and Ugolini, S. (2011). Innate or adaptive immunity? The example of natural killer cells. Science 331, 44 49.

13. O'Rourke, R.W., Gaston, G.D., Meyer, K.A., White, A.E., and Marks, D.L. (2013). Adipose tissue NK cells manifest an activated phenotype in human obesity. Metabolism 62, 1557-1561.

14. Wouters, K., Gaens, K., Bijnen, M., Verboven, K., Jocken, J., Wetzels, S., Wijnands, E., Hansen, D., van Greevenbroek, M., Duijvestijn, A., et al. (2017). Circulating classical monocytes are associated with CD11c+ macrophages in human visceral adipose tissue. Sci Rep 7, 42665.

15. O'Rourke, R.W., Meyer, K.A., Neeley, C.K., Gaston, G.D., Sekhri, P., Szumowski, M., Zamarron, B., Lumeng, C.N., and Marks, D.L. (2014). Systemic NK cell ablation attenuates intra-abdominal adipose tissue macrophage infiltration in murine obesity. Obesity 22, 2109-2114.

16. O'Rourke, R.W., Metcalf, M.D., White, A.E., Madala, A., Winters, B.R., Maizlin, II, Jobe, B.A., Roberts, C.T., Jr., Slifka, M.K., and Marks, D.L. (2009). Depot-specific differences in inflammatory mediators and a role for NK cells and IFN-gamma in inflammation in human adipose tissue. Int J Obes (Lond) 33, 978990.

17. Preis, S.R., Massaro, J.M., Robins, S.J., Hoffmann, U., Vasan, R.S., Irlbeck, T., Meigs, J.B., Sutherland, P., D'Agostino, R.B., Sr., O'Donnell, C.J., et al. (2010). Abdominal subcutaneous and visceral adipose tissue and insulin resistance in the Framingham heart study. Obesity 18, 2191-2198.

18. Chiossone, L., Chaix, J., Fuseri, N., Roth, C., Vivier, E., and Walzer, T. (2009). Maturation of mouse NK cells is a 4-stage developmental program. Blood 113, 5488-5496. 
19. Fu, B., Wang, F., Sun, R., Ling, B., Tian, Z., and Wei, H. (2011). CD11b and CD27 reflect distinct population and functional specialization in human natural killer cells. Immunology 133, 350-359.

20. Ross, G.D., and Vetvicka, V. (1993). CR3 (CD11b, CD18): a phagocyte and NK cell membrane receptor with multiple ligand specificities and functions. Clin Exp Immunol 92, 181-184.

21. Kusters, Y.H., Schalkwijk, C.G., Houben, A.J., Kooi, M.E., Lindeboom, L., Op 't Roodt, J., Joris, P.J., Plat, J., Mensink, R.P., Barrett, E.J., et al. (2017). Independent tissue contributors to obesity-associated insulin resistance. JCl Insight 2.

22. van Bussel, B.C., Ferreira, I., van de Waarenburg, M.P., van Greevenbroek, M.M., van der Kallen, C.J., Henry, R.M., Feskens, E.J., Stehouwer, C.D., and Schalkwijk, C.G. (2013). Multiple inflammatory biomarker detection in a prospective cohort study: a cross-validation between well-established single-biomarker techniques and an electrochemiluminescense-based multi-array platform. PLoS One 8, e58576.

23. Allavena, P., Paganin, C., Martin-Padura, I., Peri, G., Gaboli, M., Dejana, E., Marchisio, P.C., and Mantovani, A. (1991). Molecules and structures involved in the adhesion of natural killer cells to vascular endothelium. J Exp Med 173, 439-448.

24. Viel, S., Besson, L., Charrier, E., Marcais, A., Disse, E., Bienvenu, J., Walzer, T., and Dumontet, C. (2017). Alteration of Natural Killer cell phenotype and function in obese individuals. Clin Immunol $177,12-17$.

25. Schram, M.T., Sep, S.J.S., van der Kallen, C.J., Dagnelie, P.C., Koster, A., Schaper, N., Henry, R.M.A., and Stehouwer, C.D.A. (2014). The Maastricht Study: an extensive phenotyping study on determinants of type 2 diabetes, its complications and its comorbidities. Eur J Epidemiol 29, 439-451.

26. Donath, M.Y. (2014). Targeting inflammation in the treatment of type 2 diabetes: time to start. Nat Rev Drug Discov 13, 465-476.

27. Defronzo, R.A., Tobin, J.D., and Andres, R. (1979). Glucose clamp technique: a method for quantifying insulin secretion and resistance. Am J Physiol 237, E214-223.

28. Fuentes, L., Wouters, K., Hannou, S.A., Cudejko, C., Rigamonti, E., Mayi, T.H., Derudas, B., Pattou, F., Chinetti-Gbaguidi, G., Staels, B., et al. (2011). Downregulation of the tumour suppressor p16INK4A contributes to the polarisation of human macrophages toward an adipose tissue macrophage (ATM)like phenotype. Diabetologia 54, 3150-3156.

29. van Bussel, B.C., Henry, R.M., Schalkwijk, C.G., Dekker, J.M., Nijpels, G., and Stehouwer, C.D. (2012). Low-grade inflammation, but not endothelial dysfunction, is associated with greater carotid stiffness in the elderly: the Hoorn Study. J Hypertens 30, 744-752. 


\section{Supplementary material}

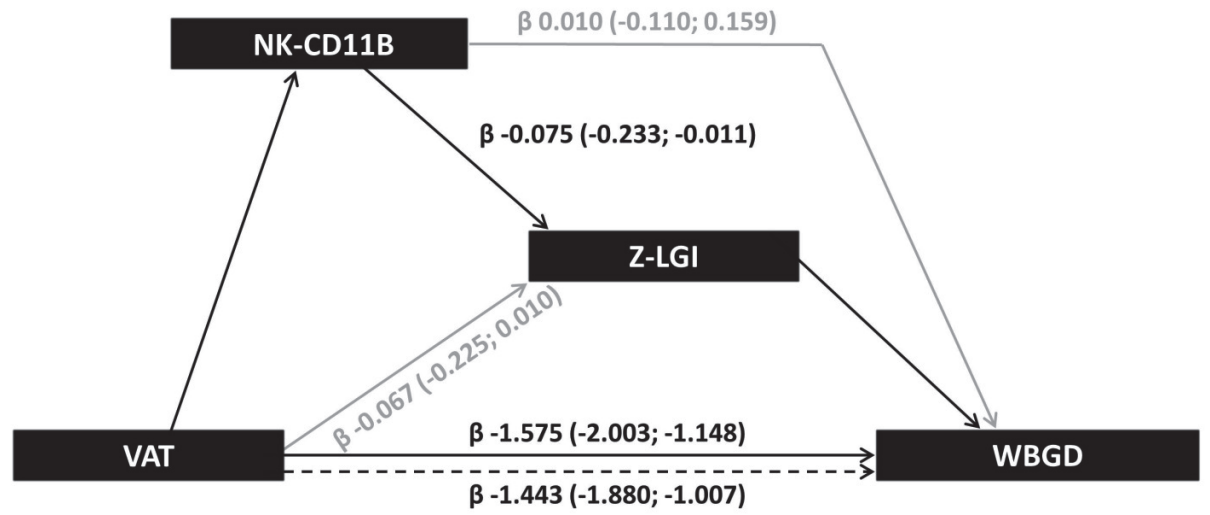

Figure S5.1 - Pathway analysis. Serial multiple mediator model in which CD11B expression on circulating NK cells (NK-CD11B) statistically significantly contributes through low-grade inflammation (z-LGI; composite z-score of CRP, SAA, IL-6, IL-8, sICAM-1, and TNF) to the association between abdominal visceral adipose tissue (VAT) and insulin resistance by means of whole-body glucose disposal (WBGD; $n=63$; age-adjusted). Data presented as $\beta$ of mediated effect (bootstrapped $95 \%-\mathrm{Cl}$ ). Significant associations are represented by black lines, whereas grey lines represent associations that are not statistically significant. 
Table S5.1 - Biopsy study population characteristics.

\begin{tabular}{|c|c|c|c|}
\hline & $\begin{array}{c}\text { Lean } \\
(n=15)\end{array}$ & $\begin{array}{c}\text { Obese } \\
(n=17)\end{array}$ & $\mathrm{p}$-value \\
\hline Age $[\mathrm{Yr}]$ & $52.1 \pm 6.1$ & $49.5 \pm 5.8$ & 0.215 \\
\hline Weight $[\mathrm{kg}]$ & $76.0[73.0-81.0]$ & $115.0[111.2-133.8]$ & $<0.001$ \\
\hline Fat Free Mass [kg] & $58.2 \pm 5.8$ & $76.2 \pm 7.9$ & $<0.001$ \\
\hline Fat Mass $[\mathrm{kg}]$ & $16.2[14.7-20.5]$ & 41.8 [36.9 - 48.9] & $<0.001$ \\
\hline BMI $\left[\mathrm{kg} / \mathrm{m}^{2}\right]$ & $23.6[22.7-24.1]$ & 37.1 [35.1 - 38.7] & $<0.001$ \\
\hline Waist Circumference [cm] & $89.0[86.0-93.0]$ & $124.0[121.3-130.3]$ & $<0.001$ \\
\hline Hip Circumference $[\mathrm{cm}]^{a}$ & $92.5[89.5-94.5]$ & $114.8[111.6-118.8]$ & $<0.001$ \\
\hline HOMA-IR & $1.73[1.27-3.30]$ & $5.63[3.54-7.16]$ & $<0.001$ \\
\hline Fasting Plasma Glucose [mmol/l] & $5.44 \pm 0.93$ & $6.08 \pm 0.97$ & 0.069 \\
\hline $\mathrm{HbA} 1 \mathrm{c}[\%]$ & $5.2[5.1-5.5]$ & $5.6[5.5-6.1]$ & $<0.001$ \\
\hline Diabetes Status [Y/N] & $0 / 15$ & $3 / 14$ & $\mathrm{~N} / \mathrm{A}$ \\
\hline Glucose lowering Therapy $[\mathrm{Y} / \mathrm{N}]$ & $0 / 15$ & $3 / 14$ & N/A \\
\hline Systolic Blood Pressure [mmHg] & $132.3 \pm 15.1$ & $145.6 \pm 18.1$ & 0.053 \\
\hline Diastolic Blood Pressure $[\mathrm{mmHg}]^{\mathrm{b}}$ & $83.6 \pm 9.2$ & $83.8 \pm 8.4$ & 0.956 \\
\hline White Blood Cell Count, Blood [x10^9/L] & $7.81 \pm 2.27$ & $6.63 \pm 1.39$ & 0.094 \\
\hline Neutrophilic Granulocyte Count, Blood [x10^9/I] & $4.62[3.61-6.18]$ & $3.70[3.11-4.70]$ & 0.235 \\
\hline Eosinophilic Granulocyte Count, Blood [×10^9/I] & $0.22[0.20-0.38]$ & $0.15[0.11-0.26]$ & 0.040 \\
\hline Basophilic Granulocyte Count, Blood [x10^9/I] & $0.05 \pm 0.02$ & $0.04 \pm 0.02$ & 0.105 \\
\hline Lymphocyte Count, Blood [x10^9/I] & $1.99 \pm 0.50$ & $1.78 \pm 0.69$ & 0.333 \\
\hline Monocyte Count, Blood [x10^9/I] & $0.46[0.37-0.69]$ & $0.54[0.41-0.57]$ & 0.761 \\
\hline NK Cell Count, Blood $\left[\times 10^{\wedge} 9 / 1\right]^{a}$ & $0.20[0.14-0.41]$ & $0.28[0.15-0.44]$ & 0.401 \\
\hline NK-CD11B MFI, Blood [AU] ${ }^{\mathrm{C}}$ & $4953 \pm 1083$ & $7126 \pm 1342$ & $<0.001$ \\
\hline SAT NK Cell Count [\% of Live] ${ }^{d}$ & $3.52 \pm 2.10$ & $3.77 \pm 1.84$ & 0.758 \\
\hline VAT NK Cell Count [\% of Live] ${ }^{\mathrm{e}}$ & $2.70[1.64-4.09]$ & $3.79[2.66-6.02]$ & 0.025 \\
\hline VAT M1/M2 Ratio & $0.78[0.62-1.09]$ & $1.05[0.85-2.55]$ & 0.074 \\
\hline VAT TNF Expression [Fold of Control] ${ }^{f}$ & $0.66[0.48-1.33]$ & $1.28[0.71-2.17]$ & 0.062 \\
\hline
\end{tabular}

Data presented as mean \pm SD or median [IQR]. Baseline differences between lean and obese men were assessed by means of independent Student's T-test or Mann-Whitney U test, where appropriate. ${ }^{\text {a }}$ Analyzed in 15 lean and 16 obese men; ${ }^{b}$ analyzed in 11 lean and 17 obese men; ${ }^{c}$ analyzed in 14 lean and 16 obese men; ${ }^{d}$ analyzed in 12 lean and 14 obese men; ${ }^{e}$ analyzed in 15 lean and 16 obese men; ${ }^{f}$ analyzed in 15 lean and 16 obese men. 
Table S5.2 - Metabolic phenotyping study population characteristics.

\begin{tabular}{|c|c|c|c|}
\hline & $\begin{array}{c}\text { Lean } \\
(\mathrm{n}=22)\end{array}$ & $\begin{array}{c}\text { Obese } \\
(n=42)\end{array}$ & p-value \\
\hline Age $[\mathrm{Yr}]$ & $55.0[23.2-61.2]$ & $52.4[46.5-61.4]$ & 0.661 \\
\hline Weight $[\mathrm{kg}]$ & $75.8 \pm 8.2$ & $96.4 \pm 8.8$ & $<0.001$ \\
\hline Fat Free Mass [kg] & $62.8 \pm 5.6$ & $70.6 \pm 6.0$ & $<0.001$ \\
\hline Fat Mass $[\mathrm{kg}]$ & $13.0 \pm 4.6$ & $25.9 \pm 4.8$ & $<0.001$ \\
\hline $\mathrm{BMI}\left[\mathrm{kg} / \mathrm{m}^{2}\right]$ & $23.4 \pm 1.9$ & $30.1 \pm 2.0$ & $<0.001$ \\
\hline Waist Circumference $[\mathrm{cm}]$ & $85.8[80.6-89.8]$ & $106.6[103.5-109.1]$ & $<0.001$ \\
\hline Hip Circumference $[\mathrm{cm}]$ & $96.8 \pm 4.4$ & $107.3 \pm 5.5$ & $<0.001$ \\
\hline Visceral Adipose Tissue Volume [I] ${ }^{\mathrm{a}}$ & $0.872 \pm 0.434$ & $2.384 \pm 0.751$ & $<0.001$ \\
\hline Subcutaneous Adipose Tissue Volume $[\mathrm{I}]^{\mathrm{a}}$ & $1.437 \pm 0.527$ & $3.067 \pm 0.798$ & $<0.001$ \\
\hline Whole-Body Glucose Disposal [mg/kg/min] & $6.85 \pm 1.85$ & $4.04 \pm 1.23$ & $<0.001$ \\
\hline HOMA-IR & $1.7 \pm 0.5$ & $2.9 \pm 1.3$ & $<0.001$ \\
\hline Fasting Plasma Glucose [mmol/l] & $5.36 \pm 0.28$ & $5.66 \pm 0.46$ & 0.002 \\
\hline $\mathrm{HbA} 1 \mathrm{c}[\%]^{\mathrm{b}}$ & $5.15 \pm 0.38$ & $5.28 \pm 0.39$ & 0.211 \\
\hline Systolic Blood Pressure [mmHg] & $116.5 \pm 8.1$ & $122.1 \pm 8.4$ & 0.012 \\
\hline Diastolic Blood Pressure [mmHg] & $71.1 \pm 8.6$ & $79.7 \pm 6.9$ & $<0.001$ \\
\hline White Blood Cell Count, Blood $\left[\times 10^{\wedge} 9 /\right]^{c}$ & $4.89 \pm 1.32$ & $5.67 \pm 1.25$ & 0.027 \\
\hline Neutrophilic Granulocyte Count, Blood [x10^9/I] & $2.59 \pm 0.88$ & $3.16 \pm 1.01$ & 0.032 \\
\hline 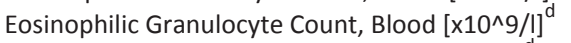 & $0.22 \pm 0.13$ & $0.21 \pm 0.13$ & 0.789 \\
\hline Basophilic Granulocyte Count, Blood $\left[\times 10^{\wedge} 9 / /\right]^{d}$ & $0.03[0.00-0.05]$ & $0.03[0.00-0.06]$ & 0.894 \\
\hline Lymphocyte Count, Blood $\left[\times 10^{\wedge} 9 / I\right]^{d}$ & $1.60 \pm 0.37$ & $1.77 \pm 0.46$ & 0.151 \\
\hline Monocyte Count, Blood $\left[\times 10^{\wedge} 9 / /\right]^{d}$ & $0.46 \pm 0.14$ & $0.52 \pm 0.15$ & 0.128 \\
\hline NK Cell Count, Blood $\left[\times 10^{\wedge} 9 / I\right]^{d}$ & $0.10[0.08-0.15]$ & $0.14[0.10-0.19]$ & 0.037 \\
\hline NK-CD11B MFI, Blood [AU] & $10999 \pm 2445$ & $12865 \pm 2664$ & 0.008 \\
\hline Low-grade Inflammation z-score & $-0.21 \pm 0.73$ & $0.11 \pm 0.60$ & 0.059 \\
\hline Plasma TNF $[\mathrm{pg} / \mathrm{ml}]$ & $1.85[1.50-2.05]$ & $1.96[1.62-2.31]$ & 0.161 \\
\hline Plasma IL-6 [pg/ml] & $0.58[0.32-0.97]$ & $0.64[0.47-0.90]$ & 0.344 \\
\hline
\end{tabular}

Data presented as mean \pm SD or median [IQR]. Baseline differences between lean and obese men were assessed by means of independent Student's T-test or Mann-Whitney $U$ test where appropriate. ${ }^{\text {a }}$ Analyzed in 21 lean and 42 obese men; ${ }^{b}$ analyzed in 22 lean and 41 obese men; ${ }^{c}$ analyzed in 21 lean and 39 obese men; ${ }^{d}$ analyzed in 21 control and 38 obese men. 
Table S5.3 - Validation study population characteristics - The Maastricht Study.

\begin{tabular}{|c|c|c|c|c|}
\hline & $\begin{array}{c}\text { NGT } \\
(n=480)\end{array}$ & $\begin{array}{l}\text { Prediabetes } \\
\quad(n=109)\end{array}$ & $\begin{array}{c}\text { T2DM } \\
(n=250)\end{array}$ & $\mathrm{p}$-value \\
\hline Age $[\mathrm{Yr}]$ & $58.5 \pm 8.5$ & $60.3 \pm 8.5^{* * *}$ & 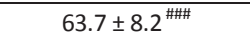 & $<0.001$ \\
\hline $\operatorname{Sex}[M / F]$ & $199 / 281$ & $49 / 60$ & $160 / 90^{\# \# \#}$ & $<0.001$ \\
\hline Smoking Status [never/former/ current] & $207 / 218 / 55$ & $35 / 56 / 18$ & $78 / 130 / 42^{\# \#}$ & 0.010 \\
\hline Weight $[\mathrm{kg}]$ & $74.1 \pm 13.2$ & $78.1 \pm 12.9^{* *}$ & $87.5 \pm 15.9^{\# \# \#}$ & $<0.001$ \\
\hline Fat Free Mass [kg] & $47.4[40.9-57.7]$ & $49.7[41.3-57.0]$ & $55.8[46.6-62.3]^{\# \# \#}$ & $<0.001$ \\
\hline Fat Mass [kg] & $23.9[20.0-28.8]$ & $26.8[22.0-34.8]^{* * *}$ & $30.9[24.4-39.4]^{\# \#}$ & $<0.001$ \\
\hline BMI $\left[\mathrm{kg} / \mathrm{m}^{2}\right]$ & $25.5 \pm 3.5$ & $27.5 \pm 4.4^{* * *}$ & $29.9 \pm 5.1^{\# \# \#}$ & $<0.001$ \\
\hline Waist Circumference $[\mathrm{cm}]$ & $89.4 \pm 10.9$ & $96.7 \pm 11.2^{* * *}$ & $105.1 \pm 13.1^{\# \# \#}$ & $<0.001$ \\
\hline Hip Circumference $[\mathrm{cm}]$ & 99.2 [95.0 - 104.0] & $100.5[95.8-107.1]^{* *}$ & $103.6[99.0-111.3]^{\# \# \#}$ & $<0.001$ \\
\hline Visceral Adipose Tissue $\left[\mathrm{cm}^{2}\right]^{a}$ & $112.8[69.4-172.9]$ & $160.8[117.0-220.7]^{* * *}$ & $248.5[171.0-317.3]^{\# \# \#}$ & $<0.001$ \\
\hline Fasting Plasma Glucose [mmol/l] & $5.20 \pm 0.41$ & $5.85 \pm 0.61^{* * *}$ & $7.61 \pm 1.51^{\# \# \#}$ & $<0.001$ \\
\hline HOMA-IR ${ }^{b}$ & $1.20[0.88-1.65]$ & $1.71[1.21-2.70]^{* * *}$ & $2.27[1.30-3.19]^{\# \#}$ & $<0.001$ \\
\hline Matsuda Index ${ }^{c}$ & $4.27[3.10-6.18]$ & $2.07[1.34-3.44]^{* * *}$ & $1.79[1.10-2.97]^{\# \# \#}$ & $<0.001$ \\
\hline $\mathrm{HbA} 1 \mathrm{c}[\%]$ & $5.3[5.1-5.5]$ & $5.6[5.3-5.9]^{* * *}$ & $6.6[6.1-7.0]^{\# \# \#}$ & $<0.001$ \\
\hline Systolic Blood Pressure [mmHg] & $130.2 \pm 17.0$ & $133.8 \pm 16.0^{*}$ & $138.4 \pm 16.9^{\# \# \#}$ & $<0.001$ \\
\hline Diastolic Blood Pressure [mmHg] & $77.4 \pm 9.9$ & $76.3 \pm 9.6$ & $75.5 \pm 9.5$ & 0.125 \\
\hline Glucose lowering Therapy [\%] & 0 & 0 & 75.6 & N/A \\
\hline Blood Pressure Lowering Therapy [\%] & 20.8 & $44.0^{* * *}$ & $69.2^{\# \# \#}$ & $<0.001$ \\
\hline Lipid Lowering Therapy [\%] & 14.2 & $39.4^{* * *}$ & $72.0^{\# \# \# ~}$ & $<0.001$ \\
\hline Anti-inflammatory Therapy [\%] & 12.7 & 16.5 & 13.2 & 0.572 \\
\hline History of Cardiovascular Disease [\%] & 11.9 & 17.4 & $25.6^{\# \# \#}$ & $<0.001$ \\
\hline White Blood Cell Count, Blood [x10^9/l] & $5.05[4.30-5.90]$ & $5.60[4.70-6.80]^{* * *}$ & $6.00[5.10-7.30]^{\# \# \#}$ & $<0.001$ \\
\hline $\begin{array}{l}\text { Neutrophilic Granulocyte Count, Blood } \\
{\left[\times 10^{\wedge} 9 / I\right]}\end{array}$ & $2.76[2.24-3.35]$ & $3.23[2.47-4.14]^{* * *}$ & $3.46[2.85-4.19]^{\# \# \#}$ & $<0.001$ \\
\hline $\begin{array}{l}\text { Eosinophilic Granulocyte Count, Blood } \\
{\left[\times 10^{\wedge} 9 / I\right]}\end{array}$ & $0.14[0.09-0.20]$ & $0.17[0.11-0.22]^{*}$ & $0.17[0.11-0.24]^{\# \# \#}$ & $<0.001$ \\
\hline Lymphocyte Count, Blood [x10^9/I] & $1.63[1.37-1.98]$ & $1.72[1.43-2.07]$ & $1.84[1.52-2.24]^{\# \# \#}$ & $<0.001$ \\
\hline Monocyte Count, Blood [x10^9/I] & $0.42[0.34-0.50]$ & $0.46[0.36-0.58]^{* * *}$ & $0.48[0.40-0.61]^{\# \# \#}$ & $<0.001$ \\
\hline NK Cell Count, Blood [x10^9/I] & $0.19[0.13-0.27]$ & $0.21[0.14-0.27]$ & $0.22[0.14-0.31]^{\#}$ & 0.121 \\
\hline NK-CD11B MFI, Blood [AU] & $8866 \pm 2188$ & $9140 \pm 2200$ & $9419 \pm 2291^{\# \# \#}$ & 0.006 \\
\hline Low-grade Inflammation Z-score & $-0.34 \pm 0.92$ & $0.27 \pm 0.94^{* * *}$ & $0.53 \pm 0.91^{\# \# \#}$ & $<0.001$ \\
\hline Plasma TNF [pg/ml] & $2.06[1.75-2.40]$ & $2.17[1.93-2.62]^{* * *}$ & $2.46[2.15-2.82]^{\# \# \#}$ & $<0.001$ \\
\hline Plasma IL-6 [pg/ml] & $0.47[0.30-0.71]$ & $0.59[0.42-0.90]^{* * *}$ & $0.81[0.56-1.10]^{\# \# \#}$ & $<0.001$ \\
\hline
\end{tabular}

Data presented as mean \pm SD or median [IQR]. Baseline differences between individuals with prediabetes and normal glucose metabolism (NGM), and type 2 diabetes (T2DM) and NGM were assessed by means of independent samples Student's T-test, Mann-Whitney $U$ test, or chi-square test where appropriate. P-value prediabetes compared to NGM; ${ }^{*} \mathrm{p}<0.05,{ }^{* *} \mathrm{p}<0.01, * * * \mathrm{p}<0.001$. P-value T2DM compared to NGM; $\# p<0.05,{ }^{\#} p<0.01, \# p<0.001$. Differences between all groups were assessed by means of one-way ANOVA, Kruskal-Wallis test, or chi-square test where appropriate; respective $p$-values reported in separate column. ${ }^{a}$ Analyzed in 405 NGM, 93 prediabetes, and 198 T2DM; ${ }^{b}$ analyzed in 310 NGM, 73 prediabetes, and 179 T2DM; ' analyzed in 313 NGM, 71 prediabetes, and 156 T2DM. 
Table S5.4 - Associations between NK-CD11B and z-LGI, plasma TNF or plasma IL-6 ( $n=839$ ).

\begin{tabular}{|c|c|c|c|}
\hline \multirow{4}{*}{ NK-CD11B (x1000) } & \multirow{2}{*}{ Model } & \multicolumn{2}{|c|}{ z-LGI } \\
\hline & & $\beta(95 \%-\mathrm{Cl})$ & p-value \\
\hline & 1 & $0.039(0.010 ; 0.067)$ & 0.007 \\
\hline & 2 & $0.028(0.000 ; 0.055)$ & 0.048 \\
\hline \multirow{4}{*}{ NK-CD11B (x1000) } & \multirow{2}{*}{ Model } & \multicolumn{2}{|c|}{ z-TNF } \\
\hline & & $\beta(95 \%-\mathrm{Cl})$ & $p$-value \\
\hline & 1 & $0.040(0.011 ; 0.070)$ & 0.007 \\
\hline & 2 & $0.034(0.005 ; 0.064)$ & 0.023 \\
\hline \multirow{4}{*}{ NK-CD11B (x1000) } & \multirow{2}{*}{ Model } & \multicolumn{2}{|c|}{ z-IL-6 } \\
\hline & & $\beta(95 \%-\mathrm{Cl})$ & p-value \\
\hline & 1 & $0.073(0.044 ; 0.102)$ & $<0.001$ \\
\hline & 2 & $0.042(0.014 ; 0.071)$ & 0.004 \\
\hline
\end{tabular}

Model 1: Adjusted for age, sex, and glucose metabolism status. Model 2: Fully adjusted model (model $1+$ systolic blood pressure, total-to-HDL cholesterol ratio, smoking status, prior cardiovascular disease, and use of antihypertensive, anti-inflammatory, glucose-lowering or lipid-lowering medication). Multiple linear regression analyses in individuals with normal glucose metabolism $(n=480)$, prediabetes $(n=109)$, and type 2 diabetes $(n=250)$. The beta of each model is presented along with its respective $95 \%-\mathrm{Cl}$ and $\mathrm{p}$-value. 


\section{Star*methods}

\section{Experimental model and subject details}

\section{Biopsy studies}

Age-matched men who were scheduled to undergo abdominal or bariatric surgery were recruited. The decision to undergo surgery was made independently of this research protocol, between patient and physician. The control group consisted of 15 lean men. The obese group was composed of 17 men. Within obese individuals there were three patients with type 2 diabetes, each was on glucose-lowering medication. Six obese individuals were on lipid-lowering medication and 10 used antihypertensive medication. None of the lean individuals used any medication. Lean individuals were included due to surgery of inguinal hernia, except for one person undergoing laparoscopic cholecystectomy. Clinical characteristics of the individuals included in the study are summarized in Supplementary Table S5.1. Major exclusion criteria were presence of a history of heart, lung or kidney disease, and/or presence of endocrine anomalies. The study protocol was approved by the Medical Ethical Committee Jessa hospital and Hasselt University, Hasselt, Belgium, in accordance with the Declaration of Helsinki, and all individuals gave their written informed consent before participating in the study. Body weight, height, waist/hip circumference, and blood pressure were determined at the morning of surgery. Fat and lean body mass were estimated by bio-electrical impedance analyses (Bodystat 1500; Bodystat Ltd., Isle of Man, U.K.). Fasting venous blood samples were collected after an overnight fast for measurement of plasma glucose, serum insulin, and glycated hemoglobin. Plasma glucose was measured by the glucose oxidase method using an AU2700 analyzer (Beckman Coulter, Brea, CA, USA). Serum insulin was assessed by immunoassay (ADVIA Centaur Insulin IRI; Siemens Medical Solutions Diagnostics, Tarrytown, NY, USA). Glycated hemoglobin was assessed by high performance liquid chromatography using a HA-8160 Hi-Auto A1C analyzer (Menarini, Zaventem, Belgium). Blood cell counts were done with ADVIA 2120 Hematology System (Siemens). After an overnight fast, blood was drawn and adipose tissue biopsies were taken from the abdominal subcutaneous adipose tissue depot (SAT) and the omentum majus (VAT). For each adipose tissue depot, approximately 1-3 g adipose tissue was collected. The tissue was immediately brought to the laboratory for further processing. Stromal vascular fraction (SVF) cells were obtained by collagenase digestion of adipose tissue fragments in Dulbecco's Modified Eagle's Medium (DMEM)-Ham's F12 with Collagenase 11 (Sigma Aldrich C7657, $0.0875 \mathrm{mg} / \mathrm{ml}$ ), collagenase 1 (Sigma Aldrich C0130, $1.216 \mathrm{mg} / \mathrm{ml}$ ) and DNAse 1 (Sigma Aldrich DN25, $0.09 \mathrm{mg} / \mathrm{ml}$ ) under gentle shaking $\left(60 \mathrm{cycles} / \mathrm{min}\right.$ ) at $37^{\circ} \mathrm{C}$. The resulting suspension was filtered through a 200 
$\mu \mathrm{m}$ filter and fat cells were removed as floating fraction after centrifugation (5 min, $1250 \mathrm{rpm})$. SVF cells were washed once with DMEM-Ham's F12 to eliminate collagenase, filtered through a $70 \mu \mathrm{M}$ filter and stained for flow cytometry. In an additional study, we collected adipose tissue biopsies from female controls and female obese women (BMI = $28.1 \pm 3.1$ vs $42.6 \pm 1.6$; $p=0.001$ ) for assessment of adipose tissue NK cell subsets.

\section{Metabolic phenotyping study}

In this cross-sectional study with blinded analyses, 53 abdominally obese and 25 lean men were recruited by advertisements and enrolled at the Maastricht University Medical Center in Maastricht, The Netherlands, from August, 2012 to May, 2014 as described previously. ${ }^{21}$ Participants were aged $18-65$ years, non-smokers, nondiabetic, free of CVD, had a waist circumference below $94 \mathrm{~cm}$ (lean) or between $102-110 \mathrm{~cm}$ (abdominally obese), and a stable body weight for at least 3 months. Men were excluded when fasting plasma glucose was $>7.0 \mathrm{mmol} / \mathrm{l}$, when $\mathrm{HbA} 1 \mathrm{c}$ was $>6.5 \%$, when serum total cholesterol was $>8.0 \mathrm{mmol} / \mathrm{l}$, when serum triacylglycerol was $>4.5$ $\mathrm{mmol} / \mathrm{l}$, when they had a contra-indication for MRI, and/or when they used medication affecting blood pressure, or serum lipid or glucose metabolism. Clinical characteristics of the individuals included in the study are summarized in Supplementary Table S5.2. All participants gave written informed consent. The study was approved by the institutional medical ethical committee (NL41397.068.12) and performed in accordance with the Declaration of Helsinki.

Metabolic and vascular measurements were conducted in a temperature-controlled room $\left(\mathrm{T}=24^{\circ} \mathrm{C} \pm 0.5^{\circ} \mathrm{C}\right.$ ) after a 12 -hour overnight fast with the individuals in the supine position. Individuals were instructed to refrain from alcohol and meals rich in lipids for a period of 24 hours prior to each study day, and strenuous physical exercise for a period of 48 hours prior to each study day. After insertion of two intravenous catheters and a 30-minute acclimatization period, baseline vascular measurements were performed and blood was taken and frozen for flow cytometry analysis. Metabolic insulin sensitivity was assessed by a $1 \mathrm{mU} / \mathrm{kg} / \mathrm{min}$ euglycemic insulin clamp as described previously. ${ }^{27}$ Briefly, insulin (Novorapid, Novo Nordisk, Bagsvaerd, Denmark) was infused in a primed continuous manner for 180 minutes. Meanwhile, isoglycemia was maintained with a variable rate $20 \%$ glucose infusion. Metabolic insulin sensitivity was estimated from the steady-state glucose infusion rate (90 - 150 min of the clamp). Information on visceral and subcutaneous adipose tissue volumes was obtained through two-dimensional T1-weighted turbo spin echo (TSE) imaging on a 3.0T Philips Achieva MRI scanner with a dedicated sixteen-element torso coil (XL Torso coil, Philips Healthcare, Best, The Netherlands). Nine $5 \mathrm{~mm}$ thick transverse slices with $10 \mathrm{~mm}$ gaps centered at the top of the $\mathrm{L} 4$ vertebral body were 
acquired using the following scan parameters: repetition time $(T R)=526 \mathrm{~ms}$, echo time $=10 \mathrm{~ms}$, turbo spin echo factor $=4$, number of signal averages (NSA) $=1$, field of view $(F O V)=400 \times 322 \mathrm{~mm}$, acquired matrix size $=308 \times 164$, acquired in-plane voxel size $=1.3 \times 1.96 \mathrm{~mm}$, reconstructed matrix size $=512 \times 412$, and a reconstructed voxel size of $0.78 \times 0.78 \mathrm{~mm}$. Images were analyzed offline after completion of the trial with dedicated software (Hippo Fat, IFC CNR, Pisa, Italy) to provide subcutaneous and visceral fat volumes.

\section{Validation study (The Maastricht Study)}

For this validation dataset we used data from the Maastricht Study, a populationbased cohort study. The rationale and methodology have been described previously (Schram et al., 2014). In brief, the study focuses on the etiology, pathophysiology, complications and comorbidities of T2DM and is characterized by an extensive phenotyping approach. Eligible for participation were all individuals aged between 40 and 75 years and living in the southern part of the Netherlands. Individuals were recruited through mass media campaigns and from the municipal registries and the regional Diabetes Patient Registry via mailings. Recruitment was stratified according to known T2DM status, with an oversampling of individuals with T2DM, for reasons of efficiency. Clinical characteristics of the individuals included in the study are summarized in Supplementary Table S5.3. For this study, fresh whole blood of 1104 participants of the Maastricht Study consecutively enrolled between January and November 2013 were used for flow cytometry. The examinations of each participant were performed within a time window of three months. The study has been approved by the institutional medical ethical committee (NL31329.068.10) and the Minister of Health, Welfare and Sports of the Netherlands (Permit 131088-105234-PG). All individuals gave written informed consent.

To determine glucose metabolism, all individuals (except those who used insulin or those with a fasting glucose level above $11.0 \mathrm{mmol} / \mathrm{l}$ ) underwent a standardized seven-point oral glucose tolerance test after an overnight fast as previously described. ${ }^{25}$ Diabetes mellitus and prediabetes were defined according to the WHO 2006 criteria, the latter defined as presence of either impaired fasting glucose or impaired glucose tolerance. People with diabetes mellitus and people who used glucose-lowering medication were considered as having type 2 diabetes if they had no self-reported type 1 or other specific type of diabetes. Fasting blood samples were collected from all individuals and $\mathrm{HbA} 1 \mathrm{c}$, and total, LDL and HDL cholesterol were determined as described elsewhere. ${ }^{25}$ Office blood pressure was determined according to a standardized protocol. Smoking status was assessed by questionnaire, and history of CVD and medication use during an interview. The magnetic resonance images were acquired using a $3 T$ MRI system (MAGNETOM Prisma ${ }^{\text {fit }}$, Siemens 
Healthineers, Erlangen, Germany) with body matrix and supine radiofrequency coils. Subjects were positioned supine. After an initial scout view, a single-slice transversal image at the top level of the $L 4$ vertebral body was obtained during breath-hold to assess areas of the visceral and subcutaneous adipose tissue compartments using a T1-weighted TSE pulse sequence with the following parameters: acquired and reconstructed in-plane voxel size $2 \times 2 \mathrm{~mm}^{3}$, slice thickness $8 \mathrm{~mm}$, TR $550 \mathrm{~ms}$, NSA = 1, parallel imaging (GRAPPA) factor $=2$, turbo factor $=7$. Depending on the size of the patient, the FOV was $384 \times 312 \mathrm{~mm}^{2}$ with a TE of $36 \mathrm{~ms}$ or $500 \times 406 \mathrm{~mm}^{2}$ with a TE of $38 \mathrm{~ms}$.

\section{Method details}

\section{Flow cytometry}

Fresh heparinized whole blood (50 $\mu$ ) (study 1 and 3) or thawed whole blood (study 2) was used for staining for flow cytometry using CD3-fitc (BD 561807), CD19-fitc (BD 555412), CD66b-fitc (BD 555724), CD56-PE (BD 345810), HLA-DR-V500 (BD 561224), CD14-APC-H7 (BD 641394), CD16-PerCP (BD 560717), CD11B-BV421 (BD 562632), CD11C-PE-CY7 (BD 561356), and CX3CR1-APC (Biolegend 341609). The complete gating strategy was published elsewhere (Wouters ${ }^{14}$ and Supplemental Figure S3.3 in chapter three). Briefly, from single blood cells, live cells were gated based on forward and side scatters. From live cells, NK cells were gated as negative for CD3 (T cells), CD19 (B cells), CD66b (granulocytes), HLA-DR (monocytes, dendritic cells) and positive for CD56. For samples from female donors, we used PBMCs and stained them with CD16-FITC, CD56-PerCP-Cy5.5, NKP46-PE, NKG2D -APC, and CD11B-Horizon V450. Singlets were gated based on both forward and side scatters. Live cells were defined as negative for live-death staining. NK cells were CD3- and CD56+, which were subdivided according to CD56 and CD16 surface expression.

Isolated SVF cells were stained with CD45-PE-Cy7 (BD 557748), CD3-fitc (BD 561807), CD19-fitc (BD 555412), CD56-fitc (BD 562794), CD66b-fitc (BD 555724), CD11B-BV421 (Biologend 301324), and CD11C-APC-Cy7 (Biolegend 337218). Cocktail 2 included CD45-PE-Cy7 (BD 557748), CD3-V500 (BD 561416), CD4-PerCP (Biolegend 300528), CD8 APC-H7 (BD 641400), CD19-BV421 (Biolegend 302234), and CD56-APC (Biolegend 318310). SVF cells from VAT and SAT were gated for live single cells based on forward and side scatters. Immune cells were selected based on CD45 expression. Lymphocyte populations in AT were identified based on CD19 for B-cells and CD3 for T-cells. T-cells were further subdivided in $\mathrm{CD}^{+}{ }^{+} \mathrm{Tc}$ cells and $\mathrm{CD} 4^{+}$Th cells. Non-B- and T-cells were gated for CD56 to identify NK cells (cocktail 2). From CD45 ${ }^{+}$cells B-cells (CD19), T-cells (CD3), NK cells (CD56) and granulocytes (CD66b) were excluded for the identification 
of macrophages (defined as $C D 11 B^{\text {hi }}$ ), which were subdivided in $C^{2} 11 B^{+} C D 11 C^{-}$and

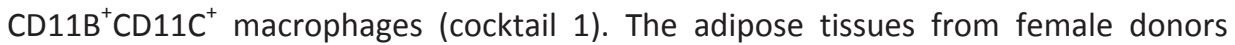
were stained with CD16-FITC (BD 555406), NKp46-PE (BD 557991), CD56-PerCP-Vio (Miltenyi 130-100-681), NKG2D-APC (Miltenyi 130-096-610), CD3-APC-Vio770 (Miltenyi 130-096-610), CD11B-V421 (562632), and a fixable viability stain V510 (BD 564406). SVF single cells were identified based on scatter parameters, and live cells

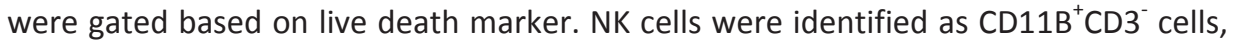
which were further subdivided according to CD56 and CD16 expression. Samples were measured with a FACS-Canto II (BD Biosciences). Results were analyzed with FACSdiva software (BD Biosciences). Each panel was optimized using fluorescence minus one (FMO) controls and isotype controls, yielding similar measures as auto-fluorescent samples. For each experiment, an auto-fluorescence control was performed.

\section{NK cell isolation and measurements}

PBMCs were isolated from fresh blood using density gradient centrifugation (Histopaque, Sigma-Aldrich H889-500ML). For flow cytometry of surface markers, 250000 PBMCs were stained with Live/death fixable viability stain (BD 564406), CD3-APC-Vio770 (Miltenyi 130-096-610), CD56 PerCP-Vio700 (Miltenyi 130-100-681), CD11B BV421 (BD 562632), CD16 FITC (BD 555406), NKp46/CD335 (Miltenyi 130-092607), NKG2D (Miltenyi 130-092-673), and measured with with a FACS-Canto II (BD Biosciences). Results were analyzed with FACSdiva software (BD Biosciences). Singlets were identified based on scatter plots. Live cells were gated using the viability stain, after which NK cells were identified as $\mathrm{CD}^{-} \mathrm{CD} 56^{+}$cells.

For intracellular staining assays and for co-culture experiments, PBMCs were used for NK cell isolation using magnetic bead separation assays (Human NK isolation kit, Miltenyi 130-092-657). Per well, 50,000 NK cells were plated in 96 round-bottom plates. Monensim (BD \# 554724) and Brefeldin (BD \# 51-2301) were added according to manufacturer's instructions for 15 hours. Hereafter, cells were stained with viability stain (BD 564406), CD3-APC-Vio770 (Miltenyi 130-096-610), CD56 PerCP-Vio700 (miltenyi 130-100-681), CD11B BV421 (BD 562632). Hereafter Fixation and permeabilization solutions were added (Invitrogen 00-5123-43, 00-5223-56, 00-833356). After incubation, TNF-PE (Biolegend 502909) and IFNg-V450 (BD \# 560371) antibodies were added, and measured with with a FACS-Canto II (BD Biosciences). Results were analyzed with FACSdiva software (BD Biosciences). Singlets were identified based on scatter plots. Live cells were gated using the viability stain, after which NK cells were identified as $\mathrm{CD}^{-} \mathrm{CD} 56^{+}$cells. All experiments included isotype controls and auto-fluorescent controls. For co-culturing experiments, human peripheral blood cells from a healthy donor were differentiated into human monocyte-derived macrophages as described previously. ${ }^{28}$ In short, $5 \times 10^{6}$ PBMCs 
were plated in 24-well Primaria plates (Corning 353847). After $2 \mathrm{~h}$, non-adherent cells were discarded and culture medium was added (RPMI1640-Glutamax, Gibco \# 61870010; Pen/Streptomycin 5000 U, Gibco \# 15070; Sodium Pyruvate 100mMol (100x) Gibco \# 11360-039; NEN-AminoAcids (100x) Gibco \# 11140-035) supplemented with 10\% Inactivated Human AB serum; Milan Anal. \# 000084; lot\# 00625. Cells were differentiated for 7 days before further use. M2-polarized macrophages were obtained by incubation with $20 \mathrm{ng} / \mathrm{ml} \mathrm{IL-4}$ (Miltenyi 130-093-924) and $100 \mathrm{\mu g} / \mathrm{ml} \mathrm{IL-10}$ (Thermofisher PHC0105) for 16 hours. Next, 50,000 isolated NK cells were added on confluent macrophages for $24 \mathrm{~h}$. Hereafter, cells were harvested for flow cytometry analysis using Live/death fixable viability stain (BD 564406) and CD64-BV421 Biolegend 305019), CCR7-FITC (Biolegend 353216), CD86-APC or CD206-BV421 (BD 564062) and CD209-FITC (Biolegend 330103) for flow cytometry.

\section{Plasma biomarkers of low-grade inflammation}

The assessment of biomarkers of low-grade inflammation (C-reactive protein, serum amyloid A, interleukin 6 , interleukin 8 , soluble intercellular adhesion molecule 1 , and tumor necrosis factor) were assessed by a multiarray detection system based on electro-chemiluminescence technology (MesoScaleDiscovery, SECTOR Imager 2400, Gaithersburg, Maryland, USA) as described previously. ${ }^{29}$ Briefly, this system uses multiarray plates fitted with multielectrodes per well with each electrode being coated with a different catching antibody. The assay procedure then follows that of a classic sandwich ELISA with any of the analytes of interest captured on the relevant electrode. These captured analytes were then in turn detected by a secondary analyte-specific ruthenium-conjugated antibody, which is capable of emitting light after electrochemical stimulation. A particular advantage of this system is the ability to measure different biomarkers of low-grade inflammation and/or endothelial dysfunction simultaneously in relatively small ( 25 or $50 \mu \mathrm{l}$ ) serum samples.

\section{Quantification and statistical analysis}

For each analyses, the number of individuals, data expression, and statistical test used are indicated in each figure and table legend. Throughout the results section, data are expressed as mean \pm SD or median [IQR]. Differences between groups were assessed by means of two-tailed independent Student's t-tests or Mann-Whitney U tests where appropriate. We used Pearson's correlation coefficients and linear regression analyses to investigate the associations between VAT, VAT NK cells, CD11B surface expression, z-scores of LGI, plasma TNF levels, and insulin resistance where appropriate. Log transformation, square root transformation, or reciprocal transformation of variables were performed if warranted to not violate the assumptions of the statistical tests. 
Analyses were performed using SPSS version 20. Multiple mediation analyses were carried out with the PROGRESS plug-in for SPSS version 2.13 (A.F. Hayes, Ohio State University, $\mathrm{OH}, \mathrm{USA}$ ). All regression and mediation models were adjusted for potential confounders and specified per analysis. Two-tailed $p$-values of $<0.05$ were considered statistically significant.

\section{Additional resources}

The first biopsy study (ClinicalTrial.gov, NCT02598544) and the metabolic phenotyping study have been registered (ClinicalTrial.gov, NCT01675401). The validation study is registered at the Dutch research database ToetsingOnline (NL31329.068.10) and has been approved by the Minister of Health, Welfare and Sports of the Netherlands, on the basis of the Health Council's opinion (Permit 131088-105234-PG). 




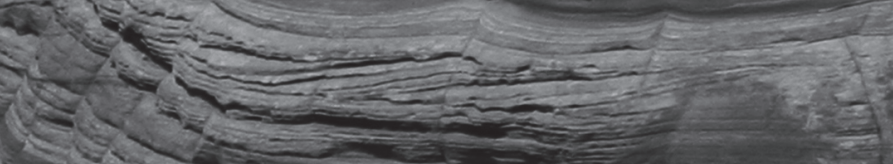
$\operatorname{lin}_{2}$

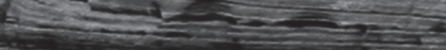

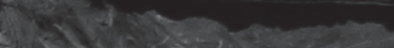

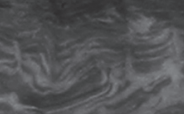

$+2$

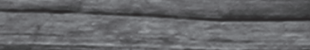

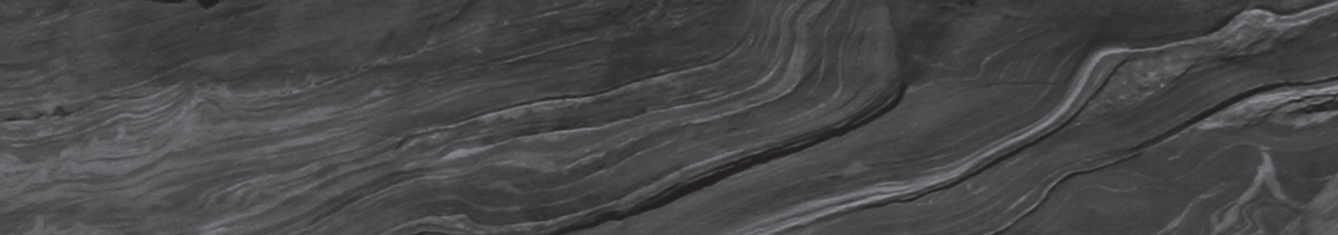

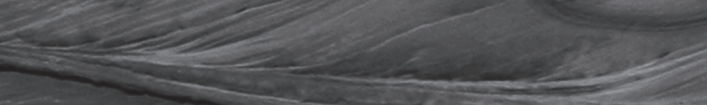

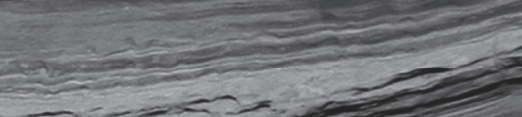

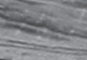

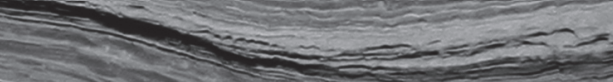




\section{Chapter 6}

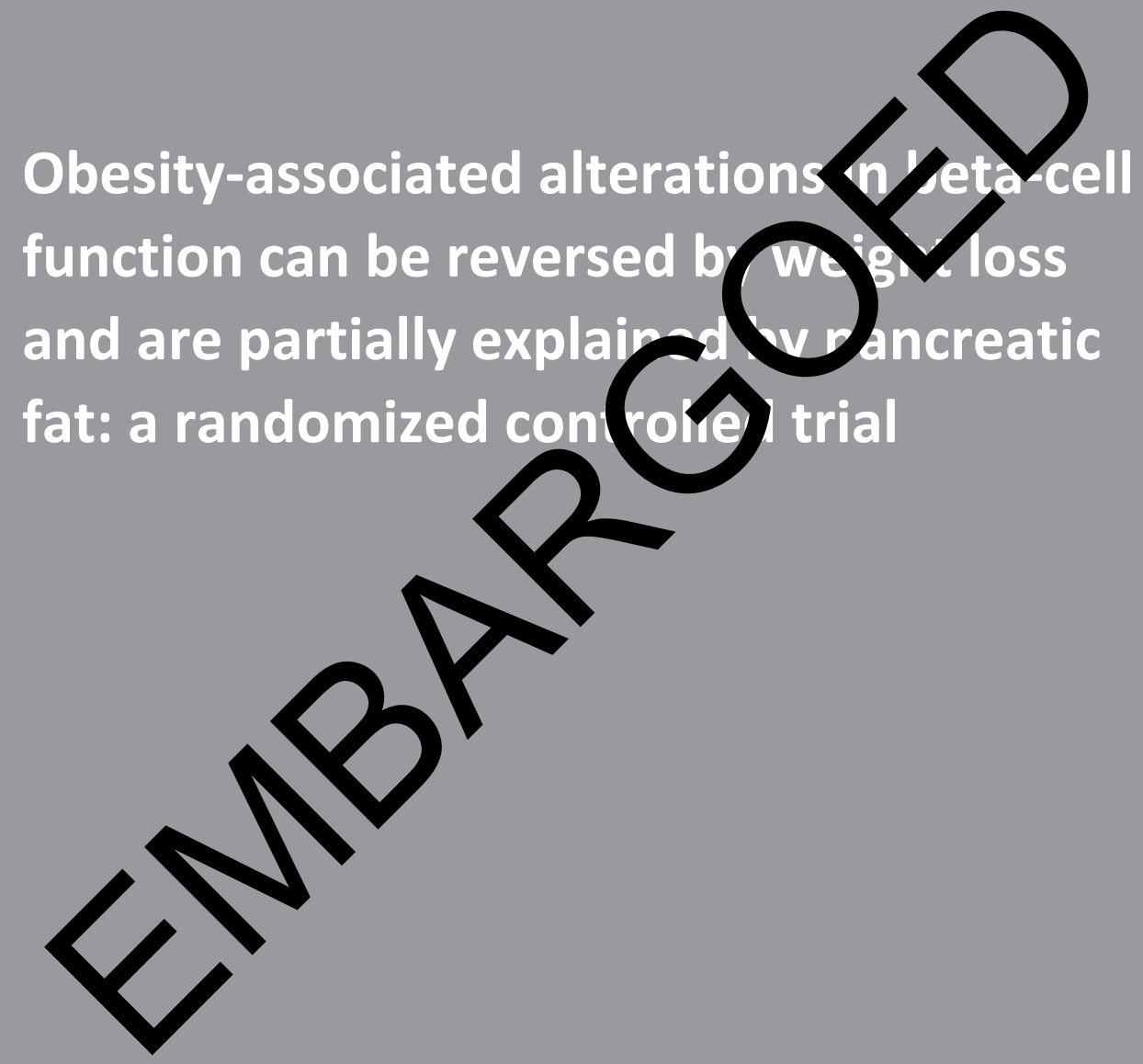

Yvo H.A.M. Kusters, Simone J.S. Sep, Casper G. Schalkwijk, Alfons J.H.M. Houben, M. Eline Kooi, Peter J. Joris, Jogchum Plat, Ronald P. Mensink, Andrea Mari, Ele Ferrannini, Coen D.A. Stehouwer 
This chapter is embargoed at request

\section{Chapter 7}

Diet-induced weight loss improve not only cardiometabolic risk mark ercsu also markers of vascular fur on

\section{a randomized controlled tr}

\section{in abdominally obese hen}

Peter J. Joris, Jogchum Plat, Yvo H.A.M. Kusters, Alfons J.H.M. Houben, Coen D.A. Stehouwer, Casper G. Schalkwijk, Ronald P. Mensink 
This chapter is embargoed at request

\section{Chapter 8}

\section{General discussion}

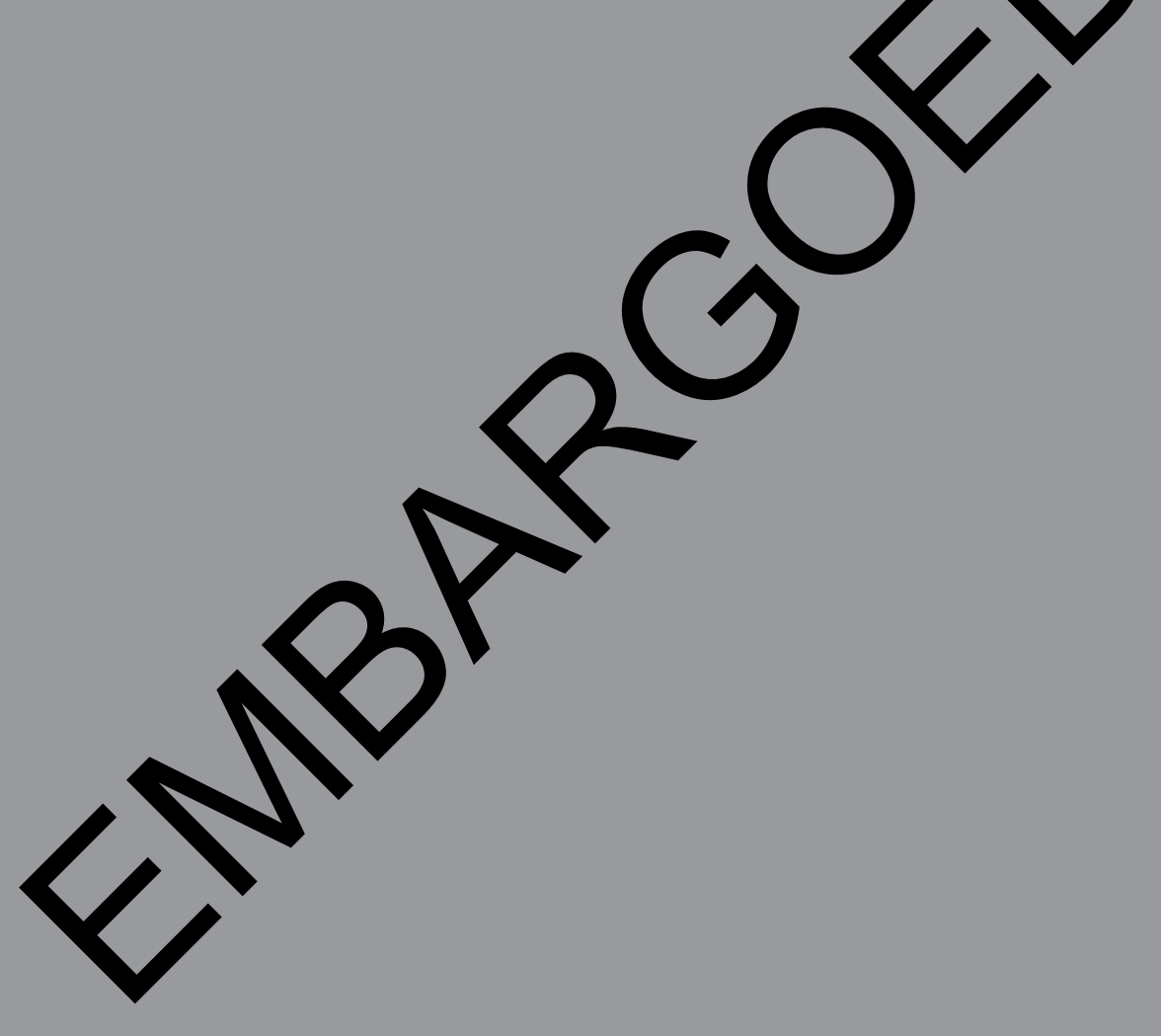





\section{Nederlandstalige samenvatting}

Wereldwijd lijden steeds meer mensen aan overgewicht en obesitas, waardoor er tevens meer mensen ziektes als diabetes (type 2 ) en hart- en vaatziekten ontwikkelen. Deze ziekten leiden op hun beurt weer tot veel ziektelast, ziektekosten en overmatige sterfte. Eerdere onderzoeken hebben getoond dat er een aanzienlijke overlap is tussen de risicofactoren voor diabetes en hart- en vaatziekten.

Wanneer iemand diabetes ontwikkelt, zijn er vaak twee cruciale veranderingen in het lichaam. Enerzijds raakt het lichaam ongevoelig voor de werking van het hormoon insuline, hetgeen men insulineresistentie noemt. Anderzijds kunnen de bètacellen in de alvleesklier onvoldoende insuline aanmaken om de glucosewaarde in het bloed (de "bloedsuiker") onder controle te houden.

Deze twee processen houden nauw verband met elkaar. Insuline is immers nodig om voedingsstoffen als glucose te verplaatsen van het bloed naar andere organen, zoals het hart, spieren en vetweefsel. In het geval van insulineresistentie is er meer insuline nodig om dit effect te bereiken, waardoor de bètacellen in de alvleesklier meer insuline moeten aanmaken. Als de bètacellen echter onvoldoende aan die verhoogde vraag kunnen voldoen, zal diabetes ontstaan. Het onvoldoende aanmaken van insuline door bètacellen (hetgeen men bètaceldisfunctie kan noemen) is echter niet zwart-wit, het ontstaat waarschijnlijk geleidelijk. Het is echter onduidelijk of bij mensen met obesitas er reeds sprake is van enige vorm van bètaceldisfunctie. Bijkomend probleem is dat het moeilijk is om bètaceldisfunctie te onderscheiden van de noodzakelijke compensatie voor insulineresistentie.

Bij de ontwikkeling van hart- en vaatziekten zijn er een aantal welbekende risicofactoren als hoge bloeddruk (hypertensie), hoog cholesterol (hypercholesterolemie), roken en oudere leeftijd. Bij de algemene bevolking zijn enkele risicofactoren minder bekend die wel belangrijk zijn, zoals insulineresistentie en verslechterde functie van de bloedvaten (vaatdisfunctie). Op zijn beurt kan vaatdisfunctie zich op verschillende niveaus manifesteren. Zo kan de werking van de binnenste laag cellen van de bloedvaten, het endotheel, verminderd zijn (endotheeldisfunctie), maar ook de elasticiteit van de grote slagaders kan afnemen (vaatverstijving). Endotheeldisfunctie kan ook in de kleinste bloedvaten (de microcirculatie) van spieren voorkomen en leiden tot insulineresistentie. Dit mechanisme, alsook andere functies van de microcirculatie in de spieren, worden in hoofdstuk twee verder beschreven en hieronder beknopt besproken. 


\section{Microcirculatie van de spier}

In de skeletspieren lopen de allerkleinste bloedvaatjes (de capillairen) parallel aan de spiervezels, waardoor deze optimaal voedingsstoffen (zoals glucose, aminozuren en vetzuren) en zuurstof aan spiercellen kunnen aanbieden en afvalstoffen kunnen afvoeren. In rust is slechts een deel van de bloedvaatjes van de spier doorbloed. Er is dus een grote reservecapaciteit die benut kan worden, zoals bijvoorbeeld tijdens sporten. Ook een stijging in insuline - zoals na het eten van een maaltijd - leidt tot doorbloeding van meer bloedvaatjes. Hierdoor wordt het contactoppervlak voor (glucose)transport sterk vergroot. Dit is mogelijk doordat het endotheel van de allerkleinste aanvoerende bloedvaten, de terminale arteriolen, stikstofoxide produceren als de insulinespiegel in het bloed stijgt. Stikstofoxide zorgt voor vaatverwijding van de terminale arteriolen, waardoor er meer capillairen doorbloed worden; dit wordt microvasculaire rekrutering genoemd (grafisch weergegeven in figuur 2.1). Enerzijds wordt door microvasculaire rekrutering een normale glucosespiegel in het bloed hersteld en anderzijds wordt er energie opgeslagen in de spieren voor toekomstige inspanningen. Bij mensen met obesitas is er vaak sprake van onvoldoende microvasculaire rekrutering als gevolg van endotheeldisfunctie: er wordt minder stikstofoxide geproduceerd en er ontstaat weinig tot geen vaatverwijding. Hierdoor kan het lichaam voedingsstoffen als glucose niet goed opslaan, stijgt de glucosespiegel in het bloed tot hogere waardes en blijft deze glucosespiegel ook gedurende langere tijd verhoogd. Mede hierdoor kan op den duur onherstelbare schade ontstaan, bijvoorbeeld aan slagaders in het hele lichaam en de microcirculatie van bijvoorbeeld ogen en nieren.

\section{Doelstellingen van dit proefschrift}

Het onderzoek beschreven in dit proefschrift had diverse doelstellingen, te weten:

1. Welke mechanismen leiden, onafhankelijk van elkaar, tot insulineresistentie? (hoofdstukken vier en vijf)

2. Is er reeds sprake van veranderde bètacelfunctie bij mensen met obesitas en draagt vervetting van de alvleesklier hieraan bij? (hoofdstuk zes)

3. Leidt gewichtsverlies tot verbeterde insulinegevoeligheid, bètacelfunctie, vaatfunctie en een gunstiger cardiovasculair risico? (hoofdstukken vier, zes en zeven)

4. Hoe betrouwbaar en nauwkeurig zijn de meetmethodes die we hebben gebruikt om bovenstaande te onderzoeken (hoofdstuk drie)?

Een verschil in aanpak ten opzichte van voorgaande onderzoeken is dat wij gebruik hebben gemaakt van een statistische methode genaamd meervoudige mediatieanalyse. Hiermee konden meerdere alternatieve hypotheses in één statistisch model getoetst worden, met onder andere als doel om de onafhankelijkheid van bepaalde 
mechanismen te onderzoeken. Onafhankelijkheid is essentieel, als er immers verschillende manieren zijn om ziek te worden, zijn er ook verschillende behandelingen mogelijk én noodzakelijk. In het vervolg van deze Nederlandstalige samenvatting worden de belangrijkste bevindingen van dit proefschrift beschreven.

\section{Belangrijkste bevindingen van dit proefschrift}

\section{Onderliggende mechanismen van insulineresistentie}

Als obesitas ontstaat, kunnen er diverse veranderingen in het lichaam optreden. Zowel onderhuids (subcutaan) vet als vet in de buikholte (visceraal vet) nemen toe, er kan leververvetting optreden en er kan sprake zijn van verminderde microvasculaire rekrutering in de spieren. leder van deze veranderingen zou kunnen leiden tot insulineresistentie. Echter, of dit onafhankelijke bijdragen zijn, was niet eerder onderzocht. In hoofdstuk vier hebben wij laten zien, mede met behulp van meervoudige mediatie-analyses, dat subcutaan en visceraal vet, leververvetting en microvasculaire rekrutering - onafhankelijk van elkaar - een deel van de insulineresistentie in obesitas kan verklaren. Dit betekent dus dat ieder een separaat behandeldoel vormt in de preventie en behandeling van insulineresistentie. Bovendien hebben we, door een deel van de mensen met obesitas af te laten vallen, onderzocht of veranderingen in subcutaan en visceraal vet, leververvetting en microvasculaire rekrutering leiden tot minder insulineresistentie. Het bleek dat veranderingen in leververvetting en microvasculaire rekrutering onafhankelijk van elkaar de verbetering in insulineresistentie kunnen verklaren. Hoewel gewichtsreductie ook tot vermindering van subcutaan en visceraal vet leidde, droegen zij niet statistisch significant bij aan de vermindering van insulineresistentie.

Als we verder inzoomen naar de wijze waarop een overmaat aan visceraal vet kan leiden tot insulineresistentie, dan blijkt dit deels verklaard te worden door een laaggradige ontstekingsreactie (inflammatie) die ontstaat in het viscerale vetcompartiment. In het viscerale vet zijn macrofagen (een type witte bloedcel) verantwoordelijk voor de productie van inflammatoire signaalmoleculen (cytokines), zoals tumor necrosis factor. Wat ertoe leidt dat macrofagen aanwezig zijn in visceraal vet en deze ontstekingsreactie op gang brengen, is onduidelijk in mensen. In hoofdstuk vijf hebben wij in vier onafhankelijke studies onderzocht of een toename van natural killer cellen (NK-cellen; een ander type witte bloedcel) in visceraal vet kan leiden tot een toename van inflammatoire macrofagen in visceraal vet, laaggradige inflammatie en insulineresistentie. 
Onze volgende bevindingen ondersteunen de betrokkenheid van NK-cellen:

1. mensen met obesitas hadden meer NK-cellen in hun visceraal vet;

2. de hoeveelheid NK-cellen in visceraal vet was geassocieerd met inflammatoire veranderingen van macrofagen;

3. als NK-cellen en macrofagen buiten het lichaam samengebracht worden, zorgen NK-cellen afkomstig van mensen met obesitas ervoor dat macrofagen inflammatoire veranderingen ondergaan;

4. de mate van CD11B (een eiwit aan het celoppervlak) expressie op NK-cellen in het bloed was geassocieerd met de hoeveelheid NK-cellen in visceraal vet;

5. CD11B expressie was geassocieerd met tumor necrosis factor productie door NKcellen, bloedspiegels van inflammatoire cytokines en insulineresistentie;

6. meervoudige mediatie-analyses ondersteunen de hypothese dat meer NK-cellen in visceraal vet leiden tot laaggradige inflammatie en insulineresistentie;

7. al deze observaties waren specifiek voor visceraal vet en werden niet gevonden in subcutaan vet;

8. de associatie tussen CD11B expressie, laaggradige inflammatie en insulineresistentie werd bevestigd in een groot onderzoek uitgevoerd bij bewoners van de regio Maastricht (de Maastricht Studie).

In eerdere onderzoeken in muizen werd het mechanisme hoe NK-cellen macrofagen beïnvloeden en tot inflammatie en insulineresistentie leiden reeds gedetailleerd beschreven. Derhalve zijn wij van mening dat onze onderzoeksbevindingen een sterke aanwijzing zijn dat NK-cellen ook in mensen betrokken zijn bij het ontstaan van insulineresistentie.

\section{Onderliggende mechanismen van bètaceldisfunctie}

Als insulineresistentie ontstaat, produceren de bètacellen in de alvleesklier meer insuline als reactie op de stijgende glucosespiegel in het bloed. Bij mensen met diabetes is er sprake van een gestoorde bètacelfunctie: de insulineproductie kan de insulinebehoefte niet meer bijbenen. Het is plausibel dat er reeds in een vroeger stadium, bijvoorbeeld bij mensen met overgewicht of obesitas, een zekere mate van maladaptie van bètacellen is.

Tevens kan er bij mensen met obesitas vervetting van de alvleesklier ontstaan. Een dergelijke vervetting van de alvleesklier zou de werking van de bètacellen kunnen belemmeren; wellicht dat zo een subtiele vorm van bètaceldisfunctie kan ontstaan. In hoofdstuk zes hebben wij onderzocht of er - rekening houdend met de mate van insulineresistentie - aanwijzingen zijn voor bètaceldisfunctie bij mensen met obesitas. Een van de eigenschappen van bètacelfunctie (de zg. potentiatie factor) bleek te zijn veranderd bij mensen met obesitas. Door gewichtsreductie bij mensen met obesitas 
herstelde deze bètacelfunctie zich tot het niveau van slanke mensen. Bovendien kon, met behulp van meervoudige mediatie-analyses, een mogelijke betrokkenheid van alvleeskliervervetting meer aannemelijk gemaakt worden. In onze studie kon de exacte locatie van de vetstapeling in de alvleesklier niet vastgesteld worden. Naar aanleiding van deze studieresultaten en eerdere observaties van de microcirculatie in de spier hebben wij de hypothese geformuleerd dat vetcellen die zich in de nabijheid van de kleine bloedvaten van de alvleesklier bevinden, aldaar via endotheeldisfunctie leiden tot afname van vasodilatatie en bètaceldisfunctie.

\section{Effecten van gewichtsverlies}

In de meerderheid van de hoofdstukken in dit proefschrift zijn de effecten van gewichtsreductie bij mensen met obesitas onderzocht. In hoofdstuk vier hebben wij laten zien dat gewichtsreductie leidt tot een verbeterde microvasculaire rekrutering in spier en een afname van subcutaan vet, visceraal vet, leververvetting en insulineresistentie. Vervolgens werd in hoofdstuk zes beschreven dat gewichtsreductie leidt tot een herstel van bètacelfunctie, mogelijk door afname van alvleeskliervervetting. Tot slot laten wij in hoofdstuk zeven zien dat traditionele risicofactoren voor hart- en vaatziekten, zoals hypertensie en hypercholesterolemie, verbeteren door gewichtsreductie. Anderzijds werden diverse aspecten van vaatfunctie onderzocht, hetgeen wisselende resultaten opleverde. Door gewichtsreductie verbeterde de microcirculatie van het netvlies (de retina): de verhouding tussen de diameters van retinale arteriolen en venulen werd genormaliseerd tot het niveau van slanke mensen. Bovendien daalde de bloedspiegel van sE-selectine, een maat voor endotheeldisfunctie. Echter, een andere veelgebruikte uitkomstmaat voor endotheeldisfunctie (flow-mediated dialation) verschilde in onze studie niet tussen mensen met of zonder obesitas en verbeterde ook niet door gewichtsreductie. Tevens zorgde gewichtsreductie niet voor een statistisch significante verbetering in vaatstijfheid van de grote lichaamsslagaders. Dit is ook niet te verwachten, aangezien de verstijving van bloedvaten een langdurig proces is, waarvan de reversibiliteit door een kortdurende interventiestudie (een gewichtsreductieprogramma van acht weken in ons geval) waarschijnlijk zeer beperkt is.

Samenvattend toont onze interventiestudie dat gewichtsreductie bij mensen met obesitas enerzijds leidt tot een verbetering van de processen die leiden tot diabetes (insulineresistentie en bètaceldisfunctie), alsook verbeteringen van traditionele risicofactoren voor hart- en vaatziekten (hypertensie en hypercholesterolemie). Anderzijds zagen wij dat gewichtsreductie leidde tot een verbetering van enkele vaatfunctiemetingen (bijv. microvasculaire rekrutering, vaatdiameters in de retina, sEselectine), doch niet alle (bijv. flow-mediated dilation en vaatstijfheid). Hoewel het 
reeds duidelijk was dat gewichtsreductie bij mensen met obesitas leidt tot minder diabetes, blijft het onduidelijk of het ook leidt tot minder hart- en vaatziekten.

\section{Conclusie}

Samenvattend laat dit proefschrift zien dat:

1. visceraal vet, subcutaan vet, leververvetting en microvasculaire rekrutering in de spier onafhankelijk van elkaar bijdragen aan insulineresistentie en verbeteren door gewichtsreductie bij mensen met obesitas;

2. NK-cellen in visceraal vet geassocieerd zijn met inflammatoire veranderingen van macrofagen, laaggradige inflammatie en insulineresistentie;

3. er veranderingen in bètacelfunctie zijn bij mensen met obesitas, welke herstellen na gewichtsreductie en mogelijk ten dele verklaard worden door veranderingen in alvleeskliervervetting;

4. gewichtsreductie leidt tot verbetering van traditionele risicofactoren voor harten vaatzieken en enkele, doch niet alle, vaatfunctiemetingen; en

5. de in dit proefschrift gebruikte meetmethodes betrouwbaar en nauwkeurig waren.

De bevindingen beschreven in dit proefschrift kunnen enerzijds leiden tot het formuleren en testen van gerichte preventie- en behandelstrategieën en anderzijds aanleiding geven tot gericht vervolgonderzoek naar de rol van bovengenoemde processen. Tot slot illustreert dit proefschrift de meerwaarde van intensieve samenwerking tussen diverse disciplines, alsmede het simultaan onderzoeken van diverse hypotheses. 
Chapter 9 




\section{Valorization addendum}

Besides education and research, valorization is a main task of universities; the impact of research to society is hereby maximized. Here, the valorization potential of this thesis' main findings will be discussed. We will address the relevance and innovations of this thesis, the framework for future studies on insulin resistance and beta-cell dysfunction, the value of reliability data, and the need for in-depth phenotyping studies.

\section{Relevance of the findings}

In order to develop successful strategies to prevent or treat obesity-associated conditions like type 2 diabetes and cardiovascular disease, a thorough understanding of the pathophysiological processes involved is vital. As a substantial proportion of the general population is obese, advances in this area could substantially impact obesityrelated morbidity, loss of quality of life, mortality, and health care costs. In this thesis, we identified independent contributors to insulin resistance and beta-cell dysfunction, the two core processes involved in the development of type 2 diabetes. First, we showed that visceral and subcutaneous adipose tissue, intrahepatic lipid and muscle microvascular recruitment are independent contributors to insulin resistance. This means that they constitute separate targets for intervention. Second, we identified NK cells in visceral adipose tissue to induce local and systemic inflammation and thereby contribute to insulin resistance. Third, we identified, in abdominally obese individuals, early alterations in beta-cell function independent from compensatory changes due to insulin resistance, as well as demonstrated that a weight loss intervention can restore these alterations. Fourth, we showed that a part of these obesity-induced changes in beta-cell function could be explained by intrapancreatic lipid. Finally, we demonstrated that a weight loss intervention improved traditional cardiovascular risk factors (e.g., blood pressure, serum cholesterol levels, insulin resistance), as well as some, but not all, vascular function measurements.

Likely, the identification of the independent contributors to insulin resistance and beta-cell function will have a societal impact. The novel findings mentioned above could eventually lead to therapies aimed to intervene with these pathways to prevent, delay the development, or treat type 2 diabetes and cardiovascular disease. Moreover, these findings could lead to the identification of distinct subtypes of obesity, each of which may require a different treatment strategy. Nonetheless, several future studies should be undertaken before these contributors can be considered a true - and safe - therapeutic target. Hence, several ideas for future studies, as well as how their results may impact prevention and treatment strategies will be further discussed below. 


\section{Future studies on insulin resistance}

Besides the identification of independent tissue contributors to insulin resistance, our novel finding that NK cells in visceral adipose tissue appear to be involved in local and systemic low-grade inflammation and subsequent insulin resistance is particularly valuable. Even though research in rodents demonstrated NK cell accumulation in visceral adipose tissue is an early event into the development of low-grade inflammation and insulin resistance, the cross-sectional design of our studies in humans precludes any conclusions about a temporal association of NK cell accumulation to induction of inflammation and insulin resistance. To provide further evidence for NK cell's involvement in insulin resistance in humans, valuable information can be obtained by studying individuals in whom either NK cells are depleted or who have a loss-of-function mutation. First, those individuals could be evaluated for inflammatory changes in visceral adipose tissue and insulin resistance. Second, an intervention study subjecting NK cell depleted individuals as well as individuals with normal NK cell numbers and function, to short term overfeeding. Ideally, such a study could involve repeated visceral adipose tissue biopsies along with the assessment of insulin resistance. Third, repeated visceral adipose tissue biopsies obtained in intervention studies in obese individuals who are scheduled to undergo repeated abdominal surgery (e.g., bariatric vs. non-bariatric surgery) may provide valuable insights on NK cell's contribution to insulin resistance, as well as the reversibility thereof. Finally, Mendelian randomization techniques may be used to evaluate NK cell involvement in obesity-associated insulin resistance, type 2 diabetes, and cardiovascular disease. Currently, to the best of our knowledge, neither of those study ideas are being investigated. As the data on NK cells in this thesis was the result of a remarkable cooperation between departments, universities and hospitals in this region, the infrastructure to successfully execute studies as those outlined above is already in place.

\section{Future studies on beta-cell function}

Whilst the contributors to beta-cell dysfunction are incompletely understood, endothelial dysfunction and lipid accumulation in the pancreas may be involved. To evaluate endothelial dysfunction, the vasodilatory potential of pancreatic arterioles could be determined by means of imaging techniques or ex vivo pressure myography. In humans, pancreatic arterioles are difficult to obtain and the pancreatic vasculature is difficult to assess with current imaging techniques. To probe the concept of pancreatic endothelial dysfunction, studies in animals could be considered to gain arguments for its involvement in beta-cell dysfunction. In addition, the involvement and localization of intrapancreatic lipid can be evaluated by means of electron microscopy images of distinct proportions of human pancreas. Herewith, one can assess whether beta-cells of obese individuals contain intracellular lipid depositions, 
as well as identify adipocytes in the direct vicinity of pancreatic (micro)vasculature. As electron microscopy images of relatively large proportions of human pancreas have been collected in another Dutch research project (Nanoscopy project), it should be feasible to demonstrate whether intracellular lipid depositions in beta-cells of obese individuals exist.

\section{The value of reliability}

The reliability of many measurements used in research or clinical practice appears to be misused, incompletely considered, or ignored altogether. Nonetheless, by properly assessing and interpreting the reliability of measurements, study designs, power calculations and decision making in clinical practice could benefit substantially. In this thesis, the reliability of a multitude of anthropometric, vascular, metabolic and inflammatory measurements has been assessed. Reliability data, as presented in this thesis, has been combined with information on a measurement's responsiveness to a dietary weight loss intervention. As a result, the study design, power calculation, and selection of measurements has already impacted several studies at our department. Moreover, insight into sources of error have been identified and addressed accordingly. Collectively, this reduces the amount of money wasted on studies with a high probability of a type 2 error (e.g., due to overestimation of a measurement's reliability), as well as the time and money spent on measurements that are unsuited for a certain study design or population.

\section{The potential of in-depth phenotyping in intervention studies}

Perhaps above all, this thesis illustrates the potential of combining in-depth phenotyping, accurate and state-of-the art measurements, and multiple mediation analyses. It allowed for the identification of mutually independent contributors to insulin resistance and beta-cell dysfunction. In contrast to the majority of research papers in this field, we probed competing theories within a single study. By performing multiple mediation analysis in a randomized controlled trial, we could probe whether changes in certain variables contributed to changes in an outcome variable. Hence, this provided additional arguments for the involvement of certain pathways. If this approach (i.e., the simultaneous measurement of potential contributing variables to an outcome, ideally with little measurement error) were implemented more often in clinical trials, competing theories could be tested. Such an insight would lead to more targeted therapies, as well as reduce the number of studies needed to be conducted in a field of research. 



\section{List of publications}

Kusters YH*, Wouters K*, Bijnen M, Wetzels S, Zhang X, Linssen PB, Gaens K, Houben AJ, Joris PJ, Plat J, M. Kooi ME, van der Kallen CJ, Mensink RP, Verboven K, Jocken J, Hansen D, Blaak EE, Ehlers F, Wieten L, Rensen S, Greve JW, Stehouwer CD, Schalkwijk CG. NK cells in human visceral adipose tissue contribute to obesity-associated insulin resistance through macrophage polarization and low-grade inflammation. Under review.

Kusters YH, Sep SJ, Schalkwijk CG, Houben AJ, Kooi ME, Joris PJ, Plat J, Mensink RP, Mari A, Ferrannini E, Stehouwer CD. Obesity-Associated Alterations in Beta-Cell Function Can Be Reversed by Weight Loss and Are Partially Explained by Pancreatic Fat: a Randomized Controlled Trial. In preparation.

Schütten MT, Kusters YH*, Houben AJ*, Niessen HE, op 't Roodt J, Scheijen JL, van de Waardenburg MP, Schalkwijk CG, de Leeuw PW, Stehouwer CD. High and low salt intake and metabolic and muscle microvascular insulin sensitivity: role of glucocorticoids. Under review.

Joris PJ, Plat J, Kusters YH, Houben AJ, Stehouwer CD, Schalkwijk CG, Mensink RP. Effects of diet-induced weight loss on postprandial vascular function after consumption of a mixed meal: Results of a randomized controlled trial with abdominally obese men. Clin Nutr 2020 - Accepted for publication.

Telgenkamp I, Kusters YH, Schalkwijk CG, Houben AJ, Kooi ME, Lindeboom L, Bons JA, Schaper NC, Joris PJ, Plat J, Mensink RP, Stehouwer CD, Brouwers MC. Contribution of Liver Fat to Weight Loss-Induced Changes in Serum Hepatokines: A Randomized Controlled Trial. J Clin Endocrinol Metab 2019;104(7):2719-2727.

Talbot CP, Plat J, Joris PJ, Konings M, Kusters YH, Schalkwijk CG, Ritsch A, Mensink RP. HDL cholesterol efflux capacity and cholesteryl ester transfer are associated with body mass, but are not changed by diet-induced weight loss: A randomized trial in abdominally obese men. Atherosclerosis 2018;274:23-28.

Schütten MT, Kusters YH, Houben AJ, Scheijen JL, van de Waarenburg MP, Schalkwijk CG, Joris PJ, Plat J, Mensink RP, de Leeuw PW, Stehouwer CD. Aldosterone Is Not Associated With Metabolic and Microvascular Insulin Sensitivity in Abdominally Obese Men. J Clin Endocrinol Metab 2018;103(2):759-767. 
Kusters YH, Schalkwijk CG, Houben AJ, Kooi ME, Lindeboom L, Op 't Roodt J, Joris PJ, Plat J, Mensink RP, Barrett EJ, Stehouwer CD. Independent tissue contributors to obesity-associated insulin resistance. JCI Insight 2017;2(13).

Joris PJ, Plat J, Kusters YH, Houben AJ, Stehouwer CD, Schalkwijk CG, Mensink RP. Diet-induced weight loss improves not only cardiometabolic risk markers but also markers of vascular function: a randomized controlled trial in abdominally obese men. Am J Clin Nutr 2017;105(1):23-31.

Kusters YH, Barrett EJ. Muscle microvasculature's structural and functional specializations facilitate muscle metabolism. Am J Physiol Endocrinol Metab 2016;310(6):E379-87.

Gijsbers L, Dower JI, Schalkwijk CG, Kusters YH, Bakker SJ, Hollman PC, Geleijnse JM. Effects of sodium and potassium supplementation on endothelial function: a fully controlled dietary intervention study. Br J Nutr 2015;114(9):1419-26.

Kusters YH, Stehouwer CD. Capillary recruitment: lessons from skin microvasculature. Crosstalk Series: De novo capillary recruitment in healthy muscle is/is not necessary to explain physiological outcomes. J Physiol 2015. 




\section{Dankwoord}

In dit veelal goed gelezen hoofdstuk wil ik graag mijn dank uiten aan iedereen die een bijdrage heeft geleverd aan het tot stand komen van dit proefschrift.

Allereerst mijn dank aan eenieder die heeft deelgenomen aan een van de klinische studies in dit proefschrift. Zonder jullie waardevolle bijdrage aan de wetenschap zouden we geen steek dichterbij een succesvolle oplossing voor chronische aandoeningen als diabetes en hart- en vaatziekten komen.

Mijn promotor, prof. dr. C.D.A. Stehouwer. Beste Coen, ondanks de vele promovendi die je begeleidde, was je altijd betrokken bij mijn onderzoek. Ik bewonder je haast onuitputtelijke kennis, integriteit, werktempo en vermogen om complexe zaken scherp en beknopt te formuleren. Onze inspirerende - en soms intense wetenschappelijke discussies hebben mij naar een hoger niveau gestuwd. Ik ben trots dat ik in jouw team en onder je supervisie mag promoveren.

Mijn copromotor die promotor werd, prof. dr. C.G. Schalkwijk. Beste Casper, toen ik tussen mijn coschappen bij jou op het lab mocht aansluiten, vond ik dankzij jou en je collegae toentertijd mijn passie voor wetenschap. Ik ben je enorm dankbaar dat je mijn promotor wilde zijn, op een klinische studie nota bene. Jouw betrokken en kundige wijze van leidinggeven, met aandacht voor de persoon, is heel bijzonder. Dank voor je vertrouwen, geduld, begrip en veelzijdige hulp door de jaren.

Mijn copromotor, dr. A.J.H.M. Houben. Beste Boy, je hebt mij, toen ik vers uit de schoolbanken kwam, direct geholpen met het doorgronden van de vele facetten van de microcirculatie. Ik kan me nog menige wetenschappelijke discussie herinneren die wij in de aanloop naar de afvalstudie gevoerd hebben en waardoor deze naar een hoger niveau getild werd. Dank voor je vertrouwen en je hulp.

Alle leden van de beoordelingscommissie. Prof. dr. E.E. Blaak, prof. dr. L.J.C. van Loon, dr. E. Serné en dr. ir. M.C.J.M. van Dongen, hartelijk dank voor het beoordelen van mijn proefschrift. Prof. dr. N. Stefan, thank you for participating in the Assessment Committee of my PhD thesis.

Mijn opleider binnen de interne geneeskunde, prof. dr. R.P. Koopmans. Beste Richard, jouw vertrouwen en inspanningen dateren reeds uit mijn tijd als coassistent bij de Interne Geneeskunde. Mede dankzij jouw passie en dagelijkse portie onderwijs destijds, mij in contact brengen met Casper, maar ook door jouw vele inspanningen in de afgelopen jaren, heeft mijn loopbaan zijn huidige vorm gekregen. Ik zal je hier mijn leven lang dankbaar voor zijn. 
Mijn mentors, dr. W. Mulder en prof. dr. N.C. Schaper. Beste Wubbo, tien jaar geleden vroeg je mij wat ik wilde doen als ik later groot was. Mede dankzij jouw steun en (bij)sturing sta ik nu hier. Beste Nicolaas, er lijkt geen probleem in het leven te bestaan waarover jij geen zinnige adviezen hebt of over weet te reflecteren. Dank voor je betrokkenheid en steun.

Prof. dr. E.J. Barrett, dear Gene, you made it possible for me to learn all about CEUS at your lab and write a review together. Your knowledge, leadership, kindness, and hospitality are as impressive as they are inspirational. Thank you for the unique opportunity to work with you.

Dear Linda, not only did you teach me how to perform CEUS, with lunches, dinners, bike rides, swims, and what more, you also made sure I had a great time in Charlottesville.

Dr. A.L. Klibanov, dear Sasha, thank you for your unique and in-depth insight into microbubbles' characteristics and possibilities. I hope there will be future projects we can collaborate on.

Dear dr. A. Mari and dr. S.J.S. Sep, thank you for collaborating and reflecting on our beta-cell function paper.

Beste Jos, Belg van adel, samen hebben we een aantal bijzondere studies uitgevoerd; we konden met elkaar lezen en schrijven. Jouw kundigheid en onderhoudende gesprekken met de deelnemers hebben bijgedragen aan onze bijzonder lage drop-out rate, tevreden deelnemers en nauwkeurige metingen.

Aan eenieder binnen de afdeling radiologie die geholpen heeft bij onze studies. Prof. dr. M.E. Kooi, beste Eline, dank voor de intensieve samenwerking voor, tijdens en na afloop van onze studies. Christine en Lucas, dank voor het optimaliseren, implementeren en aanleren van ${ }^{1} \mathrm{H}-\mathrm{MRS}$. Roland, bedankt voor het inplannen van alle MRI-scans, alsook aan alle MRI-laboranten voor jullie toewijding.

Aan de collega's binnen de afdeling Humane Biologie, Prof. dr. R.P. Mensink, Prof. dr. J. Plat en dr. P.J. Joris. Beste Ronald, Jochem en Peter, dank voor jullie bijdragen binnen de TIFN projecten. Het waren intensieve studies die we samen tot een goed eind gebracht hebben. Tevens een bijzondere dank aan diëtistes Nina Wystyrk en Daisy Luiten, door jullie bevlogen begeleiding behaalden we grote effecten en lage drop-out rates. 
Tevens dank aan eenieder van het Top Institute Food and Nutrition (TIFN) en Stichting de Drie Lichten voor het financieren van de studies in dit proefschrift.

Beste prof. dr. L.W.E. van Heurn, Givan en Yvonne, dank voor de aangename samenwerking aan de BASIC studie. Hopelijk kunnen we in de nabije toekomst mooie resultaten van deze unieke studie publiceren.

Aan de collegae binnen de afdeling Biomedische Technologie prof. dr. ir. A.P.G. Hoeks, dr. ir. K.D. Reesink en dr. F.C.G. van Bussel. Beste Arnold, Koen en Frank, bedankt voor jullie bijdragen op het gebied van meetmethodes, reproduceerbaarheid, validatie, innovatie en het programmeren van diverse applicaties.

Beste dr. C.J. van Gool, beste Christel, bedankt voor het onderwijs binnen en buiten de master epidemiologie en je begeleiding bij mijn scriptie.

Aan al mijn vroegere en huidige collega's binnen onze onderzoeksafdeling. Amy en Dennis, bedankt voor het bijbrengen van en sparren over de metingen aan de microcirculatie. Beste Claudia, José, Katrien, Margee, Maria, Marjo, Mitchell, Olaf, Suzan en Vicky, bedankt voor de samenwerking bij ex vivo experimenten, jullie ondersteuning op het lab en bij de logistiek rondom onze studies. Pauline, bedankt voor je hulp met de dataset van de Maastricht studie. Dank aan het managementteam van de Maastricht studie voor de samenwerking bij de MRI- en reproduceerbaarheidsdata.

Elisabeth, Johanna, Lian, Marcelle, Marleen, Nick en Roel, bedankt voor jullie hulp bij epidemiologische vraagstukken. Barry, bedankt voor het mooie figuur. Jean, dank voor de fijne samenwerking op het werk en voor de vele foto- en photoshopsessies door de jaren heen, het resultaat was altijd prachtig! Teba en Stijn, bedankt voor alle gezellige gesprekken. Nordin, niet alleen je bijdragen aan de wetenschap en de unieke sfeer op de afdeling waren bijzonder, maar onze zwemtrainingen zijn echt legendarisch. Thomas, bedankt voor de gezellige etentjes en fietstochten, hopelijk gaan er in de toekomst nog veel volgen. Monica, Hanneke, Nynke en Mathias, het was een genoegen om te helpen bij jullie onderzoeken op het circulatielab, veel succes met jullie verdere loopbaan. Bas en Dionne, geruime tijd zaten wij samen bij elkaar op de kamer. Dank voor de gemoedelijke, maar ook stimulerende, sfeer. Bas, dank dat ik jouw paranimf mocht zijn, het was een hele eer!

Arts-assistenten en stafleden, bedankt voor jullie interesse in mijn onderzoek en de aangename samenwerking in de kliniek. 
Mijn paranimfen, Petra en Kristaan. Beste Petra, al vanaf het moment dat ik als vrijwilliger tussen mijn coschappen op de afdeling kwam om labonderzoek te verrichten, ondersteun jij me in meer opzichten dan ik hier kan opnoemen, ontzettend bedankt! Beste Kristiaan, onze wederzijds onbaatzuchtige instelling heeft niet alleen tot een goede samenwerking en mooi manuscript geleid, maar ook de basis gelegd voor toekomstige projecten; ik kijk er al naar uit!

Mijn trainer uit mijn tijd als wielrenner, Tim Heemskerk. Los van de sportieve successen wist jij niet alleen mijn enthousiasme en eigenwijsheid in goede banen te leiden, je leerde mij ook om "met de benen te spreken."

Mijn vrienden, familie en schoonfamilie, bedankt voor jullie gastvrijheid, alle gezellige momenten en het feit dat jullie altijd voor me klaar staan. Een bijzonder dankjewel aan tante Yvonne, nonk René, Monique, Mart, Dave en Daniëlle. Van jongs af aan mocht ik aansluiten bij jullie gezin en door de jaren heen hebben we al veel mooie herinneringen gecreëerd.

Mijn best man Martijn, bedankt dat je altijd voor me klaar staat. Talloze ups en downs hebben we gedeeld sinds we 15 jaar geleden aan geneeskunde begonnen. Veel succes met je eigen promotie en dat er nog veel fietstochten en bieravonden mogen volgen.

Mijn ouders, die mij op zo veel manieren hebben gesteund om de doelen die ik mij stelde te halen. In een knus thuis en met aandacht voor school en sport groeide ik op. Van jongs af aan hebben jullie mij bijgebracht dat waar een wil is, er ook een weg is; opgeven is geen optie. Later pasten jullie het hele huishouden aan, zodat ik maximaal kon presteren tijdens mijn tijd als topsporter, zonder ooit school of studie uit het oog te verliezen. Bedankt voor alles wat jullie voor mij hebben gedaan.

Mijn kinderen, Sebas en Avalon, jullie zijn de vrolijkheid zelve en de bright shining lights in mijn leven. Papa's verhaaltje is nu echt klaar!

Lieve Lianneke, ik kan je onmogelijk genoeg bedanken voor alles wat je door de jaren heen voor mij hebt betekend. Je bent zo veel meer dan mijn steun en toeverlaat, je bent mijn alles. 



\section{Curriculum Vitae}

Yvo Hubert Anna Maria Kusters was born on June 9, 1986 in Heerlen, the Netherlands; he grew up in Simpelveld. He graduated from secondary school in 2004 (VWO, Bernardinus College, Heerlen, cum laude). In the same year, he started medical school at Maastricht University, and in January 2011 he obtained his medical degree (cum laude). Whilst studying medicine, he completed the Honors program Research in Medicine, was awarded the top 3\% student award, and was a (semi-)professional cyclist. In March 2011, he started his PhD research under supervision of Prof. Coen Stehouwer, Prof. Casper Schalkwijk and Dr. Alfons Houben at the Department of Internal Medicine of the Maastricht University Medical Centre, within the CARIM School for Cardiovascular Diseases. In 2015, he obtained a Master's degree of Science in Epidemiology at Maastricht University (cum laude). During his PhD project, he worked at the University of Virginia in the United States of America for nine months, under supervision of Dr. Eugene Barrett. In March 2016, he started his residency in Internal Medicine at Maastricht University Medical Center. In June 2019, he started his fellowships in Nephrology and Intensive Care Medicine. 
